\title{
CONIFERS
}

\section{AND THEIR CHARACTERISTICS}

COLTMAN-ROGERS 

TEBRARY

NEW YORK

BOTANIRE

SANICAUL: 



\section{CONIFERS AND THEIR}

CHARACTERISTICS 



\section{CONIFERS AND THEIR CHARACTERISTICS}

BY CHARLES COLTMAN-ROGERS

WITH ILLUSTRATIONS

\section{TIBRARY \\ NEW YONK \\ BOTANICAL \\ LONDON}

JOHN MURRAY, ALBEMARLE STREET, W. 
$\angle 20$

- A lu

C 6

c. 2

Ali Rights Reserved 


\section{PREFATORY}

Drat the trees, says I, to be sewer I haates 'em, my lass,

For we puts the muck o' the land, an' they sucks the muck fro' the grass.

Tennyson, The Village Wife.

THERE are several inducements that have prompted me to put together this little summarized table of the chief characteristics of Conifers. In the first place I was instigated to do so for my own personal edification. I found that, unless you were perpetually in their midst, the various differences and characteristics of trees were not quite so reproducible on occasions as could be wished, and that often when the moment came, the man, and his stores of ready wit, were not forthcoming. Their little idiosyncrasies, sometimes even their very name, with which in calmer moments you were perfectly acquainted, had an evasive way of slipping both your mental and vocal efforts. Sometimes these lapses of memoria technica would be followed by a little doorstep wit, or some such method of recognition, of a mere momentary nature, and afterwards made good after a consultation in an up-to-date library, populous with arboricultural works.

If you are not out for effect, and effect with you is not a primary consideration, why not let written memoranda do some of the carrying trade of the intelligence department? You may lay yourself open to the challenge that your hat (or in this case your notebook) contains more than your head, a suggestion from the audience that once a young 
budding orator was constrained to overhear, when observed to be poring a little too attentively over the notes in his hat lining. But be that as it may, we think with those who think it's better to recall from notes, than never to recall at all.

I have the key part of this book transcribed in pocket form. It has been an added interest to me, as a visitant to Kew, or a pedestrian in Pinetums, to have a reference book, something in the shape of a Ready Recognizer, at hand to verify conjectures; and in the same way, and under similar circumstances, I hope this idea may be found capable of being carried out by others, and that it may prove of the same use as it has been to me on such a visit. You cannot -it is too heavy a strain-stow away in the recesses of your coat pocket volumes of Trees of Great Britain (Elwes and Henry). On such occasions, Bean (Trees and Shrubs), though smaller, would be an uncarryable load; Veitch's Book of Conifers a prohibitive encumbrance; Clinton Baker's volumes, if nicely bound, a sheer impossibility. If you are able to store up all their definitions in your head, and outpour them at will at the psychological moment, all well and good; there would be no need of a pocket edition of "What's what in Conifers," or any other such cold comforts of the kind, and which abridged editions are wont to confer. It is for those not able to accomplish this kind of carrying trade to their own satisfaction that I plead justification for this effortand fearlessly I own-collected from the writings of those at whose feet I would sit, and gladly have sat, and among them are some who shall be nameless, but whom I shall ever d deem it a privilege to have known in the flesh. I make no apology for reproducing, even in exact words, on occasions throughout these Identifying Tables, the written writings of authors of mighty works and of monumental fame. 
The pursuit of every study must have a beginning, and every wandering quest its inspiration.

If this rudimentary effort should perchance implant a love anywhere of Tree Study, depend upon it the victim of the craze will not rest until he has acquired and ransacked the great works of past masters of the art. But be it remembered, a Greek scholar does not commence his studies with Plato.

Again, any apology is discounted by the fact that all distinguished and exhaustive writers upon such subjects, and cognate subjects, go back to the investigation of their predecessors in the shades. They work on the land prepared, and add a little to its fertility each time they plunge their spade. Our object is far more lowly; it is to make the wellturned soil more friable, a little more easy to work.

Loudon wrote exhaustively up to date, but his date became out of date, and some of the works of to-day, complete and exhaustive as they are, will become out of date in their turn, and have to be written up to time. Chinese plants introduced by Wilson and Forrest will have grown up and awakened new interests. Further observations will have been made of them, and they will call forth a new writer to portray them, to sing their merits, or sound their requiem.

The great writers of to-day will in their turn become the predecessors in the shades, and new scribes will arise to carry still farther forward the mighty tasks of investigation they so ably in their day chronicled. There's a running truth in the lines of Rudyard Kipling, which underlies the action of many authorities of many 'ologies:

It all comes out of the books I read,

It all goes into the books I write.

I am one who unhesitatingly and unrepentantly pleads guilty to this indictment. 
If we have borrowed their thunder, let them be assured that it is only with the hope that an echo of its reverberation may reach those at a distance, and those who, had they been brought nearer to its sound, might have been awed by its big intensity of volume, or mentally distracted by the polyglot and polysyllabic expressions these subjects demand.

While paying due homage to all these illustrious extenders of a deep knowledge, and in no way wishing to minimize the deep obligations that we owe them, we read that it has been truly said, that when a book is a large one, the majority of its readers become only acquainted with it by extracts and abstracts. Stupendous bulk is forbidding to those whose space of time allotted to them by reason of other duties in life is limited to the short-cut route to a port of lesser understanding. Piles of pages, and learned dissertation in a language only half understood, appal them, and they retire from the charge discouraged. They clamour for a more unperplexing catechism. Give them the abridgment process, wherefrom they can perchance see a little daylight peeping through the chinks of less thickened walls, and maybe they return to the charge, even to the time when they feel empowered to renew battle against the very forces that at first so overwhelmingly discomfited them.

There are others we hope to help. We refer to those upon whom but limited chances of travel are bestowed, whose walks in life are far removed from recurring opportunity of visiting those scenes where objectlessons can be viewed at leisure. The fascinations of Kew are to them a far cry, or a rare jaunt in the midst of a busy life. The glories of our best-stocked Pinetums are, again, to them often an unblessed vision altogether, or at most a breve gaudium upon a 
rare holiday. Various other causes militate against such expeditions-want of leisure, lack of wherewithal, and yet one more still cogent reason, brevity of life.

"Of making books," said the preacher, "there is no end," and of hunting up trees, say we, there is no finality.

A survey from China to Peru, if carried out in entirety, would not exhaust the question.

Then, again, it should be emphasized that nothing is written here with any remote idea of aiding the expert; our sense of proportion is far too acutely alive to nourish for a minute such a thought. The book is addressed only to those who take up such subjects more in the light of a secondary or subsidiary accomplishment. To the few only is it given to pursue to the core any pet scheme of life. The majority have to spend a larger proportion of their time upon earth in following up duties that give them rather less than great abstract pleasure. There are many, to employ university metaphor, who though they are debarred by the perversities of fate from aiming at a class in the Honours school, may be desirous of matriculating in the subject, or perchance even obtaining a testamur in the pass examination tests. One thing, we are told, leads to another, and if this little effort on the behalf of arboriculture induces any to go farther in Altiora Peto spirit, and to try to scale the more Olympian heights of a fascinating subject, the labour will not have been in vain, and the labourer's light task more than amply recompensed. 



\section{CONTENTS}

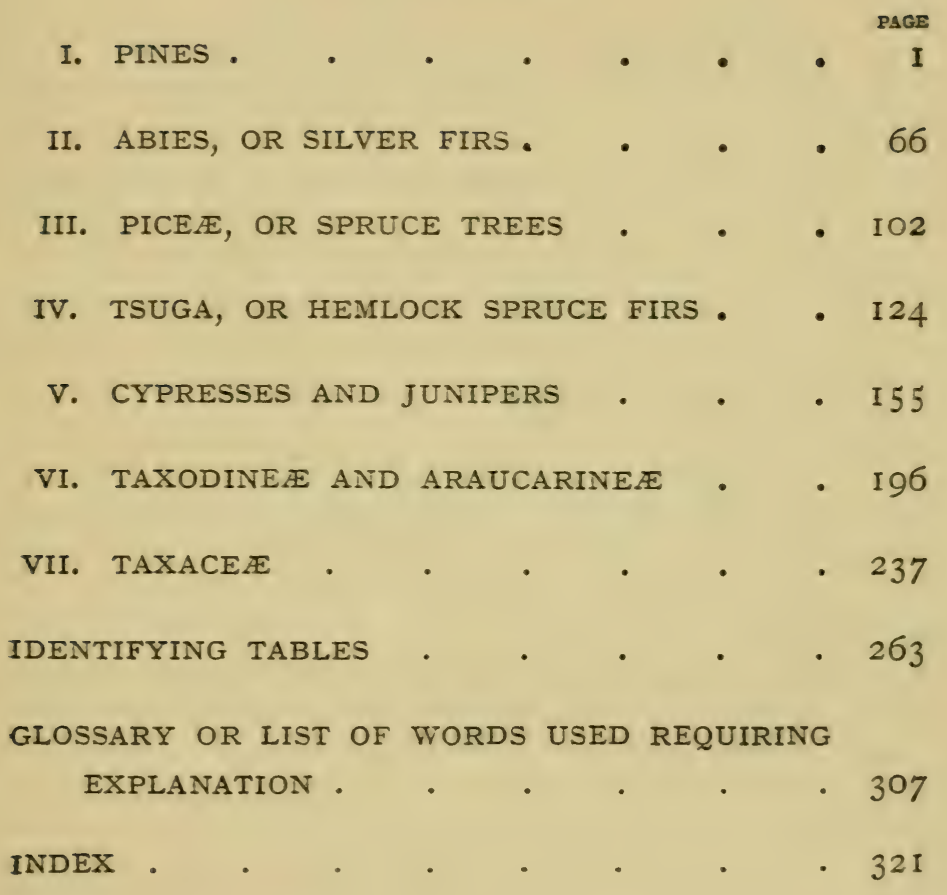





\section{LIST OF ILLUSTRATIONS}

DIFFERENCE OF SHAPE IN APEX OF LEAF OF SILVER FIRS DIFFERENT SURFACE CHARACTERISTICS OF THE BRANCHLETS OF SILVER FIRS . DIFFERENCES OF SHAPE IN TRANSVERSE SECTION (MAGNIFIED) AS BETWEEN THE FOUR-SIDED AND FLAT (OR TWOSIDED) LEAVES OF SILVER FIRS AND SPRUCE - facing IO4 DIFFERENCES IN THE CONE OR STROBILE STRUCTURE OF VARIOUS SPECIES OF THE CUPRESSINEA TRIBE OF TREES:

(a) C. SEMPERVIRENS, C. TORULOSA, C. MACROCARPA $\quad$ • . . . . . .

(b) CHAM ECYPARIS LAWSONIANA, PISIFERA, AND NOOTKATENSIS; THUYAS ORIENTALIS, OCCIDENTALIS, AND GIGANTEA (OR PLICATA) • • facing I58

(c) LIBOCEDRUS DECURRENS, THUJOPSIS DOLABRATA . . . . . . . . facing I59

DIFFERENCES IN SHAPE OF THE FRUIT OF THE PRUMNOPITYS

ELEGANS, CEPHALOTAXUS FORTUNEI, AND PODOCARPUS • 239 



\section{ERRATA \& ADDENDA}

"CONIFERS छ THEIR CHARACTERISTICS," By CHAS. COLTMAN-ROGERS.

Page 59, line 10, for "S. American "read" Canadian." Pages 106, 108, 280, 328, for "Shrenkiana" read "Schrenkiana."

Page 112, line 36, for "Royama " read "Koyama."

Page 118, line 23, for "from each as they" read "from such as they."

Pages 134, 136, 138, 140, 142, 144, 146 (headline on pages), for "Tsuga or Hemlock Spruce Firs" read "Larches."

Pages 141, line 12, for "Arboricultural Journal " read "Quarterly Journal of Forestry."

Page 142, lines 25-26. Note, Mr. F. R. Balfour's article referred to was published in Journal R. Scott, Arb. Soc. xxi. 121-130 (1908).

Page 143, line 16, 286, 327, for "Kaemferi" read "Kaempferi.",

Page 176, line 31, for "Cedrus" read "Citrus."

Page 159, line 18, for "they" read "the scales of the cones."

Page 165, line 34, C. Torulasa, or as others say, "from the slight swellings at intervals on ultimate branchlets."

Page 175, line 2, for "the cones" read "the scales of the cones."

Page 182, line 16. Other derivations of name Lebanon are : (1) from the snow that lies on its summits, (2) from the limestone cliffs on its ranges.

Page 190, line 32, 294, 325, for "Phœnicia" read "Phœnicea."

Page 193, line 2, for "S. France" read "Italy."

Page 277. Under observations on A. Magnifica. For "tree of the Plains " read " a tree for Lawns."

Pages 279, 316, 322, in "Pseudo-tsuja " read "Pseudotsuga." 



\section{TREES}

I

\section{PINES}

(OF THE NATURAL ORder OF CONIFERÆ, OF THE

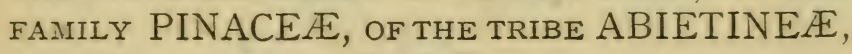
OF THE SUB-TRIBE PINEÆ)

We paused amid the pines that stood, The giants of the waste,

Tortured by storms to shapes as rude As serpents interlaced.

Shelley, The Pine Forest.

The division of Pines into the descriptions of soft and hard-or Pitch, as Prof. Sargent of American fame differentiates them-presents rather a deeper dip into the mysteries of the subject than most are desirous of fathoming. Although it is a matter of critical import to the producer, seller, or buyer of timber, and to the utilitarian world at large, these wood-structure distinctions cannot be expected to arouse the same interest among those unblest with broad acres, or unaffected by trade interests, nor, for the matter of that, among the well-filled ranks of those who are possessed of no sky-high botanical aspirations, but are only prompted, in Wanderlust moments, by a simple-minded desire to better their acquaintance with the works of Nature, and by quiet contemplation to regain a soul lost in the turmoil of city occupation. 
We have explained the salient differences of these two types of Pine trees in our definition of botanical terms for our readers, and will leave it at their disposal, that those who run may read, or those who are not that way inclined may skip. The easily acquired mastery of the number of leaves or needles in a bundle or cluster obtained is the first rung on the ladder of knowledge on which to secure a footing. That humble position reached, the first awakening into the mysteries of a differentiation of Pines has begun. These groups of leaves, it will be noticed, are held together at their base by a wrapper-looking arrangement, varying in length and habit, and which in form and general appearance bears certain resemblance to those strips of cloth that encase the legs of khaki-clad warriors, and are known as puttees.

An accurate observance of this little binding, which is termed, in the phraseology of the cult, a leaf sheath, or leaf scale, comes in on occasions opportunely, and helps to dispel doubts of identity. Sometimes it is persistent, at other times deciduous; occasionally, in the case of the so-called Fox-tail Pines, P. Balfouriana and P. Aristata, and the members of the Cembroides group, it splits into shreds and forms itself, with its reflexed remnants, torn (so to speak) into ribands, into a rosette-shaped appearance. One inestimable boon has been conferred by Nature upon those (with whom we should always be in sympathy) who move slowly along the more stony path of hard work in their start upon any quest, and it is this, that no mathematical brain-worrying is incurred in the task of counting these leaves in a bundle. Indeed, should there be among us that unbrightened star of an age that seems to have passed, who has only learned to cipher upon his fingers, the task is rendered of easy manipulation even to him, and for this reason, that the 
number of leaves to be found in a bunch is bounded by a count of fingers and thumb found on the hand of normal man. To put it still more simply-if it requires simplifying-the number of leaves per bundle range, like Nature's digits, from one to five, and the most common, indigenous, and beautiful of our Pines, the so-called Scots Pine-and take heed, all who talk names, that, in deference to your fellow countrymen north of the Tweed, you do not speak of it as Scotch, neither of them, nor of their Pines as Scotch, but always Scots-which contains two in a bundle, gives the beginner his first intuition upon the problems of an absorbing subject. This counting of leaves by no means exhausts the Alpha and Omega of the art, it only starts us on a long journey, a veritable Via Dolorosa of difficulties. We submit a few points for observation of their component parts that are quite within the scope of the more unversed, and necessitate no deep dive into botanical depths.

Leaves.-The number in a bundle. The length of the leaf. The length of the little covering which encases the base of the leaf, and which is called the basal sheath, and whether that sheath remains (persistent) or drops off (deciduous) or tears away (rosette-shape, e.g. Pinus Aristata, Balfouriana, and Cembroides Group). The margins of the leaves, whether serrulate (jagged), or entire (smooth).

N.B. - In point of fact all Pines are serrulate more or less except these : the Flexilis, Pumila, and Albicaulis, the Aristata and Balfouriana; and of these the second and third mentioned are practically nonexistent in Great Britain. This characteristic is one for the microscope to solve.

Buds.-Their shape, whether resinous or nonresinous. As an object-lesson at hand to all, the buds of the Scots Pine are resinous, those of the Common Spruce non-resinous. 
Cones.-Shape, size, their habits, whether persistent, deciduous, dehiscent (falling to pieces), whether erect or pendulous, shape of scales, length of stalk, or whether stalkless or sessile (very shortly stalked). We allude to this point further on.

Resin Canals. - This is a subject for the magnifying glasses at home rather than the pedestrian abroad, and is explained in the glossary.

Shoots. - Their colour, whether pubescent (downy) or glabrous (smooth); this can be seen with the naked eye, but more adequately with a lens.

Stems.-This is a matter of experience, and it is difficult to lay down a rule upon points to be observed. Trunks vary in different localities, and at different ages.

Flowers.-All Conifers are monœcious (having male and female flowers on the same tree), except Fitzroya and Araucaria, which are irregular, sometimes monœcious, sometimes diœcious. Floral structure of Pines, Silver Firs, and Spruce. The male flowers are in clusters near the ends of previous year's shoots; the female (ovuliferous) solitary, or in clusters, on ends of the preceding year's shoots.

How they carry their leaves from their branchlets is often a sign-manual of great significance. When they are uncompromisingly pendulous, as the Pinus Excelsa (par excellence), the Weymouth, the Armandi, etc., or when they are uncompromisingly vertically situate, of which style the Fox-tail Pines are the champion exponents, the road to recognition is smoothed. To exemplify by homely illustration: the pendulous appearance resembles the natural fall of a horse's mane from the crest of his neck, while the vertical style can be likened to the more unnatural state produced by hogging that article; or if we were to draw a simile from a more remote time in equine history, we should say that one resembled 
the tail-lock fringe, and the other the upright mane of the specimens of a prehistoric age represented by Prjevalsky's ponies, from the Gobi desert of Siberia.

Many of them are not of sufficiently pronounced. habits either way to give our identifying faculties a little first aid in their directions. We must seek inspiration elsewhere.

Of the fifty-two different species (without counting what are classed as varieties) as enumerated by Elwes and Henry, twenty of these have five leaves in a bundle.

We have not so far mentioned perhaps the most complete of all clues to identification-we allude to the cones. These fruits of coniferous trees give a maximum of information for a minimum of study. Unfortunately they are not always so forthcoming as they might be; more often, to put it mildly, very much the contrary. To make a collection of them is an interesting pursuit, and they act as a useful reminder on many an identification question. This perhaps, is a remark that it may be said goes without saying, but at the same time it is not a task accomplished without some doing.

Perhaps few cones are obtained with more difficulty than those on the commonest of trees in our midst, the Silver Fir (Abies Pectinata). In the first place these cones have a way of appearing only on the topmost height of what is generally the highest tree in the district. In the second place they have a way of dehiscing and falling to pieces at the precise moment you think you can secure them. It is a task that calls for a towering ambition on the part of someone concerned, and usually for a forthcoming coin of the realm to the simian acrobat who performs the crowning feat and gathers the forbidden fruits. These difficulties surmounted, and the psychological 
moment taken advantage of, you can fill a cart with them.

Some, on the other hand, are easily obtained. In the case of the trees that produce cones of the asymmetrical and persistent type, the difficulties of the collector diminish. Where the tree is, there also are the cones, generally as plentiful on the stems as blackberries - when they live up to their reputationin October.

Other types with other habits, the Nut Pines and the Albicaulis perhaps in particular, have devastating enemies to contend with, and are only obtained with greatest difficulty upon this side of the water, and then only after having been conveyed overseas from the limited supply on the other side.

Children from village schools-and at times other bipeds of more adult experience-squirrels in England, chipmunks in America, all these, for various reasons, upon various trees wage a predatory warfare, and against their fruit production. With the representatives of the higher creation, it is the rare sight of, say, a Coulteri cone in all its monstrous proportions that prompts the appropriating impulse. With the representatives of the lower creation, it is the dainty delights of the edible inside that attract their greed. We will not compare further the strength of the temptations that assail, or the motives that move these two classes of voracious sinners against the statute-made laws that define the difference between meum and tuum (mine and yours). The writer knows of many a whacking specimen of Coulteri cone that adorns the mantelpieces of homes located in the environment of their production. Of the Sabiniana and Ayacahuite doubtless the same story could be told. The Lambertiana, or Sugar Pine, is another which produces giant specimens, but it seldom cones in England, and when it does, hardly comes up to 
the expectation of it formed from American descriptions and experiences of specimens brought from their endemic home in California. With all these, and perhaps with others, the early-bird habit stands in good stead to the collector.

When the collector has satiated his curiosity upon the outward and visible signs, if he is possessed of the true spirit, and vital spark of the inquiring mind, he will not rest content until he has pulled his specimen to pieces, looked at it by bits, and examined every detail of its external and internal economy. $\mathrm{He}$ can then make minute observations and mental notes-if his enthusiasm still carries him onwardof the shape and size of each scale, the situation and number of seeds and wings, the length of stalk, of cone; the configuration of the margin of these scales, whether they have entire, unbroken margins, or whether these same margins have a frayed, jagged or erose appearance-all three meaning much the same thing; or again, whether the scales are pointed, double pointed, or rounded. In the case of the Common Spruce, all three variations are said to occur.

A knowledge of the shape of these scales adds cubits to the intellectual stature of the student of these subjects, and moreover without calling upon any profound botanical knowledge. This solid fact remains, not perhaps a very worthy one, and only adduced as a labour-saving apparatus, that the sight of a familiar cone at foot has saved many a questioning glance upward, and brought forth a ready answer to the less-equipped inquirer. 


\section{STROBI GROUP}

You may as well forbid the mountain Pines, To wag their high tops, and to make a noise, When they are fretted with the gusts of Heaven.

SHAKESPEARE.

Strobi Group of Pines: P. Excelsa, Peuke, Ayacahuite, Buonapartea, Lambertiana, Monticola, Strobus, Parviflora

The first group of the Quinæ-or five-leaves-in-abundle Pines-take their group name from the P. Strobus, an individual member of the group, that we know more familiarly as the Weymouth Pine.

This P. Strobus owes the origin of its name to a Pine encountered by Pliny the Elder of Pompeian and eruptive Vesuvius fame. We learn from the original authority of his own pages (in his work entitled Naturalis Historia) that Pliny godfathered surnominally a Pine to which he gave the name Strobus. What tree precisely the renowned naturalist and historian had in mind when he bestowed the title there is neither jot nor tittle of evidence extant to give us information. At this distant date we take it that anyone who so wishes may be allowed to picture for himself, without consulting further any modern authority, his own conception of the tree that Pliny was thinking about, so long as that idea coincides with the idea of the original description.

We know-or, to put it more correctly, we have

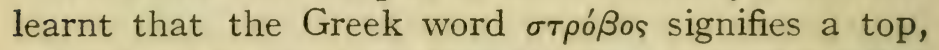
so we have to conclude that the tree named recalled to the mental vision of this great Roman, Caius Plinius Secundus (to give him his name in full), the material outline of the fashionable top of his day. Many kinds of tops at the suggestion of this simile at once flit before our half-forgotten memories of an 
earlier day. We can recall peg-tops, whipping-tops, and humming-tops, and probably there are many more revolving tops than these, whose existence has escaped our memories. What was the shape of a standardized Roman top in the Augustan Era it would be presumptuous to hazard opinion upon; but if it was more or less the same sort of top as its Great Britain representative of the Victorian Erathat is to say, a sort of top-heavy-shaped object, sometimes answering the description of pear-shaped, at others and by others described, as an inverted conoid, with a weighty head supported by a slender pegthere would, I imagine, among Mediterranean Pines be claimants in number for the honour of a name conferred by such a celebrity, since many a Pine in those regions assumes a shape consonant with this rather discursive description. Personally, I should have looked to the P. Pinea to turn up the winner among all other competitors.

Whether it is an ascertained truism that Pliny's Strobus and Linnæus's Weymouth Pine are one and the same is a point of evidence that we do not believe even the great Swede himself, with all his glory, and founder of the Linnean Society, who christened it or rechristened it some I 700 years and more after Pliny's day, could conscientiously have sworn affidavit upon. But why cavil at a name that is both brief and easily spelt, and so long as it distinguishes, and creates no confusion of mind?

There is a provoking similitude both of cones and leaves in the construction of four at least of this group (P. Excelsa, Peuke, Monticola, and Strobus), which calls for a strained docility on the part of the ordinary student. The points of difference in some cases are so slight that they belong rather to that class of subtle intricacies that many do not care to tackle. Those there are who only can, or only 
care to, snatch occasional moments from the many counter-attractions of a country-spent life, from sports and games of bandied balls, and not only from such pursuits as are of a more pleasurable nature, but also from those inglorious-because they who follow them are not glory seekers-and accumulating duties of county civic life, and they in number are many; while those who can find the time to devote a life or even a decade of life to the closer study of one subject, and make of it an absorbing and pet distraction, are few, very few.

This must be our apology for venturing on an exposition of a few points, and their family differences. In two of them, namely P. Excelsa and P. Strobus, let it be noted the leaves are arranged after the pendulous or flowing-mane fashion, while the other two, P. Peuke and Monticola, follow the vertical or hogged-mane type. These two modes of leaf habit (commented on previously) put up such a different show that the P. Excelsa and P. Strobus ought to be discriminated from the P. Peuke and P. Monticola at a glance, and divided as surely as sheep were ever divided from goats by the eye of practised shepherd. This point of difference of appearance only carries us part of the way. It offers no suggestions as to how we are to pick up the Excelsa from the Strobus, or, to give them their English names, the Bhotan from the Weymouth. As these two trees happen to be precisely the two Pines that those "who go to and fro in the earth and wander up and down it " are more constantly encountering perhaps than any other of its imported species, it is quite worth while calling a little attention to some of their phases and forms.

P. Excelsa is the larger edition of the two all round. It has longer cones, leaves, and basal sheaths; its bark is more fissured than the smoother grey-barked Weymouth. But a larger and a smaller edition, when 
viewed separately, are not always the simplest of sights to arrive at an opinion upon. Let us take, for purpose of illustration, the case of resembling brothers. Smith Minor and Smith Major, in the absence of one or the other, are not always objects to measure accurately at a glance by those outside the more immediate family circle. Smith Major may be in tails, and Smith Minor only in jackets, but the Minor in spite of this is often as tall as the Major, and, deprived of distinguishing sartorial adjuncts, may be easily mistaken for his brother. In music sometimes the original or first subject resolves into the dominant, and at other times into the subdominant, and so, to pursue the musical metaphor into the company of the brothers, the major may become the sub-dominant, or equally the dominant may revert into the minor.

To follow up these upsetting effects upon the habits of trees: the length and leaf of cone, subject to the mysterious property of air, climate, and soil, often vary so much that the greater may easily appear to be the lesser, or the lesser to be taken for the greater. There may be, and there are, other minute differences, stomata, evanescent pubescence, and even shape of leaf, between these two, but they are all infinitesimally small and microscopic. The tapering point of the Weymouth Pine cone, to the more unenlightened amateur, tells its story of identity perhaps with more regularity and outstanding clearness than any other symptom of difference, perhaps even more so than the difference of length of leaf, which is considerable, though inclined often to be rather variable.

We will call short attention to a few points of similarity of cones that these four members of the Strobi group present. Although it may not help much to recognize them one from the other, it will 
help to distinguish them from those belonging to other groups of Pines.

They are all longer than they are broad. They are all cylindric, or sub-cylindric in shape. They are all erect when growing, and pendulous eventually. Their scales all have thin margins, and finish off with umbos. They are very variable in size on all four, but as a rule P. Excelsa has the longest cone, and P. Strobus, which represents the eastern side of America, the shortest; P. Monticola, which represents the West Pacific slopes and Rocky Mountain regions, is the half-way house between the two in the matter of size of cone, while P. Peuke represents the biggest girth measurement of the clique. Further, the scales of P. Peuke are striated (marked with channelled stripes and streaks), and exude resin freely, so also does the P. Strobus, but not so profusely. Parenthetically we might add that this is a little untidy habit they all four have a propensity to indulge in. The description of the P. Strobus cone, as having a pointed apex and tapering in shape, we have alluded to, and as cones are to be found in plenty under both, this ought to be a help in distinguishing it from the P. Excelsa cone.

Cloud-piercing Pine Trees nod their troubled heads.

WORDSWORTH.

Ayacahuite, Lambertiana.-As the P. Lambertiana, the Sugar Pine of California, is the mightiest in height among Pine trees, it claims to deserve the Homeric epithet of cloud-piercing above all others that we have made mention of.

If cones would always put in an appearance when wanted, it would considerably add to the convenience of the identifier. These two members of the Strobi Group carry giants in the shape of cones. The Lambertiana has only one rival in the championship, 
and if the Coulteri carries off the welter-weight prize, the Lambertiana outpaces its rival in the long-distance stakes, while the Ayacahuite is a close runner up. The cone of the P. Lambertiana in shape takes after the shell case of a 6-inch gun, and that of the P. Coulteri and P. Ayacahuite follow more after the family figure of the pumpkin.

When we come to a comparison of leaf appearance, as between the Excelsa and Ayacahuite, we are approaching another of those Tweedle-dum and Tweedle-dee differences that seem to be created to perplex. But as eventually it was generally admitted by posterity that in reality a great gulf, in a matter of prowess, separated the two rivals, Handel and Bononcini, who inspired Dr. Byrom's rhyme,

Strange all this difference should be,

'Twixt Tweedle-dum and Tweedle-dee,

so does one very marked difference, luckily for us, in quest of simple clues, divide in character unmistakably these two trees. While the Excelsa twigs are smooth as marble, those of the Ayacahuite-and it can be easily seen-are densely covered with tufts and reddish-brown down or pubescence.

While the P. Excelsa hails from the Himalayas, the Ayacahuite and its name come from that Paradise of Pines the Mexican territory. To the question, who gave it this name, the answer is the aboriginals of that country, and the natives of a country who perhaps, brought up on the slopes of Popocatepetl, had learnt to love the music of high-sounding names. To the question as to what this name means, our only reply must be that as our liege lords of tree lore have failed to inform us, no answer can be forthcoming here; and if still further pressed upon the subject of its phonetic pronunciation, our answer would be the same. We note that Sargent in his manual of 
North American trees refers to what has been called by others the Colorado variety of Ayacahuite, a tree growing on higher slopes, and with the natural resultant of sporting shorter leaves and smaller cones, as the P. Strobiformis. It seems rather a dull performance to give a Greco-Roman name to such a stranger, and to a variety of a tree that enjoys such a crisp-sounding vernacular appellation of its own.

With the remark that the Lambertiana carries the hall-mark of its identity in the grassy green colour of its leaves, and that the Buonapartea or Veitchii, a variety of the Ayacahuite, elects to have its cone scales incurved rather reflexed to assert an independence, we approach towards the end of our dissertation on the subject of these white, soft-wood Pines, the Strobi Group.

To sum up some points of difference : the P. Ayacahuite must be dissociated from the P. Excelsa by the conspicuous down it exhibits on the twigs, a symptom in marked contrast to the smooth surface noticeable on P. Excelsa branchlets.

From the Pinus Strobus it can be identified by its longer leaves and dense pubescence. We might also notice that whereas there is every probability of an abundance of cones in the vicinity of the Weymouth, the mighty cone of the Ayacahuite is still a rare sight with us.

For a prompt recognition of the Lambertiana, the colour-test observance should be relied on. The bright yellow-grass-green hue of its leaves is quite. unlike any other colour scheme of the group.

Before leaving the subject of the Ayacahuite, there is still another Pine, the P. Armandi, that may easily delude the more unsophisticated, in the absence of cone clue, into the belief that he is sampling an Ayacahuite. It is written down as not belonging to 
this group, but to that of the Cembræ. By its leaves, pendulous, bent, and spreading, like several of the Strobi Group, it seems to clamour at their gates for admission. It has, so far as we can see, been sternly denied admittance on account of the shape of the cones it carries. They are thicker, it is true, than most of the Strobi, and for the matter of that longer than most of the Cembræ. The Strobi Group, it must be concluded, appears to be very sensitive on this point, and rather pride themselves on this slender cone habit. We discuss the Armandi farther on, where its name is to be found under the ægis of its family group the Cembræ.

P. Parviflora.-We have now only the P. Parviflora of the Strobi Group to deal with. How it contrived to obtain an entry into this exclusive family circle is a matter of wonder to the less deeply initiated. Although we may amuse ourselves by carping at the position it takes up generically, it must be clearly understood that we have nothing to urge against it for the position it takes up geographically; on the contrary it is a tree that with general acceptance is looked upon as decorative, and peculiarly suited to many sites. The tree distinctly has its charms, but among the other members of the Strobi it looks as a parvenu in their midst. It is a short-leaved, short-coned, with short sessile stalks (the reverse of a Strobi characteristic), and short-grown specimen by the side of its more elongated fellow tribesmen in every phase. Although its presence is rather apologised for by those who have placed it there, and looked rather more carefully into the details of its passport than we are able toalthough it is rather hinted even there that it is to be looked upon more in the light of a missing link between the Strobi and Cembræ-the fact cannot be 
forgotten that it started life with the reputation of the Cembra's double. The number of cones at an early age it carries of sometimes three or four mounted to face around, like guns in a barbette, its vertical short leaves, showing the white stomata so remarkably that its leaves at a short distance appear to be streaked with silver threads among the green, and shaped after the manner of a Fox-brush Pine-all these traits conspire to assist identification, and again, lest we forget, it has been assigned to the Strobi Group, from where no ejectment process can remove it.

It has adopted as a motto for its family abidingplace the words attributed to Marshal MacMahon in the Crimean Redan, "J'y suis, j'y reste" (Here I am, here I stay).

\section{GROUP OF CEMBRÆ, OR STONE PINES}

O sovran Blanc!

The Arve and Arveiron at thy base Rave ceaselessly, but thou, most awful form, Risest from forth thy silent sea of Pines.

S. T. Coleridge, Hymn in The Vale of Chamounix.

P. Cembra, P. Koraiensis, P. Armandi, P. Pumila, P. Flexilis, P. Albicaulis

The Cembræ are a group of some half-dozen mountain-bred (Alpine and elsewhere) Pines, that are chiefly characterized by bearing cones whose breadth is greater-or, to put it more correctly, whose breadth is inclined to be greater, as great, or nearly as great as their length. They take their name presumably from the name of a town in the Tyrol. What the name of the town in the Tyrol in turn takes its name from I cannot say. We may say of them, without any disparagement as to their virtues or utility, that they are just as ready to take up a residence in those localities that have been described as "Back of 
beyond " or "Never, never," as in the richer locations of the most favoured sites. Like the Syrian cony, too, they take delight in stony places for an habitation.

It will perhaps be noticed that another Pine, P. Pinea, also assumes, among many other aliases, this name of Stone Pine, and in the face of the fact that it belongs to another group, and is of a perfectly different appearance, habit, and locality. One little characteristic they have in common (these two aspirants for the honour of a name), and only one, and it is that they both evolve a large-sized seed or nut, enclosed in a hard, bony shell, which presumably has been considered to resemble a stone. We give this as the attested origin of their familiar name, Stone Pine, but are under no responsibility for the suitability of its application.

These Cembra Pines are for the most part a smaller, closer-leaved edition of a tree than, for instance, the previous group of Strobi Pines. Their cones are shorter and thicker in proportion to their length. The old definition "short and stout and round about" describes the shape of their fruit, if not the trees, admirably.

They may be said to rather represent the bantam battalions of the Pine-tree army.

As the lesser animal sometimes thrives where the larger dies, so it is with trees: the P. Cembra not only thrives but lives, it is recorded, to a most unusual length of years in places which many a statelier Pine at a bare sight of would wither, droop, and die.

We will attempt a brief account of some of the family tests held and observed in common by the members of this Cembran caste. Their leaves are of the fox-brush form, and most of the dense arrangement form of that type. Their seed is slow to germinate, and the tree itself is of more slothful 
disposition still in its efforts at growth; and when we say this we must bear in mind that naturalists tell us that the more intelligent animals take longer to grow up than the less intelligent-that, for example, while civilized man takes twenty years, uncivilized men take only fourteen; or, again, that while an orang-outang takes twelve years to mature, the lesserdeveloped Japanese ape accomplishes his destiny of a full growth in four years; last on the list comes the rat, who becomes full grown in a year. Whether this habit of slow growth has any application in the case of trees, and is a sign of a higher culture, as it is in the animals, we hazard no opinion; we cite it in a pari ratione (by similar reasoning) sense, with the remark added that it is generally conceded that slow-growing trees make the best timber, and the wood of Cembra has always been in much demand and put to many uses by the inhabitants of the country it comes from. We may add to its qualities of adaptability that it transplants, probably on account of these sluggish tendencies, with more ease than most of its kind.

Their average height as a group, however you reckon it, would have to be underwritten at considerably less than half the height of the trees of the previous group. In thus estimating them we leave out the P. Koraiensis, as it is so far an unknown quantity among us : it has not yet had time to declare its intentions as to the stature it aims at attaining here.

On the other hand, among the Strobi in this calculation we include its little misfit relation and squab of the family, the P. Parviflora, which pulls their average down badly.

These are but a few jogtrot observations upon some of their characteristics, and we confess that they shed but a dim light upon their identification, 
and that identification made easier is by way of being the leading motif of our theme. It must be pointed out that out of the six species only one is found so far as occasionally flourishing or in a state of maturity in Great Britain, and that is the P. Cembra.

\section{P. Cembra and P. Koraiensis.- \\ Aerial pines from loftier steeps ascend, \\ Nor stop but where Creation seems to end.}

WORDSWORTH.

Of all this Cembra group the P. Cembra is the only one that we are the least likely to come across in the full-grown dignity of middle or older age in any of our wanderings round the British Isles.

The Koraiensis appears in a state of adolescent age in a few favoured localities, and specimens of from 30 to 40 in. may be seen of this size at Highnam (Glos.), Tregrehan (Cornwall), and probably a few others climatically favoured elsewhere.

The tree itself was introduced in $\mathrm{I} 86 \mathrm{r}$. A great similarity exists between this Korean Pine and the Alpine Cembra. The cones are easily distinguishable, not only on account of the disparity of size and shape, but on account of the very marked appearance of the regularly deflexed scale-tips of the P. Koraiensis. While the cone of the Cembra is a little round footballshaped specimen, and often not more upstanding in length than $I \frac{1}{2}$ in., the $\mathrm{P}$. Koraiensis produces specimens of nearly 6-in. length. There are other more minute botanical differences mentioned in the tables, which are for those to investigate who have time, opportunity, or inclination.

P. Armandi, or White Pine of China, was only discovered in 1895 . The specimens at Kew are somewhere about $20 \mathrm{ft}$. and have borne cones. These cones are of about the same size as those of the 
Koraiensis, or perhaps a little larger, but without the reflexed scale symptom. Why this tree has not been given its commission in the ranks of the Strobi contingent is a matter of some wonderment to the more superficial among students. We think that here is a case when the "man in the street" or the casual onlooker would be deserving of forgiveness if he failed to apprehend its connexion with this group, and if he regarded it suspiciously in the light of recusant within a true fold.

The P. Armandi has pendulous leaves and pendulous cones, while the Cembra has vertical leaves and erect cones; moreover, the former resembles in leaf appearance and pendulous arrangement the P. Excelsa of the Strobi group. It seems rather a stretch of the imagination to perceive any family likeness between their respective cones. They are not quite "so fine by degrees and beautifully less" in shape as some of the Strobi cones, and the Strobi seem to put in a claim for a pharisaical exclusion of sect on account of this tapering cone figure that they affect. We ask again in wonder, Where are the signs of external difference between Armandi and Strobi ? There are, it must be added, some variations and mysteries as to their resin ducts (they are median not marginal, as are the Strobi), but these are intricacies rather beyond our scope and the comprehension of average man. It was Dean Swift who complained that he was an Irishman by the visitation of God. By the determination of the Fates the P. Armandi has been assigned to the Cembræ family. There let it bide and in peace.

This tree is colloquially and variously called the White, Fruit, and Cow Pine.

P. Pumila.-The P. Pumila (not to be confused with the P. Pumilio, a variation of the P. Montana), 
is a rarity that comes from northern lands and from such ice-bound regions as Lake Baikal (E. Siberia). It is of dwarf rather than of full-tree dimension, since it only attains a height of $10 \mathrm{ft}$. It has been tried at a few places : at Leonardslee, for one, by Sir Edmund Loder; so far they have only made (he tells me) a growth of 6 in. in the few years that he has attempted their cultivation, but even this effort seems to spell rapidity itself, when taken in comparison with the history of its growth at Dropmore. There it only contrived a height of 10 in. after a fifty years' attempt. At this rate it seems that many generations of owners would pass away to dust and ashes before any descendant heir-at-law would find himself able to enjoy a sight of it at full growth, much less to exhibit a plank from it, at a Royal Agricultural S.E. Forestry Show. But it is only fair to add that it never set up to be even in its Arctic homes anything greater than a dwarf or prostrate shrub, more fitted for a rock garden than a pinetum. We have made further allusion to this weird specimen of plant life under heading P. Montana var. Pumilio.

P. Flexilis.-The Flexilis we may liken, and remember it accordingly, on account of a peculiar characteristic that signalizes it, to the acrobatic performer of the fair.

In the same way that the indiarubber man of the booth can contort his frame without any apparent inconvenience to his feelings or disarrangement to his system, so a branch of the Flexilis can be twisted to any degree or angle without fear of breakage.

There is a hard-wood tree that we all know well, which is called by an ultra-opposite name, and for the very excellent reason that it possesses exactly opposite properties, and that is the Salix Fragilis, variously called the Brittle-twig and Crack Willow. 
It is so called for the obvious reason that its twigs snap upon the slightest provocation.

This Willow, then, may be said to represent the extreme party of the inflexibles, while the Pine in subject may be regarded as representing extremists of the opposition and the most flexible examples of tree structure.

If, then, in our walks we come up against a mysterious low-growing Pine, with five leaves in a bundle, directed upwards (not pendulous), of from $2 \frac{1}{2}$ to 3 in. long, not quite so thickly situated on its yellow-grey branchlets as, for instance, the above-mentioned Cembra or the Foxtail Pines (P. Aristata and P. Balfouriana), then may our suspicions be strongly grounded for believing that we have run to his place upon earth the Stone Pine from America's Rocky Mountains.

If we were wishful to make assurance doubly sure, we might go so far as to take a leaf home and put it under the tell-tale influence of a microscope. If by that process we failed to discern a vestige of jagged serrulation on its leaves, it would indeed be a case of Q.E.D. and our suspicions turned into certainty. This bending competition is what we should cordially recommend as of most powerful avail in arriving at a recognition of this rarely seen tree-to say nothing of the diversion it would afford to the experimentalists in making a trial of this peculiar quality.

P. Albicaulis.-Specimens of this tree are still fewer and farther between, if possible, than its predecessors of the group. A few of them have been tried at Kew and also at Leonardslee, and grow, as is the way with this little coterie, slowly but, so far they have grown there, surely.

It is evidently almost a facsimile in appearance to 
the Flexilis, but is distinguished from it by a minute display of pubescence.

As far as an opportunity of seeing it elsewhere or coming across it in our peregrinations, there seems to be as remote a chance as that of stumbling upon a roc's or great auk's egg.

Specimens of cones of this tree we know from experience are hard to obtain : they must be a hard nut, too, to crack (even from the rodent squirrel's point of view), since they (we read) never open out at all except under compulsory powers. The chipmunk (an American squirrel), on the principle, we opine, that forbidden fruits are sweetest, shows such a determined spirit of greed for the possession of their contents, that no one except the most persistent of men and the most undefeated among sportsmen would stand a chance of winning them for a trophy remembrance in competition against such wellequipped and advantageously situated opponents.

\section{GERARDIANA GROUP OF PLANE BARK PINES \\ P. Bungeana and P. Gerardiana \\ These trees shall be my books, \\ And in their barks my thoughts I'll character. \\ SHAKESPEARE.}

There are no trees that carry their characters more conclusively in their bark system than the two above-mentioned members of this very reduced little party of Pines. At a certain stage of their existence, their bark peels off after the manner of a Plane treeand shall we add of an Arbutus or a Birch tree that "lays aside its white skin wrapper "-and leaves as a result of this shedding process a very unusual and picturesque effect.

This seems to be quite an original proceeding, on the part of the main stem, of any middle-aged Pines. 
There is another glaring anomaly in their system, so far as ternate (three leaves in a bundle) Pines are concerned, and that has reference to the deciduous habits of their basal sheaths.

In the case of the Bungeana, it falls away the first year. In the case of the P. Gerardiana it remains until the second year, and then disappears, a proceeding which is also another novelty in all Pine tradition. Though these sort of departures from the true paths of strict orthodoxy are only questions at most of disconcerting interest to the advanced botanist, they ought to be seized upon as tokens of serviceable help to identification by the less-advanced student. They are some of those little apparitional differences that should be of subtle assistance to the dilettante, and are well worth looking out for when he comes across an unfamiliar-looking three-leaved Pine.

It is for these two habits, peculiar to themselves, among the three-leaved lot, this shedding of bark and basal sheath, that these two Pines have been handcuffed together in amicable bondage, and formed into a little duumvirate of partnership, in a group of their own.

P. Bungeana.-The branchlets of the Bungeana at Kew are of a greyish green, and the several candelabra-formed stems (of one of the two trees) are of an ashen-grey colour. This appearance may be mainly an effect due to a life spent in a begrimed atmosphere, and traceable to those same artificial causes that are so apt.to temporarily deface a chimney sweep's weekday countenance. As the tree appears there, it certainly looks to the unsophisticated visitor more like a bit of beechwood that has done time in a colliery pit, and lost the glamour of its pristine shine, than a specimen of plant life that some day 
is going to develop into a butterfly stage of brightened beauty.

In its native country, we are told-for few have had the luck to see the "Pai-koo-sung" (the native name which stands for " Pine with the White Bark") at home - that at fifty years of age this tree undergoes a remarkable transformation effect of colour scheme, and assumes a most striking and fascinating appearance. The grey and dingy bark is cast aside, the story of Cinderella is in scenic sense repeated, and the sombre dress of a household drudge, by wave of hand and in a moment of time, is changed into the radiant white of a spotless attire.

The late Lord Redesdale, in his Memories, speaks of a visit paid to China in 1865, and describes the impression this Pine, planted around the Buddhist temples near Pekin, produced upon him. I will quote his words textually: "The (Chinese) cemeteries are darkly shaded by tall Chinese Junipers, and the weird lace-bark Pines (P. Bungeana), whose stems and branches are richly embroidered with silver patches, gleam ghostlike among the more brilliant foliage."

The Chinese have always been addicted to paying more attention to the decoration of their last restingplace than the comforts of their less-abiding homes on earth. Under these rather curious-to-us thoughts and ideas, it can only be regarded as a compliment to their appearance of the highest order, that these Pine trees were found where they were-namely, in full territorial possession of the mortuary sites of Chinese scenery. The occupation of such a site, we may point out, although it may be a much-soughtafter surrounding for a Chinese native or a Chinese Conifer, is a complimentary position de luxe that hardly appeals to the representatives of either human or plant life in Western civilization. They, we think, 
would be far readier to dispense with any honour in these directions than their congeners in the Celestial Kingdom.

We must remind again those who would plant for themselves, as well as for that haunting vision lightly spoken of as posterity, that it is not until the middle ages of its existence, until after some two score and ten years have passed by, and the nursery days have been left behind some half a century, that this P. Bungeana takes upon itself to assume this white robe of glory, or penitential sheet, in whichever light you may prefer to liken its curious transfiguration.

Why, it may well be asked, was not this rare gem of the earth brought more to the notice of those who were planting rarities in the forties of the last century? Had they been, our seniors in life's progress, the seniores priores of the middle-aged and elderly to-day, might have bequeathed to us, and to the generations in life's tenure after us, an opportunity to revel in a new sight, and admire a new wonder.

The Silver Birch, or " Lady of our Woods," as the tree has been poetically described by Sir Walter Scott, although not a tree chosen to reflect white rays upon the sepulchres in a Western country burial-ground, as are the Bungeana in China, for all that are treasured by us for the conspicuous beauty of their gleaming white stems. If by chance any other species of the Birch tree arises and tries to outshine our native product-as have, for instance, the Betula Utilis from the Himalayas (in those few places where it will thrive), or the hardier P. Papyrifera (the Canoe Birch of American Redskins), and some of the forthcoming expectations from Chinese exploration-those species are eagerly sought for and planted, but the P. Bungeana seems to have been left out in the cold of neglect, 
and never been quite so worked up by nurserymen to the extent that it deserves.

An answer to these inquiries may perhaps be found in the tale told of its history. Dr. Bunge, a Russian, discovered it in 1836 . Robert Fortune sent its seeds here in 1846 , and their results to-day may be practically computed at nil, or next to nil. Since when, Wilson has walked into a goodly company of them in Central China, and some day perhaps, at too great a distance of time for most of us, our children and grandchildren may be gladdened by a sight that it was not our lot to see.

One more word upon them: the Bungeana and Gerardiana have been called at times "the Lace Bark Pine," and Elwes and Henry have entered an objection to this designation on the score of inappropriateness. It would be only the masterful mind of a bold man who would dare gainsay what this formidable duet of able men have laid down, and in this case, if anyone were to try it on, his position would be particularly untenable. It is a name that at best can convey but an indistinct idea of appearance to most. There are so many different kinds of laces of so many different hues, ranging in colour from dull ivory to alabaster white. There are so many different kinds of laces-we would plaintively plead-from so many different countries and places, from Flanders, France, Alençon, Ireland, etc., and so few tree students who possess the remotest ideas of their differences. We are grateful that Elwes and Henry have protested against the inappropriateness of the name, and afforded us protection from the confusion that such a misnomer might have created in our more inerudite ranks.

P. GerardianA. - This is another of those Pines that a rare sight of is all you can hope to obtain. It has 
generally been regarded as exhibiting an hostility to English shores; however, there is one graduating at Cambridge under the helpful tuition of $\mathrm{Mr}$. R. Irwin Lynch, in the Botanical Gardens, with every prospect of obtaining a fair degree of success. Rather, I think, on the strength of this change of attitude, in an amiable direction, towards an English climate on the part of this Pine, it has been distributed for a few trial trips in various places among enthusiasts on the subject of encouraging rarities. As far as our experience goes here (Radnorshire), they seem to be holding their own at an altitude of $800 \mathrm{ft}$. above sea-level, but only so far in the earlier stages of life. Its chief peculiarity, that of shedding its leaf sheath in the second year, has been alluded to. The leaf sheath shows an imbricated arrangement, the scales growing like the stem-clinging leaves of a Cypress with a spreading point, which is a departure from the ordinary custom of Pine trees.

It has been said that once some confusion reigned between it and another Pine called P. Longifolia, a confusion which only did, and only could, arise from a wrong label. The latter tree has, however, been relegated in authoritative writings to the position of an alien in our midst, and it is only to be found interned in hotter places, such as the Temperate House at Kew. Were it to come into evidence, the cone structure would solve the problem of identity, to say nothing of other differences. Some obtained by me of the P. Longifolia from Naples are $5 \frac{1}{4}$ in. long and $2 \frac{1}{4}$ in. diameter, while the cones of the Gerardiana obtained from India measure $6 \frac{1}{2}$ in. long and $4 \frac{1}{2}$ in. in diameter, a very substantial difference.

It was discovered by Captain Gerard in the N.-W. Himalayas; and was known as an eatable-seeded Pine of the East Indies, that went by the name of P. Neoza. 


\section{BALFOURIANA GROUP OF FOX-TAIL PINES}

Here we have another little group, merged in a class of their own, and answering to the almost appropriate name of Fox-tail. We say almost appropriate, for Fox-tail is a word that falls rather strangely upon English ears, where all, from the luckier who has the good fortune to bestride a horse, to the lowlier pedestrian and excited workmanwho invariably deserts his daily work if the hounds come by, and is as invariably forgiven by his taskmaster for so doing-are at least of one mind upon one unvexed question. All, one and all, votaries or even non-votaries of the chase indulge in but one colloquial name for this hirsute appendage of the animal in question. With one harmonious accord they call it "brush."

We note that some nurserymen, in deference to custom and accepted medium of expression, actually describe and advertise the tree as Fox-brush Pine. In so doing they cling to a name that tells its tale well and truly. The resemblance of its closely clustered leaves to the article whence it derives its name helps in, if it does not quite render unmistakable, the identification of these trees.

The two of them, the P. Balfouriana and P. Aristata, were once content to dwell together in unity of name and species. Now this harmony has been broken by some of the fixed stars of our arboricultural firmament. The P. Aristata occupies a position of the mountain, or Alpine, variety of the P. Balfouriana. Their difference seems to be that the mountain variety shows (I) more distinct pubescence on its branchlets, as is the way of mountain varieties; (2) the incurved prickle of the cone is a good deal longer than that upon the P. Balfouriana, and measures 
half an inch. These awn-like prickles suggested a name for it, and the name Aristata, derived from the Latin word arista, signifying the beard of an ear of corn, was forthwith dealt out to it; (3) the P. Aristata exudes specks of white resin on its leaves, and this should be a sure and easy method of differentiating the two. While the P. Aristata is in this way flecked, the P. Balfouriana is fleckless and unspotted, like saints on earth. By the non-cognoscenti, these white specks have been taken for some sort of Chermes' visitation, or other felted scale insect affliction, but a little further examination or micrographic investigation shows that there is nothing more amiss than a leakage of resin through the stomata.

There is yet another sure method which applies to the identification of them both, besides the densely crowded and appressed-to-stem leaves, and that is the basal sheaths break away like a torn riband, and form themselves into a rosette-shaped appearance at the base of the leaf. The margins of the leaves are entire, a rare characteristic in Pines.

The first-named was discovered in 1852 , and the Alpine variety some ten years after, so they stillespecially in view of the fact that they are slow growers-are rather innovations with us, but innovations in the shape of young trees that are yearly becoming less novel.

\section{CEMBROIDES GROUP OF NUT PINES}

P. Monophylla, Edulis, Cembroides, and Parryana (OR QuAdrifolia)

The trees in this group of four all hail from America, all have edible seeds, and each one has a different number of leaves to the cluster. From one to four are all represented, and in the order of number as above written. 
P. Monophylla, the one-in-a-cluster representative, is a very slow-growing tree, and only occasionally seen in botanical gardens. Though it is rumoured that attempts to grow them-and we may include in this remark the Edulis and Cembroides-were made many years ago, evidences of these efforts are apparently not very forthcoming. A few have, we believe, been planted of late years by collectors of the " unordinary." As the tree only seems to increase at a rate of about $3 \frac{1}{2}$ in. per annum, it must be presumed that those who plant, plant for a fardistant-off posterity. Yet even this tree, with all its sloth of habit, does not bear away the palm, under Grand National Donkey Race rules (when the first is last, and the last first), in any competition of this description among its kindred companions, since the P. EDulis grows at a still slower pace. It and the P. Parryana, or Quadrifolia (as it seems better known in America), the representative of the fourin-a-cluster member of the family, are more or less non-existent in the British Isles, though Veitch in his manual of Conifers suggests hopeful possibilities for the latter in a Cornish or Devon climate. I cannot hold out encouraging hopes to any in quest of their seed. So far it is the only one mentioned in the fifty-two species of Pines by Elwes and Henry that I have failed to add a specimen of to my cone collection.

P. Cembroides.-The three-leaves-in-a-cluster member of the group.

After diligent search, quite respectably grown specimens of this tree have been found growing in several places in Great Britain. Though not of much account evidently here, or highly recommended by the faculty, these trees bear in the central scales of their cones highly prized delicacies of an edible 
nature. Thus they more than justify their existence in the land of their origin, if they are a little reluctant in their efforts to carry on that existence here.

The identification of the only one-leaved and the only four-leaved Pine-and accordingly called " Mono" and "Quadri," " phylla " and "folia "-requires no inspired genius to distinguish, and the easiest way, if rare occasions demanded, to differentiate the twoleaved Edulis and the three-leaved Cembroides is to engrave upon the tablets of your memory that they are the only two- or three-leaved Pines that have the rosette-like leaf sheaths, described in the cases of the five-leaved Fox-tail Pines.

\section{PSEUDO-STROBUS GROUP OF PINES}

\section{P. Montezuma, Hartwegit, Pseudo-Strobus, TORREYANA}

Lo, all the stately progeny of Pines

Come with their floating foliage, richly decked

To fill that void.

W. Mason, The English Garden.

Pseudo-Strobus is the rather unedifying name given to this group. While they are hard-wood, the true Strobi are soft-wood Pines; and herein must constitute the falsity that Pseudo spells and implies, while a more outward resemblance to the distinctive features of the true Strobi must be accountable for the cognomen of their coterie. The difference between these two differently wooded Conifers is explained in the glossary, and alluded to in previous pages on Pines generally.

The first three come from Mexico, and the lastnamed, the Torreyana, hails from California. Mexico may be in theory a Paradise for the botanist and tree lover, but several circumstances seem at present to militate against a prospect of any inundation of 
plant life from these regions, or overflow into them of any surplus human kind, bitten with the selfpreservation creed, that though their shirts may be near, their skin is still nearer.

The first of these is that Mexico still is, and for a long time has been, what the President of the U.S. America describes as preoccupied in "settling: up her domestic affairs," and this state of affairs spells a very disturbing process, both to man and beast. The second is that a condition of perpetual Civil War and the more peaceful mission of the collecting botanist do not go well together; and, thirdly, that those trees that have been brought back from those regions are, for the most part, very touchy about the climatic conditions they find themselves invited to face. Like Israel's scattered race, in the words of Byron,

They cannot quit their place of birth,

They cannot live in other earth.

And this, in many cases, seems to sound the keynote of their swan song, and to express the refrain of their failure.

The P. Montezuma.-Of those that have flourished in favoured localities, perhaps the P. Montezuma and its three-leaved, in other aspects outward counterpart and fellow countryman the P. Patula (which, by the way, belongs to the Tædæ group), with their long, pendulous, mane-like leaves, would be voted by any plebiscite of approved scenery seekers the most attractive among all existent Pines. Can we sound their praises higher?

P. Pseudo-Strobus. - This Pine is so near, so very near, in so many of its similarities to the P. Montezuma, that we wonder, in our uninstructed innocence, why 


\section{PINES}

it has not a place among its varieties, instead of being starred alone in the pride of an independent species. A smoother bark and more slender branchlets are all its claims to isolation, and it is for this that the more lowly intelligence of the lesser-endowed tribunal, composed of Mankind in the Street, has to bow before the decision of the superior court of appeal.

The P.Hartwegir.-Although it is nothing else than the Montezuma of the north, and representative of higher regions and colder climes, it can produce many a testimonial in favour of its claim to a separate title. It has shorter leaves and a hardier constitution than the more tropically inclined Montezuma, and seems to be able to thrive in any English climate, favoured or unfavoured, as the authorities divide them. Where the Montezuma can only just poke up his nose, imbibe with distaste a little winter air, and then ingloriously die, the Hartwegii, like the green bay tree of the Psalmist, flourishes in the rudest appearance of unchecked health.

George Russell Shaw, in a U.S.A. Arnold Arboretum publication, mentions some eighteen species of Mexican Pines. Upon about half of these we have received our instructions from authoritative writers on Conifers. The P. Oocarpa takes after the Montezuma in the number of leaves per bundle, while seven or so of these Mexicans take after the P. Patula in that direction, and sometimes other respects. They may be found and seen, e.g. the P. Nelsoni, Teocote, Leiophylla, Greggi, in the Temperate House at Kew. Whether they take after the Montezuma and Patula, or the Montezuma or Patula after them, from a patriarchal-system point of view, is a question better settled upon outside the radius of our shores.

There are other Mexicans besides these, cropping up at intervals, and inviting attention, but they have 
no place of notice in our elementary efforts at thr elucidation of the trees more in our midst.

The P. Torreyana need not trouble the identifying intelligence of the looker around, since it is supposed there is hardly a living specimen extant with us.

\section{TED E GROUP OF TERNATE PINES}

P. Coulteri, Sabiniana, Jeffreyi, Tuberculata, Radiata (or Insignis), Patula, Teocote, Rigida, Serotina, Palustris, Teda, CanaRIENSIS.

Forth they went into the forest, Bringing firewood to the wigwam, Bringing pine cones for the burning,

By the brands that still were burning, By the glimmering, flickering firelight.

LONGFELLOW, Song of Hiawatha.

Numerically, this group presents rather a formidable list. The frightfulness of the length is considerably diminished by the fact that one and only one, the P. Radiata, more familiarly known as the P. Insignis in England, if not in America, is in what we may call a state of common cultivation with us. The four last mentioned in the list of twelve are practically non-existent with us, while among the others there are those that severally might be described as uncommon, inclined to be uncongenial, or very rare, in the British Isles.

The Latin word Tæda-the equivalent of the Greek word $\delta a \hat{\delta} \delta$ s, the genitive case of the noun substantive $\delta a s^{\prime}$-claims the honour of responsibility for the appropriate name given to the group.

When translated it will be found that these words of learned length, and in one instance (the Teocote) of still 
more puzzling hieroglyphic formation-both of them culled from the deep depths of dead languagesdenote Torch Pines, or Firebrands. Both of them, too, have similar significances, and are associated with those Pine trees that are most super-abundant in resinous qualities.

When it was thought befitting in an olden day, where primitive customs prevailed, to requisition a little illumination for the purpose of a more decorous carrying out of certain ceremonies, or orgies, as the case might be, these sort of Pitch Pine trees and their boughs were articles in great request.

If it was a marriage ceremony that was contemplated, a nuptial torch (tceda jugalis) was deemed an essential; a custom, we might add, that has its continuance in a moderr - day world. The torch dance at a royal wedding in the Prussian Court has been accounted by eye-witnesses the most picturesque episode of its drawn-out proceedings.

If a torchlight procession was considered the right thing, or regarded as a desirable adjunct in the interests of artistic effect-at one time, perhaps, on the occasion of a conquering hero's return, at another as an obbligato to the obsequies of a defunct celebrity, or even maybe as a more commonly employed accompaniment of various other kinds of jaunts, pageants, carnivals, or masquerades, either of a festal or funeral nature-these Torch Pines (todoe ardentes) were the fiery beacons that lent colour to the scenes, and gave the whole proceedings a tone.

From many of these trees enumerated in the Tædæ group, this obligation was expected to be forthcoming. They were depended upon, before the dawning days of electricity, acetylene, or kerosene convenience, to contribute those rays of primitive light that were required, and were all that at that time was obtainable to impart dignity and add 


\section{P. COULTERI AND SABINIANA}

lustre to the various ceremonies in their turn of revelry or solemnity.

\section{P. Coulteri and Sabiniana.-}

So they gathered cones together, Gathered seed cones of the pine tree, Gathered blue cones of the fir tree...

There they stood all armed and waiting, Hurled the pine cones down upon him.

LONGFELLOW.

This is how we are told in the Song of Hiawatha that the mischievous Puk-Wudjies, they " the envious little people," did to death mighty Kwasind, the strong man of the Red Indian legend.

In this affray it must have been the heavy cones of some such Pines as these that scored, and did the work of siege guns upon the sleeping head of the ill-fated giant of champion renown, and of whom it was boasted " no man dared to strive with," and " no one could compete with." A "blue cone of the fir tree," hurled, to him would have been but a popgun affair, and as an assault by a wasp on a brick wall.

On paper there seem a very few points of difference between these two Conifers-P. Coulteri and Sabiniana-beyond the shape of their both gigantic cones, yet in its native land the P. Sabiniana is accounted as of a marked unmistakable appearance.

P. Sabiniana.-In a country of luxuriantly foliaged trees (California), it alone is sparsely attired with leaf decoration. In a country of towering Pines, it alone is many-stemmed, straggly, and bushlike. In a country of rich and dark-green foliage, it alone wears leaves of palest hue. For these characteristics it has been accredited with a remotest Pine ancestry, and looked upon by some as hastily nearing that decadent 
condition and stage of existence which is generally associated with Aztecs, Australian aboriginals or bushmen, and other perishing people of the earth's surface. For these reasons it will be opined that as a tree here it is more likely to be occasionally tried by curiosity-mongers than abstract-minded admirers blest with a soul for scenic effect.

The size of the cones, both of the P. Coulteri and P. Sabiniana, which in point of fact are rarely seen, even by the most inveterate Pinetum hunters, is a matter of incredible surprise to anyone upon a first introduction. The cones of the Sabiniana are shorter longways, and more rotund broadways, than those of the Coulteri, and present quite a different appearance. Authorities have written very variable statements as to their weight. Some of the Coulteri cones that I have shown at forestry exhibitions give the following weights: An unbroken cone from the Yosemite Valley, 4 lb. I I oz. ; and two other broken cones, one from Arley Castle (R. Woodward), and another from Leaton Knolls (Colonel Lloyd, M.V.O.) weighing just over 3 lb. each.

P. Ponderosa and Jeffreyi.-It is not an easy process to distinguish these trees apart at a first glance from the preceding two that we have discussed. The cones, if they could only be persuaded to put in even a casual appearance, would opportunely come to the rescue of any worker at the riddle. While the cones on the Ponderosa are pretty plentiful, there are only a select few, be it remembered, who have ever had the opportunity of seeing cones on an English-grown Coulteri or Sabiniana. Speaking from the personal point of view, and frankly confessing the limitations of that narrowed area, the P. Ponderosa (with the exception of the P. Insignis) is by far away the most commonly met with tree of all 
this group. Whether it is that they have endured the conditions of our climate with more success than other trees imported about the same time, or whether their presence is due to the fact that those who planted them, when they preferred an off-hand request, perhaps on some visit to a nursery garden, and asked in all their innocence for a rarer Pine to plant somewhere or other, on some newly enclosed garden or ground, mead, or meadow, were, so to speak, served across the counter with the readiest-at-hand stock-in-trade article of the nurserymen, which often turned out to be the subject of our discourse, the P. Ponderosa (and which often, by the way, was distributed under the name of P. Benthamii), I am unable to do more than surmise. Those that it has been my fate to see have all exhibited the curious phase of curved and tortuous branches.

The different colour of the shoots (vide Table), and the larger cones, seem to be the best points to make for, to decide between the Ponderosa and Jeffreyi. Both seem to depend for success upon a dry soil, and to prefer a dry climate.

P. Tuberculata and the two-leaved P. Muricata have one point in common, and that is to be noticed in their cone-clusters clinging persistently on the large-sized branches. As the P. Tuberculata is a three-leaf-in-a-cluster Pine and the P. Muricata a two-leaf-in-a-cluster Pine, the problem of distinguishing the one from the other is most happily reduced to an easy process. In the case of the P. Tuberculata these cone-clusters appear in the very early stages of life in the tree. Not content with crowding themselves on the older branches, they also invade the main trunk of the tree, until at times they actually become cmbedded in it. For this reason the tree appropriately receives its name Tuberculata, a word 
which, under the process of translation, emerges as "furnished with a protuberance or any projecting substance." It was introduced in I 847, and cannot be accounted to have thrived in England.

These trees, with asymmetrical oblique and persistent cones, are spoken of among botanists as serotinous, which may be taken to mean that some untimely episode in the natural course of events happens to take place in the course of their existence, and the event referred to in this case has reference to the shedding of their seeds. Serotinous is a word which literally taken means "late in the day," and equally might apply to human action as to tree habits.

Three agents there are said to be which are responsible for this process of seed distribution, and they are : the wind, animals, and fire, and the $P$. Tuberculata is only amenable to the influence of the last. Of such a marked feature is this persistent habit in the cone life of some Conifersas, for instance, in the case of the tree in question, the Insignis, Muricata, Rigida, and others - that it has been suggested that they should be reclassified in accordance with this habit. Those who, at a humble distance, have tried to master some of the rudimentary arrangements of the past-masters of the art, and to follow the modest amendments made from time to time to a long-established classification, which has gradually broadened and developed, in unhurried discussion and with authoritative consensus, must devoutly hope and one and all pray for a deliverance from such a drastic overthrow of the prescribed rules of the game that may leave so many of us to begin anew once more, "to burn what we have been taught to adore," and to bow down before a new shibboleth. Heaven save us all from a fate like this ! 
P. Radiata or Insignis. - In spite of the contested nature of its name, this Pine from Monterey has been and will be, I strongly suspect, to most alive of over twenty years of age now, still known and made allusion to by its old name of P. Insignis. By that name we have known it, by that name where it grows in plenty it has been always familiarly greeted on sight. If we have been wrong in calling it Insignis, we have many of us been wrong through a long erroneous life, and now is too late in the day to change our habits and call it by any other name. Old friends cannot be expected to find anything welcome or irradiating in the change. Of such commanding strength is force of habit! It requires something even more compelling than royal decree or stroke of pen to change such a widely established nomenclature.

The Insignis is a tree that undoubtedly favours sea air, and grows at its best on our warmer coast lines; at the same time it can flourish, and has flourished, in some more Midland situations, and often it has been observed best, despite a saltless influence, in the more humid environment of lakes and ponds.

One tribute more must we pay to this so-called "remarkable Pine," and it is this, that where it succeeds it seems to luxuriate in the most superabundant and brilliant wealth of grass-green effects of colour, and to look as if it absolutely revelled in an irradiating glow of health, strength, and vitality. In this, its state of prime perfection, we may well say of it, in Old Testament metaphor, "that its glory covers the heavens, and that the earth is full of its praise."

\section{P. Patula.-}

And their delectable things shall not profit, but they are their own witnesses.-ISAIAH.

The P. Patula may be looked upon as the analogue of the long-leaved Himalayan P. Longifolia, to which 
allusion has been made in discussing the P. Gerardiana. We have also compared it, from a scenic point of view, with another Mexican Pine, the five-leaf-in-acluster P. Montezuma.

Both it and the P. Teocote are only to be found flourishing with us in places of exceptional climatic mildness.

The P. Patula at Carclew, Cornwall (the residence of Colonel Tremayne), is perhaps the most attractive sight that any Pine can display. It, and the bestgrowing types of the Montezuma-which are, however, generally smaller-grown specimens with uswould wring a beauty prize from the verdict of any æsthetic body of jurymen, in any competition of Pines. As a timber product it may not acquire merit in the eye of the sterner sylviculturist, but an apology for its presence anywhere that it will grow is contained in the verse of Isaiah. It is its own witness.

The P. TEосоте is a shorter-leaved, smaller-coned edition of the Patula. Diligent search on the part of Elwes and Henry has, it appears, only resulted in finding two or three specimens growing in Cornish or S. Irish climates. Only the cosiest of corners, in the most comfortable of sheltered positions, will give either of them a chance of life with us.

We are told that ocote, in Mexican vernacular, signifies much the same thing as toda does in the Latin language, and to which we have referred.

\section{P. Rigida.-}

Dark behind it rose the forest,

Rose the black and gloomy pine trees,

Rose the firs with cones upon them.

LONGFELLOW, Song of Hiawatha.

Whether Longfellow had in mind this particular Pine when he wrote his Indian Edda, we do not pretend 
to pronounce upon authoritatively, but we do claim that of the half-dozen hard-wood Pines that hail from the same district in which the scene of the Song of Hiawatha is laid, on the southern shore of Lake Superior, no tree among them could with more faithfulness depict the blackness and gloom described there than the Pinus Rigida.

If the $P$. Patula is to be regarded as rightly entitled to the award in a beauty competition, the P. Rigida can put forward a very substantial claim to a first prize in a class of precisely opposite conditions. When the P. Rigida is set beside the other members of the Abietineæ, their few deformities here and there shrink into insignificance by the side of its deformities. In a similar-conditioned show, Quasimodo, the hideous dwarf (in Victor Hugo's Notre Dame), had only to put his head in the horse collar for the briefest of moments to overmaster any opposition that could be brought to bear against him. The P. Rigida at Kew has only to be looked at for a few moments to convince any beholder of its ability to make as easy a conquest over any rival in a similar competition. With its scarcity of twisted leaves, its scrubby appearance, the unnatural look of its adventitious branches-and sometimes even staminate flowers poking their way out from the main trunk-it gives an onlooker the idea that an unkind Nature has doubled it up with every crippling complexity, and pelted it with every disability that plant life or human life could be heir to.

As a profitable institution it ranks high in its own country, and produces resin in quantities. It is called the northern, while Palustris and Ponderosa are called respectively the southern and western Pitch Pines. 


\section{P. Serotina, Palustris, Tæeda, Canariensis.-}

And he sacrificed, and burnt incense, in the high places, and on the hills, and under every green tree.-2 Kings xvi. 4 .

Although this quotation from Holy Writ had reference to events which took place in Eastern countries, the fact that the Tæda Pine numbered among its many aliases the name of the Frankincense Pine, and was so saluted by the inhabitants of the country where it grew, seems to suggest that its resinous qualities were in like demand, as were the trees of Palestine, for some ceremonial purposes in western lands.

These four Pines are hardly worth words here in addition to their description in Tables. Out-of-doors in Great Britain they have been put upon their trial by many planters, in many places, and found wanting. They belong to the hopeless category of Cometo-Nothings, as far as our climate seems concerned.

They seem to treat immigration to our shores as a pilgrim's journey, and like a pilgrim's march, with the prospect only of death at the journey's end. To expatriate them seems but to invite and condemn them,

To wander witheringly,

In other lands to die.

And whenever they are transplanted from their native surroundings, this is an ultimate end they seem speedily to achieve. 


\section{BANKSIANA GROUP OF TWO-LEAVED OR BINE PINES}

Green be those hill-side pines for ever.

WHITTIER,

P. Echinata (or Mitis), Halepensis, Brutia, Muricata, Pungens, Virginiana (or Inops), BankSIANA.

Of this group of seven there are only two, the P. Muricata and P. Banksiana, that are tolerably often to be seen with us. The majority of them are climate shy, and one, the Virginiana or Inops, has never been persevered with, for the very urgent reason that it neither brings beauty to bear on any scene nor holds out any prospect of profit to its producers.

In the two-leaf-in-a-cluster division the old order of class legislation among trees has changed, and given way to the new. The Sylvestres group has been disestablished, and two groups, Banksiana and Pinaster, set up. Most of the Sylvestres have been drafted to the ranks of the Pinasters, and the new Banksiana group takes toll from both of the old groups formerly named Banksiana and Sylvestres.

The chief difference in these two new groups is to be found in the position of their cones, and, secondly, in the manner of the growth of their shoots.

In the Banksiana group, the cones grow not only on the ends of the branchlets, but also lower down, in the middle of each year's shoots.

In the Pinaster group the cones are only subterminal, or approximately close to the end of the branchlet.

In the Banksiana group the shoots appear in more than one whorl, and are therefore described botanically as multi-nodal. 
In the Pinaster group only one whorl of branchlets, buds, and cones appear, and those approximate towards the end, or, in other words, sub-terminally, of each year's shoot. These are botanically described as uni-nodal as opposed to multi-nodal.

P. Echinata, or Mitis.-This is a Pine which one generation, or school of thought, called Echinata, and another generation fixed upon for a name the word Mitis. Echinata literally means either one or two things.

To a landsman the first translation "hedgehog" would, in all probability, satisfy his thirst for knowledge, while to a mariner or dweller by the seashore the second translation "sea urchin," a little frequenter of the salt-water element, would probably most strongly appeal. Both of them are prickly-backed representatives of the created world, and that is the main issue before us.

Such a name conveys to all the impression that the tree in question has prickly points somewhere in his composition, in common with the members of the Echinoderm family. While the other name bestowed, "Mitis," denotes a substance that spells softness. It seems a curious coincidence that this tree should be alternately called after two phases of nature possessed of two such opposite and contradictory attributes and qualifications as a hedge-pig's quills and a feather-bed mattress respectively recall.

How the rough places became smooth, and why the smooth places were called rough, is a bewildering enigma at first sight. As a matter of fact the leaves of this Pine are notoriously soft, and the cones have prickles like a great many other cones, but rather less than more aggressive than many others that we could mention-the P. Pungens of the same group, to wit. 
As long as anyone remains on English shores, they will have very little opportunity of either making trial of the softness of its leaves or experiments upon the portions of its harder externals. It is one of those many Atlantic Coast Pines that seem to derive no homely joys from any stay with us.

It is dissociated in appearance from the other short two-leaved Pines in that its leaves are threesided, while all the others are two-sided or flat. The brittle nature of its shoots, their blue-white bloom of colour, the complications of the character of its basal sheath of the leaves, all give aid to identity.

But as the tree was introduced in 1739 , and there appears to be only two or three specimens extant with us, any chances for putting into practice a little observation on these points are likely to be remotely removed from the paths in life that most of us are wont to traverse.

P. Halepensis, Aleppo, or Jerusalem Pine.-The same remarks as to their scarcity of appearance which applied to the preceding P. Echinata refer equally to this Pine. It is the commonest of the Mediterranean region, and though it has, under transportation to Australia and other places, thrived and made conquest of new lands and countries, England is not to be counted among them.

It is one of those Pines that must be remembered, among several others (Pinaster, Thunbergii), as achieving success on barren seashores. As a sanddune tree and in the production of resin, it is reported to even outclass the Pinaster of the Landes. Like a goat, that is said to thrive on orange-peel and brown paper, P. Halepensis is quite happy on soilless lands and rocks where nothing else thrives.

If by chance you came across a two-leaved low tree, with branches singularly devoid of leaves, and 
yellow-brown cones with very thick peduncles (stalks), produced sometimes singly but often in whorls, then your suspicions may be justifiably aroused to the fact that you have encountered the Jerusalem Pine. If you went one step farther and examined the buds, and found that they were non-resinous and had recurved scales, then you may be sure that it was either the Halepensis or its variety, the P. Brutia, since they alone of two-leaved Pines are formed that way. But such a chance of investigation would be far more likely to take place in a tramp abroad than a trip at home.

P. BRUTIA.- It seems to be rather a controverted point, whether this tree should be regarded as a separate species or variety of the P. Halepensis. Both sport non-resinous buds with recurved scales, and this dissociates them from the others in the group. The shoots of the P. Halepensis are grey, the shoots of the P. Brutia are green. The cones of the Halepensis point backwards, the cones of the Brutia point forwards; and as the names imply (Calabrian and Aleppo), it seems to be more a question of the divergencies of geographical habitat that must be held responsible for these disagreements in details.

P. Muricata, or Bishop's Pine.-From " Murex," a purple fish with a prickly spine, this Pine derives its Latin name. From its English name, a reader would incline to the belief that the tree has some connection with the Episcopal bench. Though rather indirectly, it is possible that some sort of ecclesiastical connection can be traced.

There is a certain district in California, within the reach of Pacific sea-breeze and salt-water atmosphere, which was named after a certain Bishop San Louis, and known as the San Louis Obispo country, at least 
so the story runs as told by some and denied by others. As we are not investigating the antecedents of the bishop, or the question of his existence or non-existence, we must merely content ourselves, and probably more than content our readers, by noting the fact that the tree grew in the Obispo country, and that Obispo means bishop in the language of Spain.

It is one of those weird objects of trees that are cone-covered with hooked spine cones of asymmetrical shape, oblique and persistent, and often in large clusters (like those, for instance, of the P.Tuberculata, Insignis, Rigida, and others), growing upon branches, branchlets, and sometimes stems. Like the Insignis, its persistent cones have the scales much thicker on the outer side towards the base. It does not, it must be remembered, go as far in its efforts of persisting as the $\mathrm{P}$. Tuberculata and retain them actually embedded in the trunk. But here similarities cease.

The P. Muricata is a two-leaf-in-a-cluster Pine, and the trees with similar cones just mentioned are all three-leaved-in-a-cluster Pines, and so tell a tale, candle clear, in the direction of identity.

Compared with the others of its group, the $P$. Muricata is far more commonly seen than any others of its family group. Not that anyone is likely to meet it in ordinary wayside wanderings or holiday rambles-we do not mean to infer that, but only that they are quite likely to come across it in those places where rare trees were planted in times gone by by enterprising collectors; and in such places as these it is that you may encounter it, and, when you do, wonder at leisure upon the curiosities of plant life that Nature has to offer for our observation and study.

P. Pungens.-Lest the serenity of mind of the 
reader of descriptions be disturbed at the similarity of this Pine and the previously described one, as it appears on paper, we offer this crumb of comfort. There is a cone difference that gives a clue. The prickles on the P. Pungens are incurved by tendency, and the prickles of the P. Muricata's cones are decidedly recurved. We might further add that the prickles on the P. Pungens are of a more substantial appearance than those of the Muricata, nor have the cones of the Pungens, at least the ones that I have seen, the thicker scales on the outer side of the base alluded to in the description of the Muricata.

Only some half-dozen or so, including two at Kew and two at Bayfordbury, seem to be the result of the attempt to grow them, and this limited little lot seems to impersonate the summum bonum of their success in England.

Consensus of opinion among the magnates on the subject concurs in the opinion that where the tree has been attempted the result has been an inglorious failure. Few have survived, and in those few places that they have, in their older stages of life have turned out the reverse of ornamental. In all probability they will be encountered in even lesser numbers in the future than they have been in the past.

P. Virginiana, or Inops.--The word "Inops" is a Latin one, and signifies indigence and want of wealth. There is a ring of poverty about the name, that is more usually connected with the indigent fate of a workhouse bratling than the idea of a desirable tree to plant out in the interests of ornamentation. We must presume, too, that it earned its name, as the uncomplimentary remarks made about it by writers ever since have endorsed this view.

It is also credited by the same writers with only a brief span of life in our collections, and perhaps that, 
under the circumstances above described, should read rather as a merit than demerit, but not in the sense that those whom the gods love die young.

The P. Echinata and P. Virginiana read rather as a complex problem for dissociating purposes.

There are these differences : the leaf of the Echinata is three-sided, the leaf of the Virginiana two-sided, and the difference of the basal sheath should be capable of affording a key to solution. The shoots of both show a bloom of blue or violet coloration.

Loudon pointed out, and it is well worth remembering by those trying to learn their trees, that only two of the two-leaved Conifers have these coloured shoots, and they are the subjects of our discussion, and that only two of the Ternate, or three-leaved Pines, had shoots of this hue, and they were the P. Coulteri and Sabiniana. To this we ought to add the P. Jeffreyi of the same group, a tree invented since the days of Loudon, the shoots of which are somewhat similar, but of a paler shade of colour, that you might better describe as of a light heliotrope tint.

The P. Echinata and Virginiana are said to be hardly distinguishable in their youth, and seemingly pretty much of the same pattern in their adolescence and old age. Yet not like Tennyson's two sisters, " both beautiful alike." They both seem cast in an opposite mould, and must have been at some distance round the corner when good looks were being distributed among the families of Pine trees.

P. Banksiana is a tree a great deal oftener seen than others of this group. Its natural habit seems to be sandy soils and the most barren of localities. It is not recommended by the faculty as a tree to cultivate, yet some who run shootings on high lands and barren tops, where coppice scarce makes show, 
are casting wistful glances on its possibilities to make good bare defects.

The tree is in shape of a stunted type. Its shortness of leaf (about $\mathrm{I} \frac{1}{4} \mathrm{in}$. long), its plentiful abundance of persistent cones, tapering to a point, and curved as a ram's horn, make it intelligibly conspicuous to any observer.

Of this tree it is written, as of most of its group, that it is of no ornamental or any other value. The old Greek gods of an ancient world had a custom of converting beautiful maidens and glowing youths in whose career they were interested, and generally those who had been cut off before their prime by some untimely fate, into the forms of trees and shrubs, or lovely flowers. What form of man, or figure of a woman, would these all-glorious old Pagan deities have selected to immortalize by converting into the shape of any member of the Banksiana group-the majority of which are inelegant, and the remainder of which are squat of shape-and converted them on their usually adopted principle of similia similibus (like to like), we tremble to think. We will leave it to our readers to select their own model, and, if they so wish, from the circle of their own acquaintance.

\section{PINASTER GROUP OF BINÆ (TWO-LEAVED) PINES}
P. Pinaster, Pinea, Sylvestris, Densiflora, Montana, Contorta, Resinosa, Thunbergit, LARICIO, LeUCODERMis.

Lift to the skies her canopy of woods.

The Pinaster Group.-The net result of opinion collected from the various sources of authorities, writers, and tree-growers of past and present days seems to amount to this : that, whereas the Banksiana 
group-at home, mind you, not abroad-has had meted out to it all round about as castigating a dose of " damnation with faint praise" as ever fell to the lot of any misfortunate man, beast, or plant upon earth, the Pinaster, on the other hand, has been the lucky recipient of praises sung by poets, of thanksgiving lip-service expressed by growers, and of high hopes entertained by theorists.

Whether there is any mysterious property of air and climate that gives an enabling power to the tree, that boasts one whorl of branchlets, buds, and cones per annum, to prosper in our island home, and withholds it from the other little coterie, that goes one better in this direction and produces more than one whorl per annum, we dare not hazard opinion. Nothing under a Royal Commission-and most Royal Commissions indulge in a minority report -appointed by the Board of Agriculture would dare essay a final pronouncement on this question, but appearances rather point that way. Possibly their finding would be that whereas most of the Banksia, five out of seven, come from the Atlantic side of America, and those districts that Professor Sargent in his conspectus marks out under the letter A, and describes as north-eastern, only one of the Pinasters comes from that tabooed district, and that is the P. Resinosa, which alone of them is labelled as unsatisfactory here.

Of the Banksia and the seven (without varieties) enumerated as belonging to it, only two appear to be moderately hardy, while of the Pinaster group, with its formidable array of independent varieties (i.e. the Austrian numbered as a variety of the Corsican), all except the P. Resinosa, and that ominously from the fatal Atlantic side of America, are good growers with us. 


\section{P. Pinea and Pinaster}

I saw far off the dark top of a pine

Look like a cloud-a slender stem, the tie

That bound it to its native earth. ...

Wordsworth, The Pine on Monte Mario at Rome.

The Pinea (Stone, or Umbrella Pine) and the Pinaster (Maritime, or Cluster Pine) run somehow concurrently in some quite well-constituted minds. Doubtless they should not do so, but it often happens, for all that, that a tree-lover, prating on trees, gets badly mixed up upon the question of their different individualities. $\mathrm{He}$ is often prone to drift towards a non-compos-mentis state of bewilderment as to which is which. When he talks of the one, often as not he means the other; and when he is thinking of this other he wanders orally away on to the aforementioned. Perhaps it is the similarity of names, added to the similarity of locality, that they affect, which is responsible for this Didymus doubt, and which exercises a beguiling effect upon the dendrologist's mental equilibrium.

The coarser leaves of the Pinaster, and its habit of leaving the remains of its buds' scales on the shoots, ought to assist us in arriving at its identity. In addition to this, the white cottony appearance of the leaf sheath, and the kind of fimbricated "froufrou " effect created about it, makes it quite different from anything else of its kind.

Both these trees have a separate claim to a notoriety of their own: the P. Pinea as an artist's model, and the conspicuous feature of a foreground in many a Turner and Claude landscape, the Pinaster as the all-conqueror of the sands; and the way it contrives to get a grip of those sands with its long perpendicular roots, with undenied resolution and consolidating effect, must excite the admiration of all who deem 
tenacity of purpose a virtue. Indeed, it seems as much at home upon a seashore as a sand-born courser ambling over the inhospitable tracts of his native wastes in Arabia Deserta.

By Pliny the Second, and in modern days by the Portuguese, the Pinaster has been called and regarded as the Wild Pine, while the Pinea has been looked upon and designated as its cultivated counterpart. Indeed, so far has this idea been carried, and to such a low depth from the position of a stately tree has the P. Pinea sunk, that at one time it was associated linguistically with the common and garden Pine Apple. It might be adduced that it is hardly as derogatory to the dignity of a Maritime Pine that a Pine Apple should put forward a questionable claim of relationship to it, as it is that an outcast nettle should have established a direct kinsmanship to our stately Elm. It should be added, that, in spite of the indignities, both have soared above and survived the ignominy of the inferences.

\section{The Scots Pine}

The Scottish Fir

In murky file rears his inglorious head, And blots the fair horizon.

Mason.

P. Sylvestris (Scots Pine) is the indigenous representative of that old-established trio of Conifers in our midst that go by the names of Scots, Austrian, and Corsican.

The three are evidently trees of affinity, but of different geographical habitat. They require here but little comment and less explanation. We should like to record that we are by no means in agreement with the drift of the poet Mason's idea of it. We have only quoted it as an expression of opinion that 
evidently held good in the darker ages of a century ago, and an opinion that was endorsed and quoted, more or less as an eternal truth, by Uvedale Price, an acknowledged authority on the subject of landscape gardening in his day, some thirty or forty years after. "De gustibus non est disputandum" (" there is no disputing about tastes "), but the idea of the Scots Pine as a blot upon the landscape would find no acceptance in present-day tastes.

This maybe, is how, three or four generations ago, some talked in their haste and saw with unprophetic eye the career to be of a tree that has ever since never failed to be anything but a joy and delight in life to the scenery lovers of the generations that succeeded them. We have recorded these old-spoken opinions, not because we deem them to be reflective of the spirit even of that age, but only because they happened to be the didactic utterances of a fashionable few who in their day were looked up to as a "light in the path and a lantern unto the feet " of the planting world.

What we say to-day, and are convinced that the vox populi would re-echo the sentiment, that as the sun never ceases to gladden the heart of man because it is the same old superannuated sun that has gladdened it for thousands of years, so sure is it that our enduring old ally of landscape effect, the Scots Pine, despite the antiquity of its reign among us, will never fail to gladden, for centuries to come, the hearts of future generations, even as it has rejoiced ours; and we feel sure that our wish, strengthened in belief by the hopeful words of a modern poet (E. M. Mills, published in Country Life, and quoted below), will be fulfilled, and that even if man neglect his duty of replanting them, Nature will step in and perform the task, and future generations witness what we have seen: 
The Little Firs-the self-sown Firs-that yet in days to be,

Shall lift plumed heads against the sky-

Shall stretch red, slender trunks on high-

Shall stand, each one a Forest Tree.

If all the people in Great Britain, who only knew one tree in the world by sight, in and out of season, and were, under penalty, enforced to sally forth, point out, and give a name to that tree which of all others they knew best, some 90 per cent., we think, would pitch upon the P. Sylvestris, and in so doing they would probably when they spoke of it-as did the poet Mason-employ the misnomer Scotch Fir, in direct defiance of all Scotsmen's susceptibilities and all arboricultural authorities, who very properly have impressed us with the desirability of alluding to it as the Scots Pine. It is a tree that, if we were to write about at length, we could not say too much in its praise and honour, and it is a tree that if we were to try and explain we could not say too little, for there is no need to hammer on at that which we all are aware is driven home.

We could not, in our desire to give it glorification, rise to the height of the occasion, and we could not, if we tried, hope to reach to the depth of its historical antiquity with us.

It is too well known and appreciated by all to need further dissertation upon here.

The name implies its origin, and the whereabouts of its localities of its native heath.

From the forests and Highlands,

We come, we come,

once wrote Shelley, and these words tell the tale of their indigenous home. 


\section{P. Densiflora and P. Thunbergit.-}

Like strange mechanical grotesques Making fantastic arabesques.

O. WILDE.

These are the trees that the Japanese in particular exercise all their topiarian ingenuity upon, by trimming, distorting, or dwarfing them into all sorts and shapes of whimsical ornamentation.

They are the Red and Black Pine respectively, and also the so-called Japanese representatives of our Scots and Austrian Pine respectively. As the date of their landing here was some fifty or sixty years ago, in the seed-stage, they have not had quite a sufficient time to make a reputation for themselves. Both seem hardy, and the P. Thunbergii is fast heaping up for itself-as surely even as it gathers together by the power attraction of its roots, the shifting sands of the sea-a character as a coast-line success that threatens to dispute the sovereignty of the sand dunes with its long-established presiding monarch, the Maritime Pine.

Both these Pines have been ladled out in time past by nurserymen as P. Massoniana, and wrongly called. Lambert's P. Massoniana is, as far as we can gather, still rather a mystery. It is probably a long-leaved more southern growing Chinese tree, and if it is in cultivation-and some of us fondly imagine that we have it -it is too early days to discuss its possibilities. P. Thunbergii is most noticeable for its curiously twisted leaves, but the similarly twisted leaves of the P. Densiflora are of softer texture than the P. Thunbergii. The long filaments of the basal sheath, which are shared in common by both, mark them out from other two-leaved Pines-as, for instance, the Scots, or Corsican Pine. Then there is the difference of barks, the one (P. Densiflora) red and the other (P. Thunbergii) dark grey; the colours of their shoots 
and leares, which are given in the Table, are characteristics which all help to solve the problem of identity.

The few specimens of the P. Densiflora that we have come across in this part of the world appear as if they might have been aptly called Densifolia, on account of the remarkable density of their foliage. The branchlets in their equipment remind one of a half-clipped tail of a poodle dog, with a cultivated and thick tuft at the extremity.

P. Resinosa is cited as the S. American representative of our P. Laricio, with these differences: it has a longer basal sheath and marginal resin canals. Both of them, be it observed, rather occult differences, that only appeal to the few rather than to the many. One point that, however, may appeal to the many is that it is most improbable that they will come across it in England. It has earned the reputation of being unsuitable to our country.

There is one question we suggest for consideration without attempting to make satisfactory answer as to these "alternates" of other countries. Controversy has often been rife upon the probable single or multiple origin of many of the beasts of creation. I do not know what may be the views of the learned as to the single and common, or the multiple and independent origin of Conifers, or even the single and multiple origin of these similarities of species; but if P. Laricio and its affinities, P. Leucodermis, Sylvestris, Thunbergii, Densiflora, Resinosa, inter alia, had once a single origin, and then were scattered to the four corners of the earth by the four winds of heaven and other agencies, and if after that they showed first slight and then gradually growing changes in process of evolution, according to their different environments, what are we to expect in the way of improved commercial timber, by retrans- 
planting them in quantity away from their naturalized or native soil, where they have set up for themselves an individuality of their own, and in accordance with the requirements of the various regions in which they have become settlers? Despite this inference on the contrary side, some of such varieties have survived their transportation well enough to justify extended attempts, and our repeating of invitations to "At Homes " here.

\section{P. Laricio, The Corsican Pine.- \\ I wandered lonely where the Pine Trees made Against the bitter East their barricade.}

WHITTIER.

It is now some seventy years since our ancestors planted Corsican Pines, and euphemistically wrote of them as the Altissima Pines from Corsica. Though not approaching in grandeur of size this tree in its native land, the trees here have attained a greater height than any other Pines, including the Scots Pine, planted in those days. To give our own opinion upon the tree, we should sum up the situation abruptly with the remark that while we all like them intensely, the rabbits with an equal intensity dislike them.

We should like-by way of an obiter dictumto recount a little homely experience on this alleged distaste of the Corsican Pine on the part of the rabbit. Some time since, from where I write, when rabbits were thick upon the ground, as thick as Milton's " autumnal leaves that strewed the brooks in Vallombrosa," a young Corsican was planted for the sole purpose of offering temptation at a spot where there passed and repassed, in numbers considerable, a host of hungry rodent rabbits, in quest of evening meal and evening drink.

Rabbits, it was generally supposed, like many another frail specimen of the animal kingdom, were 
more able to resist anything than temptation, and dubious opinions were expressed as to the strength of the temptation that a young Corsican might offer to the gratification of their recurrent appetite. The majority prophesied a short shrift and a speedy end to the sacrificial victim, and the majority were wrong: To-day, when the rabbits have since been almost improved off the face of this plot, the tree, as a respectably grown and ornamental member of the Society of Pines, remains, and is a monumental evidence to the distasteful qualities of its flavour; and the excellency of their discrimination would be endorsed, we feel sure, by any species of man or superman who would care to try conclusions with the bitter experience that a taste of its leaves produces.

Possibly this trial by taste, as a trial of vintages after the gathering of the grapes, might have some influence in deciding between a Corsican and Austrian Pine. We have referred in the Table to the difference as to shape, bark, and leaves, and in an old tree the first two of this trio of differences are the most convincing.

Many complaints have been received as to losses incurred, owing to the long tap root, in transplanting Corsicans. Professors from schools of forestry, and other wiseacres who have made the experiment, bid us plant them late in the spring, very late, even to the time when summer is upon us. When fuller grown this long tap root may have been of great service to the stability of the tree at a later date. Speaking from a limited experience, upon the point of view of quantity, of trees under immediate observation, but not from a limited or impersonal experience of the force and fury of the gales and winds (I write in I916), the Corsican has withstood the test when Scots Pines, Weymouth Pines, Silver Firs, and Spruce Trees, and many Hard-woods have strewn the ground with havoc and derelicts. 
P. Laricio var. Austriaca or Nigricans.-For the Austrian Pine I hold no brief as a planter in the Midlands. It may have its uses and serve purposes in barren places, on sandy shores, where winds unkind blow hard and cruel, and other inhospitable elsewheres of a like nature, for all I know to the contrary. The fact remains that it is neither so prepossessing in appearance nor sought after so much for sawbench requirements as its congeners the Scots and Corsican Pines. If there is any truth in this summing up of its qualities, it can only be remarked that it ought to be, in most places, discarded in favour of its affinities.

P. LEUCODERMis has been generally looked upon as the Alpine form of the P. Laricio. It hails from Herzegovina, Bosnia, and Montenegro. It was only introduced to Kew in I894. Experimentalists are trying them here, and they seem very promising. In the heights of their own country they appear equally to scorn the summer sun and winter snow. If our English hospitality may not be able to conscientiously guarantee the former and more attractive side of the picture, it can fearlessly vouch for the counter-attractive. It can offer in profusion-given time-hard winters, late frosts, snowstorms, and cold winds. It has bleak pastures in plenty, on high lands and waste places in lofty situations, all adapted eminently to the more abundant presence of tree-life. If this is not so, a false doctrine has been dinned in our ears, cast in our teeth, and thrust down our throats, over and over again, from the day when Evelyn, in 1662, wrote his Sylva, to the present time, when the latest contribution on the subject was penned and produced by Professor Stebbing.

From the tree's historical antecedents, or anything that we can learn of it, what Pine, or other Conifer, we ask, is there better constituted to make experiment 
with in these direful places than this Leucodermis tree and mountain product from Herzegovina and Balkan heights.

P. Montana and Contorta, the Mountain Pine of Europe, and the Lodge Pole Pine of America, to say nothing of several other aliases that they and their formidable list of varieties indulge in, remain the only members of the Pinaster group left unnoticed.

The Montana Pines take their name from lofty regions whence they come, the Contorta from the often apparent curious twist of its young shoots.

We have given in the Table a series of their differences, and, acting on the Cornish proverb " Enough is enough, and too much is a plenty," we will endeavour not to improve upon the occasion by purposeless repetition, and only refer to the cone structure part of the question.

The Contorta, like several of the three-leaved Pines, and the Muricata among the two-leaved specimens, sticks to its cones, or its cones stick to it, whichever you will, for many seasons. The P. Muricata belongs to the multi-nodal group of the Banksia clan, while the P. Contorta is only a onewhorl producer of branchlets a year, or a member of the uni-nodal group. The P. Muricata has longer leaves, and the P. Contorta is a practically shortleaved tree, so a little similarity of habit and cone should cause no discomfiture in the calculations of the man who would give them their name.

The often twisted young shoots - whence came the name contorted-and the persistent cone habit differentiate it from the Montana. Both the Contorta and the Murrayana, with their many stems springing low down on the trunk from the tree, produce a candelabra effect of growth that the Bungeana and some of the Thuyas sometimes affect. 


\section{P. Montana var. Pumilio.-}

Where the hill-side slopes from the covert to the peat-stained stream below,

Small and of no reputation, the children of Nature grow :

On broken banks - and ridges - and the fringe of the bog beneathAnd out on the open spaces of the wide, eternal heath.

E. M. MILLs.

The P. Montana, like the Pinus Cembra, has its prostrate and creeping representative. The Montana elects to call his miniature edition by the name of Pumilio, while the Cembra has selected the word Pumila as an appellation for the pygmies of his tribe.

In point of fact, and when translated, they are one and the same thing, these two words Pumilio and Pumilus, and what they signify also is one and the same thing, and that is "dwarf," or if you like to make use-and the dictionaries allow you the alternativeof an old word, fallen into disuse but retaining a good old Shakespearian ring about it, you may translate either of them, Pumilio or Pumilus, as Dandy-prat. Both these dwarf trees have a habit of forming themselves into a thicket of creeping, trunkless, tangled undercover, which constitutes a retreat that the foxes and wilder beasts of the country-side frequent and adore, but through which glorious man can with but difficulty crawl his way.

Two scenes in illustration of such a growth flit before my memory. The one a scene from Nature, a thick cover of P. Montana var. Pumilio, planted some years ago by J. Williams, of Scorrier (Cornwall), the other a portrayal of art in picture form, of the Cembran Dwarf Pine (the Pumila) growth, at some $6,700 \mathrm{ft}$. above sea-level in Japan, and on the sides of a mountain named Ontake in the Island of Hondo. The photograph referred to was taken by $\mathrm{E}$. H. Wilson in 1916, and appears in the publications of the Arnold Arboretum, No. 8, entitled Conifers and 
Taxads of Japan, and makes a particularly interesting illustration of the curiosities of coniferous growths. Another illustration of this curious tree is figured in The Gardener's Chronicle, May 5th, 1917, and shows the disposition of the main stems, extending themselves flatly along the ground, and is commented on there by Professor Augustine Henry.

All these shorter and more scrubby-growing twoleaved Pines I refer to the P. Echinata and Virginiana (or Mitis and Inops), Banksiana, Contorta, and Montana. All have their individualities set forth in the Table, so that in theory they ought, with a little working out, to create no puzzlement in the mind of the identifier; but, as a matter of fact they do, as many have borne me witness. The insurmountable difficulty is their rarity and the want of object-lessons. If we could occasionally see them all together side by side, difficulties would vanish like snow on a river.

Nature does not, however, permit a mastery of her secrets by any such simple, helpful processes as these, and perhaps for some reasons it is for the best, since that which is acquired easily and swiftly is often as easily and swiftly forgotten.

A perfected Pinetum, set before us in classification array, with bud and flower and cone concomitant complete, would perhaps be a duller study in reality than we imagine, and like a limiting of the lessonbooks to dictionaries and encyclopedias. Of such works, all know, we can make valuable use for reference and reminder, but cannot hope to build up from them alone a lasting interest in any subject, cult, or science. A campaign to conquer the comparative anatomies of the Conifers has to be undertaken with more Fabian methods. 


\section{II}

\section{ABIES, OR SILVER FIRS}

(OF THE NATURAL ORder of CONIFERÆ, OF THE FAMILY PINACE\& $\notin$, OF THE TRIBE ABIETINEÆ, OF THE SUB-TRIBE SAPINEA, AND GENUS ABIES)

I remember, I remember, The fir trees tall and high,

I used to think their slender spires Were close against the sky.

HOOD.

THE writer goes on to apologize for this illusion of his youth and describes it as a " childish ignorance." We, on the contrary, should pronounce it a very sound sylvicultural observation that matured wisdom would faithfully endorse.

How many tree lovers are there who have not, at one time or another of their life, been prevailed upon by some enthusiastic host, bursting with pardonable pride and parish patriotism, to make a joint expedition afoot for the purpose of viewing the giant wonder tree of the country-side, a mighty Fir, that has surpassed all compeers; and who, perhaps, after a toil and moil of many mountainous miles, have not at last been regaled with the sight of an old familiar friend, in the undisguised form of the Common Silver Fir.

This tree, which is unquestionably most divinely tall, the most divinely exalted type of its species with us, rejoices in a super-growth that so far outrivals 
in height all other competitors. Whether they will in turn be out-topped by sky-scraping Sequoias in this country, or some other competitor of their own genus, like the A. Forrestii, A. Recurvata, or the A. Delavayii, hailing from internal China, is a question for future generations to pronounce opinion upon. At present our homespun Silver Fir (A. Pectinata) towers far and above its companions of the woodlands, and stands out amongst its fellows as a demi-god Triton among minnows.

To those who would essay to dissociate the Silver Fir family, one species from another species, we would humbly suggest working them out by the groups into which they have been arranged by standard authorities, and we would submit to the reader the following points which are mainly responsible for their inclusion in the various groups to which they have been assigned.

Arrangement of Leaves.-(I) Whether they are radially (all round the stem) arranged as are the leaves in the Spruces. (N.B.-Group I, only these, the A. Pinsapo and A. Cephalonica, are thus arranged.) (2) Whether they are pectinately arranged, like a comb, as particularly and ideally in the A. Grandis in Group II. (3) Whether they are less, strictly speaking, pectinately and more $\mathrm{V}$-shaped by arrangement, and if $\mathrm{V}$-shaped, whether they are acutely divided or whether their leaves gape out more widely apart, rather after the manner of horns of cattle, as do some in Group II. (4) Whether they have, as in Group III, median leaves on the top, instead of the bare parting in Group II.

Other points in shape and habit of leaf, apart from any question of arrangement to be noticed: (a) whether the median leaves are as long as or shorter than the lower-placed leaves; $(b)$ which way these median leaves point (all except in A. 6 
Numidica, in which they point backwards, point forwards); $(c)$ whether these median leaves arise from the branchlets straight up, as, for instance, in A. Amabilis, or whether they are at first appressed - that is to say, adhere for the first part of their length to the branchlets--before shooting up in a forward direction from the stem, as in the A. Nobilis and Magnifica; (d) apex of leaf, whether sharply bifid (as e.g. Firma, Homolepis, Webbiana, etc.), or emarginate, or less sharply and more obtusely notched (as e.g. Pectinata, etc.), or whether entire, with unbroken margin (as e.g. Nobilis, Concolor, Magnifica, Lasiocarpa, Religiosa); or whether the apex is rounded, obtuse, truncate, acute, or spine-tipped, as in Bracteata.
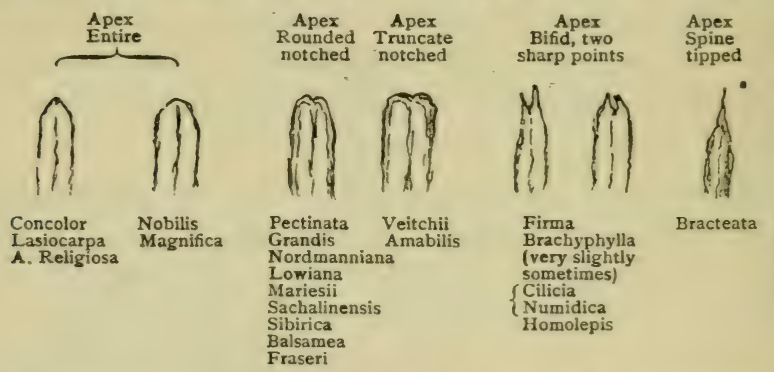

Apex
Acute

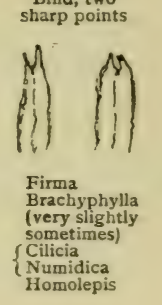

Bracteata

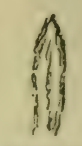

Cephalonica

Pinsapo

pen-nibbed shape.

Stomata.-Whether they show white stomatiferous bands on one side of the leaf or on both sides, as do the Spruces (Piceæ) upon all sides. The Silver Firs (Abies) are rarely stomatiferous on both sides of the leaf, and in instances where they are, often not whole-heartedly but in broken bands, or only on the leaves of the higher boughs.

The following are the exceptions among Silver Firs that show stomata on both sides of the leaf: Lowiana, Concolor, Lasiocarpa, Arizonica, Nobilis, Magnifica, Numidica, and Pinsapo, also the Cephalonica-but inconspicuously, except with the aid of magnifying glasses. I should like to add to these the A. Sachalinensis, although it does not generally appear to be 
included in this list by authorities. A specimen sent me distinctly showed them.

Branchlets and Shoots, appearance and composition of.-Points of difference to be noted: (I) the colour of the shoot; (2) whether downy or showing here and there evidences of scattered pubescence, or without any pubescence at all-that is to say, glabrous ; (3) whether in composition it is corrugated and fissured, or whether it is smooth, or perhaps in some instances slightly wavy, but not fissured with deepened grooves, as are the representatives of the corrugated clique.

This difference, as between what is corrugated and slightly wavy, we own reads somewhat perplexingly. It is far more clearly explained in the illustrations appended than by any mere little collection of words strung together by an amateur student, with best intent of purpose but with an acknowledged incapacity to make explicit this particular point by use of script alone ; but if these illustrations are even cursorily examined with the accompanying text, they ought to be of assistance to the aims of any identifier.

The difference between corrugated and smooth surface calls for little more strain on the powers of perception of ordinary man to discern than an opinion invited upon the difference in outward and superficial shape of a roof of corrugated iron and a covering of flat undented sheet-iron on some wayside farm building.

Out of the twenty-six species of Silver Firs that have been called attention to, eight are corrugated, or if another simile be permitted, shaped more after the manner of waves in a choppy sea than the more gradual and gentle gradients of a ridge-andfurrow field in a Midland county, which would be more descriptive of the branchlet explained and portrayed as of undulate surface. 
Fifteen are smooth-surfaced in branchlet and twig, and may be, to pursue the metaphor, compared to the unruffled surface of a mill pond, and in one or two instances, when described as wavy, likened to the little ripples we sometimes see making commotion in still waters which the winds of heaven have agitated.

Three of these Silver Firs, just to complicate attempts at finality of elucidation and make confusion more confounded, change their coats or rinds at different stages of life, from smooth to rough or from rough to smooth. Two of this trio of perversities show signs-more in accord with the laws of Nature-of a more roughened exterior as they get older, while one, as befits its name Religiosa, becomes more softened thereupon as it advances in life.

We append list and illustrations in exemplification of these different surface characteristics of branchlets among the Silver Firs.

TWIGS AND BRANCHLETS CORRUGATED AND FISSURED

Pinsapo (slightly).

\section{Group I}

GROUP II

Firma.

Homolepis (less corrugated 2nd and $3^{\text {rd }}$ years).

Brachyphylla (deeply).

Webbiana.

\section{GROUP III}

Sachalinensis.

Group V

Numidica (slightly corrugated).

$$
\text { GRoup VI }
$$

Lasiocarpa (more fissured 2nd year).

TWIGS AND BRANCHLETS SMOOTH, OR UNDULATE AND SLIGHTLY WAVY

Cephalonica.

\section{GROUP I}

GROUP II

Bracteata.

Grandis.

Lowiana.

Pectinata.

Fraseri.

Balsamea.

GROUP III

Nordmanniana

\section{Amabilis.}

Veitchii.

Sibirica.

Nobilis.

Magnifica.

Group V

Cilicia.

Group IV

GROUP VI

Concolor. 


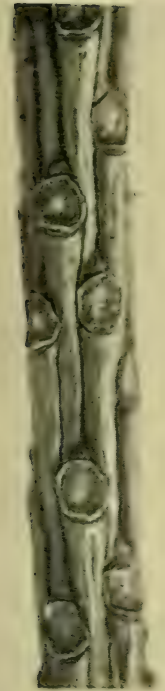

A. HOMOLEPIS.

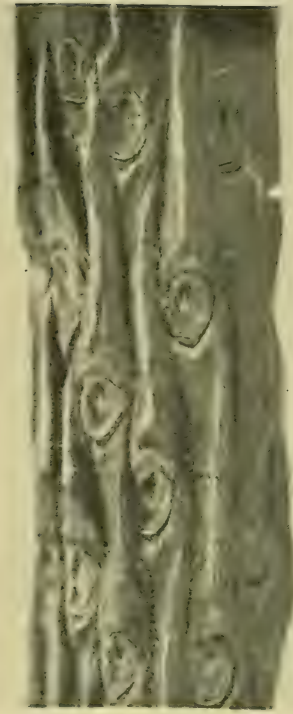

A. Webbiaxa.

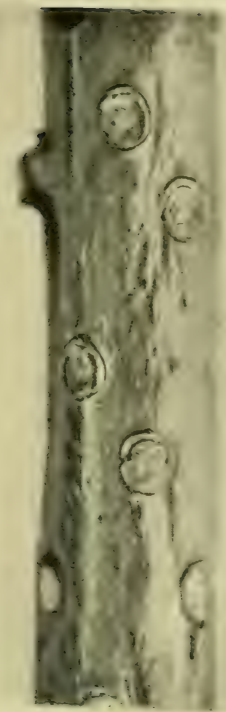

A. NORDMANNIAXA.

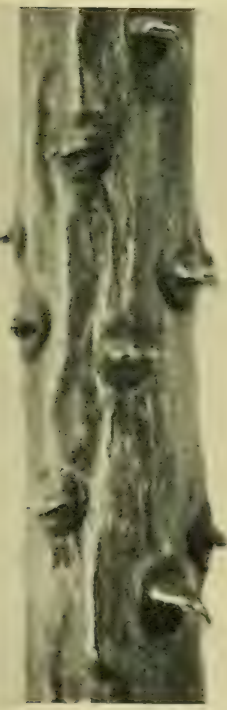

A. BRACTEATA.

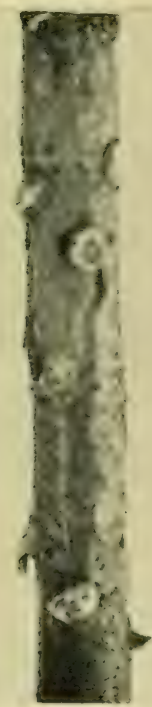

A. GRANDIS. FIG. I.

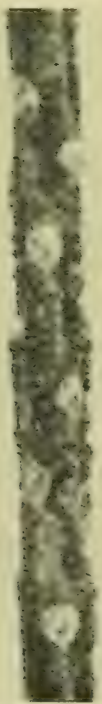

A. MARIESII.

Illustrations in Exemplification of the Different Surface 70] Characteristics of the Branchlets of Silver Firs. 



\section{A. PINSAPO AND CEPHALONICA}

\section{UNDECIDED}

Religiosa (Ist year corrugated; 2 nd year smooth).

Mariesii (smooth, but slightly fissured when older).

GROUP VI

Pindrow (smooth, but slightly fissured 2 nd year).

\section{ABIES. GROUP I}

\section{(OF RADIALLY ARRANGED LEAVES)}

\section{A. Pinsapo and Cephalonica}

The Spanish Pinsapo and the Greek Cephalonica practise the rites of unorthodoxy in their observances of Silver Fir rules, with a defiance that asks for expulsion. Their leaves are radially arranged, have spiny tips, and show white stomata bands on both surfaces, and are attenuated towards the base, where, like the Pinsapo, they take their rest on little green supports. So far they are fashioned after the manner of the Spruce tree family.

What, then, is it that entitles them to rank among the Abies? In the first place their cones are erect and dehiscent. In the second place the situation of their leaves is in accordance with the traditions of the Silver Fir. When pulled off they leave a circular scar, as is explained previously. These two points tip the beam in favour of the Abies, but it must have been a close thing at one time, we imagine, and a case for the referee to be called in. The Pinsapo takes its name from a region in Spain; the Cephalonica from the Greek Island Cephalonia in the Ionian Sea.

The rampant unorthodoxy of these two Abies simplifies the matter of their identity if it does nothing else. The much harder, shorter, lightertinted, broader, and aggressively sticking-out rigid leaves of the Pinsapo prevent any misconception arising as to which is which of these two stable companions. The new twigs of the Pinsapo are, we 
should have considered, rather more of an orange than brown colour as generally described, and as for the prominences of their slightly fissured surface, they are more after the manner of eminences in the roads of fenlands, where the gradients are so obscure that surveyors can hardly put a figure to them, and travellers in their locomotive experiences fail to observe them. The leaves are thicker nearer the base than are those of the Cephalonica, which are markedly narrowed. On both they appear as if situated upon little green plinths, or stands, and when detached leave behind the orthodox round scar of the Abies.

While the stomata of the Pinsapo are pretty clear to the naked eye, the Cephalonica stomata on the upper side call for the use of the magnifying-glass to bring them into notice. Both trees merit the universal recommendation to plant bestowed upon them by the authorities.

\section{GROUP II}

A. Bracteata, Grandis, Lowiana, Firma, Homolepis, Brachyphylla, Pectinata, Webbiana, Balsamea, Fraseri

Group II consists of Silver Firs that are described as V-shaped, while the members of Group III are credited with median leaves arranged on the upper side of the shoot.

The first thing to accomplish a mastery over is : what is meant by and what constitutes a V-shaped depression, and what appearance the Group III described as possessed of median leaves on the top presents, and even what is meant by median leaves and where do they come in in the story. We will try to briefly explain them both. 
A pectinate arrangement, by which is meant leaves on the lateral branches shaped after the teeth of a comb, should give one the idea of a flat and horizontal arrangement of leaves. Often if you turn the branchlet over, it answers the description truly enough as far as the lower side is concerned, but on the top side they vary, and do not convey the idea of regularity that you are accustomed to see in the teeth of the dressing-table article. V-shaped is when the upper leaves assume the form and lines of the alphabetical letter. A succession of them arrayed close together, if you look down their line, gives the appearance as if a plough-share had drilled a furrow down their middle. At the bottom of the furrow the stem is visible, and this parting, as on the human head of hair, is sometimes narrow, sometimes wider, according to circumstance or the age of the owner. When upon this vacant furrow another crop of leaves grows from the stem, these are called median leaves, and very properly, as they grow in the middle. Trees thus equipped are described in Group III.

\section{A. Balsamea and A. Fraseri.-This Group II} consists of some ten species, all of which, with the exception of Balsamea and Fraseri, are quite likely to be met with in Pinetums. These two, then, can be dismissed with a few words. We can almost commence with them, and end with them, by a poetical reference from Longfellow:

Give me of your balsam, O fir tree,

Of your balsam and your resin.

Seemingly it contained some very useful essential in the construction of Hiawatha's canoe, and from the description we may conclude that the value of this resinous fir was held in high estimation by the natives who lived in its vicinity and freely appropriated its uses, which included medicinal extracts and oil of fir 
obtained from its bark. A. FRASERI was introduced here in $18 \mathrm{II}$. It is a short-lived tree, and probably no living specimens of that period are in existence now. Its native countries are the Alleghany Mountains in S.-W. Virginia, N. Carolina, and E. Tennessee.

We will now take the members of Group II seriatim and in order, as placed by Elwes and Henry in the Trees of Great Britain.

A. Bracteata presentsso many obvious singularities that no one need be troubled with any misconceptions as to its identity after a first introduction.

Its leaves are spiny-tipped, the only one of the tribe which claims this very pointed distinction. They are very long; from tip to tip they span some $5 \frac{1}{2}$ inches against the $\mathrm{I} \frac{1}{2}$ inches or so of the Common Silver Fir. Its unique, long, spindle-shaped, lightcoloured bud, though not quite so long and more rotund at the base, recalls the appearance of a Beech bud.

Yet the cone presents a weirder appearance than all other strange aberrations of the Fir family put together. It has the porcupine appearance of a small cushion stuffed with very long pins.

These long, protruding, leaf-like scales are exserted bracts, a name given to those never fully developed leaves that surround the fruit or cones of the tree at its early stages, and sometimes, especially in this tree and the Douglas, have a way of poking their noses through the scales of the fully developed cone and appearing in different forms ; in the case of a Douglas in a Neptune trident form, in the case of the Bracteata in the form of a thin bent wire an inch and a half long.

The result is an uncanny quaintness of appearance that makes them look like nothing on earth and unlike anything upon trees. It is from these bracts that the trees derive their name, and the word "bract" 
in turn derives its name from the Latin word bractea, which originally meant a thin plate or leaf of gold metal.

A. Grandis, or Giant Fir, rejoices in rather a pretentious title, which it, however, contrives to live up to in its native country ; and its native country may be defined as the coast regions of British Columbia and the coast States of Western America, Oregon, and California. There it out-tops the highest of its kith and kin among Silver Firs; but among our little lot the Common Silver Fir (A. Pectinata) reigns supreme of its race. The A. Grandis was introduced about I 850 , the A. Pectinata about A.D. I600; so far, then, the championship must be regarded as undecided and any finality of opinion for the present so far upon the subject as nonproven.

With us it is recognised as in the first rank of quick growers, and we might go so far as to bracket these two first, Grandis and Douglas, as Senior Wranglers in the field of such a competition. It will stand being planted under the shade of other trees. In spite of a character for deep-root system, like many other quick growers it has its drawbacks. The root growths do not quite seem to keep pace in proportion with the trees'efforts in sky-high directions. The inevitable result of this is that they inherit a liability to topple over at any unusual provocation or extra dose delivered on the part of the elements.

We speak from the bitter experience of the I9I5 Boxing-Day gales. Without any excuse of want of sheltering influence a promising young A. Grandis of some twenty summers' experience of its position, elected, to the surprise, dismay, and mortification of its many friends and admirers, to measure its some 50 to 60 feet of length upon the ground in which we had all believed it to be firmly embedded. 
The ideally pectinate arrangement of its long grass-green shiny leaves, which span from tip to tip a good 3 inches, its upper rank leaves half the length of the lower, its notched apex and clearly-showing white stomata bands, all conspire to help identification.

Again, its olive-green and sometimes orange-brown tinted branchlets, with what is generally described as reddish, but sometimes appears as almost white, pubescence; are also characteristic. Its grey bark, with here and there the appearance of faint orange tints, is smooth but for being plentifully covered with blisters, which when broken emit a most fragrant flow of turpentine, of a most gratifying nature to the scent-sense of mar and woman.

There are other lesser aids to the recognition of a tree that future generations may have more to say about than we have, at such a comparatively early stage of its existence with us.

\section{A. Lowiana.-}

At every impulse of the moving breeze The fir grove murmurs with a sea-like sound.

WORDSWORTH.

Sometimes we have heard the A. Lowiana compared with the A. Grandis. But the A. Lowiana has its white stomatic bands on both surfaces of its leaves, while the A. Grandis has stomata only upon the lower surface. This should at once in theory-if theory goes for anything-dispose of any suspicion of their connection. If another proof were wanted, there exists the fact that the leaves in the upper rank of the Lowiana are nearly as long as those in the lower rank, while in the A. Grandis they are only a little more than half the length. Most of us have been taught that if we wish to accumulate a little mental confusion between any two trees, 
and are unable to obtain it elsewhere, an excellent opportunity is afforded to us in instituting comparisons between the A. Lowiana and the A. Concolor, and if you want to drag in another and make confusion more confounded, the A. Lasiocarpa can be called in to make a third. With this latter tree we have dealt with in its own place, and tried to show that the likeness is merely a nominal mistake and devoid of any reality.

As between A. Lowiana and Concolor, our instructions are that the apex of the leaf in the Lowiana is notched and grooved, while A. Concolor is not notched and not grooved. This, if it holds good and is subject to no saving clauses, equivocations, or exceptions, is a clear and final distinction, and one moreover within easy scope of the ability of the humblest observers.

The A. Lowiana belongs to a more northern tree region than the $\mathrm{A}$. Concolor. The $\mathrm{A}$. Concolor has the longer leaf, and both indulge in leaves with inward curls of a sickle-shaped form, and looking as if they had been subjected to an application of the curlingtongs from the hands of an expert barber. A habit which, as haj been explained, saves them from exposing so much leaf surface to the sun.

The Concolor is of a more glaucous colour, with a thicker distribution of leaves upon branchlets than the Lowiana. Both seem tolerably good doers in our climate.

A. Firma (the Common Fir of S. Japan).

A. Homolepis \} (the Mountain Firs [Dake

A. Brachyphylla $\}$ Momi] of Central Japan).

We have here a triplet of Japanese trees, which have more than done their fair share in creating perplexities and heart-burnings among the leading lights of such subjects. Whether they should have 
been more appropriately likened in number to twins than triplets, and whether consensus of opinion will some day reduce them to a dual state, is in anticipation of the results of our remarks on the subject. We will only generally add that if twins are hard to know apart, a fortiori triplets cannot be expected to do anything but treble difficulties.

The first point that we would impress is that they are trees of uncommon appearance with us. They are not the sort of plants that you are in the least likely to stumble across in an everyday walk, or even after Sabbath-day journeyings, or to alight upon in a full-grown glory of adolescence, or in their fuller maturity of a cone-clad age. But since they are Conifers that grow in England they come into our story, and must not be omitted from the programme of our curriculum.

A. Firma.-The Common Fir of S. Japan was once -notwithstanding the fact that it was a name equally applicable to several others - appositely called A. Bifida, on account of the two very evident little sharp points that surmount the apex of the leaf (vide illustration, Abies Introductory, p. 68). It occupies in its own country regions the same sort of position that the A. Pectinata occupies here, and that is, as its English name implies, the Common Silver Fir of the district.

It is in that guise, and armed with credentials as an endemic or Common Fir of another country, that the A. Firma and all that pertains to it should be enshrined in our memory leady for recall if occasion offers.

From our Common Fir it can be easily dissociated.

While the Japanese has these sharp points at apex of leaf - and which we rightly or wrongly are designating bifid, in contradistinction to the more un- 
dulating depression that we are calling notched or emarginate-has also corrugated or fissured shoots with pubescence in their grooves; has also longer, thicker, broader leaves, of a lighter, almost yellowgrass-green colour, the Anglo-Saxon representative (A. Pectinata), on the other hand, has less acutely notched or emarginate tops to leaf, of smaller size and dark-green colour, with pubescence scattered indiscriminately upon its smooth shoots.

From these more nearly allied similarities, the A. Brachyphylla and Homolepis-which we will treat here, for the time being, as one and the same, or in inseparable Siamese-twin relationship-the A. Firma perhaps differs less, but very sufficiently, when we start to sum up his points.

The A. Firma, as we have said, has pubescence in the grooves of his corrugated shoots, whereas the Brachyphylla-cum-Homolepis is devoid of anything of the sort. The leaves of the latter display very bright and conspicuous stomata on one side of the leaf, if not-and we say it with hesitancy, because it is not authoritatively admitted-occasionally a faint tracing of broken bands of stomata upon the other and upper-lying side. The stomata on the A. Firma, as the moon to the sun, are comparatively very dull affairs. They consist of two murky inconspicuous bands on one surface.

Cones received from Japan manifest clear differences. Those of the A. Firma are of more rotund and stumpy-looking proportions, larger at the base than the top, while the cones of the Brachyphylla are of a uniform, cylindrical, more elongated shape.

A few cones have appeared with us here and there, and in places the number of which you could count on one man's fingers, but, in a general way and for the most part, instituting a hunt for them in England would be a vain quest, with little more chance of a 
find than the Yankee's memorable search for a black hat; on a dark night, when it was not there.

We may add that the photographs in Clinton-Baker's clarifying Illustrations of Conifers coincide with the shape of those referred to here, and tell their own story more faithfully than words express.

A. Brachyphylla and Homolepis.-Many misgivings upon two or three questions in connection with these so-named trees seem to have arisen, and pierced the very soul of the super-conscientious botanical exponent. That is, at least, how it appears to those who, with primitive instinct, have tried to learn by reading the lines, and between the lines, of what experts have written on this vexed question.

By those who maintain their dual existence as two distinct trees, we are told that so far no Homolepis cone specimen has ever been plucked by human hands, or ever set eyes on by human being. This seems rather to indicate - if it points to anythingthat when this missing link in the shape of a cone turns up, no true alibi will be found to have been set up, and affords argument more in favour of the conclusion that it is the same individual, in spite of the assumption of two names, perhaps slightly changed, but not anything in the shape even of a masquerading double, of a different nature and composition, that has obtruded its presence upon us farther afield, and tried to take us in by methods of duplicity. We can only say that if this fruitless peculiarity of dispensing with a cone-system exists, or is going to weary us by its continuance, the tree will be occupying among Conifers as unique and forlorn a position in its place upon our earth as the man compelled-in fantastic legend-to walk through life without the companionship of a shadow.

To those who wish to puzzle out in entirety the 
intricacies of this trio of trees, in all its ramifications and variations, there is still another upstart, so far unmentioned by us, to compete with, and it is called the Umbellata. This is a tree with leaves like the Brachyphylla and Homolepis, and with cones of the colour and substance of the A. Firma; in short, it reads as a halfway house between the two, and this is what probably spells its true story of an hybrid history.

The queries, then, which trouble the mind of the more unsophisticated, and the questions that present themselves to the would-be unravellers of this tangle, seem to be very much after this pattern :

(I) Are the Brachyphylla and Homolepis one and the same tree?

Some authorities of our day have answered to this "No," distinctly if not quite emphatically, but still "No." They maintain that certain slight obscure but sufficient differences exist between them. They quote the fact that the different positions of the resin ducts substantiates their case. From this view E. H. Wilson, after a recent journey to their native country, dissents. It is true that he does not refer to these resin-duct differences, but he assuredly saves the situation for some of us and simplifies the matter for those who flounder in the sea of doubt. There are many to whom resin ducts and their position are but the by-play of a hidden mystery.

$\mathrm{He}$ (Wilson) further tells us that any little variations of form or inconsistencies of habit are traits of character, traceable to those inconsistencies of age that all life, human and plant, is liable to, and this is an arrival at opinion of natural progression that all those in the sere and yellow are easily able to comprehend, and that all those in the green of youth are too ready to jump at ribald conclusions upon, without any further encouragement from their seniors. 
(2) What is the true story of yet another disturbing element on the scene in the shape called the Umbellata, whether it is a variety of the Brachyphylla and Homolepis (regarding them as one and the same plant), or whether it is a hybrid, as between them and the A. Firma? The latter, from evidence received, seems the likeliest solution of this vexed question.

(3) Whether its presence as a new-comer in our midst has not added confusion to the scene, and given rise to the idea that four identities are in actual being-namely, Firma, Brachyphylla, Homolepis, Umbellata - whereas in fact only three are existent, Firma, Homolepis and the probably cross-bred Umbellata.

Tempus edax rerum. Time and experience some day may solve these knotty complications to the satisfaction of all, and attune the botanical world once more in a dull and an uninteresting blend of harmony upon these so far unresolved modulations. For the time being, the most convenient course to pursue, for all lovers of simplicity, is to follow Wilson, and to look upon them as one, to talk of them as one, and call them either Brachyphylla or Homolepis, but not Brachyphylla and Homolepis, as the spirit moves or fancy dictates

The A. Webbiana has not earned with us those credentials of hardiness that we might have looked for from a tree that came from Himalayan heights. The story of its failure here seems to be the want of constancy in our climatic programme. The complaint of such trees seems to be that we, as a country, exhibit a lamentable want of decision as to what sort of weather we are going to provide for them in the critical moments of early spring-time. And yet it comes from regions that must often experience a 
cold as intense as that of the historic winter in France, 1407, when, as it was solemnly declared, the frost was so bitter that at every third word the ink froze in the pens at the Court of Law, and arrested the recording of judgments.

There are times when late frosts injure particularly the young trees, or perhaps what is worse, a perpetual visitation of cold winds browns and scarifies the senior members of the Pinetum with a cruelty that is positively heartless. Men, we are told, may sometimes look on tempests and remain unshaken, but trees, unfortunately, are hardly as stoical.

In its own country the A. Webbiana enjoys immunity from inconstancy. From a hibernating stage of a winter spent under a deep snow, it emerges at a fixed date with clockwork regularity, to find itself warm and happy, under the promoting conditions of a blue rejoicing sky. That it finds our climate to be generally unaccommodating is unfortunate, since it is a tree that is all-beautiful without and as all-glorious within, as those king's daughters that we are told, upon the Psalmist's authority, at a moment of time when his heart was inditing of a good matter, were fitted to enter king's palaces. Its cones in their early stage are of a most attractive violet-purple colour. Its leaves on the underneath surface display the most vivid silvery whiteness of all well-known Conifers, so far ; and in spirit of prophecy we venture a statement that their proxime accessit, or even conqueror, in colour scheme in years to come will be the new and lately named Chinese Silver Fir, A. Forrestii.

Botanically and geographically the A. Webbiana has been mentir ned together with the A. Pindrow If the Pindrow is an affinity of it, all we can say is that, judging from outward appearances, it is a very colourless edition of the A. Webbiana. As "light 
excelleth darkness," so does the Webbiana rise superior to the Pindrow in the vivid underneath of the leaf.

The light-coloured branchlets of the Pindrow gleam at you between the leaves as they do in the Webbiana, but on close inspection they will be found to be composed of a softer and different surface than that of the corrugated Webbiana, but we have pointed out some differences, which in this case call for less mental confusion than such subjects often present.

\section{A. Pectinata, or Common Silver Fir.-}

You may tire of mountains and rivers, you may tire of the sea, but you can never tire of trees.

LORD BEACONSFIELD.

So spoke the departed statesman (more familiarly known as "Dizzy") of the Victorian era.

There are some of us old enough to recall a cartoon in Punch that depicted the eminent statesman swung in a hammock under a tree in his garden, and murmuring self-complacently a measure of an Ariel's spirit song :

Dizzily, dizzily let me drowse

Under the shadow of Hughenden boughs.

Though he, Lord Beaconsfield and ex-Prime Minister of a Victorian age, was probably reposing in Virgilian attitude, after the manner of Tityrus, under the covering of a spreading beech on this particular occasion, we take it that the quoted expression of his untiring admiration for trees referred rather to the trees of landscapes generally than to any tree in particular. Be that as it may, it was a high compliment he paid to them; and if any Conifer deserves its share of the praise bestowed more than other, it 
is the Common Silver Fir, the mightiest and the highest of them all.

As the Common Silver Fir is always a forthcoming feature on most wayside and woodland scenes, we have very little to say further of it here, unless it be to enter a caveat for the sake of the less initiated, and warn them not to be betrayed into any surprise, or deluded at any critical moment, by the different aspects and variety show that the leaves of this tree sometimes offer to observers, according to the different layers of its branches on which they grow. While on the lower stages they wear an orderly, combed and neatly parted appearance, of almost pectinate perfection, upon the upper often all these characteristics seem to have been relegated to the regions of a lost art. The leaves are apt to stand out all over the place and awry. They exhibit a crowded and comparatively shock-headed arrangement. Side by side they look like the foliage of two different trees, anyhow until more closely examined, and then-to those at least who know-they look, as they should, themselves.

As it is quite an unusual occurrence for the majority of us to come into contact with the top boughs of trees that stand over a hundred feet high, this is a little attention to detail that we can only recommend readers for their own edification to make the most of, when they happen across one of these giants prostrated by storm, and levelled to the earth by the inevitable forces of the Fates and Furies.

Witnesses of their doom may, perchance, with luck light upon another curious sight (as did the writer), of the leaves on the extremity branchlets lying upturned, after the fall to earth of the tree, and the new ones growing on the wrong side and the opposite one to that on which they did before, when their parent stem led a straight and upright life. The 
whitened stomatiferous side, which was lying wrong side up after the fall, had, from all evidences, firmly refused to face exposure to the heavens. The sun had dominated the situation and made the leaves to grow according to his lights, and that was in upsidedown arrangement. A weird picture of the rules and laws of topsy-turvydom.

\section{GROUP III}

A. Nordmanniana, Amabilis, Religiosa, Mariesit, Veitchit, Sachalinensis, Sibirica

Oh ! forest deep and gloomy,

$\mathrm{Oh}$ ! woodland, vale, and hill.

From Mendelssohn's Open-Air Music.

A. Nordmanniania. - Of all the trees in this group, first and foremost upon terms of more intimate familiarity, stands out this dark and grim Caucasian Silver Fir.

Their leaves are generally written down as dark green and glossy. Glossy they are, as the best of polished patent leather, but when you come to compare at close quarters there are many Silver Firs whose leaves are as dark and darker than are they, and there is a good deal more of the green of grass hue in their composition than perhaps in any other of the nearer relations of the family. It is rather the density of their leaf system, and the opaque shadows they in consequence cast, that suggests ideas of black forests and sombre depths with which they have been associated, or those "forests deep and gloomy" with which we announced their introduction upon our scene.

To sum up their merits, they bear a character all round for robust hardiness.

They time their annual growth to such a season that they can afford to display a spontaneous dis- 
regard for any of those little thermometric irregularities of the calendar, in the shape of late spring frosts or Etesian winds.

Neither are they hypercritical sticklers, like so many of their kind, in a choice of soil or in aspect of position. In short they accept cheerfully, in happy-go-lucky frame of mind, what their tutelary gods send them, be it situation assigned or visitation of elements. They hold better timber testimonials than the generality of the Abies Family, and they-the Silver Firs-we are constrained to say, do not hold as high a character for popularity among timber buyers as many of their owners would wish. The complaints urged against them are that they are generally of too large a size to push, move, or compete with on the saw bench. Another drawback alleged against them is that their rather porous propensities make them adapted for indoor rather than outdoor use in their final careers.

As, then, they have been acclaimed as growing trees (I) weatherproof, and (2) picturesque, (3) of accommodating disposition to soils and sites, (4) as of fairly useful timber properties, the wonder grows; why is it that our horizons, our backgrounds, our middle distances, and our foregrounds are not more often streaked with their dark masses, looming out against skylines? The answer may be that about the times they should have been or might have been planted, say, in the seventies or eighties (they were introduced about I850), to produce such effects, ornamental tree-planting was neither a favourite nor fashionable craze of the land-owning confraternity. Like Gallio, the lordly possessors of vast domains in that day were not caring very much just then about such things.

In the forties of the last century it evidently was more a matter of concern with them, and in the last 
decade or so revivalists have not spoken and written in vain. Books on the subject were published, Chinese explorers brought back arboricultural gifts rich and rare: a Royal Arboricultural Society was formed; forestry exhibitions and plantation competitions were organized by the Royal Agricultural Society; other agricultural societies followed suit. The very Board of Agriculture nodded approval and began to fumble for their purse; in short, all was going well and happy as marriage bells, till war sounded its alarum-call,-War teterrimum, horridum, infandum, heap upon it all you can recall, from languages ancient and modern, in the superlative degree for choice, but not omitting Pliny's dictum that it should be non provocandum, as a pronouncement of acquittal to those by whom it was unsought-and brought about the suppression of many an aim and object, that was careering gaily on the high road to success and many-sided improvement. Perhaps a day may dawn, in years to come, when more dark masses of the Caucasian Silver Fir will greet the eye of travellers as they journey to and fro on the highways and byways of our island home.

As experience with these relays of imported trees progresses, it gradually and slowly impresses ideas as to the chances or off-chances of success or failure that we are likely to encounter in our effort to cultivate them. If mathematically minded we might mentally review them as hardy, possible, or hopeless, or catalogue them as "Well-to-does," " Non-well-todoes," and "Ne'er-do-weels." The A. Religiosa, Sachalinensis, and Sibirica are to be classed in the third of these departments, and without much hope of any remove or redemption.

A. Religiosa, although a tall tree in Mexico, and in spite of the fact that it had a good testimonial 
A. RELIGIOSA, SACHALINENSIS, SIBIRICA 89

from Loudon, has -ver "looking to the south "ignominiously failed among us. It is possible that a few rather sketchy, dilapidated remnants may reward the curio-hunter if he makes diligent search in Cornwall or South Ireland, or some such " Ultima Thule," -or call it, if you care, El Dorado,-and that seems to be all the guide-books of tree whereabouts have to offer the tree-hunters.

It is of Mexican origin, and derives its religious name from the use it is put to in decorating churches on festal days. It is like the Abies Nordmanniana in leaf arrangement, but with fewer median leaves. The first year's shoots are corrugated, the second year's shoots less so, but the most telling evidence of its identity is that the tips of its leaves are not notched, as are all the others of this group.

The A. Sachalinensis comes from the Kurile Islands, Saghalien, and Hokkaido, the North Island of Japan, where it is the sole representative of its species, and known colloquially as Todo-matsu. We can say of it and of the A. Sibirica that their presences with us are few and far between sights, and are said to be likely to be fewer and farther between still. Its wood is very valuable.

A. Sibirica.-In spite of well-founded discouragements on every side to make attempts to grow this tree on English soil, human perversity often prevails, and sets us at times pursuing with small chance of achieving success. What we ought not to do is just what every one desires to do, and often does. If you are the recipient of a gift of one, as was the writer, what course is open to you? Surely only one, and that is to commit it to the ground and piously "wish it good luck in the name of the Lord." The one given to me and so treated, after some seven or eight years of heroic effort, and under the two distressful 
winters of 1915-16 and 1916-17, and after several quite brisk struggles for existence, has now achieved the not very giddy height of twelve inches, but otherwise the presentation of an appearance that you may describe as robust. Yet there is a memento mori atmosphere that clings to the story of the tree. Like shadows they come into the story of our trees here, and like shadows time after time have they disappeared. The likes and unlikes are called attention to in the Table, and the fact noted that the Sachalinensis has some seven or eight stomatiferous bands, the A. Sibirica only four or five.

A. Mariesil. - The Alpine Fir of Central Japan was discovered in 1878 by C. Maries, and is regarded as rare. It is accounted among the more hopeless of those plants upon which persuasion has been brought to bear to do their best under the circumstances of a strange land, and possibly in some cases of a strange altitude. There are, we think, one or two more that have not met the eye of the authorities, and that have done better than they are generally given credit for. The dark-looking branchlets are covered over with the rustiest of dark-looking chocolate-coloured pubescence that ever covered twig of tree, matted and tangled, and with as tell-tale a surface as the goat-skin which deceived the patriarch Isaac. If more tokens were called for to complete its identity, we should compare its outward appearance to a short-leaved Nordmanniana, so short that it has the resembling look of a Hemlock Spruce. Yet a Nordmanniana, with its shiny, grey-brown, smoothlooking twigs and its only scattered pubescence, has little in real common with the dark, hirsute-twigged Mariesii. Nor, for the matter of that, has the Mariesii much in common with the smoother, less pubescent, twigged Veitchii. 
A. VeItCHII.-A high-altitude variety, and the smallest of Japanese Silver Firs. Among Conifer collectors this tree seems to have attracted a good deal of attention of late. Its iridescent vivid white beneath the leaves, which at Kew seems to have been dulled by town atmosphere, makes it a general favourite. Unlike the A. Mariesii it has not escaped the attention of many patrons, and it takes its life among us with vitalised zest. Its characteristics are its smooth bark and twigs, with scattered pubescence. On the branchlets, with the pubescence upon them, the colour of the shoots appears to be of perhaps a darker tint than they really are, and the little white dots on the twigs when the leaf is pulled off show out in great contrast to the dark-looking background, like ivory specks inset on ebony. Its soft leaves, pointing forward but more upright than those of the $A$. Nordmanniana, end in a square-shaped truncate apex.

A. Amabilis.-We have kept our reference to the Amabilis to the last mentioned of Group III, since, and quite wrongly, it always seems to have been sailing in company with, and under the same flag as, the two representatives of Group IV, A. Nobilis and A. Magnifica.

Sometimes the Amabilis has been sent out under false names and the trees have turned out to be Nobilis or Magnifica, to which perhaps it may bear a superficial similitude. Any doubt can soon be put to rest by an examination of the position of the median leaves.

In the Amabilis the leaves rise up direct from the stem.

In the A. Nobilis and Magnifica they appear to lean along the stem for the first part of their length, or, to describe it more correctly, they are appressed 
for a short distance and for a part of their length to the stem.

From the A. Nordmanniana, which has a similar arrangement of leaves, the Amabilis is distinguished by its more blue colour, by its citron-like smell, and by its small and resinous winter buds. Then, again, it has no stomata on the upper side of its leaf, while the Nobilis and Magnifica have. The apex of leaf of Amabilis is notched, while of the others it is rounded and entire.

\section{GROUP IV}

\section{A. Nobilis (Noble Fir), and A. Magnifica (Shasta, OR RED FIR)}

Amidst these glorious works of Thine, The solemn minarets of the pine And awful Shasta's icy shrine.

\section{WHITTIER.}

The little differences between these two ought to be adjusted without much difficulty.

The leaf of the A. Nobilis has only two surfaces and the one on the top is grooved, while the A. Magnifica's leaf is quadrangular or diamond-shaped in section and not grooved. If taken between the fingers it will roll round easily, while the Nobilis, which is flat or two-sided, will not respond to any such rotary treatment.

\section{GROUP V}

\section{A. Cilicia and Numidica}

Group V and the following Group VI seem especially to shine in irregularities, and to comprise a sort of menagerie omne-gatherum group of unorthodoxy that have been denied admittance elsewhere, often for the merest trifle. 
Their leaf arrangement is sometimes with the V-shaped depression and sometimes with the topknot arrangement of median leaves, and it is this irregularity that has placed the A. Cilicia and the Algerian Silver Fir, A. Numidica, specifically together, in spite of their obvious dissimilarities.

As neither of them so far have put in much of an appearance in Great Britain, their nonconformity to one of these two very distinguished sects, V-shaped or with median leaves, does not so much matter.

As A. Cilicia is probably delicate, and A. Numidica for some reason best known to itself uncommon, they are neither of them likely to be a thorn in the path of the Pinetum haunter.

It should not, however, be forgotten that between the verdicts of "too delicate " and "uncommon" a wide difference exists, and that though what is "too delicate " is unlikely to make appearance, what is only uncommon may at any time be met with more frequently in the future than it has been in the past.

As the A. Numidica has not only stomata on both sides of its short, thickset-looking leaves-which, as has been pointed out, is of rare occurrence in the Abies family - but displays also the unique peculiarity of median leaves pointing backwards instead of forwards, as do those of the rest of its tribe, a clear clue to identity is always at hand. A. Cilicia seems closely allied to A. Nordmanniana, though it has lighter-coloured leaves.

\section{GROUP VI}

\section{A. Pindrow, Concolor, Lasiocarpa}

Group VI completes the last lot. They consist of three species, penned apart on account of their refusal to conform to any sufficiently established code of 
customs that entitles them to enter the ranks of other groups.

The LASIOCARPA was probably discovered during the north-west expedition by Lewis and Clark, I805, but was first collected by Douglas in 1832 . It has been variously called Balsam or Mountain Balsam, or Alpine Fir, and familiarly addressed by the less learned and Latinised of the gardener fraternity as Lazy Old Carp, and always seems to be more or less a perplexity even to those more than ordinarily acquainted with the rarities of Pinetums. That this uncertainty exists can only be due to the fact that many trees wrongly have left the nurseries under the name of Lasiocarpa or Subalpina. For the most part they have turned out to be Concolor or Lowiana. From a branch that I have before me, sent by the Forest Service of the United States, which has voyaged from Colorado to County Radnor, the very pallor of its grey-green leaves looks of a different hue from any other Conifer that I have seen. Possibly they may have faded from their pristine glory of blue. green with a silvery tinge, attributed to them by American dendrologists. The apices of the leaves of these are all rounded, sometimes we are told that on young shoots they are acute. Those on top side of branch point upward, and those below are disposed to curve in sympathy to join them. The branches were corky, fissured, pubescent, and of a light straw colour. Whare the leaf had left its appointed place, there remained an oval-shaped light-red scar. This in itself, if there were no other, is a guide to its identity safe and sure. The characteristic swelling of the nodes is very apparent.

I write of it as it lies before me and as I have found it. The cones that accompanied the branches were of variable size. Some in clusters of three and 
A. LASIOCARPA, CONCOLOR, AND PINDROW 95

practicaily sessile. They are-the cones-hard to get and bad travellers, and some-at least so I have found -of the hardest to obtain. The sharp-pointed head of the tree in its native land, which seems to run its course from Yukon to Colorado, makes it a conspicuous object for recognition to all residents versed, and travellers interested, in the ways and habits of the trees of the country.

The moral of this description is that when you notice a tree labelled Lasiocarpa or Subalpina in a nurseryman's garden, and it answers all these descriptions, and only when it does, get out your pen and write an order.

A. CONCOLOR has been dealt with in connection with the A. Lowiana, under the head Group II. It seems curious that two such closely related affinities of, moreover, a perplexing similarity of appearance, should be found herded in different pens.

Some authorities even include both the Colorado (A. Concolor) and the Californian tree (A. Lowiana) in the same name Concolor, and the same authorities upon the question of relative hardness pronounce a judgment in favour of the Colorado Concolor.

Concolor is a Latin word meaning "of the same colour "; why it was so called by Engelmann, history does not appear to relate, or perhaps crassness of intelligence fails to enlighten. It was introduced in the early seventies, or some twenty years after the appearance of the A. Lowiana.

A. PINDrow.-We have alluded to this tree in connection with its affinity, the A. Webbiana. Here again we might have expected the two to have been accommodated in the same compartment under a group system. At the same time there are several very obvious differences that meet the eye of the identifier readily. 
While the Webbiana has perhaps the most brilliant silver-white colouring on the under-surface of its leaves of all Silver Firs, the A. Pindrow only shows grey inconspicuous stomata bands. Again, while the shoots of the Webbiana have prominent Pulvini and deep grooves with reddish pubescence, those of the Pindrow are grey and glabrous in the first stage of their existence.

\section{KETELEERIA}

The KETELEERIA is so far no declared habitué of English soils. Experts do not deny it a future in such specially favoured climatic conditions as Cornwall or South Ireland afford. It hails from Central China and Formosa.

The leaves bear a prima facie likeness to the Cephalotaxus, but whereas the latter is a member of the Taxacex family, and like them has its foliage mounted on little projections, the Keteleeria takes after the Abies tribe, and displays the circular disc when the leaf is pulled away from its smooth stem.

It has a prominent midrib on both surfaces and is accredited with two stomatic bands on lower surface which are very faint and inconspicuous, to judge by some leaves sent from the Temperate House at Kew.

In cone character they break away from Abies dehiscent tradition and show persistent characteristics. The difference of the male flowers is alluded to in the table. The resin canals are as in Abies Pectinata, marginal and two in number. With the Keteleeria we should, we feel, like to become better acquainted, but its life-history reads as if there is but a faint likelihood of any fulfilment of the wish. 


\section{Pseudo-Tsuga Douglasil (Douglas Fir)}

'Tis said he had a tuneful tongue,

Such happy intonation,

Wherever he sat down and sung

He left a small plantation.

Tensysos, Old Amphion.

The Douglas Fir.-History of its introduction: Discovered by Menzies in 1792, during Vancouver's voyage round the world. Rediscovered by Douglas, 1827. Introduced 1828. Firmly established and plentifully planted since 1862 up to the present time.

What accelerating influence towards the growth of trees old Amphion possessed in the strains of music he poured forth from his melodious pipe, many of us doubtless would like to learn the secret of. We know, and that is all, that some occult influence impels the Douglas to grow with more celerity than any other forest tree we plant in masses. No trees, unless it be the European Larch, have been more widely planted of late years than the now well-known Douglas Fir. When asked, "Why is this so ?" we might make reply as the Scotsman, and answer " For every why." Its timber results are more than promising, they are an accomplished fact. Its rapidity of growth is phenomenal. The Royal Agricultural S.E. judges of the plantation competition in 1915 computed, if I remember aright, by measurement, that some of the Shropshire-grown Douglas (at Leaton Knolls, the seat of Colonel Lloyd, M.V.O.) had made several annual consecutive growths of no less than four feet.

Again, it is without doubt ornamental, and though not immune from the ravages of rabbits altogether, is certainly more distasteful, with the exception of the Corsican Pine, to them than other Conifers.

The Oregon variety is the one we are advised to plant, the Colorado the variety to avoid. A good 
object-lesson in their difference of growth was seen and commented upon by the judges of plantations referred to above, in a large wood of about sixteen acres (Plassey Plantation), planted out with pure Douglas by Lord Powis in 1906-7, at his Shropshire home at Walcot. They had been planted simultaneously but in distinct groups. The Oregon had grown to be half as high again as their Colorado confrères, which occupied about a third of the space of the ground.

The tree has been so universally planted that it has become a familiar sight of everyday walks. At the same time it reads about as complicated a question in the way of a botanical puzzle as any. In some respects it takes after the Spruces (Piceas), in other respects after the Silver Firs (Abies). On points added the Silver Firs get most marks, but insufficient to admit it unreservedly to their ranks. Veitch called it Abietia ; Elwes and Henry, and also Bean, cling to Pseudo-Tsuga nomenclature.

The cones plentifully strewn around its trunk are pendulous, as are the cones of the Piceas, but the exserted bracts are more after the manner of some of the Abies. The bright-red flowers (male) about inch long, surrounded by involucral bracts and growing on the under-side of the branchlet of the preceding year, present a very pretty spring picture. The pistillate or female flowers, mostly terminal, are composed of imbricated scales, with the three-lobed bracts, shaped like a Neptune's trident, longer than their scales, and which appear afterwards on the full-grown cone, give it an unmistakable appearance. The leaves, it will be seen, on looking at them closer, are placed on rather obscure and very slightly raised pulvini. When pulled off they make no such perceptible tear as the more prominently raised Common Spruce, neither do they leave the clean-cut circular 
disc the Abies leaves behind, but instead an oval scar on the top of a little projection.

The resin canals are as the Abies, two in number and marginally placed. The fibro-vascular bundle, too, is single. Other points of comparison and characteristics are given upon the opposite page, but we might further mention that the Colorado variety is generally known to foresters by its shape, more trustworthy evidence than judgment by colour, which is formed by ascending branches into a more bushlike plant. One crux, it may be pointed out here, that planters have to contend with in laying out woods of Douglas Firs, and it is this: the lower branches of these trees are so obstinately robust that they refuse to subject themselves to any of those selfsacrificing ordinances of self-pruning that are so essential to the well-being of their trunk system in after days. The question then arises, in face of this rather disheartening characteristic, What is the best distance apart to plant? If called in to prescribe we should suggest a distance of five feet.

The Oregon variety was first discovered, so history reads, by Dr. Archibald Menzies in I791. He first found it in Nootka Sound on the west coast of Vancouver Island. It was introduced in 1827 by the ill-fated traveller David Douglas, and the tree having been tossed about by the call of men from name to name-to wit, Red Spruce, Yellow Fir, Paget Sound Pine-finally settled down and took unto itself the enduring title of Douglas. David Douglas, the nominator, met a tragic end in the Sandwich Islands in 1833 . His mutilated body was found in a trap-pit contrived to catch wild cattle. $\mathrm{He}$ was precipitated into a pit occupied by a still alive horned inmate. The rest of the story shall be silence.

The other variety generally alluded to as the Colorado Douglas was first found by Dr. C. C. Parry 8 
in 1862. The differences between the two, and the verification of their differences, has been the text of many a debate in the fraternity of tree lovers.

Professor Augustine Henry bids us take note of these, their differences. The young twigs of the Oregon are " usually" downy, while those of the Colorado are smooth. The foliage of the Oregon is pale green, in that of the Colorado the upper surface of the needles is bluish.

The U.S.A. Department of Agriculture, in its Forest Service Contribution, goes one better. It bids us take note that while the Neptune's trident-shaped bracts on the cones of the Oregon more or less point straight up the length of the cone, those upon the Colorado variety are reflexed. If this is proved to be a universal practice on behalf of the two varieties, it is an "open sesame" to the mysteries of their botanical disassociation.

With the exception of this last remark, we have been only trying to review some English expressed views upon the subject of the two brother Douglases. We will now try to express a few American ideas on the subject of a tree that maybe is destined to play a great part in the history of the British timber industry.

The first discovered of the two is generally known as the Oregon Douglas, though its domain ranges upon long Pacific slopes, from Vancouver Island to San Francisco, while the later-discovered one hails from farther east, among the ranges of the Rockies, and is generally referred to as the Colorado species. What America has to say upon the question of the wood value should be of interest to us.

The Oregon Douglas represents the yellow narrowringed, and the Colorado the red and wide-ringedalthough the slower grower of the two-wood of the lumberman; and it is the yellow, narrow-ringed timber 
of the Oregon, that exceeds in value, because of its greater durability than that of the red wider-ringed wood of the Colorado variety.

In the contest for hardihood, the decision in favour goes to the more slow-growing later immigrant to Colorado. A want of robustness, however, can hardly be urged against either, though it is true that the quicker-growing Oregon, as he thrusts his head above his lag-behind contemporaries, is oft in need of shelter to ensure the safety of his topmost branches. It is well, then, in prospecting for them their position in a plantation, to look out for declivities sheltered from prevailing winds. They both seem to show preference for a northern and perhaps a western aspect, and bear the reputation, in their younger stages of existence, of being moderately tolerant of shade. It is estimated that they may be expected to attain a goodly old age, computed in America at from 400 to 500 years, but reckoned, according to Veitch in his Manual of Conifers, as from 450 to 750 . 


\section{III}

\section{PICEA, OR SPRUCE TREES}

(OF the Natural oRder of CONIFERA, of THE GENUS PINACEÆ, OF THE TRIBE ABIETINEÆE, OF THE GENUS PICEA)

\section{INTRODUCTORY}

Yet green are Saco's banks below, And belts of spruce and cedar show Dark fringing round these cones of snow.

WhitTIER, Funeral of the Sokokis.

PICEA is the Latin name given to the family of trees more familiarly spoken of as Spruce Firs, and the English name accorded can be traced by usually employed processes-namely, the searching of dictionaries and the excavating of derivations-to an adjective that implies something natty, smart and dandified. While in many instances the various species of these Spruce trees, like the Socialists of old and to-day, hold ideas as to the possession of certain properties in common, they, notwithstanding, contrive to draw the line at the participation of other points at issue when it happens to suit their particular fancy or convenience, or, more correctly speaking in an application to trees, the exigencies of their geographical situations.

We will instance some of their features in common. Their trunks taper, their crowns are pyramid-shaped, and their branches grow in regularly distanced circles 
or whorls. Their leaves are spirally or radially arranged-that is to say, they cover the stem and lateral branchlets on all sides, and do not leave bare spaces upon the latter in lines like the V-shaped, or pectinate arrangement, of the Silver Fir.

Needle-like in shape their leaves arise singly from the stems and branchlets. On examination it will be found that they are placed upon little raised woody excrescences of the stem. These are variously called pulvini, or cushions, peg-like projections, or stumps. In golf phraseology they would be called "tees," and not inaptly, since a tee is a base which intervenes between the ground and the ball placed upon it, and so in like manner is this projection, nothing more or less than a base that intervenes between the leaf and the stem.

Pulvinus is the Latin for a cushion, and a cushion is a commodity commonly considered in the Western grades of refined civilization to imply something that is soft and yielding, and this impression it conveys to nearly all except perhaps to a Japanese, who, in spite of all these opportunities of mollifying influences that civilization has flung in his face, still prefers to lay his Spartan head on a wooden rest. The object of our description is, however, anything but soft and yielding; on the contrary, it is hard and wooden as the Japanese head-rest. The simile does not seem a very happy effort upon the part of the author of it. Anything more anti-pulvinate, in the European acceptance of the term, could not be conceived by any one who seeks enlightenment from the meaning of language.

However you like to think of it, whatever you care to call it, this fact is assured, that leaf and pulvinus are in relation of clinging affinity, and you cannot pull the one off without tearing away the other. Prince Houssain, of Arabian Nights fame, stuck no 
more firmly to his magic carpet than do these young leaves to their so-called cushions.

The two great divisions of the Picex are differentiated by the shape of their leaves. While the true Spruce Firs have four-angled, four-sided (tetragonal) leaves, the Omoricas have only two-sided leaves, and are flat-leaved like the Abies. As has been pointed out before, this difference is easily ascertained by rolling them between thumb and finger. We give illustrations, two of each, of how a flat-leaved specimen looks when cut transversely and enlarged by magnifying process, and how a four-sided or tetragonal leaf appears treated similarly.

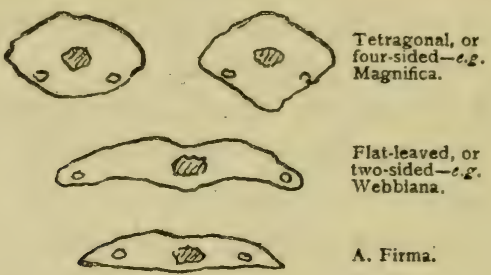

TRANSVERSE SECTION OF LEAVES (MAGNIFIED).

It will be seen by this that the difference that exists between a paper-knife and kitchen roller, or, to pursue our metaphor on more strictly analogous lines, between a sawn two-inch plank and a naturally grown rounded tree-stem, if subjected to the same process, is hardly more pronounced. Most of these generic characteristics appear in the table, pp. 280-282. We have only to supplement them with the fact that on both the male flowers are solitary and situated in the axils of the top leaves, while the female flowers are solitary and terminal-that is to say, growing at the end of the branches. And of the cones we would add, in the case of the Omorica group, at times, when for instance they grow in clusters (as on the Omorica species 
itself), or terminally as on the Hondoensis, it may be said with accuracy that they do not quite assume a strict pendulous habit, though they make a good try for it.

These are some of the generic characteristics of the Spruces, and now we approach the question of the best method of reducing identification difficulties.

There are fifteen of the true Spruces (Eupicea) enumerated by Elwes and Henry, for the most part recognized and naturalized habitués of Great Britain. These fifteen are divided into three groups, consisting one of seven, another of two, the third of six. It seems as if the determining factor of their arrangement was based upon the pubescent condition of their branches and branchlets. Thus, the members of Group I are returned as glabrous, or non-pubescent. One only, the P. Bicolor-we cannot explain his presence, we can only apologize for it as a little rift within our lute-has slipped into this group without complying with the condition.

Group III is composed of Spruces whose branchlets are all pubescent; and as between the sheep and the goats an intermediate stage of animal life exists, known as the alpaca, so also there is between the pubescent and non-pubescent Spruces a betwixt-andbetween couplet, labelled as Group II, and advertised as equipped only with minute and scattered pubescence.

Pubescence and non-pubescence certainly play the most prominent part in the identification process in a genus where (unlike the Abies) the roughness or smoothness of branchlet, or apex of leaf, of a Spruce counts for so little. Colour of leaf may help and does help in some cases, since some of the Spruces are glaucous green, or even bluish-white, others are of a brighter and more yellow hue. The length of leaf 
question dissociates some of them. Of the longerleaved lot we should include-

IN GROUP I

Smithiana.

Shrenlkiana.

Pungens.

Polita.

Bicolor.

IN GROUP II

Excelsa.

Albertiana.

IN Group III

Engelmannii.

Of the shorter-leaved lot we should count-

IN GROUP I

Alba.

Maximowiczii.
IN GROUP III

Nigra.

Rubra.

Glehnii.

Orientalis and Obovata.

In the Omoricas the margins of the plentifully found cones, whether they are entire, frayed or jagged, and of whatever shape at the apex, tells a tale, but rather an obscure one, we own, of their identity. This applies also to the Engelmannii, Bicolor, and Pungens in the Spruce Group. These cones and those of the Sitka; Ajanensis, and Hondoensis, bear a certain similitude in appearance, and their scales seem all composed of the same soft, spongy, squeezable, light-brown material. Most of the others, like the Eupiceæ (the Common Spruce, Morinda, etc.), seem to be made of a much more leathery and tougher dark-brown substance.

The application of the name Abies to Silver Firs, and Picea to Spruces, has b en a dispute of many years' standing. Whether the one word was-as some authorities have suggested-derived from the Latin word $a b e o$, and used in an ascendant sense, "abeunt in nubila montes" (as the mountains rise to the skies), may or may not be, but if it is so, it is and was the Silver Fir that indisputably represented 
height, and the Spruce that provided the pix. liquida, the boiling liquid pitch, that was-but is not now-employed for purposes of torture in the days of the early Roman Empire.

In the long-ago past of pre-Virgilian days maybe there was some cause for confusion as to whether the word Abies referred to Silver Fir, or whether Picea stood for a Spruce, or whether, vice versa, a Spruce was an Abies and a Silver Fir a Picea. This difference seems to have developed into quite a long-standing cause célíbre in the courts of botanical jurisprudence. As a contest of wits it was a case of a lead-off between two no less renowned Romans than Pliny called the Elder on the one side, and Virgilius Maro of Georgic fame on the other. In the courts of appeal the verdict has gone in favour of Virgil, and from our point of view rightly. Virgil was born and lived on his parental farm, while Pliny led the life of a soldier and barrister-at-law in turn. Virgil lived a generation before Pliny and so was first in the field, not only agriculturally speaking, but from a previous generation point of view, if that goes for anything, at a date when the laudator temporis acti is apt to be quoted at a discount. One more word in favour of this judgment: either the author of the Georgics was an authority on country life, or vast sums of parental money have been from time immemorial thrown away on the public schools' curriculum in England. From an extract in his oftconstrued epic poem, the $\mathbb{E}$ neid, it has been shown (v. Veitch's Book of Conifers) that he referred to the existence of Abies growing in a locality in which Silver Firs have always been known to flourish, and where Spruces-it is equally well known-have never seen the light of day, or still less those heights in the heavens that so many of the Abies reach.

If this is not conclusive reasoning that the Silver 
Fir should appropriate the name of Abies, and that the Spruces, as residuary legatees of the only other left in the market, should assume the name of Picea, nothing, we contend, can ever be in a contentious world written down as final, or even of passing worth.

\section{GROUP I}

P. Smithiana, Maximowiczit, Shrenkiana, Pungens, Polita, Alba, Bicolor (or Alcockiana)

P. Smithiana.-As far as the names go the vernacular aliases (e.g. Morinda) of this tree have-with all apologies to Sir E. Smith, first President of the Linnæan Society, and after whom it was named-a far more pleasing ring than the name finally bestowed on it by priority of publication, but not given, we mark, by priority of name as bestowed upon it by the natives and European dwellers before the date I812, when it was described and figured by $\mathrm{Dr}$. Wallich. It is certainly a tree that impresses the memory of the most casual of observers. Its long pendulous leaves, hanging like dangling tassels on its long pendulous branches, are accountable for its home circle and Anglo-Indian name of the Weeping Spruce of the Himalayas. They are as unlike as can be, in outward appearance, to the more ordinarylooking Spruces. Yet if examined closely, they comply with all the requirements of the class in such essentials as pulvini, acicular leaves, etc.

P. Shrenkiana.-Perhaps the nearest to the above-mentioned in appearance, only with leaves much shorter, pointing forwards, and lying even nearer along the branches than an American jockey ever lay along his horse's neck, is the Siberian P. 
Shrenkiana, which so far with us ranks among the rarities. As far as a limited and local experience goes, this tree seems to thrive in some of the highly situated positions of this neighbourhood (the borders of Herefordshire and Radnorshire), localities which are counted by unkind critics from more balmy regions as examples of climatic severity. Two or three young specimens have weathered the conditions of 1915 and 1916, which included fourteen degrees of frost on May 2oth in one year, and the coldest succession of continual north wind blasts we, or any one living, can ever remember, and which for the first time in the memory of man "browned " the exposed side of many of our inland-growing Conifers.

Its appearance rather suggests a pocket edition of the Smithiana. The leaves are shorter, and those on a bough before me are from $\frac{3}{4}$ to $\mathrm{I}$ in. long, and mounted on unusually high pegs or pulvini. They not only point forward, but point forward so pointedly that their tips almost touch the branch.

Another peculiarity of its appearance as a tree is the long terminal shoot, which is twice the length of the longest branchlet in the whorl and more than twice as thick. The terminal shoot before me measures nearly two inches round its base. The cones on a local tree are $2 \frac{1}{2}$ in. long (W. Banks, Esq., Hergest Croft, Kington), while of those I have obtained from the Royal Botanical Gardens, Petrograd, the longest measures 4 in.

P. Pungens, especially in the blue form (var. Glauca) is seen everywhere, and often called Parryana, after its discoverer, Dr. C. C. Parry, who found it in 1862. A form called Kosteri Pendula claims to be, and is, more brilliantly blue still. Many trees that are written down Engelmannii turn out to be P. Pungens. 
P. Engelmannir.-To identify the true Engelmannii you must invoke two of the five senses, the sense of sight and smell-the sense of sight to perceive the pubescence, the sense of smell to detect its rank odour; and these two accomplishments brought to bear will enable you to pronounce opinion upon which is which of the P. Pungens and P. Engelmannii; P. Engelmannii, we reiterate, is pubescent and $\mathrm{P}$. Pungens non-pubescent.

P. Polita.-To identify the Polita you must invoke the last of the five senses-the sense of touch ; and anyone who can recall the acute experience of the point of a perch's fin ought to have no diffculty in making out and remembering the strong spiny-tipped leaves of the Polita.

Nursery maids, instructresses and caretakers of our well-being in infantile days, were wont to exhort us always to grasp the nettle, a process, if I remember right, they were always more prone to preach than to practise. Had they urged us to grasp the Polita leaves, and had we done so, I feel sure its identity would have lingered in our memories for many a long day after the pain in our hands had subsided. E. H. Wilson describes a forest of pure Polita he met with on Lake Yamanaka, in his 1916 visit to Japan, as one of the finest and most unique sylvicultural sights he ever contemplated.

The orange-red branchlets of the tree, with its very pronounced markings and grooves, not to mention the spear-point, perch-fin prickle armament of the leaf apex, ought also to aid anyone in grappling with its identity.

P. Bicolor, or Alcockiana.--The christening of this tree seems rather after the manner of the naming of the Smithiana or Morinda, a close race for prece: 
dence between a human celebrity and a vernacular or a descriptive rendering of title. In both cases, some even modern authorities call it the one, others the other, a state of affairs which offers to all a happy and unconcerned freedom of tongue in any discussion that may arise upon it.

The name Bicolor was bestowed upon it because it broke away from the traditions of the true Spruces, and exhibited conspicuous white bands of stomata upon only half of its surfaces (for it is a fourangled-leaf tree); on the other halves the stomata, though they are there, are sufficiently invisible to render a green effect. These white and green effects are-it must be presumed-responsible for the $\mathrm{Bi}$ color name. If this were not sufficient, the marked contrast of colour, as between the creamy or pale primrose-white shoots of the year, and the dark-red, cherry-coloured shoots of that preceding, carries on the " of two colours" name and tradition with great emphasis, and suggests a colour scheme of as marked a contrast as that between the red flank and white face of a prize Hereford cow.

Upon many descriptive points in writing the P. Bicolor and our Common Spruce read much alike. The stomata differences do not convey any very illuminating clue to the ordinary observer, even under the microscope. It is this dense, close-crowded foxtail growth of the leaves that makes you aware you are looking at something out of the common in the Spruce line. Possibly it may look like our old friend, the P. Excelsa, at the first glance, but a second look shows you a new face of foreign features.

Most of the trees that lay a claim to the name Bicolor, or Alcockiana, are in reality Hondoensis, and this is due to some such dull and sublunary prosaic mistake as a luggage label going wrong in a 
past day, when they were first sent over to England. There is this wide difference between them, that the Alcockiana is a four-sided leaf with stomata more or less on all surfaces. The Hondoensis and Ajanensis (its near affinity) are flat-leaved trees, with stomata only on one side.

The leaves of Alcockiana are stiff-curved with a cartilaginous point, the leaves of the others are blunter.

The branchlets of the Alcockiana show pubescence in the grooves of the branchlets. The Hondoensis and Ajanensis do not.

The resemblance between them and the Hondoensis, then, is reduced to a mere nominal confusion, due to no similarities of any natural construction.

The Alcockiana is not recommended by the faculty as a " thing of beauty or a joy for ever," to anyone who wishes to plant with these desirable objects in view.

Note I. - The latest description of this tree comes from E. H. Wilson, in an account of it published in the Arnold Arboretum publication, 1916, and entitled Conifers and Taxads in Japan.

The shoots he describes as at times quite glabrous, but on adult trees and their principal shoots pubescent.

The leaves he describes as rhombic (quadrilateral) in section, of a bluish-green colour, oblique at apex, with small cartilaginous points. They and the cones are much the same as described by other authorities, from whom the details, as they appear in table, p. 280 , are collected.

Note 2.- There are two varieties of the P. BicolorAcicularis and Reflexa-called attention to in The Gardener's Chronicle, August 14th, 1915, by the great Japanese authorities, Shirasawa and Royama. Both have slightly different cone scale features, but are 
not of sufficiently pronounced difference to call further attention to here.

Note 3.-We are told now that two forms of Bicolor exist, or have been tried, in England; one has main twig pubescent and lateral leaves smooth, the other is glabrous in both.

P. Maximowiczir, Glehnir, Orientalis, Obovata, are all of them short-leaved Spruces bearing some resemblances. It will be seen that we are discussing them more from the point of view of certain outward observances than in strict accordance with their group systems.

There is little call to prate on trees of which so little is to be seen as the P. Maximowiczii and Glehnii. The former belongs to the glabrous, the latter to the pubescent in the furrow division. Both hail from Japan, and the Maximowiczii seems even to be a rara avis in the path of the Japanese botanists in search after it on its native soil. It has short leaves, resinous buds, reddish glabrous branchlets. These are some of the descriptions it will be called to make good to the identifying investigators. It seems to have claimed for it various relationships to various Spruces-Obovata, Bicolor, Polita-by various authorities in various countries and localities. The Japanese regard it as a diminutive edition, or a strong-family-likenessed little daughter of the Polita. They call it Hime-Bara-Momi, the daughter of the Bara-Momi, the vernacular name for Polita, signifying a sharp-leaved tree.

P. Glehnir.-Should anyone come across some of the very few young specimens that are being tried with us, we would emphasize a few points for his particular attention. The branchlets are reddish and pubescent in furrow as stated. Its buds are like the 
Nigra and Rubra, which are explained in our descriptions. Its leaves are like the P. Orientalis.

P. Orientalis.- - This tree is common enough with us, and planters of Conifers are beginning to reawaken to its ornamental merits. With its brilliant crimson staminate flowers and short leaves it is quite unique among the more elderly specimens of the Spruces seen with us. A tree planted here in 1845 measures close upon $90 \mathrm{ft}$. in height and $7 \mathrm{ft} .7 \mathrm{in}$. in girth, and this is $2 \mathrm{I} \mathrm{ft}$. higher, and I in. less in circumference, than the champion specimen (Dognersfield, Hants, Sir H. Mildmay) mentioned in Trees of Great Britain.

P. OBovata is still more or less a stranger in our land. It is accredited with a propensity to quarrel with our climate on account of its too genial warmth. If so we can only say that it is a curious taste on its part, and an unusual complaint to hear charged against our country.

Its leaves are shorter and more pointed than those of our Common Spruce. They appear to spread out more from the stem, or, to use a Cypress phrase, look "freer at the apex" than the generality of Spruces. Their branchlets are of a greyer colour, and by way of being more pubescent than those of our Spruces, which when in good health are of a redder hue.

Their cones are very different. Whereas the usual length of a P. Excelsa cone is somewhere about 6 in., the cones of the Obovata sent me from Russia measure at most but $2 \frac{1}{2}$ in. The difference in the margin of their scales gives a valuable clue to their identity. The margins of the cone scales of the P. Obovata are round and entire, while those of the P. Excelsa are in most cases either one or two pointed.

The small tree growing here so far promises well, and looks particularly happy in its surroundings, 
even after an endurance of the late severe May frost of 1915 , and the unusually long visitation of cold late winter winds of 1916 and 1917.

\section{GROUP II}

P. Excelsa, Rubra, Nigra, Alba, Albertiana Whilst towering firs in conic forms arise, And with a pointed spear divide the skies.

M. PRIOR.

The primary instinct of an uninstructed mind would in all probability regard the Common Spruce ( $P$. Excelsa) as the representative type of what all properly conducted Spruces should and ought to be. Possibly, if his inclinations carried him a little farther on the paths of investigation, he would notice that the leaves of some of these similarities were a little longer than others, and also that perhaps a different hue of colour here and there was apparent, and one or two little minor differences of this sort. But, on the whole, he would concur that the majority of Spruces, although labelled by the doctrinaires with different names, partook of a sufficient resemblance to the Common Spruce to justify him in including them mentally in one self-same category. If he went a little farther still upon his journey of investigations, the chances are he would soon be induced to modify his opinions.

Let us suppose that he came across a Picea Rubra, he would at once notice a certain resemblance that it bore to the Common Spruce. He would perceive that the leaves of the P. Rubra were, on the whole, shorter than those of the P. Excelsa. While the Picea Rubra's leaves reach about half an inch in length, those of the Excelsa average about twice the length. Yet a young and weakly Common Spruce can often be found with leaves as short. The colour, too, is the same, we might almost say precisely the same. So far we have not got much forwarder. 
The Picea Rubra's leaves on closer investigation are more densely crowded; they are also very remarkably incurved, while those of the Common Spruce point in a very distinctly upward attitude. Here is a very telling difference, but a still more telling one is the dense pubescence on the P. Rubra branches, white on the young shoots and brown on the older branchlets. The P. Excelsa here and there shows evidence of a few scattered downy tufts on the young stems, and this wears off considerably on older branchlets. But these scattered tufts of minute pubescence present a very marked difference of appearance from the dense down of thorough-going pubescent specimens. Here is an unmistakable difference and a lesson easily learnt. The cones differ entirely, as the table, p. 28I, shows, but cones are not very forthcoming; if they were, many identifying difficulties would vanish.

As the P. Rubra is a very rare tree, and only a few can have seen its cones growing, I make no apology for volunteering this home experience of them. I have before me a branch taken from the top of a specimen grown here, and planted about 1845 (vide Elwes and Henry, vol. vi. p. I379), and which is now nearly $8 \mathrm{o} \mathrm{ft}$. high. It tapers to a point and is about a foot broad in its widest part. In some 18 inches length of this little arrangement of branch and branchlets there are collected together some eighty cones, sessile in character, and as pendulous in position as they can contrive to be in their overcrowded dwelling sphere. If you wish further to dissociate these two trees Rubra and Excelsa, the buds will help you. If you look at the buds of the Rubra, and also of the P. Nigra, which in common shares this peculiar characteristic, it will be seen that their terminal buds are enveloped, for more than from head to foot, with long, narrow-pointed, hairy 
leaf-scale coverings, while the P. Excelsa has, comparatively speaking, only a commonplace-looking hard dry bud, destitute of any such singular trappings.

To take two more nearly allied instances and dissociate them, the P. Nigra and the P. Alba have bluish glaucous-coloured leaves, quite unlike the more grass-green colour of the P. Rubra, or for the matter of that the P. Excelsa. But the P. Alba is quite devoid of any pubescence, and that is where it shows its marked independence of character in this rather perplexing trio of the Spruces-Red, Black, and White. Finally, if you aspire to add to the sum of your accomplishments an intimacy with the different Piceas, we would strongly recommend a close observance of the presence or absence of pubescence on their branches, as well also the colour shape and direction of their leaves, the margins of their scales of their cones, whether entire, delicately frayed on the fringe, or ruthlessly jagged in appearance. All these points become convincing evidences of the individuality of the tree in question.

\section{VIOLINS AND SPRUCE TREES}

That small, sweet thing,

Devised in love and fashioned cunningly

Of wood and strings.

Before quitting the subject of the Common Spruce we should like to converse on one little sidelight of its wood value. In face of the fact that it has been so disregarded by writers on trees, we feel no occasion to offer apology for a brief reference thereto. You do not often hap upon a student of wood values and a devotional lover of viols combined in one and the same personality. And so it is that one little episode in the life-history of the Spruce tree has gone by, for the most part, unheeded by tree historians, and in undeserved escape of notice from the musical 
fraternity. By the former it is described as White Deal, by the latter defined as Swiss Pine. Yet it was from these trees, rated at lowliest of value in the timber marts of the world, holding even the worst fame of creosoted estate experiment, that a few square inches of surface measure, with a depth little more than that required for a thin plating of veneer, of a price value an unappreciable fraction of the lowest current coin of the realm, were appointed to make history. It was from these trees, and in preference to all other trees that grow, that were requisitioned nearly half the component parts of certain little musical instruments, made up from "wood and string," and destined often to draw four golden-figured prices from eager buyers. From these lightly regarded Mountain Spruces, growing in their grandeur of loneliness, sometimes moved and stirred but never affrighted, as were the unrighteous people, told of by Solomon in his Book of Wisdom, by the portents that surrounded them, "The whistling of the wind, the melodious noise of birds among branches, and the pleasing fall of waters running violently "; from each as they were formed and created, these instruments of subtle shape and make, ordained at some long-distant day to enrich our galleries of Art, and make addition to delights of sound.

From them the frontal part of the great violins, violas, and 'cellos, of Brescian and Cremonese fame, and of all other earlier and later viols, viols diskant and tenor, viols bass and double bass, were nearly half constructed, and these were those articles of vertu that were ultimately fated to fetch fabulous prices from succeeding generations of collectors and players.

When we think of the part played by the highaltitude-growing specimens of this tree, it conjures up many a picture to the fiddle lover. Of Antonius Stradivarius and Joseph Guarnarius Del Jesu-in 
reference presumably of his connection with the Society of the Jesuits, and as he signed himselfand the lesser but still renowned members of their family, selecting with crafty care choice specimens of wood from the best of their growths; of another, old Jacob Steiner of Salzburg, the German fiddle designer, exploring the woodlands and mountainsides in quest of them, and tapping their trunks, like a hungry woodpecker, in zealous endeavour to discover which responded most musically to the vibrations of desired sound, or on other occasions standing on the precipitous edge of some gorge or ravine, and hearkening eagerly for a stray sound of some tone or overtone as they toppled over, and crashed down crag and rock, felled by the hand of skilled fellers.

It seems then, even from these few particulars of its back history, that the Spruce of the higher altitudes, in those latitudes and the outlying mountain lands of Lombardy, has yet much of its history to be written of, and more than that, many of its ancient secrets to be rediscovered, and perhaps some of those lost chords of its musical mysteries to be reawakened, if it is ever to attain a well-deserved apotheosis.

\section{OMORICA, OR FLAT-LEAVED SPRUCES}

Group I.-Hondoensis, Ajanensis, Sitkensis, Morindoides (Shoots Glabrous)

Yet through the gray and sombre wood Against the dusk of fir and pine.

WHITTIER,

The flat-leaved Spruces are so called for the allsufficient reason that their leaves are flat, like the Abies, and not four-sided as the afore-discussed Eupiceæ; on this point they have strayed from the fold of the true Picex. That they are not ranged with the Abies is due to the fact that their leaves 
are mounted on those little woody excrescences which professors call pulvini (or projections). Then, again, their leaves are spiny and pointed. This is all in accordance with the habits of Piceæ and not in accordance with the practice of the leaves of the Abies, which are dented at the apex as a rule.

They are also credited with only showing white stomata bands on the under-surface of the leaf. To this statement, which most authorities have endorsed, we make differential and deferential demur, since on the higher branches of a Sitka Spruce here, over I $26 \mathrm{ft}$. high, we have found leaves with visible indications of stomata also on the upper-side. Indeed, the very leaves from the upper regions of this tree seem almost to belong to another specimen of the arboricultural race altogether. Although they have the same botanical characteristics, with this exception of stomata, an exception that does not descend to the leaves on the lower part of the same tree, they are thicker in shape, and more densely crowded in habit. The leaves in question were sent to the authorities at $\mathrm{Kew}$, and opinion arrived at endorsed. They were commented upon in the $\mathrm{Ar}$ boricultural Journal, I9I5-16 vols., by Bean and others.

This little disturbance of the accepted theory that no flat-leaved Spruces exhibited stomata on both sides of the leaf, we should like to add, ought in more justice to be attributed to the officious action of a tree squirrel who had bitten off some top twigs of a high tree, rather than to any commonplace observational tendencies on the part of the owner and writer. Palmam qui meruit ferat (Let him who has deserved the palm, bear it).

To differentiate at sight between the Sitka and the Omorica would be no easy task for the amateur, had it not been for the fact that the Omorica is obligingly 
accommodated with pubescent evidences, while the Sitka remains equipped with smooth and glabrous stems. The cones of these two are obviously unalike. Around the Sitka the ground is plentifully strewn with soft, featherbed-feeling, light-brown specimens, while the cones of the Omorica are only half the size, hard and dark-coloured.

We must not leave the subject of the Sitka without referring to the fact that it is reputed to flourish as the Willows by the water-courses. The faculty are strongly recommending the planting of it in all available wet places, and this advice has been carried out largely in Ireland by the Government. This partiality to damp places, however, cannot be taken to prove that as a tree it is incapable of growing on drier ground. The big Sitka here (Stanage Park, Radnorshire), which measured in 1916 126 ft. high and $12 \mathrm{ft}$. girth five feet from ground, grows upon a Ludlow rock geological formation some $800 \mathrm{ft}$. above sea-level. Possibly, if its underground secrets were unearthed, it would be found that a percolating water-spring beneath ministered to its presumed aquatic wants. Its large and buttressed base, its protruding-out-of-the-ground roots, are very charac teristic of its kind, and its natural inclination to a watery base.

P. Hondoensis and P. Ajanensis.-As between the Hondo and Ajan Spruce there exists mystification, and consequently a good deal of botanical argument as to "what's what " and "which is which " has been waged. The Ajan Spruce is the representative of the northern island of Japan, while the Hondo is the representative of the main island of that country.

Perhaps the question may be set at rest between these two, and the occupation of the controversialists 
with regard to them be brought to a timely end, by the explorer, E. H. Wilson, who was making an expedition there in I914..$^{1}$ We will, as far as any reference goes to them here, run them in couples and treat them as one.

The differences of their cones may be a help to the identification of the Japanese trees and the Sitka. From the many thousand specimens fallen from the Sitka, and that I have had before me, the cones have always been of a uniform size, and that size is 2 in. long.

Of the Japanese tree, and from cones sent me from that country, the Hondo and Ajan are considerably longer than the specimens of our homegrown Sitka, but the point of difference to note is that while the margins of the scales of the Sitka cones are only minutely frayed in appearance, and even sometimes slightly wavy or entire, the Japanese representatives present torn and tattered appearance of margin with their jagged edges. The leaves of the Japanese, too, are shorter.

This disposes of the list of the up-to-date naturalized Spruces which have made appearance in our islands, with the exception of the Morindoides (now rechristened Spinulosa), a native of Sikkim. This tree has the appearance of a short-leaved Morinda, or Smithiana (Himalayan Weeping Spruce), and several we saw in a very promising condition have come to untimely ends, at even such climatically favoured situations as Castlewelan, County Down.

1 E. H. Wilson's ultimatum on this long-standing vexed question, after a careful investigation of the two trees in their native islands, Hondo and Hokkaido, during his $19 \mathrm{r}^{-\mathrm{I}} 6$ expedition, gives out that they are one and the same tree, the Hondoensis and Ajanensis; and, moreover, that they are the only flat-leaved Spruce, so far found, existent in N.-E, Asia and Japan, 


\section{Group II.-Omorica, Breweriana (Shoots} Pubescent)

The BREwerIANA, which shows a fastigiate-looking crop of leaves, is still rarer. Probably at this moment the length of all the trees of this species in cultivation with us here would not reach higher than the length of a long man, $6 \mathrm{ft}$. high in his stockings. If ever the day dawns when either the Morindoides or Breweriana has learnt to flourish in our country, there will not be, we apprehend, much difficulty in dealing with their identities.

All these Weeping Spruces exhibit a certain outward and visible resemblance. While the Smithiana (or Morinda) and the Shrenkiana have four-angled leaves, the Himalayan Morindoides and the American Breweriana sport flat leaves, an emphatic difference easily discerned.

As between the Morindoides (or Spinulosa) and the Breweriana, there exist these marked differences. The branchlets of the Morindoides are glabrous and the branchlets of the Breweriana pubescent. Again, the cones of the Morindoides are rather larger at the base than they are at the top, and the margin of their cone scales are frayed; while those of the Breweriana are narrow at both extremities, especially so at their very marked tapering base. The margins of their cone scales also differ, and are rounder in shape and entire on margin. 


\section{IV}

\section{TSUGA, OR HEMLOCK SPRUCE FIRS}

(OF THE NATURAL ORDER OF CONIFERA, OF THE FAMILY PINACE\&, OF THE TRIBE ABIETINEÆ, OF THE GENUS PICEA, AND SUB-DIVISION TSUGA)

\section{INTRODUCTORY}

O Hemlock tree! O Hemlock tree! How faithful are thy branches, Green not alone in summer-time,

But in the winter's frost and rime,

O Hemlock tree! O Hemlock tree! How faithful are thy branches.

LONGFELLOW.

WE who perforce in early days of life sallied or were sent forth from home in quest of knowledge, to drink at the Pierian springs of Greek history within the classical courts of our public schools, may be prone to jump wrongly to a conclusion that the Hemlock tree had some connection with a certain deadly drug, that we were instructed by school-books was meted out to those who were regarded in the light of a social or political inconvenience by the pro-tem. Government of the day which ruled in mighty Athens.

That the historical cup of Hemlock ( $\kappa$ '́velov, or in Latin language, Conium Maculatum), which quenched for centuries the bold spirit of philosophy had any connection with the tree under discussion would be quite an erroneous basis for our investigations. The Hemlock plant-not tree-is a wild umbelliferous poisonous plant of the genus Conium, 
and how our well-known tree came by the same name I have been unable to ascertain. The second syllable "lock" signifies plant, as it does in the case of Charlock, Garlic, etc., but that leaves unexplained the "Hem" ; which fact seems to indicate that a stitch has been dropped somewhere in the interweaving of the tree's history.

We will ask pardon for a little digression upon the Hemlock plant, a subject apart in all but name from our main theme, the Hemlock tree. Of whatever ingredients the poisonous cup at Athens was composed, it seemed at times to somewhat lack the quality of either potency or the blessings of quantity.

It appears that in carrying out these sentences, conceived in a laudable spirit of Euthanasian finality, one little ungenerous flaw-a flaw which always seemed strongly to impress even the most unpromising student of scholastic days-had crept into their system.

In a characteristic spirit of economy on the part of the democratic Government of the day, the money paid over for the dose was calculated upon with such an exact degree of nicety that at times, and unless everything went well, it barely sufficed to carry out the amiable intentions of the promoters and executors of the scheme.

Socrates, whose mission it was to lecture-great Socrates, who adored speaking at all times, and who not only adored speaking, but adorned those to whom he spoke with a cloak of infinite wisdom, was enjoined - even if imperatively, let us hope at least in tones of politeness - by the performing clown of the gruesome scene, at the neurotic moment of his last drink upon earth, to keep silence and hold his tongue, and for no other substantial reason than that it might retard the action of the draught, and thereby involve the executioner in an uncalled-for expenditure in the 
purchase of more poison drug from the innermost recesses of his private purse!

Phocion, the Athenian general, was another of these inconsiderately treated victims of a State's parsimony. He complained bitterly-and not without good reason, we think-that he was called upon to subscribe the money from his personal income upon " extras," for the purpose of enabling the executioner to brew the dose in proportions strong enough to accomplish its purpose.

But, as we have said, this graceful tree, known as the Hemlock Spruce, in our midst, though it may have contrived a nominal connection with the poisonous plant, is quite absolved from any participation in these scenes described.

The Hemlock plant (Conium Maculatum) is a smooth, purple-spotted, hollow-stemmed biennial, which is practically full of poison in root, seed, stem, and leaf, and which grows in hedgerow and ditch,a plant that is credited with killing children who partake of it in mistake for parsnips; and violently disagreeing with others who, lured on by the joys of musical delight, attempt the use of its hollow stem for penny-whistle purposes. And while on the subject, let it not be forgotten by experimentalists in these directions, and also by the guardians of flocks and herds, that there are other Hemlocks-for instance, the Water Hemlock (Enanthe Crocata)-of umbelliferous affinity and like evil reputation, deservedly credited upon flagrante-delicto evidences, of distributing, with fatal results, its poisonous properties to man and beast. The Hemlock Spruce, on the other hand, is a dignified tree, with a grave and massive squareness of outline, with a record behind free and flawless of crime, that occupies frontal positions on many a lawn and pleasure-ground ; and, moreover, is a tree which no one has ever repented 
of planting, or ever been called to repentance for having planted. There is no more goodly tree in Christendom.

It would make an interesting incursion into the realms of imagination to hazard an idea as to what impressions a Hemlock Spruce would create in the mind of anyone suddenly called into the presence of tree-life for the first time and asked to dissociate them one from another. If, for instance, they were called in before the Flood,-a rather extreme metamorphic process once suggested by Voltaire-and had placed before them branches, say, of a Hemlock, Silver Fir, and Yew, for the purposes of dissociation, generically and tribally, what opinion would they form of their relative alikes and unalikes?

There may be said to be a certain rough-and-ready resemblance between the leaves of the Hemlock and those of the Silver Fir, since the leaf appearance of the Hemlock has a look of a minuter edition of the Silver Fir. That is a result which takes very little disposing of to-day, but it might have taken longer once, and not have been arrived at so easily. It will be seen on closer inspection that-

(I) The leaves of the Hemlock are mounted on those same little projections that the Spruces' are, and the Silver Firs' arising from circular bases are not, as has been pointed out on previous pages.

(2) The bark of the Hemlock is red-brown, that of the Silver Fir of a grey colour.

(3) The shape of the head of the tree and the foliage arrangement are more after the manner of the generality of hard-wood trees, and look as broad in effect as they are high, while the Silver Fir towers to the heavens with church-spire grandeur. The 
branches of the Hemlock jut out irregularly from all sides of its trunk the branches of the Silver Fir are regularly whorled-that is to say, shaped after the Radiata outline of a starfish arranged round a central axis, or the spokes of a cart-wheel laid upon the ground. The leaves of the Silver Fir are notched at the apex, those of the Hemlock are not. The cones of the Silver Fir are upright and large, those of the Hemlock pendulous and small, and so ad infinitum.

Then there is the question of the Yew. The leaves may be arranged similarly, and there begins and ends any similitude. Its leaves are much longer than the Hemlock's. Underneath them the colour is yellowgreen, showing no white stomata bands as do the Hemlock's. The twigs of the Yew are yellow-green and smooth, those of the Hemlock large and downy. Thus is disposed of any hint of relationship between the two, without even trenching on the subject of the wide difference of their fruits.

All these little disquisitions on obvious differences may read to some like a return to the more primal ways of nursery life, but it must be admitted in equal fairness that infants must walk before they run, and that the lower rungs of the ladder of knowledge must first be trod before the heights can be scaled.

\section{SPECIES AND VARIETIES OF HEMLOCK SPRUCE FIRS}

Where the hemlocks grew so dark That I stopped to look and hark.

WHITTIER.

The list of Hemlock Spruces in cultivation in Great Britain consists of seven species, to which we have 
added the latest Chinese importation, and this specimen we will eliminate from our discussions summarily, with the remark that the descriptions of the newly imported Western China trees are reservoirs that so far even the most athirst can only hope to sip from.

Before instituting any comparison of the differences of the remaining more fraternal seven, we can dismiss from troubling us, upon any question of identifying, the T. Pattoniana, and for the reason that it does not conform to the in other cases strictly observed custom of wearing the leaves in pectinate arrangement. Besides this unorthodox radial arrangement of its much narrower leaves, it breaks another rule by sporting stomatic bands on both the upper and lower side of its leaves. These traits in its character render it easily distinguishable from other Hemlock Spruces; but before leaving the subject of this West American tree, variously alluded to as Hookeriana, Mertensiana, and Pattoniana, we should like to add a personal expression of opinion upon it. Notwithstanding these deviations from the paths of strict Hemlock Sprucian rectitude, this tree, which was introduced in 1854 , has undoubtedly winning ways with it. From all accounts, it prefers a certain humidity of atmosphere; and had it lived in mythological days, doubtless it would have been committed to the care of Dione, the goddess of moisture, or to some clique of sorrowing and Stellular Sisters whose mission it was to shed tears and produce rain-drops. Had it been relegated to the especial attention of the great cloud-compellor himself, Jupiter, son of Kronos and lord of the storm-cloud, it would have deserved the high patronage showered upon it. Whatever is required to be showered upon it, and whatever is showered upon it, we firmly believe that blessings will be bountifully poured by posterity upon those 
who plant it to-day, and recall yet another Whittier description :

How yonder Ethiopian hemlock,

Crowned with his glistening circlet, stands,

What jewels light his swarthy hands.

For the purposes of identification one way we might suggest would be to divide the remaining six into two groups, and seek help from the diversity of shape in the leaf margins.

In the case of the T. Canadensis, T. Albertiana,

T. Brunoniana, the leaves are serrulate.

In the case of the T. Sieboldii, T. Diversifolia, $\mathrm{T}$. Caroliniana, the leaves are entire.

We must make this reservation with regard to this method of identifying-namely, that these distinctions, as between serrulate and entire, by reason of the almost invisible obscurity of these leaf marginal signs, do not extend to the groping student, even with the aid of magnifying glasses, that generous help that might have been expected from the promising announcement.

Loudon describes the T. CANADENSIS as slightly denticulate, so it is not to be wondered that more amateur and unequipped observers have difficulty in finding the signs with the naked eye. Under a good glass you can perceive clearly some little perchback-looking protuberances, situate at rather long intervals apart, and this proclaims their serrulation.

Of all Hemlocks perhaps the T. Canadensis and the T. Albertiana show the nearest resemblance, and since they are the same tree of the same country, only with a different geographical habitat, there is no particular reason why they should not. Perhaps their greatest difference exists in their shape and growth. As the Deodar differs from the Cedar of 
Lebanon and grows in shape of slender spire against a sky, so similarly does the T. Albertiana differ from the T. Canadensis. While the more Western Hemlock at quieter rate of growth tapers upward, the Canadian Hemlock, like the Cedar of Lebanon, displays a lateral top growth, which nursery gardeners more bluntly call clump-headed.

Two more signs of recognition must be looked for, as between these two, the stalkless cone and lessdefined hue of the white stomata on lower side of leaf of the new-comer, by which the Albertiana proclaims his whence and title to a separate name.

T. BRunoniana is the other of the serrulate-leafed trio, the Himalayan representative of the Hemlock Spruces. Its much longer leaves, their brilliantlylighted-up silvery under-surface, their longer conicalshaped yellow-brown cones, make the tree, which unfortunately does not acclimatize well with us, an easy target for identification.

We now come to the entire-leaved-margin trionamely, the T. Sieboldir, T. Diversifolia, T. Caroliniana.

Of these the T. Sieboldii asserts the individuality alone among Hemlocks of glabrous shoots. Its leaf is longer than any except that of the Brunoniana. From the Brunoniana it also differs, as has been pointed out, in leaf margin. There is yet another marked difference. While the apex of the leaf of the Brunoniana is acute, that of the Sieboldii is rounded and notched.

The Si boldii also again can be distinguished from another Japanese representative, the Diversifolia, by the fact that its shoots are glabrous while the Diversifolia's are pubescent.

The Caroliniana Hemlock, discovered by Professor Gibbes in the Blue Ridge mountains of $\mathrm{N}$. and $\mathrm{S}$. 
Carolina, reads in description very similar to that of the Diversifolia, of which it is the American representative. Sometimes difficulties of recognition have a way of clearing a way for themselves. A deus ex machina steps in and lends us his aid. In this case its rare presence and so far diminutive size (it was introduced in I886) seldom give the tree-hunter a chance of any spectacular illumination. Its cones at maturity have a habit of expanding widely, and this is a noticeable peculiarity among its kind. Its leaves, too, if they fulfilled the function attached to them of being only minutely notched or even mucronate, ought to be another aid of research in these directions.

\section{LARCHES}

(OF the NATURAL ORDER OF CONIFERÆ, OF THE FAMILy PINACEÆ, OF THE TRIBE ABIETINEÆ, OF THE SUB-TRIBE LARICE $\mathbb{E}$ )

Such a green gown God gives the larches, As green as $\mathrm{He}$ is good.

E. Nesbit.

THE Larch as a tree is too serious a subject for the commercial-minded to rhapsodize over in any abstract flights of poetry. It is too much of a business proposition for those engrossed in occupations of other ultimate aims, to spend time in musing over the fresh green gown that God gave it, or the invigorating freshness of its early spring attire. The primates of song, on the whole, have left it alone as an imaginable noun of composition, and fought shy of it as an expression for their flights in air. Tennyson talks of it as perky, "There amid perky larches and pine," among which, we read further, stood a new-built mansion of an upstart millionaire, whose walls held 
within a very Helen of Troy, and attraction of rival affections, in the person of "Maud, with her exquisite face."

Perky, we take it, means trim, smart, or saucy, a compliment that is more usually applied to certain types of human life, usually engaged in the more coquettish avocations of life, which we will leave to the reader's imagination to supply their own ideas of, and designations for. The adjective well denotes, however, the neat shapeliness of the tree.

If the Larch, then, as a word of construction hardly accorded to a poet's idea of that flow and sound which their craft crave after to ornament their versification and attune their lyrics, and on that account was left somewhat severely alone by them, we too, but for other reasons, will follow suit, and in consideration of its prior claim to native worth on more worldly grounds, waive further apostrophe. But in so doing let there not be attributed to us any base slander that we fail in appreciation of its natural and especial spring beauty.

All these points can be fairly put forward on its behalf, and in some explanation, or in extenuation if required, of its numerical preponderance in our more lately planted areas to-day:

(I) Upon no tree in existence has more money been spent in planting.

(2) Upon no tree in existence has so much money been expended by nurserymen and cultivators.

(3) Upon no tree has the money of all the trading fraternities of timber buyers and timber sellers been so freely circulated.

(4) Upon no tree have so many uses on estates and various other works depended.

It may be that its origin as a name comes from 
the Hebrew word erez, derived from an Arab root, and a word applying to a firmly rooted and a strong tree. From el erez to Larch is a corruption and contraction that may easily have arisen.

The Greek word $\lambda a \rho i \xi$ makes appearance, duly entered and certified in authorized Greek Lexicons, and is translated "the Larch tree", ; so the name of such a tree is one of respectable antiquity whatever else may be conjectured about its antecedents.

But whoever was responsible for the name-Hebrew, Arabian, Greek, or Pelasgian-it would not have been inappropriate if it had been traced etymologically to the Etruscan word lar, which represented the tutelary overlord and genius of the destinies of the household. The two words may have no-or even have not-remote connection, but had the derivation held good it would have been no misnomer, for the Larch has certainly earned an honoured position among the Lares and Penates of many who own broad acres of woodlands, and done its bit for those who occupy great territorial possessions.

We have been told how the clansmen of the house of Argyll were wont to shower religious blessings on their chieftain, and cry aloud in gratitude " God bless the Duke of Argyll," as they rubbed shoulders against the posts he had erected for their creature comforts, or the creature comforts more primarily intended for use, we opine, among their more bestial brethren of the animal kingdom.

With tenser impulse still must successive generations of another ennobled (Scottish) house have, we think, had reason many times to bless the memory, and cry aloud their gratitude, when they remembered their progenitor, the 4th Duke of Atholl.

The Planting Duke, John the Planter, or the Tree Monger, as he was variously called, it has been 
stated, in 1774 put into 15,000 acres of his ducal soil more than $27,000,000$ Larch trees, and put them into I 5,000 acres of ground, moreover, that had previously lain waste. What a relief from that nightmare vision of the yellow-coloured paper that so mutely, surely tells its yearly tale of ever-growing demand notes and insatiable tax-gatherers must it have been to the lineal inheritors of those broad acres when their eyes removed and rested upon the green of those long stretches of well-grown Larches fringing those hills from whence was to come their help!

Let, then, all croakers and blind worshippers of the Eternal Yesterday, who deprecate and have deprecated the introduction of new trees from distant lands, ponder on this little venture, undertaken once upon a time long ago in the shape of the importation of a new tree at Dunkeld, planted in I 738 by James, 3rd Duke of Atholl, at a time when the Larch was still a stranger in our land, and looked upon as an alien with a questionable past and with a future of doubtful utility.

The history of the Larch contains a long Black List of those enemy hosts that assail tree life. They have been stricken more than their share with the plague of pests, and afflicted with the curse of canker from within and without, at one time so much so that their very prestige was shaken. Beetles, the larvæ of many moths, woolly-white aphides, have been reckoned among their foes, and prepared the way for the more subtle influence of fungus organisms to complete a ruin.

As trees of great importance, they have in consequence made themselves conspicuous before the footlights of the botanical, zoological, and mycological world. The learned attention of savants - and not in vain-has been directed upon the life-history of the 
pests that visit them and the cankers that would destroy them.

Interwoven with these questions, the collective wisdom of scientific and practical man has been brought to bear on the various systems of planting that have been devised for their successful propagation. Questions have been asked, raised, and considered, as to whether Larch should be planted pure. Collective experience seems strongly against this, unless with the exception of only upon the very best of forest soils. Whether they should be planted with Spruce, with the knowledge before us that Spruce is the host plant of their mutual enemy, the Chermes; whether they should be planted with Douglas Beech, or other hard-woods (N.B.-Larch with Pine-two light-demanding trees-is the latest Swedish recipe for a mixture); whether Larch should succeed Larch, and how to deal with it in oak coppice; or how long a time should elapse before replanting after felling; what visitations of sun, air, and wind, it best bears ; the respective merits of the Scottish and Silesian seeds, and the comparative demerits of seed from the Tyrol, -all these are long questions, and burning questions, and they have been treated capably by those most capable of treating them, in many books and writings, in arboricultural journals, and in Board of Agriculture leaflets. Upon one point are all agreed, that Larch should not be planted in low-lying damp situations.

Whether the last word has been said on the subject, whether any of the systems advised will become subject to variation, are questions for the experience of another generation to decide upon. It has always been held as a golden rule among musicians that composers should know all the rules of harmony, modulations, and progressions, before they presume to break them. In like manner, let all planters of trees study the rules of the game of their cult before 
they plant, and so act in an obedience to a golden rule.

The Larch is by nature a cold-country tree. From green forests in northern lands it hails.

In its characteristics it is a plagiarist of deepest dye. In the more essential part of those characteristics it shows no originality, unless it be that the Larch is the basement type, and that these others undermentioned as prototypes should offer submission to him, not he to them.

In its two kinds of branches, long and arrested, in the crowded fascicles of its leaves, produced on spurs, tufts, or short-arrested branches, in the position of its resin canals and undivided fibrovascular bundle of its leaf structure, it resembles the Cedars, and very properly joins their family circle under the family name Lariceæ.

So far right, but when it produces cones with persistent scales like the Piceæ, which are at the same time of upright position, as are the Abies, and when its flowers are as the Tsugas, the charge of nonoriginality cannot be said to have been sounded in vain. If it lays claim to any individuality among these evergreen trees that it has taken its various cues of character from, it is that, unlike any of them, it holds to deciduous ideas and habits, and they do not. Perhaps it is because it hails from northern lands, with their winters of daylightless days and prolonged nights, that it feels, like many northern men and beasts, a natural inclination to take to hibernating ways, and preparatory to that, to follow the custom of civilization accredited to the former, of taking off its clothes before the operation. At the earliest sign of spring it is the first of trees to hurry them on again and set a good example of early rising.

L. Leptolepis (Japanese Larch).-The Common 
Larch is a tree that is generally known; but there is another which is beginning to attract attention, a tree that grows up quickly in its first twelve years of life, that displays a red appearance of branch that in winter lights up the landscape, and gives a sort of Red Cardinalis willow effect to the scenes that it occupies.

This is the Japanese Larch, or Larix Leptolepis, which is being now extensively planted, but which has already begun to falsify the hastily formed expectations that it would enjoy immunity from Chermes and canker, and so rise superior in a popularity above that of our older friend the European Larch.

With the exception of these two, all the others are rarely to be found, and the Japanese Larch must still be regarded as untried and in statu pupillari, and several others are nothing more yet with us than babes in the wood or nurseries; for such are so far the Lyall, Kurilensis, Occidentalis, and Sibirica, the last a tree which is evidently unfitted for our climatic conditions.

This tree apparently seems to entertain a rooted objection to any intermediate stage of climatic condition between that of a sun-kissed or frost-bound earth. And this is all we propose to say about it here.

L. Dahurica AND L. Europea.-Amongst the rarities this tree claims perhaps our first attention, since it is among the few of alien origin that have, on a few occasions, risen to eminence of growth upon British soil.

Between the L. Europæa and the L. Dahurica only minute differences exist. Looking at two specimens before me, I should say that the branches of the Dahurica are darker, and do not 
show the linear pulvini which mark the two-year.old branches of the L. Europæa. The cones of the L. Dahurica are longer, are not so thick through, and are more tapering. The leaves, it is alleged, are more pointed, but they are not conspicuously so. In the bark there is a marked difference, and it is much smoother than the L. Europæa, but comparative terms in tree descriptions make obscure comparisons to most. That it is finely scaled and with less wrinkled rind, is a distinction that may appeal to some.

Since writing this a new and interesting light has been thrown upon the life-history of this so-called Larix Dahurica. Professor Augustine Henry, than whom perhaps no greater living authority exists (vide Gardeners' Chronicle, September I8th and $25^{\text {th, }}$, and October 9th, I915), has now arrived at the conclusion that the previously described L. Dahurica (two of which mentioned in Trees of Great Britain grow here) are not the true Asiatic tree, but a cross-bred tree between the Europæa and American Larch (or as Americans still style them, L. Decidua and L. Laricina), and should more correctly be named the Larix Pendula ; a name, we note, that was bestowed upon them when they were planted here some seventy years ago.

To go back to the old name, then, is assuredly a great compliment to the sagacity of our predecessors in the shades.

It would be rather an interesting question to put to many-I do not refer only to those who take but little note of trees, but I am also alluding to those who take more than ordinary interest in them, and are more than in an ordinary way connected with them-and the question I should like to propound to them is this : how many of you have ever seen and known that you have been looking at or walking 
under any full-grown Larch tree other than the Common Larch? To illustrate the direction of my thoughts in the case of the L. Dahurica (or L. Pendula), did it happen, for instance, to grow near some frequented path, "where up and down the people go "? as they went on their road to Camelot in sight of the ill-fated Lady of Shalott, how many of these passersby, in spite of its smoother bark and less rough exterior, would dissociate it in their minds from the accustomed sight of the Common Larch?

Of other Larch that call for attention there are the three varieties that hail from Columbian shores -by name the Americana, Occidentalis, and Lyalli.

The Americana or Tamarac is the lover of swampy wetlands, the natural frequenter of dreary morass and marshland grounds. Why we have not tried it in such places, why we have not been directed by the schoolmen of forestry institutions and advisors of improved methods to plant them in such places alongside the much-prescribed Sitka, is a question that must remain unanswered here and relegated to the interrogative as far as we are concerned, but we sometimes wonder.

It is noted for its little leaves, and shares in common with the Kurile Larch the reputation of bearing the tiniest of cone fruit. The Tamarac is the tree that has earned still further fame in directions aquatic, for the important part it was called upon to play in the constructive scheme of Hiawatha's canoe:

Give me of your roots, O Tamarac,

Of your fibrous roots, O Larch tree,

My canoe to bind together,

So to bind the ends together

That the water may not enter,

That the river may not wet me.

We can only piously hope that it gave satisfaction 
to the naval constructor and the crew concerned in the waterproof rôle it was relied upon to perform.

L. Occidentalis.-Of this representative of our American trio great things are expected. It is a mighty tree in its own country, and some see in it a mightier future even that that achieved by the European utilitarian champions of our landed estates. It was only introduced to Kew in $188 \mathrm{r}$, and this seems a distance of time to some of us advancing in life such a very short time since. It has been tried, among other places, at Brocklesbury (Lord Yarborough's), and written of in Arboricultural Journal (I9I2) as not found wanting, by such a capable judge of the merits and demerits of tree life as Mr. Havelock.

This Western Larch clearly reveals its individuality by the long, bristle-like bracts that are exserted from between the cone scales, and which point outwards, protrusively and aggressively in contradistinction to the other prominent rival in the field on this particular point-the L. Griffithii, whose bracts point upward.

Of the medium-sized-cone competitors, the cones of the Occidentalis may be estimated to rank as the smallest.

L. Lyalli.-If this distinguished stranger among trees with us were momentarily permitted power of speech, with some show of justice perhaps it might prefer complaint in that no mention of it was made as among those Larches famed for their displays of exserted bracts. To which we, in admission of guilty plea, would make reply and urge that it is so far a tree so very new, so very strange to us; and in humbly praying forgiveness for omission, further urge that its coning days in England have not 
yet arrived. When that time comes it will be found, we dare predict, that, as it is a tree blest with so many other distinguishing marks peculiar to itself, it can quite well afford to dispense with extra emphasis on this particular cone phase.

Some of us who have had cones and branchlets sent home to us fondly imagine that no difficulties in the way of giving this tree its right name at a glance will arise and stare anyone in the face, upon that day, whenever or if ever it dawns, that the Lyall larch learns to make his presence felt and seen among us.

The first thing that strikes the eye, as you look for the first time upon a sample of Lyall, you are struck with the ostentatious display of branchlet and bud. The branchlets look as if bleached in streaks with bands of white lines, and the buds as if plastered with a profuse application of the scatterings of a powder-puff.

We read from time to time stories of scenic effects produced by them from travellers who have made pilgrimages to see them in their own Montana home, where they flourish in scenes of Alpine grandeur at some 6,000 feet above sea-level. Such an account I read, written by Mr. F. R. Balfour (in our Arboricultural Journal, if I remember aright). In it he describes the vivid delight he experienced as a treelover at a sight of it there.

But a spectacle here like this there seems little chance of futurity ever beholding, a fact we regret when we reflect what a pre-eminently irradiating green coat has God given these trees. They flourishalas!-far away, but if they grew in the garden of the Hesperides itself the chance of seeing them in their prime, for most of us, could not be more remote.

L. Griffithil comes from the Himalayas, and 
like many trees from that rather disappointing region of tree exportation, seems inclined to quarrel with our seasons. Cornwall seems to almost claim a monopoly of success with it. From a cone point of view, it is an easy winner in any size competition of fruits. Their long exserted bracts, directed upwards, culminating in a long protruding point, or mucro, stick out like the sharp-pointed instruments of an angry insect. Of the size of many a common Spruce Fir cone, they also imperceptibly recall, both in build and bract, the familiar appearance of a Douglas Fir cone, with this reservation, that the spike of this Larch bract arises from a truncated, squarer-shaped lower portion of bract, while the Douglas protrudes in the well-known shape of a Neptune trident.

\section{Pseudo-Larix KeMFERI.-}

Give fools their gold, and knaves their power,

Let Fortune's bubbles rise and fall,

Who sows a field, or trains a flower,

Or plants a tree, is more than all.

WHITTIER.

No one outside the ranks of some little circle of ungrateful churls would begrudge posthumous praise to that predecessor who had planted and persuaded to flourish one of these exceptionally ornamented specimens of tree-life upon any land which it was his good fortune to be called upon to occupy.

It is colloquially called the Chinese Golden Larch and is of fascinating appearance and colour.

It was introduced by $\mathrm{J}$. Gould Veitch in $\mathrm{I} 86 \mathrm{I}$.

It is one of those trees that would seem to prefer, if not require peremptorily, a Castle-Welan (co. Down, Ireland) atmosphere, or a Cornish-Riviera condition, to persuade it to grow as quickly as we would wish. 
At the same time it grows here (Radnorshire), and continues to grow, slowly it is true, where we have planted it, at an altitude of some 700 feet above sea-levèl.

Its thick-set, short cones, often as broad as long, call to mind the shape and appearance of a cone from the Japanese Umbrella tree, or a small-fruited Nut Pine. If not disqualified from the competition on account of its un-Larchy deciduous cone scales, it is next on the list to the Larix Griffithii in a size-measurement contest of Larch cones. It is a tree that for any differentiation purposes calls for no further comment here than that accorded to it in our Table ; and for this reason, that it is so un-Larchy in appearance by the side of the truer-to-type other Larches. It is on account of these differences that it has incurred and deserved its prefix Pseudo, or False.

\section{CHINESE LARCH NOVELTIES}

There are also a few novelties that we can only offer the briefest of jog-trot observations upon, that are coming, or have very lately come, from Chinese regions. Among them are the L. Potaninii-perhaps an intermediate form between the L. Lyallii and the L. Griffithii-and its affinity, the L. Mastersiana, of abnormal-cone-bract fame. A rather dilapidated cone of the latter was sent me from Szechuen and from near the Chino-Thibetan frontier. It shows evidences of a large wedge-shaped bract, overhanging the scales, and which in the case of the L. Potaninii is represented by a smaller edition of that accessory. While the cone of the L. Potaninii measures nearly 2 in. by $\mathrm{I}$ in., that of the L. Mastersiana is $I \frac{5}{8} \mathrm{in}$. by $\frac{3}{4}$ in. in breadth. Others brought to light lately are the true Asiatic Dahurica-not the so-called L. 
Dahurica of England's growth, which is now to be re-called the L. Pendula-and its impersonator or variety the L. Alaskensis. Other Dahurian affinities and varieties quoted are the L. Principis Rupprechtii, a large-coned variety, and the L. Japonica or Kamtschatica. This tree has a reddish-brown pubescence, in contrast to the almost glabrous and whiter branchlets of the Asiatic Dahurian.

Two more about complete the list of these perplexities. One is the L. Chinensis mentioned by Elwes and Henry. It is described as of nearest affinity to the L. Occidentalis and grows at high elevations. Another, the L. Cajanderi, was discovered in 1897 in E. Siberia-a swamp-loving tree, possibly a variety of L. Dahurica, but showing tufts of white pubescence absent in L. Dahurica.

This is only a collection of the latest things in names of Larches, and some of the superscriptions written over them by discoverers, tentative travellers, and prima-facie observers. It has no pretence to be any sort of contribution towards an unravelled subject, which at some future day will stand in need of a thorough-going sifting and a putting into right places by eminent authorities, before the world at large will have a chance of becoming wiser on the question.

\section{IDENTIFICATION OF THE VARIOUS LARCHES}

We now approach the perplexing questions : How are ordinarily observant humans to arrive at even a rough-and-ready estimate of the various members of the Larch family?

There are, in the first place, the leaves, whether keeled on both surfaces or only on the lower; how many in a bundle, length and breadth or shape of 
apex. All these points, we humbly submit, are too much in the form of minute points of microscopic mystery for any, outside the select few, to contend with. And the same may be said of the stomata, how many lines or whether conspicuous or nonconspicuous; points, all of them, a little too close up to the profession for the generality of tree friends.

Then there are the buds, which grow from three points of the branchlet-at the end of the long shoots, at the end of the short shoots, and in the axils of the leaves. This, again, is a little too ultrabotanical for the ambition of most, and a very unrecallable item of differentiation for even the more attentive of students.

Next are the branchlets. The colour of some (and we instance that of the red-twigged Japanese Larch) we are willing to admit as of helpful significance at times. But their pubescence or non-pubescence, which in so many cases tells its story clarion clear, we contend is rather a broken reed to depend upon in the case of some Larch. The Japanese is generally accredited with pubescence, yet you may pluck shoot after shoot, from tree after tree, time after time, and find their twigs as innocent of down as any chitty-faced babe girl's complexion in earliest nursery days.

So far we have made but little advance in our quest, the aim of which is how to distinguish the species of the Larch tribe. At this stage of the proceedings we feel almost inclined to abandon the chase, to hobble our hobby in the stable for good and all, and lock the door. In our despair we must look to the cones and their attendant sprites, the bracts they bear, whence will come help. It would perhaps be of benefit if, in this effort at arrangement, we were allowed to borrow metaphors from the prize-ring confraternity, and adopt some of their 
expressive language-so far only, in deference to timidity we hasten to explain, as pertains to their drawing-up conditions for classification according to weight. In that case we should like to suggest arranging these trees, as do the managers of such scenic effects above referred to, into three classes, according to weight and size, and label them heavy, middle, and feather or bantam. In the heavy-weight division, as bearing the largest-sized cones, we place first the Larix Griffithii, and as his proxime accessit the P. L. Kæmferi. Among the middle weights, and defining them as averaging in length from $\mathrm{I}$ in. to $I \frac{1}{2}$ in., we place the L. Europæa, L. Leptolepis, the ex-Dahurian (now called Pendula), the Sibirica, Lyalli, and Occidentalis, whose cones scale in weight the lightest of this lot, while those of the Japanese, with their self-evident reflexed scales, are the most rotund and tubbiest of shape. The bract manifestations and the light they shed on the scene we have already discussed, in reference especially to the Occidentalis and Lyalli. Of the remaining three of these Larch trees so classified-namely, the European, Pendula, and Sibirica - their cones are of such apparent sameness that their differentiation becomes a puzzle, which Lord Dundreary might have reasonably included as among those problems which " no fellah could understand."

We had almost overlooked the bantams. They are represented in the competition by the Tamarac and Kurile Larches, and the tininess of their cones eases the situation for identifiers as far as they are concerned.

Finally, on this question it may be said that Larch trees are more obliging in their ways and means of dispensing information to those who seek it, by displays of cones, than are most others of their coniferous kith and kin. As a rule their fruits are very forthcoming. 
(SUB-TRIBE LARICEÆ-continued)

\section{Section CEDARS}

In the midst

A cedar spread his dark-green layers of shade.

TEnnyson, Gardener's Daughter.

If trees were adjudged upon their appearances and divided into two classes, pretty and majestic, the Cedar of Lebanon would pre-eminently find its place in the ranks of the latter.

It is a tree that has been written of by poets and writers, of all ages, in many countries. It has been sung of in David's Psalms and Bible verse. A halo of sacred association surrounds its patriarchal head. It is a tree that was regarded by Biblical writers as an emblem of strength, and the look of the tree as it is presented to us, with its short thick trunk, its massive branches breaking out from it like muscular arms, suggests the sculptured strength of the statue known as the Farnese Hercules rather than the figure, with its more graceful and slimmer lines, of the Apollo Belvedere.

While the branches of most trees spring from the trunk, in the case of the Cedar, as in the Oak, they seem rather to divide from the trunk and carry зway with them some of its substance. Both Oaks and Cedars, with their fortes ramos (stout branches), and ingentem umbram (expansive spread), fulfil the Virgilian idea of mightiness in forest trees.

"The voice of the Lord breaketh the cedars of Lebanon," so wrote Isaiah, and his expressions and figures of speech concede to it the strongest power that imagination and illustration at that day could offer.

The prophet priest and Jewish exile in Chaldæan land, Ezekiel, describes it as a tree "with shadowing 
shroud," referring to the thick leaf canopy, and as a tree "of high stature and among thick boughs" in allusion to the lateral growth of its topmost boughs and its flat, or so-called to-day in a less polished lingo, clump-headed appearance, caused by the bending down of its topmost shoots. Again, "that his boughs were multiplied, and his branches became long," are points to which in other language modern botanists have pertinently and constantly called our attention at later times.

The name, and what it stands for, are associated with many scenes from Bible lands, and recall the building of the Temple of Solomon, where "all was cedar, there was no stone seen." The Cedar was the greatest, and the Hyssop on the wall the lowliest, type of plant life. An old Christmas carol quaintly alludes to the two extreme positions they were estimated at in the vegetable kingdom in illustration of the humble and lowly birth of our Lord :

The Cedar of Lebanon,

Plant of renown,

Has bowed to the Hyssop

His wide-spreading crown.

The Hebrew word erez, which was equally applied to Larch and Cedar, implied "firmly rooted," a " strong tree." Without wishing to detract from its character of mightiness, in all fairness it must be said that in its native land it had not formidable competition to wrest such fame from. The scenes of its triumphs were otherwise treeless regions, composed of such arboricultural representatives as stunted Scrub Oak, Palm, and gnarled Olive trees. The ages of the Cedars of the Bsherreh Grove at the head of the Kedisha Valley, and other groves in these regions that are still extant on the seaward slopes of the Syrian Highlands, have been surrounded with every 
queer fantasy that imagination run riot or poetical licence could picture. Whether they are as old, or are the lineal descendants of trees as old as the Song of Solomon, the Norman Conquest, or even whether they dated back to the times of the first created being in the garden of Eden-and all these suggestions have been put forward in distinguished prose and immortal verse,-the ordinary listener to such stories, or readers of such references, seem more disposed to regard them rather in the light of picturesque fairy tales than actual prosaic and established facts.

From descriptions and pictures these trees of Palestine, from whose groves Babylonian temples were built, and whose beauty was sung of in verse and psalm, look bigger, more battered and ancient, than do our more modern productions of lesser age, 200 years or so. The huge forests spoken of have disappeared, and all that remain of them are groves. It is historically asserted that the tribes of Judah and Ephraim cut them down indiscriminately, without any recourse to economic replanting. Had this act of vandalism been perpetrated in a modern-day world, and the facts brought to the notice of some rating authority, we should have suggested that these improvident sons, and perhaps too the women-workers implicated, the daughters of Judah and Ephraim, should have been forced to pay annual tribute to their county coffers upon a high agricultural assessment of that land, until they had made good on behalf of posterity their wanton depredations.

The calculations of modern man put the expectancy of life in a Cedar at from 500 to 800 years, yet as a matter of history the oldest Cedar in England cannot be much over 250 years of age. It is a tree that to all outward appearances seems to attain maturity of height, if not diameter, in a much shorter space of time. 
Before it has accomplished a century, or a century and a half of existence, a Dies Iree in the shape of snow-storms often overtakes its chances of attaining any fame in the annals of a blasted antiquity. Under an inflicted weight of such a visitation rather than under any disabling weight of age, its boughs and branches, with a prelude, crack like the sound of great guns, snap off, and so-sic transit gloria mundithe professional beauty of one day becomes the wreck of ages of another. It is at such moments as these that we recall the words of Tennyson :

O, art thou sighing for Lebanon,

.... sighing for Lebanon, dark Cedar?

And like children crying for the moon, they still sigh on, and in vain.

How well I can remember on a cold winter night succeeding in averting such a disaster to a favourite tree, by dislodging from its tabuliform branches, with the aid of a fire engine and other chilly helpmates, collected masses of fallen snow.

The Cedar may, and possibly does, enjoy immunity from the shrivelling - not always - effects of lightning, but the season of snows-like the whirligig of timemakes counter revenges and takes a heavy toll. On one day it is accounted the pride and glory of the lawn or country-side ; in a few succeeding hours the scene may have changed, disastrously changed. The storm may have broken upon it, and there may only remain a memory of lost delight amid a débris of broken boughs.

The true Cedars do not enjoy that monoply of name that they, de jure and de facto, are entitled

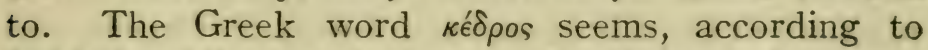
Liddell and Scott and other pundits of classical renown, to have applied more to the Juniper than the Cedar 
in question. Even in Holy Writ the word "cedar" is used to denote other trees - to wit, probably the P. Halepensis, the Aleppo or Jerusalem Pine, and the Juniperus Excelsa. But even in the latter days the Cypresses, Thuyas, Junipers, and Sequoias have all in turn and at times masqueraded under the shelter of its name, and out west in American and Canadian lands we read of Red Cedars, White Cedars, Canoe Cedars, Pencil Cedars, Incense Cedars, and I dare say many more so-called Cedars, with many more descriptive adjectives. Lumbermen and settlers out there, like timber dealers and carpenters sometimes at home, seem in sheer bravado to take unholy delight in upsetting the conventional applications of nomenclature which scientists and botanists have prescribed, with the rather direful result of making confusion confounded in many a mind where light might otherwise have dawned.

As the muezzin from the minaret declares that there is only one Prophet, so do we from our housetops proclaim that there is only one family of true Cedars in the meaning of the word to-day, and that the Cedar from Lebanon, the African Cedar from regions in reach of Sahara Desert air (C. Atlantica), and the Indian Cedar (C. Deodara) from the humid Himalayas in the Far East, are, they and they only; the nearly related representatives of the true Cedar.

To differentiate one from the other in these three affinities never seems to present much difficulty to the more casual observer. If any confusion is created it is between an Atlantic and Lebanon clad with the same coloured foliage. In their identification papers they read much alike, the same number of leaves in a tuft, much the same-sized cone, and the more regular pubescence on the one (the $\mathrm{C}$. Atlantica)-all these are details that do not tell much to the more unscrutinizing of tree-lovers. Shape must be the 
stand-by. The stiffer shape of the Atlas Cedar, its more ascending branches of unequal length, its less flattened head, and the often shorter and more crisp expression of its leaves, these must be made the ground of judgment.

The Cedrus Atlantica takes its name from the North African Mountain range, Mt. Atlas, which for reasons more mythical than geographical, was supposed to be situate on Atlantic shores. These mountains in turn derive their name from the great titanic champion and weight-carrier of mythological history. It will be remembered by all boys, let us assume, who have enjoyed the privileges of a classical education in our public schools, that the defeated giant was condemned by the superior authorities of the Court of Jupiter to carry the heavens upon his shoulders. Doubtless as a conquered victim he was subjected to a heavy penance in life, but when that ceased he acquired a certain compensating consolation in a posthumous fame, both in verse-

On Atlantean shoulders fit to bear,

The weight of mighty monarchies-

and in the bestowal indirectly of a name upon a tree that has become a great favourite with us.

The C. Deodara is not to be outdone in a claim in the direction of religious or secular association by other Cedars. The word is derived from Sanscrit language, Deva (Deity) and Dara (wood). It was the Devadara, the tree god of the Shaster, the sacred book of the Hindoo religion.

The C. Deodara with us, with its longer leaves, its spiry pyramidal form, its long drooping terminal shoots, is a familiar figure. These, so far-it was only introduced in $183 \mathrm{I}$-are the characteristics of the tree with us here. It is so common with us, 
and so different in appearance to the other Cedars, that it needs no further description here.

Let us take leave of our subject with a quotation from a modernised "Te Deum" by J. Oxenham:

For the great cedar's benedictory grace, We thank thee, Lord. 


\section{V \\ CYPRESSES AND JUNIPERS}

(OF the Natural oRder of CONIFERÆ, of the FAMILY PINACEE, OF THE TRIBE CUPRES. SINEE, OF THE SUB-TRIBE THUYINE)

Early History of the Cypress Trees: IntroDUCTORY

Know ye the land where the cypress and myrtle, Are emblems of deeds that are done in their clime?

LORD BYROx; Bride of Abydos.

THE Cypress as an object of beauty had evidently its circle of admirers among the ancients. It was because of this reputation, it is recorded, that the Island of Cyprus was so named. The mythological story of the island connection with the goddess of beauty runs on this course, that Venus, after her seafoam birth and sea-nymph cradling among the coral caves of the vasty deep, was wafted by Zephyrus, the south wind, to the Island of Cyprus.

The inhabitants of that sea-girt isle seem rather to have affected a fine taste for the "exquisite " in more than one direction. Venus, the goddess of beauty, took a title from its name and became known among students of the classics as the Cyprian goddess, and this record seems to bear witness that the worship of her there was by no means a neglected cult. For fear of misconstruction it is only fair to add that the leaders of scholastic opinion of that day and in those 
regions regarded the "beautiful" and the "virtu. ous" as the same thing and convertible terms.

Like many other trees, shrubs, and flowers, mythology allotted to the Cypress a human pre-existence. Of this particular specimen of plant life the story runs that Apollo took on a youth named Cuparissos as his companion in sporting enterprises. Tradition describes this youth as a " clever hunter," but inasmuch as he contrived to shoot a pet stag, presumably in mistake for a wild one, we cannot but opine that he hardly justified the renown. Unfortunately for him this pet stag was the property of what would be described in modern-day parlance as the senior partner of the sporting venture, and this happened to be no more or less than the great Grecian divinity Apollo himself. Cuparissos was evidently a young man who allowed trifles to prey upon his mind. Shortly after this little mistake of identification he sickened, and, like his victim, died. On Apollo's part there seems to have been no ill-feeling cherished of any kind, for he turned the lifeless clay of the hapless free-shooter into a Cypress tree, and assigned to it (or to him that was) the special function of shading the graves of those who have been greatly beloved in life. In the annual processions of Pan-Athenaic fame, the goddess Venus never appeared without a Cypress bough made manifest in her retinue, a symbol expressive of her grief upon the death of Adonis.

The "Serviceable " was another cult worshippedif we remember aright-by the academic Athenian. As a utilitarian timber tree, the Cypress must have been far-famed in olden days, since the words " coffers " and " coffins "were both derived from its name, and both from that day to this have become household words of recognized expression, as well as customary receptacles of their different suggested consignments. 
The Cypress tree is held to be identified with the Gopher tree of the Bible. The ark, "pitched within and without," was made of Gopher, and to the wood of the C. Sempervirens, or Roman Cypress, in particular is accorded the honour of supplying the material of its construction. And this is all we propose to narrate here concerning a semi-historical, semi-court guide, description of this tribe of trees.

\section{Identification of the Cypress, Thuya, AND JUNIPER}

The less adept, or the less enterprising, or even, if you like so to characterize it, the more idle-minded, are quite content to generalize when they refer to trees, and to sweep into one network of nomericlature all trees that bear more or less an outward and visible resemblance. Such a system may have its merits from a convenient, but not from an elucidating point of view. It is all very well for those who would dance through life, but from those who live in its midst more is expected and more should be forthcoming.

For instance, the Cypress, the Thuya, and often the Juniper-in a more limited way-display many of such resemblances. They all have similar-looking green branchlets (more or less), columnar or pyramidal habits, and so forth. The name most usually employed by the unversed to designate such trees is Cypress. They are all colloquially alluded to by this one all-embracing name. At the same time, and for many years after the great inundation from America of Thuyas - that is to say, about the middle and latter part of the last century, the name Arbor Vitæ was often applied to the same object. This name, in a popular sense, seems to have rather died out of late or become superannuated. 


\section{Some Points of Difference among the}

\section{Cupressinea Tribes}

All those who start upon the long, long quest of a perfected knowledge in all the varied intricacies of the family tree of all the Cupressineæ cannot hope for anything otherwise than to find themselves puzzled on the early stages of their journey, if not hopelessly adrift amidst the clouds of embarrassment. And further, it will probably call forth no mean exercise of patience on the part of the more perfunctory student-I exclude from this category the botanical expert and specialist-before he can hope to see these clouds lift. An ascendancy over the initial mysteries of the cone differences is the first rung of the ladder of experience upon which to obtain a footing, and this will carry the aspirant farther, anyhow, than many of those that he meets in the ordinary walks of life.

Differences in the Cone, or Strobile, Structure of the Cupressinee Tribe of Trees

The cones, or strobiles as they are sometimes called, of the Cupressi, Thuyas, and Junipers-all of them sub-tribes of the great Cupressineæ Tribe-are of a totally different appearance. When you have even glanced at an illustration of them you cannot but feel that you have conquered the first position of the entanglement. The acquired knowledge of the difference between chalk from cheese is an accomplishment that calls for no more power of attainment than mastery over the differences of a Cupressus and a Thuya cone, and the fact that these members of the Coniferæ are prolific cone bearers and cone dispersers adds materially to the ease and convenience of the would-be student. 

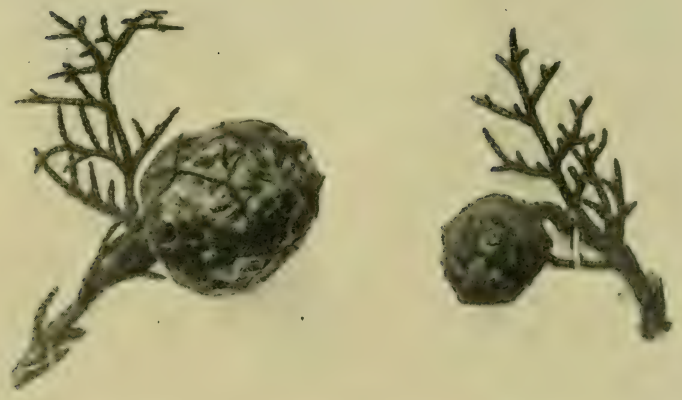

C. SEMPERVIRENS, OR ROMAN, ITALIAN, OR MEDITERRANEAN CYPRESS, SHOWING THE CHARACTERISTIC OF DIFFERENT-SIZED CONES.

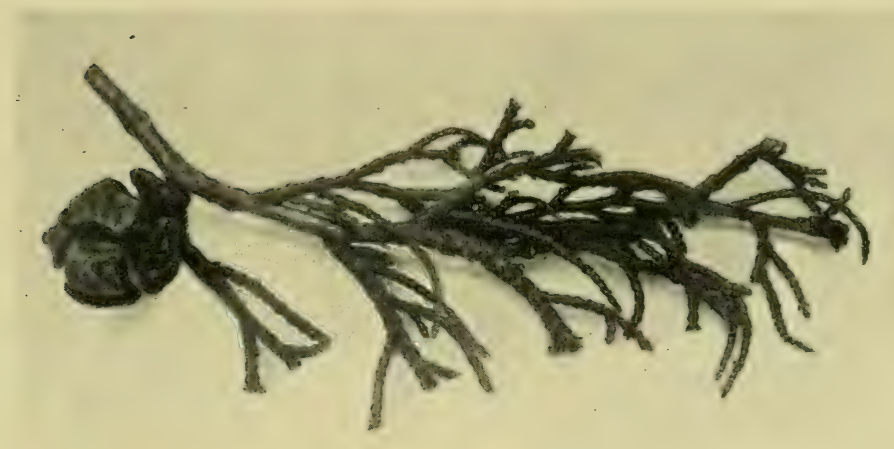

C. TORUlosa, the himalayan, BHotan, oR twisted CYPRESS.

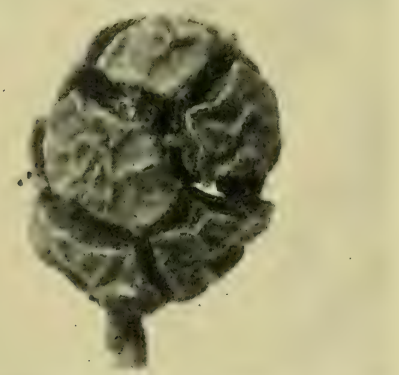

C. MACROCARPA, OR MONTEREY CYPRESS.

FIG. II.

Illustrating Differences in the Cone or Strobile Structure of the Cupressineæ Tribe of Trees. 

I

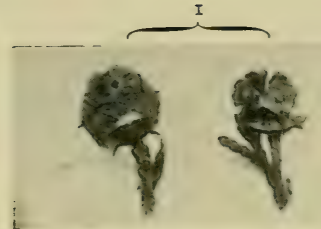

I, C. IAWSONIANA. 2, C. PISIFERA, OR SAWARA CYPRESS.

3, NOOTKA SOUND CYPRESS, C. NOOTKATENSIS.

$\mathbf{c}$
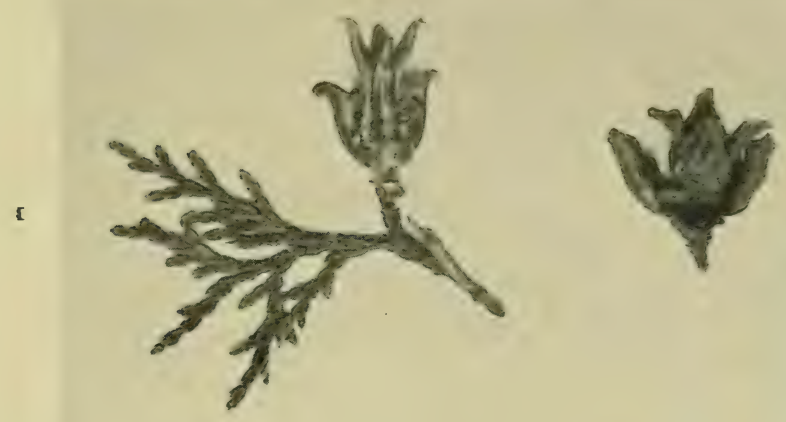

3

4

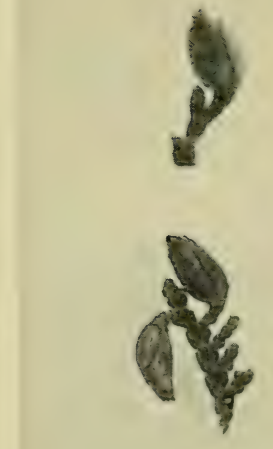

6
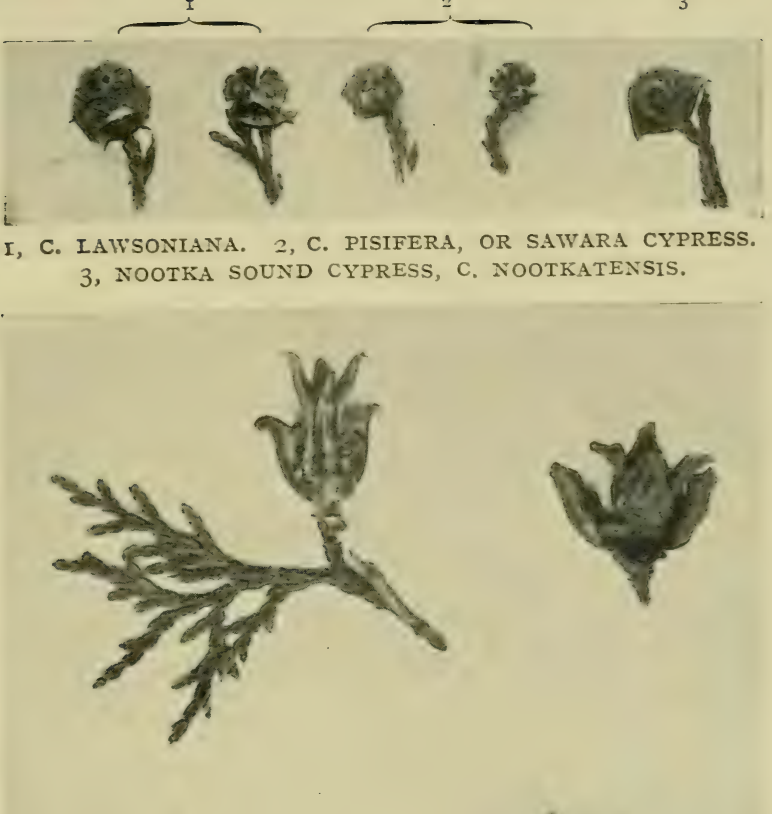

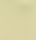

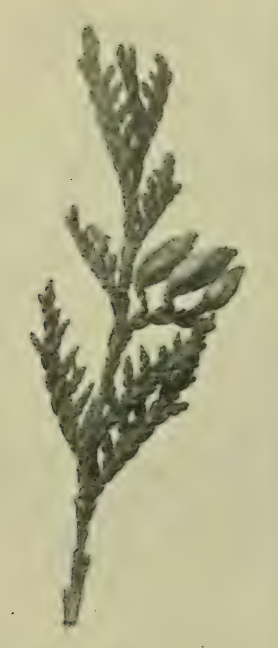

5

2

7

I AND 2, THUYA ORIENTALIS (SECTION BIOTA); 3, 4, AND 5, THUYA OCCIDENTALIS; 6 AND 7 , THUYA GIGANTEA (OR PLICATA). FIG. III.

$\mathbf{I} 58 b^{\circ}$, 




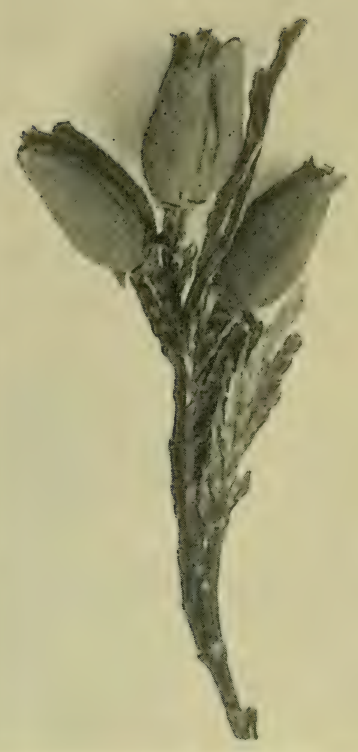

IIBOCEDRUS DECURRENS.

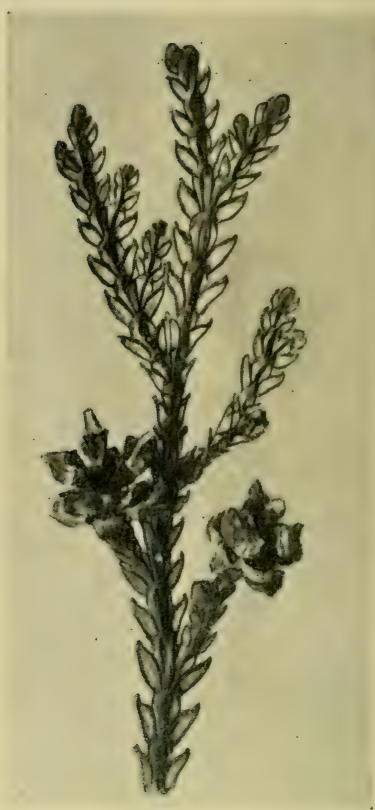

THUJOPSIS DOLABRATA.

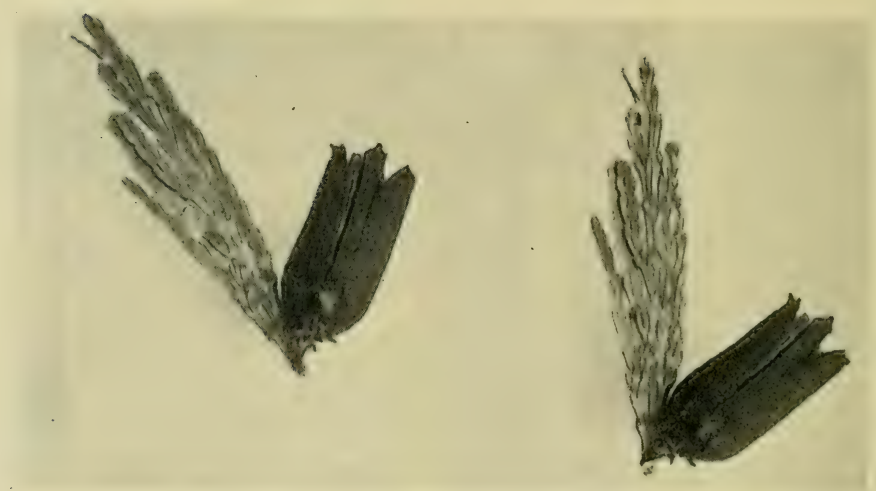

IIBOCEDRUS DECURRENS, ALSO LIBOCEDRUS DECURRENS.

FIG. IV. 
Briefly defined the cones of the Cypresses are rotund and sub-globose in shape. The cones of the Thuya are oblong, conical, or, as some describe them, ovoid-cylindrical, while the fruit of the Juniper is no ligneous cone at all, but merely a little succulent blue-black and brown berry, with mucronate fleshy scales maturing the second year and bearing 2 to 5 seeds ; and we may add, while we are about it, that the Cupressi bear from 15 to 20 , and the Chamæcyparis 4 to 5 seeds. Even these brief definitions disclose a state of palpable differences, upon which, however, we will expatiate a little further.

The cones of the different Cupressi are of different sizes.

The Eu-Cupressi have large ligneous, more or less rotund, strobiles.

The Chamæcyparis group have small, woody, subglobose cones. In both cases they are what is called peltate. Pelta is the Latin word for a targetlike shield, and these scales, fixed to the stalk by the centre, describe the construction of what is called peltate cones. Like the shields of the ancient Britons or Gauls, they too have a boss enlargement, and in some cases-e.g. the C. Nootkatensis-they show some half-dozen little horn-like protuberances in the middle of these shield-like scales. When the cone of a Lawson Cypress breaks and scatters to the four winds of heaven its seed, the little brown ligneous framework-all that is left of its light-green glory of the previous year-when set upright and looked at from a side point of view, develops, with a little effort of imagination, the outlined appearance of a Maltese Cross.

Looking, then, at the cones from these points of view, a Cypress need never be taken for a Thuya, and much less a Juniper for either. The suspicious likeness of the adult leaves of a Juniper is our only 
apology for dragging into the arena the Juniper at all. A Juniper's foliage can generally be detected by the presence of two quite different-looking kinds of leaves. It is a tree that in the case of one group (the Sabinæ) changes, after twelve years or so, its acicular, primordial, or juvenile leaves into a more Cypress-looking foliage. As it, however, retains the evidences of its youthful leaves in patches among the adult leaves, it bequeaths a very telling evidence as to its real origin which need not, and should not, be lost sight of.

Differences in Shape of Branches and BranchLETS OF THE CUPRESSINEE

The first point about the branchlet shape of the different members of this tribe that our attention is called to by eminent writers is that some of them are flat-leaved and others tetragonal, or, in other words, equal- or four-sided. This does not refer to the older branches and stems; they are round in appearance, and what is more properly described as equal-sided. It is only the green leaflet-covered herbaceous-looking little extremity of branchlet arrangement-if we may be permitted the use of a rather unbotanical use of language - to which we refer, and a discerning between them as to what is flat and what is round should not constitute a greater difficulty of discrimination than an adjudication upon the difference in shape of a lemon sole and a normally nourished whiting, if displayed for our examination upon a fishmonger's slab.

To sum up, then, the Eu-Cupressi are the representatives of the rounder or quadrangular, and the Chamæcyparis of the flatter-leaved fraternities of the Cupressineæ race, and respectively also of the 
sprays irregularly arranged and not in one plane, and of sprays arranged in one plane, which we will call attention to under the headings of branchlet systems.

Differences in the Branchlet System, or Arrangements of Branchlets, of the CUPRESSINEÆ TRIBE

This so-called branchlet system has nothing to do with what we have previously discussed, namely the shape of the ultimate branchlets. It has only reference to the way in which branchlets are placed on their parental stems, and the different way they grow out from them.

One habit is what botanists allude to as being arranged "in one plane." The other, or contrary habit, is simply expressed by negative form, and as "not in one plane."

"In one plane" is an arrangement after the manner and plan of a common fern. "Not in one plane" is when the branchlets stick out radially from the parental stem, and from different points of situation of that stem; or to put it in another way, when the branchlets jut out from the stem at different angles in a sort of radial method, as do the leaves of the Spruce.

To take, for example, a spray of a Lawson Cypress, which is described as arranged "in one plane": if we pick a branchlet off and lay it upon a table, it should lie out flat, because its branchlets, like our human arms, are naturally situated in one plane and spread out evenly from only two sides of the branch. But if you take the leaf of "not in one plane" branchlet system, Cypress (e.g. the Macrocarpa, or Sempervirens), a branchlet similarly treated cannot rest flat on a table, because its branches, like the 
Oak tree or other hard-wood trees, stick out at all angles.

Sometimes authorities talk of this characteristic branchlet system as "flattened," which means in one plane, but care must be exercised that no confusion arises between the two terms "branchlet system flattened " and "flat-leaved," ultimate branchletshape expressions which allude to two entirely different features in the structure of the tree, as we have tried to explain; but both are terms in vogue among the authorities and fixed stars of the arboricultural firmament.

\section{Differences in the Leaves of the Cupressinea TRIBE OF TREES}

The leaves of this tribe are not, more than in any other part of their structure, to be denied a prominent part in the telling of their differences, in spite of the fact, too, that their presence is perhaps the least apparent and felt of those of any trees that we encounter. They call for a microscope to investigate them satisfactorily, and only tell their tale with reserve.

The little stem-clasping apologies for leaves upon these Cypresses are hardly what our primitive instincts were awakened to regard as leaves. They do not appear to maintain that separate existence from the branch that the more ordinarily well-conducted leaves we were once led to suppose were expected to exhibit.

Nor on the deciduous day of their decease do they fall away and wither separately as they ought to do, but instead, at the fateful moment; the herbaceous branchlet browns and dies and with it still in clinging affinity, do they also pass away and perish. Yet leaves they are, these little minute overlapping scale appurtenances, and as leaves they have to be reckoned 
with, and every detail of them to be inquired minutely into, for the purposes of telling the tale of their various individualities.

This falling away of these extremity leaves and ultimate branchlets, sometimes after two, sometimes after three and four years' growth, sheds light upon the story told of a curious Mohammedan superstition, existent among the natives of Ceylon. The idea prevalent there is that he who eats of a Cypress leaf, which he chances to see fall in natural and by timeexpired process to the ground, has restored to him the priceless boon of rejurenated youth and vigour.

Whittier, the American poet, depicts the venerable jogees, or saints, as sitting patiently, expectantly, in silence and motionless, under the shadow of a Cypress tree in Ceylon, awaiting in optimistic endurance the falling of this much-prized leaf. These are two of his descriptive stanzas on the subject :

They sat in silent watchfulness,

The sacred Cypress tree about,

And from beneath old wrinkled brows

Their failing eyes looked out.

They waited for that falling leat,

Of which the wandering jogees sing;

Which lends once more to wintry age

The greenness of its spring.

As, and as we have said, there is a triennial persistency about these leaves, this process must, then, have often entailed a long sitting, and one that may have called for an equivalent persistency of a patient and pathetic nature on the part of these holy men, which invites sympathy even among those who regard their problematical reward as doubtful and distant.

\section{Leaves AND THeir Position}

In some cases the leaves are, from head to base, wound round tightly to the stem, so to speak, for the 
whole of their length. They are then described, according to Cocker, as appressed. In others they fall and break away at the summit of their growth into a state of disarray from their hold on the branchlets. When that happens they are described by the masters of the Arts Botanical as free at the apex.

The apex-that is, the top of the leaf-varies in shape; sometimes it is obtuse, at others acute or triangular in its outlines.

The shape of the leaf if closely looked at indulges in variations. Sometimes it is (I) spatulate. "Spatulate" is derived from the Latin word which stands for a little spade, and it is generally connected in more ordinary minds with the form and feature of a beaver'stail arrangement. (2) At others it is ovate or eggshaped; or (3) awl-shaped, a name derived from a pointed instrument to be found in every tool-chest of a village carpenter, and an implement of familiarity to the world at large. (4) While in others it is described as boat-shaped, in form familiar as an Indian dugout or canoe.

In some cases of flat-leaved Cypresses the facial leaves on the upper and the corresponding leaves on the lower surface (described as dorso-ventral) are of a different shape from those on the lateral sides. For instance, on the branchlets of the Thujopsis Dolabrata, a branchlet upon which it is very easy to discern the shape, the dorso-ventral leaves are spatulate while the lateral leaves are boat-shaped. Sometimes these herbaceous branchlets have leaves arranged round them in four ranks, sometimes in two ranks, and arranged opposite to each other. The white lines or streaks on the under-side of the leaf, present in some of the species, absent in others, help greatly the process of differentiation. For instance, under the leaf of the Lawson will be noticed these white lines, but under the leaves of the Nootkatensis, 
its nearly allied affinity, no such lines appear. Or, again, in the case of two Thuyas of near affinity, the T. Plicata (or Gigantea) and the T. Occidentalis ; the former has white streaks on the under-side of leaflets, the latter not.

The glands, the little swollen protuberances, or secretory vessels, situate on the end of the leaf and quite visible to the naked eye, are often a help to identification. In such trees as the Thuya Plicata, or Gigantea, it will be noticed that the very evident presence of glands upon the Thuya Occidentalis is unseen upon the T. Plicata. All these traits in their characteristics are a mere generalizing of differences, and but a tuning of fiddles before the grand Devil's Opera. The study of Cypresses calls for a close and minute attention upon the part of the tree lover, but a good general idea of "what's what" and "which is which " among their ranks can be obtained from these sources suggested-namely (I) the Cones; (2) the shape of the ultimate branchlets, whether flat or tetragonal; (3) the branchlet systems " in one plane," or " not in one plane"; (4) the leaves, and in connection with them not forgetting the existence or non-existence of white streaks underneath, and the presence or absence of glands on the end of the leaf.

\section{CUPRESSINE $\mathrm{E}$ TRIBE}

(OF the sUb-DIVISION EU-CUPRESSI, of THE SUBTRIBE THUYINÆ)

C. Torulosa, Macrocarpa, Sempervirens

Their sweetest shade

A grove of cypress trees.

SHAKESPEARE.

C. Torulosa, so called presumably from the presence of glands on the leaves, so far as leaf appearance goes, exhibits a very perplexing likeness to some 
of its fellow Eu-Cupressi, the C. Macrocarpa, and C. Sempervirens Goveniana ; or even, to go farther, to some of the Junipers in an adult state of foliage. The fact that the C. Torulosa, through a magnifyingglass, shows the presence of glands, while others among his similarities do not, offers some, if not very palpable, help to the student. That, presumably, is why the C. Torulosa is put in one group and the C. Macrocarpa and Sempervirens in another group of the Eu-Cupressi. There is more comfort to be derived from a comparison of the size and date of ripening of the cones of this trio. Those of the Torulosa do not ripen until the second year. They are uniformly about the size of the smallest of the cones to be found among the variably-sized cones of the C. Sempervirens, which ripen in the winter of the first year. The cones of the Macrocarpa ripen at the same time as the Torulosa, the second year, but they are consistently nearly twice their size. A surer hope of recognition will be forthcoming in a comparison of their branchlet systems. If a spray of the Torulosa is laid upon the table, it will be found that the branchlet system is more or less arranged in one plane, and that consequently it will lie pretty nearly flat upon the surface of the table; while in the case of the other two, the spray is supported by branchlets which grow indiscriminately all round the stems at different angles. Sometimes the Torulosa deviates a little from the strict path of rectitude in these directions, but is quite sufficiently orthodox to show a distinction from the other two.

Where the shape of the Macrocarpa and Sempervirens may be often described as columnar, the shape of the Torulosa in its sub-fastigiate form-and it is in this form that it generally makes its appearance with us-is what is called flame shape and running into a peak-shaped top. Though this characteristic 
may not, in the opinion of some, shed any very lambent light on the subject, still it may be the first awakening to the fact that we are looking at a tree of far rarer appearance in England than the Macrocarpa, or even the Sempervirens or Roman Cypress.

It may interest readers to learn that there is a tree growing here (Stanage), at an elevation above the sea of a very little less than 800 feet, planted in December I842, and, according to an old family document, referred to as the C. Tomentosa Torulosa. It measures $42 \mathrm{ft}$. in height, and in girth $6 \mathrm{ft} .2$ in., and so compared with others mentioned in the Walhalla of remarkable trees of Great Britain (Elwes and Henry), according to measurements and age, was deserving of a niche in those palaces of immortality. Had the authors paid a visit to it before instead of after their Cypress chapters had been published, it would have been accorded, we were informed, the honour of a site therein.

\section{EU-CUPRESSI}

Group A: C. Funebris, Lusitanica, Arizonica, Macnabiana, Cashmeriana; and Group B: Goveniana

Oh, lady, twine no wreath for me

Or twine it of the cypress tree.

Sir WAlter ScotT.

The C. FunEbris has the reputation of being not hardy, but of some capability of endurance in the climates of the south-west of England and in Ireland. Its life's history with us in brief is: it is a native of Central China; it was discovered in 1793 by Sir George Stanton, attached to Lord Macartney's mission, in an appropriately entitled locality, from whence it was to derive a subsequent name, called the Valley of Tombs. It came to England in 1804 ; failed, and was tried again in 1848 . It has a weeping, 
pendulous habit, and is spoken of as the most ornamental of all Asiatic Conifers.

The Lusitanica, in Group A, by reason of its striking colour and its vivid-hued cones, does not constute such a puzzle to the identifier as many others. Its herbaceous branchlets are less crowded and farther apart than most of the Cypresses. It is, somewhat on the lucus a non lucendo principle, familiarly called the Cedar of Goa. As a matter of historic and endemic fact, it is not a Cedar and it did not come from Goa. It must have been named thus in the same spirit of perversity that described a Crab as a little red fish that walked backwards, in spite of the natural history incontrovertible fact that it happened to be a little blue crustacean that moved sideways. It would be nearing stricter truth to allege that the Portuguese had it from Mexico, and that the people of Goa (India) were indebted to the Portuguese for plentifully planting it among them.

The ARIzonICA, its more northern representative, can be recognised by its display of little white specks on the leaves, and which are explained as exudations of resin from the circular pits. The Lusitanica does not manifest these displays, and so one can be known from the other.

There is another more compact shaped, recently discovered, Arizonica Cypress, called the Smooth Cypress (C. Glabra). It is described as a tree from 25 to $30 \mathrm{ft}$. high, with thin, smooth, dark-purple, or red bark, bright blue-green glaucous foliage, and small spherical cones (vide U.S.A. Dep. of Agriculture Bulletin, No. 207, July I915). Seeds are being tried here, and possibly many other places in England. Perhaps some day hence, when Father Time has taken extended toll, and more waters have flowed under 
bridges, a day may dawn when all these three, Lusitanica, Arizonica, and Glabra, will be regarded as still nearer akin, if not as actual identities, and one and the same, rather than in the character that they are now looked upon, as tricky impersonation agents one of the other.

The C. Macnabiana, a native of California, is a bushy several-stemmed tree, that makes but an infrequent appearance with us. It came to England in the middle of last century. It has been found short-lived here, and has not been in much request for cultivation.

The CASHMeriana may have, and has, we are told, many merits of beauty and interest, but as it only seems to flourish in hot-houses, with one exception mentioned at Rostrevor (Sir John Ross), it rather passes away from any category of trees that we are likely to meet with.

The Goveniana (from California) though possessing some points of comparison to which we have called attention, never seems to have gained the confidence of nurserymen or planters, and for the substantial reason that it has been tried and found guilty of an unpardonable brevity of life in English climates.

\section{CHAMECYPARIS}

Group A: C. Lawsoniana, C. Nootkatensis, C. Obtusa, C. Thyoides, C. Pisifera

When I am dead, my dearest, Sing no sad song for me;

Plant thou no roses at my head Nor shady cypress tree.

Christina Rossetti,

C.Lawsoniana.- - When we read that the Lawson Cypress has no less than forty-eight varieties it is 
enough to create dismay amongst the ranks of the most undaunted of tree-history students. Like the historic miller of the Dee, he begins to feel he cares for none of them, " no, not he."

What there is in the organism of their nature that permits this unfaithfulness to tradition, and allows them licence to produce all this confusion in growth and consequent confusion of mind in our midst, we hazard no explanation. The tree certainly seems to assume as many shapes as a genie in an Arabian Night story. Scientists, when they speak of it, call it polymorphous, and in tones of apology, or sometimes, in tones of appreciative satisfaction, refer to the vagaries of descent that this tree offers to the world at large and the Mendelian world in particular.

Some of these freaks in descent-so reads their unstable history-are columnar, some fastigiate, some pendulous, some spreading, some dwarf, in habit. But this is not all; of the coloured varieties, some are globose, some are plumose, and the rest of them are too many in number and too various of nature to narrate of further here. One immoral lesson to be learnt from their multitudinous ubiquity is, that the venturesome man, minded to pose as bene doctus upon questions of tree lore, has only, when in doubt upon any Cypress identity, to answer Lawson. Not invariably, but on many occasions he will be quite apt to have answered correctly. And your assurance will be relying on firmer foundations if you have made sure of the existence of those white linings on the under-side leaves that we have called attention to.

A rather curious translation of the Greek word $\kappa v ́ \pi \rho \circ$ occurs in Liddell and Scott's celebrated Greek Lexicon, which made a first apparition in 1845 " as a tree growing in Cyprus, now called Lawsonia Alba."

The date of the introduction of 'our Cypress in 
question was some nine or ten years later, when it was introduced in Lawson's nursery at Edinburgh and brought before the notice of cultivators This conflict in names and dates reads like the perpetration of an anachronism somewhere. Perhaps the learned lexicographers were among the prophets, or men in advance of their time. The C. Sempervirens, or Roman Cypress, is the native tree of Cyprus.

We read in an Eton boy's verse, that-

Many a Greek historian's riddle

May be solved by Scott and Liddell.

One seems to have been propounded here by the authors of the sources of solution.

This very fact, that it has so many forms, may be a reason that we find it to be planted more abundantly than any tree of its kind in the gardens and grounds of Great Britain. Like a fashionable sartorial establishment, it has styles to suit all forms and shapes. It has varieties that suit all environments, from such earthly distances as a mixed plantation to a walled-in cemetery. So far we have not seen it under agricultural conditions, with self-pruned trunks and bared stems. At some future time perhaps another generation will meet it more often as a tree under these conditions, both it and the Thuya Plicata. Perhaps some day belts of them will be cultivated as wind screens, and left standing for the next crop to seek their shelter from, until such a day when its economic value is appreciated at a value as it is in its Oregon native home, and it finds a home in our English timber yards and lumber markets.

Upon some comparative differences of these four species of Chamæcyparis, Lawson, Nootkatensis, Obtusa, Pisifera, we have made analysis in the Table of Differences and will proffer a few more remarks on the subject. 
C. Nootkatensis.- - The larger cones, the darker pendulous foliage, the absence of white streaks on the leaves beneath, the yellow flower, make the identification of the Nootkatensis, as apart particularly from the C. Lawsoniana, as clearly outstanding as an undraped nigger in a snowfield.

The distinction between the Lawson and the ordinary C. Pisifera is a far harder nut to crack. In using this metaphor it must be explained that we are rather referring to the leaf than the cone differences. Undoubtedly, if looked at closely, the leaf of the C. Pisifera is a differently formed, more sharply pointed leaf, and there seems little else to go by. As the more original and natural form of Pisifera is far more seldom seen than its more fluffy variety, the Plumosa, or its more acicular silvery-looking variety, the Squarrosa (which, by the way, is more commonly spoken of as the Retinospora Squarrosa), the situation of being called upon to decide between the two will probably not be of frequent occurrence.

C. OBtusa.-The intricacies of the Obtusa, and any family likeness it may show to those in the same Group, requires no genius to cope with. You have only to look at the more densely crowded, thick, cobby appearance and character of its shapes and its leaves to arrive at a quick and sure conclusion. If you look at it more closely, the small, round-shaped little leaf on the upper facial (dorso-ventral) surface in the middle, shouldered in between his two big brother lateral leaves, recalls the impression made in our early days of the picture of the Dormouse snuggled up between the Hatter and March Hare, at the mad tea party in Alice in Wonderland.

As a tree it bears no mean record in his native country Japan. It has a royal halo about it, since it is reserved for uses imperial. It has also a religious 
halo about it, since it is the sacred tree of Shinto worship.

It is in great request for building purposes, and temples are made of it. It makes excellent panelling, and shows a very good figure. It takes to lacquering well by reason of its fine grain, and is much used for this treatment. It is well known to us here by the little, contorted, dwarf-grown Japanese cultivated specimens that so many of us have been induced to buy for curiosity's sake, and we hope this short account of its career will convince readers that we are discussing a tree of no ordinary interest or merit.

It, too, has its varieties, and one called Tetragona Aurea displays great garden merit. We have in our mind two planted by Mr. E. Miller Mundy at Shipley, in Derbyshire. They make a particularly picturesque show in those garden grounds. In thirty years they have only grown ro ft. 6 in., while the one at Castlewelan contrived only $5 \mathrm{ft}$. in twenty years-an increase of development which seems more on a par with the leisurely growth of a geological tertiary formation than what we would expect from an ascendant tree.

This compactness and density of growth absolve them to some extent from wrong-doing in their deficiency to rise to greater heights.

Wanting the sun, why does the caltha fade?

Why does the cypress flourish in the shade?

M. PrIOR.

The C. THyordes remains alone of this Group A now unmentioned. It was introduced in 1736 , but has never got a hold in our English climate and estimation, in spite of its many natural fascinations. Either the swamps where it was placed proved too cold for it, or the summer is not warm enough, or we have not found the exact spot of the judicious mixture 
of damp and soil that it requires. In its branching it seems to show its independence of character more than anything. It is said to shed its branchlets in fan-shaped pieces. The situation of the green tufts of leaved branchlets, upon the top of elongated twigs curling upwards bared and brown, looks peculiar. Hold up by hand a branchlet and it looks like some miniature-shapen Stone Pine, or even a toy representative of the top ramification arrangement of a clean-boled Scots Pine.

A juvenile form, called either Leptoclada or Ericoides, has raised questions as to whether it belongs to the true fold of the Thyoides.

It, like the Thyoides, is spoken of as ornamental. There is one planted here some $800 \mathrm{ft}$. above sea-level, and though it grows slowly it grows steadily. It reminds one of a miniature, reduced four dimensions, Cryptomeria Elegans, but the branchlets turn red while the Cryptomeria retains its yellow-green colour.

(Sub-DIvision EU-THUYA, OF THE SUB-TRIBE THUYINÆ, AND OF THE TRIBE CUPRESSINEÆ)

ThuYAs, or ARbor Vitæ.-

The true and only friend is $\mathrm{He}$,

Who, like the arbor vitæ tree, Will bear our image on his heart.

Sir W. JONES.

When the foliage part of the question comes into the region of discussion, it is pretty well agreed that the Thuyas and the flat-leaved, small-coned Cypresses (Chamæcyparis) are more or less at one. In both instances the branchlet systems are in one plane.

It is on the cone question that they come to loggerheads, and the rift in the lute here is, that while the scales of the cones of the Thuya are imbricated- 
that is to say, over-lapping, like tiles on a building roof-the cones of the Cypress are peltate, formed like a shield. This is a question already discussed at length here and efforts at explanation adduced. If we referred to it here further, and again, we might (and rightly, too) fall under the shadow of superfluous wordiness. So much are their habits alike, their leaves in frondose arrangement on one plane and flattened, that the botanists of a previous day lumped them both together into the same family circle.

At this date the importance of the cone differences has over-ridden the importance of the leaf arrangement, and they are placed en famille, as we have placed them here.

The fact that many of them are credited with a smell of their own must really be left to the delicatenosed independence and taste of the variously constituted nasal organs of the aspirant assayers to work out the scent for themselves. Quot homines tot sententice; so many men, so many opinions, or shall we translate it so many sensibilities?

Some seem to think them all more or less agreeable; others that some are agreeable, others disagreeable.

For instance, the $\mathrm{C}$. Nootkatensis has a reputation for being far more evil-smelling than the C. Lawsoniana. Among the Piceæ and Abies the Amabilis has a reputation for agreeableness. Its smell has been compared to that of a citron or tangerine orange, a reputation that many think ought to be equally shared by several, especially the glaucous-coloured trees-to wit, the Pungens, Arizonica, Nobilis, and Concolor Violacea. The particular perfume ascribed to them is generally spoken of as like that of the citron or tangerine orange. But let all these high-scented ideas, as we have intimated, be settled according to the perceptions of the individual. We only add that 
"aromatic" in botanical writings generally refers to what is fragrant, and sometimes to what seems to be doubtfully fragrant; whereas "rank" expresses forcibly that our perceptions are not to expect any pleasant impressions therefrom,-and these are descriptive adjectives that appear frequently upon the pages of standard authorities.

In the specimens where the juvenile form of leaf is retained, and before the day when scientists had proved that they were one and the same, only in youthful guise, they were named Retinospora. Today a commonly planted tree is more often spoken of as the Retinospora Squarrosa, whereas, if you give it its full and real title, it should read Cupressus Pisifera var. Squarrosa. Several of the Thuyas-the Orientalis, e.g.-masquerade in this juvenile attire. The Occidentalis and Orientalis are particularly inclined to this little habit.

The Orientalis, or Biota, to which we refer later on, like the Cupr. Lawsoniana, is of a very polymorphous habit.

The word "Thuya " is an old Greek word, Ovía, connected with an old Greek verb $(\theta \dot{v} \omega)$ that expressed action in the direction of burnt sacrifices and incense, and became thus associated with the more fragrant woods employed in places of worship.

Our old schoolboy recourse to the meanings of these mysterious Greek-lettered words, Liddell and Scott, tells us that it was a name applied to an African tree with sweet-smelling wood, and that its Latin synonym was cedrus; whether it was Cedar, an African Arbor Vitæ (Callitris Quadrivalvis) was a matter in dispute. But these unde derivatur excursions into the halfburied past afford us more recreation than enlightenment upon the problems of the present day.

The Thuyas of to-day are divided into three sections: (I) the Eu-thuya, comprising three species 
and their variations ; (2) the T. Orientalis, or Biota, containing one and its many varieties; and (3) the Thujopsis has a group to himself with some, and even a genus to himself with others.

In reading differences of the Table there should be no difficulty in pronouncing judgment as between the T. Plicata and the T. Occidentalis. The one (T. Plicata) has white streaks on the under-leaf, and the other (T. Occidentalis) has not. Not even Bertillon, with all his thumb-print successes, could have invented a better system of identification than this. If more evidence is wanted, we suggest a look at the glands conspicuous on the one (T. Occidentalis), and inconspicuous on the other (T. Plicata). The Plicata must be identified from the Japonica by its finer leaves, denser habit, and several other points noted in the Table. It will be seen there that C. Japonica has coarser leaves, with blunter obtuse points, and here is constituted perhaps its most telling and easily appreciated difference from the other two. It has also more vertically placed boughs, and grows more closely than the other Thuyas. The question of smelling out trees or, to put it more prettily, the art of telling trees one from another by the scent they produce, comes to the fore particularly among this group of trees. Lest any one smile at the idea, we ask in all faith and simplicity, Why should not a tree be known by its smell when it is the proud possessor of an odour peculiar to itself, equally and for the same reason that a rose, which, called by any name, still smells the same, or a violet, or any other flower is so known? Why should one product of the vegetable world have a monopoly of dispensing education in this direction? When we come to consider it further, it is a power undenied to a turnip, or garden cabbage, not to mention an onion; and when we venture our ridicule on the onion, let it not be forgotten that a saying runs, 
"Nowhere does the rose bloom so sweetly as when planted near the onion."

To sum up the case of the three species-Plicata, Occidentalis, Japonica-before us in the dock or at the bar of olfactory opinion, and arrive at conclusion as to which distils sweetness and which imparts disflavour: In the case of the T. Plicata the jury seem agreed that the smell is far more pleasant than otherwise, though some seem to think it is nothing to rave about. In the case of the $T$. Occidentalis the jury are disagreed. It has been accused of being aromatic, pleasant, acrid, pungent. Consequently, we must leave it to each individual, if he so desires it, to nose out this question further for himself. The case of the $T$. Japonica presents no hesitation on the part of the jury. It has been adjudged, nemine contradicente, guilty of a failure to minister to the lords and ladies of creation those voluptuous delights accredited by poets to the perfumes of Araby that their souls desire. In writing a short monograph upon these three trees, and putting aside for the moment the question of identifying marks, we would say a few words on their uses.

The Thuya Plicata, or Gigantea, the giant Arbor Vitæ of North America, was discovered between the years 1789-94 by Louis Née, on Nootka Sound, and introduced to England in 1853 . Its habitat extends from southernmost Alaska to almost San Francisco. It ranks among the monster trees of those regions, and attains stupendous heights and massive girths. Yet it is a wood that is the lightest of the light, and famed for durability in wet ground. It has an estimated life at from 800 to 1,000 years, and holds valuable testimonials from valuable sources as to its economic value. All, from the severest and most cautious of scientific sylviculturists, speak well of it. 
Many others sing its praises. White settlers, lumbermen, tree planters, tree writers, tree fanciers, and pheasant fanciers.

Why, in the face of all these expressions of opinion from so many profound sources, it has not been more extensively planted in the woodlands of England, we cannot pretend to explain or understand. Perhaps in some future or more philosophical age it will come into its kingdom of appreciation.

As a timber tree we have very little to recount of the character received of the Occidentalis. To sum up its virtues, it has been said that it makes good hedges, and this seems but damning with faint praise. The cones on the Occidentalis grow in such close communication that you can gather into the palm of your hand a bunch that contains more than a hundred of its cones. This gives sometimes a whity* yellow aspect to the tree that can be seen at a long distance.

Like the Lawson Cypress it is polymorphous and has many shapes and varieties. How these mysterious symptoms occur, whether transmitted by some far-away ancestor or some cross purposes, or what wild deviation from normal rules brought it about, has yet to be clearly explained.

The $T$. Japonica goes rather one worse from the point of view of wood value. In its native country it has been known to make good roof shingles.

Thuya Orientalis, Biota, or Chinese Arbor Vite.-Perhaps a few points added to the abridged Table may help those for whom we write towards a surer acquaintance with this ornamental garden product from China, and its reticulated or graceful appearance of foliage. If this name Biota has any connection with the Greek word Bıtós-and there is nothing to suppose anything to the contrary-it 
conveys a high compliment, since the Greek word implies something worth living for.

It is more often than anything little more than a twenty-foot high, many-stemmed shrub, though two at Hampton Court, Herefordshire, planted by the late J. H. Arkwright, have risen to twice that height.

Its branches, except perhaps the lower ones, rise vertically, and the branchlets also, like some varieties of the C. Lawsoniana-to wit, the Allumi and Erecta Viridis-also assume this vertical habit.

Like the C. Lawsoniana and the Occidentalis it breaks away in many (over twenty) polymorphous strains-coloured, dwarf, fastigiate, and pendulous with whip-cord branchlets. Juvenile and coloured forms are fully dealt with in detail by our more luminous and voluminous authorities.

The leaves are described as without white streaks on the under-surface by Elwes and Henry, but are by Bean notified as with white streaks. The one we have before us here shows white stomata scattered in the middle of the leaf on the under-side. They are further described as in decussate pairs, but do not show to the tyro much difference from the dorsoventral and lateral leaf arrangement. Down the middle of the leaf there runs a depression, or groove, which is explained as of glandular cause and effect. The lateral leaves curve away from the centre. The leaves are triangular in shape, with a little sharp point at their ends. The cones are always erect and not deflexed ultimately, as in other Thuyas. They are of a soft blue substance at first, and showing six or seven horn-like protuberances. As age advances they become harder and more ligneous, and eventually gape apart as do most of the Thuyas.

Thujopsis Dolabrata, or Japanese Thuya.The T. Dolabrata, by its greater breadth and boldness 
of foliage, by its leaves as if splashed with thick patches of whitewash between its very distinct green upraised margins on the under-side of the leaf, calls for very little help from anyone to make it easily distinguishable.

It is the one case, above all, among all Cypresses and Thuyas of which we may say with confidence that a sight will suffice, and that ever afterwards a remembrance and recognition of it should remain implanted in the eye and mind of the Conifer student. It hails from Japan, and though it was heard of and en évidence as far back as the eighteenth century, it does not seem to have come to stay until the middle of the next century ; and when it did, owing, it must be presumed, to some climatic conditions, it did not attain the height to which it grows in its native lands. It is said to show partiality for shade and moisture, and to grow better from cuttings than from seed. The wood is well spoken of. A full description of its cones and leaves appears in the table, p. 292 .

Libocedrus Decurrens, or Incense Cedar.-

Numa the rites of strict religion knew,

On every altar laid the incense due.

PRIOR.

It has not often fallen to my lot to play cicerone among trees, and then only more among the trees of my own homestead. On those infrequent occasions it is seldom that I have been questioned as to the origin of a name. One only exception there is to a normal quietude upon such subjects, and that is as to the derivation of the name Libocedrus. It was once asked whether the name had any occult connection with a Cedar that had taken a liberty, meaning thereby whether it was a freak or sport produced from that venerable tree they all knew so well by 
name and sight as the Cedar of Lebanon, and thereby rather intimating that some occult connection existed between the first half of the tree's double name and the Latin word liber (free); whereas the origin, in reality, is to be found in that Greek word $\lambda$ ía avos, which comes to refer to the incense used at religious functions. The mountain chain after which the tree was named had the same derivation as the Libo in Libocedrus. The word "cedar" is derived from the

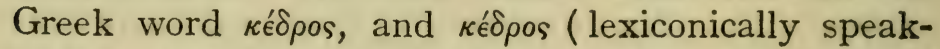
ing) is translated as "the cedar tree, the wood of which was burnt for perfume or used to scent ointment."

Mt. Lebanon, from which our Cedar of that name took its title, is called the White Mountain-it is said, on account of the white resin of the coniferous trees that bedeck the scene. The resin of certain trees-not very easily distinguishable-was used as a chief ingredient in the preparation of the frankincense used alike by pagans and true believers for purposes of ritual or sacrificial fumigation. The Libocedrus of the west, be it added, has no more a monopoly of its production in the West than has any one or particular Cedar or Conifer of it in the East. The Cedar of Lebanon is not the tree from which an idolatrous people probably extracted their resin to transform into the incense they burnt "upon the hills, under the Oaks and Poplars and Elms," in the days of the prophet Hosea. It may have been equally or exclusively applied to some other Conifersthe Roman Cypress, the Juniper, or Pinus Halepensis -for all we know. Thus, although there is no confusion of appearance as between Libocedrus and Cedrus Libani, there is between them a certain connection in the derivation of the names that have been bestowed on them. The Libocedrus is known colloquially by the name of Incense Cedar, and in 
California by several other cognomens-to wit, White, Bastard, and Post Cedar. I leave the subject here for readers at their will to work out the connection of name and non-connection of form. They are not hard conundrums to cope with.

The appearance of the trees from a scenic point of view shall shortly be reviewed here. The Lombardy Poplar may be cited as its analogue in form and structure for those situations where you seek a column or chimney, or may we add campanile, effect ; and when we cite this comparison we must ask readers to bear in mind that we are not disregarding the fact that chimneys in the abstract do not produce one and the same effect in all places from a landscape point of view.

There are the huge chimneys of the Midlands, used in connection with commercial enterprises, and they, all must concede, are a blot hideous enough, in all conscience, to disfigure the charm of any landscape that Nature has ever produced. Then, again, on the other hand, we have the perfectly designed chimneys evolved by the best of architects, in an Augustan age of literature and art, in the times of Queen Elizabeth, and later Stuart days when many of the best so-called Elizabethan buildings were designed and erected, and which are the glory of their art and the pride of a nation.

When a tall, towering, columnar tree of almost maypole slenderness of form comes to be planted, the position has to be selected with a more than ordinary care than that often bestowed upon many other heroes of the forest and glories of the glade. It has more than ever to be placed carefully and considerately, according to the circumstances and agencies of its surroundings. All this should go without saying, yet we take the liberty of repeating it with a view to emphasize the fact that we believe many 
situations could be bettered for the beautiful by making judicious use of its stately and formal shape.

What the Lombardy Poplar has accomplished for the Plains of Lombardy as seen from Milan Cathedral, what it has done to beautify our rich, low-lying valleys of England, so equally can the well-placed Libocedrus play an ornament rôle in many places of our grounds and gardens.

Of the Libocedrus group which appears in our own Table, when we come to call the muster-roll and reckon the rarities as absentees, the task of identifying becomes lightened. Of the eight mentioned, three are not introduced, three are very rare, and the Chilensis only seems to flourish under exceptional climatic conditions. This leaves us, then, only more or less confronted with the botanical details of one specimen, the Libocedrus Decurrens, to contend with. The long length of their leaves, appressed to the stem, the vertical growth of their branches, the attenuated lengthy appearance of the tree as a whole, their unlike-any-other terminal cones, render them easy of recognition. Should you chance on a rarity of their race-and we think it would only be on the rarest of rare occasions - the differences alluded to in the Table should not present insuperable difficulties to those students who have gone far enough in their observational career to know that a Libocedrus is a Libocedrus. We should here call attention to the fact that the Libocedri break away from the Thuya conditions in two points: (I) A greater number of stamens in the male flower. (2) And secondly, which is the more easily apprehended of the two, in the matter of cone construction. Whereas the scales of the true Thuya are more or less of equal size and overlap each other, the scales of the cones of the Libocedri are of unequal size, and do not overlap, but are united by the margins only. To it 


\section{LIBOCEDRUS TETRAGONA AND MACROLEPIS I85}

is attributed a fragrant odour. Our own verdict of it would be that while it has a flavour of fragrance, that flavour is of a very low standard of power. From the Chilensis the Libocedrus Decurrens can be told by the absence of white stomata and glands. The Tetragona and Macrolepis can be told by their octagonal, not flat, branchlets. The Tetragona has often been confused with the Fitzroya Patagonica, and we experience little wonder. While no one unread in tree-lore, and unversed in the ways and reasonings of the deeper-minded botanists, would on sight ever associate a L. Tetragona with a L. Decurrens, they certainly could, without straining a point, easily confuse the Tetragona and Fitzroya, notwithstanding the fact of their difference of fruit and leaf. The leaves of the L. Tetragona are in opposite pairs and stick away out from the adnate base. In the concave or upper side they show thick splotches of white stomata and their apex narrows to a blunt point, while the leaves of Fitzroya Patagonica are in whorls of three and show white stomata on both sides of the leaf.

The Libocedri rank up generically alongside of the Thuyas and under the wide, outstretched family wing of the Cupressineæ. Possessed of many and various vagaries in form and character, they cannot be an easy species to precisely locate in any family-tree sense. We must search Kew's lists, and there seek the information we desire. And this is what we learn of them from those unquestioned sources: That they are of most undoubted Cupressineæ persuasion ; they they are to be found in congregation with a sub-tribal sect, entitled Thuyinæ, a sect that includes such divergencies as Cypresses, Fitzroyas, Thuyas, and Biotas ; and that there among them, but seated alone, they occupy a pew to themselves in nearest proximity to the latter mentioned. 
Of the wood uses of the Libocedri we only get such sketchy descriptions that are hardly worth producing. We hear of them being used for shingles, as are many of their tribe. If some day wooden shingles come into demand for the more ornamental annexes of houses, for verandahs or porches, and take the place of the old heavy but picturesque stone tile, all these sorts of Cupressineæ wood may be sought after and have their day in the markets of the world.

\section{JUNIPERS}

(OF THE NATURAL ORDER OF CONIFER $Æ$, OF THE FAMILY PINACEÆ, OF THE TRIBE CUPRESSINEE, OF THE SUB-TRIBE JUNIPERINÆ)

The hirch-tree swang her fragrant hair,

The bramble cast her berry,

The gin within the juniper

Began to make him merry.

Tennyson, Old Amphion (1857 ed.).

THE origin of the name Juniper is to be traced to the Latin words juvenis (young) and the verb parere (to produce). Presumably it was so named on account of a curious habit that it displays, in many of its species, of producing two entirely differentlooking sets of leaves upon the same tree-namely, the gossamer-looking, awl-shaped, acicular young or juvenile leaves, and the mature, appressed-to-thestem, Cypress-in-appearance, adult foliage. The French call the tree Genévrier, or Geniévre, and from the first syllable of this word a spirituous compound, familiarly known in all alcoholic circles by the labelled title of Gin, derives its name, as if in mutual obligation and acknowledgment of the fact that the drink derives the benefit of its flavour from the fruit of the tree.

Nor is it a tree without its little accompaniment 
of myths and legends. The Juniper was consecrated to the Furies, and the smoke of its green branches was the incense offered to the Infernal Gods, while its berries were burnt at funerals to keep off evil spirits. The renowned lexicographer, Dr. Johnson, hurls unsubstantiated charges of the most venomous nature at its devoted head. He writes that its shade was baleful, that its taste was bitter, that its shelter was a dangerous zone to man and beast to be fled from precipitately by all cautiously inclined, and by those who walk the earth in fear of evil consequence from superstitious influences. As a tree we neither know nor can find any basis for these assumptions. In the face of all these disheartening qualities, many would-be gardeners and seekers of scenery revel to this day in its presence, and take delight in a sight of it upon many a bank and hill-side devoted to its production.

In the Bible we hear much of the Juniper in the wilderness. As a phrase it "falls pleasantly " on our ears, for some reason as unexplained as the why and wherefore that the word Mesopotamia affected the old lady of fiction. It brought "great support and comfort to her," she confided to her pastor.

In the incidents spoken of in Holy Writ the Juniper seems to have conferred the blessings of both shade and food to many a weary wanderer in the sunscorched desert. Job pictures one, a melancholy derelict, who, having suffered from the derision of man, had sought the solitude of its sandy tracts, and was reduced to making a meal off the roots of a Juniper bush under which he rested. It reads unappetising as a diet, but still, for aught we know, it may have given temporary satisfaction to a hungry outcast sunk low in his own estimation and far removed from any pleasures of the table; but it is a recital of an experience that must not be reckoned 
upon to create any restaurant precedent for its appearance on the better-furnished tables of the more epicurean.

To return to our inquiry into the origin of the word Juniper and its application. The Greek word ä $\rho \kappa \epsilon v \theta$ s is translated Juniper, but Heaven only knows how wide was the application of these two frequently

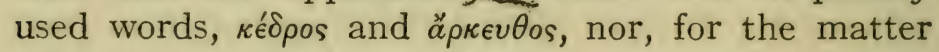
of that, is it a subject of much consequence in any present-day commentary. The name Arceuthos has been applied by the Kew authorities to the Syrian representative of the family which goes by the name of J. Drupacea, and to which reference is made farther on.

Writers of a past day have described the Juniper as a plant with an aromatic smell, and tell us that its wood emitted the fragrant odour connected with incense. While the leaves of the J. Sabina emit a striking and independent odour, and one quite unmistakable from that, say, of a Cypress or Thuya, some of the other species hardly betray any sign whatsoever in these dispensing directions. The smell of the Sabina has been described by some as fragrant, by others as disagreeable. While personally in favour of the first pronouncement, we can only suggest, as we have in similar cases and under similar circumstances, that each one should work out his own instincts on this subject, and put a thoughtful nose to an acute consideration of its merits or demerits. After that experiment they can arrive at in independent judgment upon these opposite allegations urged.

As a timber tree modern writers appraise it rather cheaply. Older writers give it a better character. It has certainly been extensively used from times immemorial, for many purposes, which range from cedar pencil making to gin flavouring. In an olden 
day another use that it was employed upon was as an ingredient of the medicine-bottle. It was also, according to old writers, applied to other purposesmarquetry, veneer, making cups as well as filling them with the afore-mentioned distillations from the berry. The oil of Juniper, we are also told, made good picture varnish. As there does not seem much probability of making a fortune out of it by growing it here, for timber, or drinking, or any other purposes, the economic part of the question hardly merits further attention.

We have only tabulated nineteen of the Juniper species. There are many others that have been brought to our notice. All countries surveyed by tree-hunters, from China to Peru, in all regions, from mountain tops to Mexican plains, from Arctic heights to tropical circles, claim their own particular locally established Juniper. Kew lists, Veitch, and Clinton Baker touch upon something over thirty different species, while Elwes and Henry deal specifically with some twenty-two species. Of the total number mentioned, Bean suggests more or less for planting with us sixteen of the species, and of these especially recommends nine. Many so far have not flourished or even been introduced among us. In this list may be mentioned the Macrocarpa, Occidentalis, Brevifolia, Squamata, Flaccida, Bermudiana, Thurifera, Procera. Of these the Flaccida and Thurifera grow at Bicton, and the Procumbens form of the Squamata is often seen in rockeries.

On the three Sub-divisions of the Juniperine: (i) Sabine; (2) Oxycedri ; (3) Arceuthos

We have now come to the question of how to start upon an identifying pursuit of these Juniperinæ. The quest is made easier by one very striking differ- 
ence that calls for no undue strain of the mental powers. Half of the Junipers tabulated here belong to a section called the Sabinæ, and the other half practically to a section called the Oxycedri. Upon the Sabinæ group there are two forms of leaf upon the same tree at an age of ten or twelve yearsnamely, the gossamer-looking, awl-shaped, needlelike, acicular young leaves, and the adult, appressed, Cypress-in-appearance foliage. Unfortunately for the peace of mind of many a casual observer, this golden guiding rule is broken in the case of the J. Recurva and its near relations, the Squamata and Procumbens, and for the reason that their leaves happen to be put on differently, not jointed at the base as are the Oxycedri, but appressed to the stem, as is the custom among the Sabinæ.

Upon the Oxycedri group there only appear the juvenile and acicular representatives of leaf formation. Here is a clue that divides one half of the Junipers mentioned from the other half as clearly and surely as ever sheep were divided from goats, and thereby reduces numerically the difficulties of dissociating Junipers by one-half.

The next or second point of observation is whether the leaves grow in groups or whorls of three, or in pairs placed oppositely on the stem. In all the Oxycedri group the leaves are found in whorls of three. In the Sabinæ group, the Virginiana, Sabina, and Excelsa, all three are in opposite pairs, and occasionally the Chinensis. In the others mentioned in the table, pp. 294-295-i.e. the Pachyphlœa, Phœnicia, Wallichiana-they are in whorls of three.

Other minor points of difference are to be sought for in the length of leaf, the apex of the appressed leaves, whether acute or obtuse, the margin of the leaves, whether light-coloured (as in the Chinensis), or without white rims (as in the J. Virginiana and 
others). This doubling of the leaf character (called dimorphic) may, at first sight, appear as not quite a fair impost upon the intellectual department of the student. One set of leaves he might regard as quite a sufficient task upon his energies and capabilities.

As it so happens, quite the contrary is the fact. This habit turns out to be really a great convenience in discerning the nature of the plant, and as between it and a Cypress. When his practised eye observes the unmistakable acicular leaves of the Juniper in small branches, nestling among the mature foliage, he at once dissociates from his mind any Cypress confusion, and feels grateful to the members of the Sabinæ group that when they commence their age of the sere and yellow they still retain, like many a human prototype, the semblance of youth, and do not at one bidden moment from the clock of Time cast away all juvenile associations and youthful reminders. Hereby they constitute a glorious example to all lords and ladies of the higher creation, in their life's progress towards the serener stages of the Middle Ages.

If we were to make a few general remarks on a few of the Junipers perhaps most commonly seen amongst us, we should venture the remark that probably of the Sabinæ, Virginiana, Chinensis, and Excelsa were most likely to be met with in the more frequented paths of life. The Virginiana is a tree and the Sabina a shrub, or at most a shrub-like tree in its best arborescent form, and as such distributes an unappreciated smell, and the J. Virginiana lacks any.

The J. Excelsa from the Virginiana is a hard matter to dissociate, very hard. The acicular foliage in the case of J. Excelsa in a cultivated, not wild, state often makes no show. The real difference is that the fruit is larger and contains more seeds. But this is a worked-out, and not one of those every-day apparent 
signs of difference that sets our minds at rest and at a glance restores confidence. We must content ourselves, if puzzled, with the reflection that they are probably the same tree but of different geographical habitat. One, the J. Virginiana, hails from the swampy lands of North America ; while the other, the Excelsa, comes from the higher regions of the eastern hemisphere. Some of them are very rare. The Pachyphlœa, and some of its acicular, silvery, juvenile-leaved varieties, have of the last few years been sent out by nurserymen, and so far as we hearthough in its arborescent form they were rather discredited by long-ago experience-they have endured well a few years of life, and even survived the extreme winter severities of 1915-16 and 1916-17. Many varieties of the Sabinæ, in particular, are constantly seen in rock gardens, and not only of the Sabinæ but varieties of the acicular-leaved J. Communis. Of the latter, a variety more rightly entitled compressa, but more regularly, and at the same time with irregularity, designated as Hibernica, a name upon which the fastigiate Irish Juniper claims a prior call. Of the Oxycedri, Bean recommends especially the Communis and its varieties Compressa and Fastigiata, and the Drupacea. We could not obtain advice from a better authority. One more word on this J. Communis. E. Wilson describes its habitat, or accomplishment of its territorial occupation, as "Circum-Polar," a word certainly of a far-ranging ring, that would almost seem to fit in with a modern Prussian sense of appropriation.

I must not close the chapter on Junipers without reference to the long, acicular-leaved (nearly an inch long) J. Drupacea. It has not so far produced fruit in England. As the tree is diœcious it must be presumed that we only possess male specimens. A short time ago I received a branch and some fruit 
specimens from Sir E. Loder, grown at La Mortola (S. France). The fruit is nearly round, of a brownypurple colour, about twice the size of other Juniper fruits, and nearly an inch in diameter. As in leaf structure does the J. Oxycedrus look like an elongated and thickened edition of the J. Communis, so does the J. Drupacea appear by the side of the Oxycedrus. On account of the fact that the seeds are coalescent in the centre of the fruit this Juniper has been given a group of his own called Caryocedrus.

It must not be thought that in our story of the Juniper, and in our comments on its leaf likeness with certain Cypresses, we have inadvertently omitted to mention the outstanding difference which places it severely apart as far as tribal relationship goes, namely, the different composition of its fruit. We have referred to this at length in previous pages upon the Cypress, and called attention to the fact that, while the fruit of the Cypress is a ligneous, variously shaped cone, that of the Juniper is a darkblue berry.

Whittier, the American poet, bears witness to its effect in an autumnal woodland scene, and tells us in verse how an appearance of a tree in fruit impressed his poetical senses:

And on a ground of sombre fir

And azure-studded juniper,

The silver birch its buds of purple show.

The drawback to this picture, as a means of identification, is that Junipers do not invariably wear these azure studs at the precise moment you are bringing your discerning powers to bear upon the subject of differentiation. Then it must be remembered that Junipers are one of the few exceptions to conifer customs in that they are often diœcious; in other words, that the tree is generally male or female, and 
does not produce male and female flowers on the same tree. The Cypresses, which are always monœcious, are much more accommodating in this respect of disclosure of identity.

Mr. E. Wilson has sent back from Japan (1914) a quantity of the seed of the J. Littoralis (or J. Conferta), and in some cases they are being given a trial trip by certain inland growers. Whether they will sigh for those sea-shores-with which their name implies association-eventually, as did Tennyson's cedars for their native Lebanon, is one of those problems that we must leave for the futurists to cope with. So far, there seems a certain lack of midstream directness about the relations of these various Junipers, vouchsafed to us by the High and Mighties, that hardly helps to guide struggles on the straight current of a sure course.

We complete the subject of Junipers with this consoling reflection: that here there is a wide field open for the close student to occupy an industrious mind upon. When he has achieved an intimate acquaintance and a thorough mastery over all the Junipers all the world over, he will find himself occupying a very unique position among the savants of his art. To us, such a mastery of detail looks very like one of those puzzles at which "the world grows pale."

Note-For those who wish to pursue further the intricacies and ramifications of the family tree in the Juniperinæ Tribal History, we append some other names of species not commented upon here, for one, either, or all of the following reasons:

(I) That they are species that have been tried and found unsuitable to our climate.

(2) That as a species their individuality is still undetermined, and hardly so far emerged from the regions of controversy among eminent authorities.

(3) That they have only been recently discovered, or imperfectly described.

(4) That they are discarded synonyms. 


\section{OTHER JUNIPERS}

Names found of Junipers and commented upon in books of English authorities (e.g. Loudon, Veitch, Elwes and Henry, Bean): Barbadensis, Bermudiana, Brevifolia, Californica, Flaccida, Macrocarpa, Mexicana, Nipponica, Occidentalis, Procera, Tetragona.

Rocky Mountain Region, U.S. America (G. H. Sudworth, Bulletin No. 207, U.S.A. Dept. of Agriculture).

Megalocarpa, Monosperma, Occidentalis, Sabinoides, Utahensis.

Japan (E. H. Wilson). Communis; var. Montana. (Aliases: Sibirica, Canadensis, Alpina, Pygmæa, Dealbata.)

Chinensis var. Sargentii.

China (E. H. Wilson). Squamata, var. Fargesii, Saltuaria, Convallium. 


\section{VI}

\section{TAXODINE $E$ AND ARAUCARINE $\mathbb{E}$}

(OF the NATURAL ORDER CONIFER E, OF THE

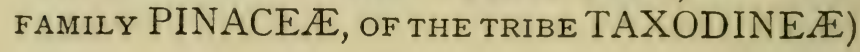

Any man that walks the mead, In bud or blade or bloom may find A meaning suited to his mind.

TENNYSON.

THIS is a small group of coniferous trees of very different appearances, of little outward and visible resemblance often one to another, for the most part of seemingly rather far-fetched affinity, and they rejoice in the one tribal name of Taxodineæ.

There must have been, we think, something just a little inconsiderate in the nature, and something just a little stubborn in the attitude, of the advisory committee of our botanical experts, in their methods of prescribing lasting names of the tribes, orders, and species of that day, when they singled out for this omne gatherum group a name which vibrates in such a propinquity of sound to that of the Taxacean family.

When we reflect that, on account of a certain approximation of appearance, this name must have been given to them, yet at the same time, on account of a certain ascertained non-approximation of some botanical characteristics, they were denied admittance to the honourable company of the Taxacean family, we plead guilty to a sense of mystification. We 
cannot help thinking that, under these circumstances, this rather heterogeneous group might have been invested with a title that showed a little more originality and marked a little more individuality. But, not content with overrating the capacity of the ordinary human intelligence to analyse long names, these learned pundits of a name-bestowing fame have among the inner ranks of the Taxaceæ themselves, in all conscience, truly piled Pelion on Ossa. They have rung the changes with a vengeance upon the tossed-to-and-fro names derived from the once more or less mono-meaning Greek word $\tau a \dot{\xi}$ os, and sown confusion among those who have little time or opportunity to attempt the profundities of the art botanical.

If a student were called upon to define genealogically, according to Cocker, which for the purpose we may define as Kew Lists, the Common Yew Tree, he would have to write it down as a Taxad, of the scientific and generic name Taxus, of the sub-tribe Taxeæ, of the tribe Taxineæ, of the family Taxaceæ, etc., a definition which sounds rather like an answer to a question set by some stony-hearted examiner in an Oxford Responsions school.

But what matter? The self-taught tree lover can, if he so wish and as he often does, contrive to find and pursue a mitigated pleasure in the cult, without recourse to any attempt at unravelling such inner mysteries of the craft, and which we must acknowledge in all honesty the necessity of, even if at times we indulge in a cavil at their intrusion.

From this genealogical point of view we must add that the Taxodineæ are a tribe of the family Pinaceæ, and of the order of Coniferæ. Their situation as a tribe is adjoining the domains occupied by the Cypress and Araucarias, one on each side of them, and parenthetically we may say, that some members 
of these neighbouring tribes bear resemblance to the Taxodineæ.

This group of Taxodineæ trees comprise (as far as we are concerned with here), six different species; the Athrotaxis, the two Sequoias, the Cryptomerias, the Deciduous Cypress, and the Japanese Umbrella Tree (Sciadopitys Verticillata).

The points of difference between the various members of this little confraternity are so apparent, and the points of resemblance so un-apparent to the ordinary man, that no effort on the part of any intelligence department need be called upon to discriminate between them. The puzzle, indeed, is to find the links that bind, not the distance that divides, and these are points to be sought for in the more minute points of flower and cone structure.

The members of this little coterie of alikes yet unlikes originate from different and widely scattered geographical regions, but they have one point in common. They, all of them, date back to remote geological periods, and all of them somehow look as if they did. They all of them appear as if they once had an intimate connection with and a direct interest in those dark, dank, dismal places, that " wetter wet and slimier slime" (as Rupert Brooke, the poet, describes such scenes and haunts), which pictures only have made us acquainted with, and where the great Amphibia of a carboniferous systemfrom all we hear-were wont to wander and to wade.

They all of them wear an old-world look. In the Sequoias, the scattered leaves that cling to the older stems like barnacles to a hulk, have a left and forgotten expression of appearance, as if their presence were unwelcome among the newer generations of foliage, as if their dinginess were hardly in keeping with the brighter green of the more closely clustered leaves that grow upon the latest edition of the new 
branchlets. Looking at them from these points of view, they seem to bear a nearer relationship with some other members of their band.

The Cryptomerias are much in the same way of habit; the more elderly leaves, on the more elderly branches, seem to keep in a closer touch of general appearance with the younger generation than they do in the case of the Sequoias. They seem to assert themselves more successfully in competition with the rising sun of the latest production of leaf foliage, and to hold their own a little better among the younger upstarts. They also, which is rather an unusual trait in this clan, bear a certain outward resemblance to the Athrotaxis. Of the remainder of the Taxodineæ the differences of appearance are still more pronounced. There is the swamp-loving Deciduous Cypress of deciduous habits, and the like-nothing-on-earth Sciadopitys Verticillata, the Umbrella Tree of Japan. This completes our list of this menagerie group, to which we will refer separately.

\section{Sequoia Sempervirens (Taxodinee).-}

Give me of your boughs, O Cedar, Of your strong and pliant branches My canoe to make more steady, Make more strong and firm beneath me.

LONGFELIOW.

This is how Longfellow, in defiance of ail decorum in the rules of botanical nomenclature, describes the finishing touches that Hiawatha contemplated putting on to the construction of his Birch-bark (Betula Papyrifera) canoe. Whether it was any hero-worship consequence of a great national poet's utterance we cannot say, but the fact remains that to this day what books of all nations call Sequoias men of 
America call Cedars-the Red Cedar tree, around which, Tennyson tells us, the red men danced.

The name Sequoia was bestowed upon them in honour of a certain Cheroke Indian chief who rejoiced in the name of Sequoyah. Now this chief must have been a very remarkable man, with a lifehistory well worth looking into, but it is not a story here to attempt any exhaustive narration of. He seems to have been a good farmer and successful silversmith, but his accomplishments did not end here. In addition to these two avocations, we read that he contrived to invent an alphabet of his own; so these trees, the mightiest among trees, without shadow of doubt, obtained their nam: from a man of no mean or ordinary abilities.

Between the two Sequoias, while there are great affinities in the shape of their cones and in the colour of their corky, cinnamon, red-brown-coloured trunks, their leaves are as different as, say, the leaves of a Macrocarpa Cypress and a churchyard Yew Tree.

The leaves of the S. Gigantea (Wellingtonia) are affixed to the herbaceous-looking branchlets that hang out like so many strings of frayed whipcord, and the frayed appearance is caused by the detachment of the end of the leaf from the stem, a system which is generally described in the Cypresses as exhibiting freedom at the apex.

The leaves of the S. Sempervirens upon the lateral branches, on the other hand, recall the leaves of the Yew. At a second glance they are easily discernible from those of the Yew, inasmuch as the Sequoia has pale, but very distinct, white stomatiferous bands upon the under-surface, where the Yew displays a dull yellow colour. Recent observers of the tree in its native country tell us that the leaves on the top of an old Sempervirens show a tendency to assimilate themselves in shape, more in accord with those of 
the Gigantea. If this little metamorphic habit turns out to be an established truth, we can only remark that a touching tribute to the lasting strength of family ties, reminiscent of the mythological story of the two old Phrygians, Philemon and Baucis, may be derived from the incident. It reveals the home truth that any little differences that may occur between the members of the Sequoia family in early days, are made up as between them, in the after-times of advancing life.

One word more on the pretensions and record of these two Sequoias: the wood of the Sempervirens is vastly superior to that of the Gigantea.

\section{Sequoia Gigantea or Wellingtonia.-}

Cleave with their dark-green cones the silent shies.

SHEIIEY.

Shelley must have been dead some twenty years before European eyes, in the person of J. Bidwell, in the year of our Lord I 84I, first beheld the big trees of the Calaveras Grove, and it was not until ten years later than that that authentic accounts and seeds were brought back to England by W. Lobb; but no tree then or since could better, more deservedly, have drawn from poet's pen a tribute to the glory of stature.

By the familiar name Wellingtonia this tree is commonly and colloquially known. In the more orthodox circles it rejoices in the name of Sequoia Gigantea, and as a giant, so far among us, has continued to run its course.

As the Duke of Wellington was often spoken of as "The Great Duke," so did the newly discovered tree become the holder of the same honorary title, and became known as the Wellingtonia Gigantea. In course of time for some reason, perhaps because the 
name Wellington, without any further say, implied greatness, or it may have been in mere deference to a love of simplicity, in a mute obedience to $R$. $L$. Stevenson's expressed objections to the presence of adjectives, this qualifying tribute receded into oblivion. But, whatever was the cause or were the causes, somehow or another, the Gigantea applied to Wellingtonia is dropping into disuse, and the tree is now spoken of as Wellingtonia by those who talk in English, or Sequoia Gigantea by those who affect the Latin language; while the other Sequoia is similarly known and spoken of as Californian Red Wood, or Sequoia Sempervirens.

The trees of the Mariposa and Calaveras groves are well known to the host of travellers who have toured the Yosemite Valley, and one Wellingtonia there, that goes by the name of the Grisly Giant, has attained a special notoriety by granting a way-leave through the usually wayless passage of an archway cut in its massive trunk, through which a coachand-four (or six), at regular intervals, carrying annual relays of tourists and globe-trotters, is allowed to pass.

If the tree permitted this indignity to be offered to its mighty frame for the purpose of advertisement and on the principle-

That they who in this world would rise Must either bust or advertise,

the object has been attained. It has not only, by these methods, advertised its existence, its greatness, its locality, its surroundings, but it has been made the medium itself of advertisements, and buyers of Californian brands of fermented and spirituous drinks have been lured on to purchases under the shadow of its " Big Tree" influence.

There is another characteristic that is beginning 
to become familiar in our eyes about the Wellingtonia, and that is its thick buttressed trunk. In shape it resembles, with its tapering stem, the familiar form of that Dairy Company's milk-can that we all know so well and hear so often, to the disquietude of our system and the disturbance of our nerves, rolled and jangled along the platforms of our island home railway stations. The comparatively small branches that shoot out from the inordinately thick bole make the contrast as between shoot and stem a marked feature in its general appearance, and recall the nursery children's description on the disproportions of the elephant.

\section{When people call this beast to mind \\ They marvel more and more, \\ At such a little tail behind \\ So large a trunk before.}

Where groves have been dedicated to their preservation, we are told that invariably these buttressed symptoms decrease, and show signs, as time goes on, of a more sylph-like waist measurement.

The question which is the biggest tree covers a large refought, over and over again, battle-field, and contains the wrangles of many writers. Which is the winner of the Champion Cup in this soar to the skies? Aurigation competition depends very much on the conditions of the class. If it is for height alone, the S. Sempervirens seems to hold the record for livetree height of $340 \mathrm{ft}$. against the S. Gigantea's $320 \mathrm{ft}$.

But the Sequoia Gigantea has entered for competition a dead trunk that exceeds it. The question arises, Is this to be a disqualification? A live dog is better than a dead lion it may be argued, but, whichever way the stewards of the competition decide, it will not alter the fact that the height, or the nearly approaching height, of the tallest spire in England 
(Salisbury Cathedral), has been reached by growing trees of both species.

We have not brought so far the claims of the Australian Blue Gum (Eucalyptus Globulus) into the arena of competition, since these claims have been disqualified on the grounds of exaggeration by describers, and their pretensions thereby rather discounted. But if the class were for height and size, or on the block system in use at fat stock Christmas shows in Smithfield precincts, which we may put together and call magnitude, the S. Gigantea wins, and wins easily. If we were to take it on the group system, again the S. Gigantea triumphs. Let him therefore take the prize among trees, and be called the greatest of then upon the living earth.

In any competition for longevity-what a lacklustre contest of superiority for anything else than inanimate objects to engage upon ! - the Wellingtonia looks like a winner all over. It seems to have fairly established a claim to an average life of 1,500 years, a tenure that emulates that weary, dreary, worldwithout-end existence upon earth, that the unhappy Struldbrugs of Luggnagg (encountered by Captain Lemuel Gulliver) were compelled to endure.

There is a specimen trunk of one of them at the British Museum, which-if we remember aright-is credited with a count of something between I, 300 and $I, 400$ rings of annual growth. But, even as there were brave men before Agamemnon, it is stated that there are extant trees of still greater magnitude and age, which must have begun life some considerable time before this particular tree saw the light of day.

About 300 years seems to be the more moderate duration of life allotted to our everyday trees. The Oak, among our long-established hardwoods, is regarded as victor in any old-age stakes. Dryden has standardized the entrances and exits of its 
existence, and partitioned them in three stages, a simplification of the seven stages of human life mapped out by Shakespeare :

The Monarch Oak, the Patriarch of Trees

Shoots rising up, and spreads by slow degrees.

Three centuries he grows, and three he stays

Supreme in state, and in three more decays.

Multiply these years by two, and you have neared the asserted age of Wellingtonias.

The Yew Tree, the Cedar, and the Deciduous Cypress, among others, all lay claim to probabilities and possibilities of an arrival at longevity; but, more often than not, there is produced only insufficient data in the way of evidence on their behalf that would scarce serve to satisfy the most complaisant and cousin-connected of Old Age Pensions Committees ever congregated in the please-all atmosphere of a local tribunal.

The Bö Tree (Ficus Religiosa), sacred to Buddha, Prince of Siddartha, in Ceylon, claims an existence of 2,000 years; but, as it is no native, nor even naturalized, subject of Great Britain, it must be at once nonsuited here, and any pros and cons, in the nature of evidence adduced, declined politely but firmly with thanks.

We must say a word upon the probable scenic effect of this tree in our country-sides. You not uncommonly hear disparaging remarks made about their toy Noah's Ark, or Christmas Tree appearance, and, so far as they have gone with us, this is a shape they have assumed. We must enter this plea on their behalf upon this charge, that the average length of their life is estimated at from I,500 to 2,000 years. A Wellingtonia at fifty years - and this approximates the age of those grown in our British Isles, has only completed $\frac{1}{80}$ th or $\frac{1}{10}$ th perhaps of its life; while many 
others of the surrounding trees that we know so well have in the same time-namely, fifty yearsaccomplished $\frac{1}{6}$ th of the briefer span of life allotted to them on the law of averages. Our Wellingtonia may, then, be not inappropriately likened to a large, overgrown pup, disporting himself in a kennel, among the more symmetrical and finished forms of full-grown animals. Whether he grows here to anything like the height he attains on his native heath, or whether, if he does, he may not mar the proportionate effects of our home scenes, these are matters to be adjudged upon by future generations, in that indeterminate date called æons to come. At present it is the Silver Firs and a few Douglas and Sitka planted sixty and seventy years ago that occasionally dwarf their surroundings, but not with any bad effect. Perhaps in days to come they will succumb to the superior height of the Sequoias.

We must recollect, too, that the placing and planting of trees should always be, as far as possible, according to the determining agencies of the surrounding circumstances. With the exception of Puzzle Monkeys, Wellingtonias are probably the most misplaced of trees planted in the reign of Queen Victoria. At this present moment their unpopularity is just now at its meridian. When the Sequoias have outgrown all the improprieties of youth, when they have become more square-headed at their summit, when they have reached the dignity of old age, or, like Ezekiel's Cedars, when they have "formed their heads among the thick branches " what will be the view taken of them? When the grandchildren, or more so still, the great-great-grandchildren of those to-day have become, in the inevitable course of time, grey-headed and old, as did their forefathers before them, and when they come to look upon these trees advanced to their nearer full, what will be the view 
taken of them ? That is a question that, as futurists, we may derive some little interest in conning over.

Perhaps, then, their popularity will have mounted to zenith, and owners of large groups of "Grisly Giants " will, in the pangs of pride in their priceless possessions, simply and quietly bow their acknowledgments as proprietors, and we hope not altogether gracelessly-

\section{Gather as their own}

The harvest that the dead have sown-

The dead, forgotten and unknown.

Athrotaxis.- "Better a wee buss than nae bield," was reported to be a favourite expression of the Scotch poet Burns. "Bield " in Scotland signifies a shelter, and the words quoted, interpreted into a more usual vernacular, would read : "Better a small bush than no shelter at all."

By indirectly hinting, from the use of these words, at a comparison between the Athrotaxis and a wee bush, it may be said that we have belittled the pretensions of the Athrotaxis.

In the reduced area of its only remaining natural habitat, the island of Tasmania, we hear stories of long-stemmed trees, with thick bushy heads, towering to a height of Ioo feet and producing useful timber. The same tree here-that is to say, the A. Selaginoides, which is the big brother of the trio-breaks the record in Great Britain at a considerable drop from half that height. Whatever claims to greatness they assume out there, in our more perfidious climate they have assuredly-with the fewest possible exceptions-fallen from their high estate, and degenerated into the lesser and more humble companionship of bush society.

The Athrotaxis ranks among the unusuals and curiosities of tree life domiciled in Great Britain. It 
was introduced in 1857 , and the few places where it has made any show seem to be the warmer and more humid parts of the country, in Cornwall, in Ireland, especially at such particularly favoured places as Castlewelan, County Down (Earl Annesley), where it has enjoyed all the advantages of care, culture, and climate. Its name is derived from the Greek words

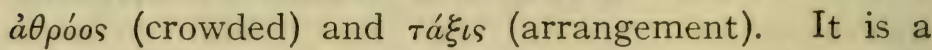
native of Tasmania and a native of no other place. It once existed, or something very like it, so geological research and deposits assert, in the Eocene period in Great Britain. All we can say, in its return journey back, after many million years, to its once native habitat among us, it seems signally to have failed to retouch the Happy Isles.

There are three of these trees, and all to be met with on only the most infrequent of occasions. The A. Cupressoides, with its smaller cones, with its closely appressed leaves, has for all the world the character of the leaf-attached Cypress, from which it takes its descriptive second title.

Then there is the A. Laxifolia, of an intermediate resemblance, as to size of cone and length of leaf, between the other two. Possibly a hybrid origin may be responsible for this appearance.

They are generally spoken of as Cypress Trees; but the A. Selaginoides, with its much thicker incurved leaves, rather calls to mind some of those Araucarias that we can in England only see in the Temperate House at Kew. I refer to the A. Cunninghamia, the Queensland Moreton Bay Pine, and perhaps others labelled Rulei and Goldieana, trees that are strangers in our land, but that look to the amateur observer as showing a suspicious leaf affinity to the trees of our subject in question. In point of fact, it is their cone differences which forbid the banns of Araucarinian relationship. By authorities they are ac- 
corded a nearer affinity with the Sequoias of North America and the Cryptomerias of Japan, to which subject we have made further allusion under the heading of Cryptomeria.

\section{The Deciduous Cypress (Taxodium Dis- TICHUM).- -}

I hate those trees that never lose their foliage.

They seem to have no sympathy with nature;

Winter and summer are alike to them.

W. S. LANDOR.

The Deciduous Cypress is the one recusant representative of the Taxodinean fold, in that it does not conform to the established custom in force among its other fellow tribesmen, of submitting to evergreen practices. Were the tree gifted with a power to understand, we can imagine with what satisfaction it would hail the one-sided bitterness contained in the words of the above-quoted poet, and spoken in condemnation of undeciduous ways.

As the Cupr. Lusitanica is spoken of as the Cedar of Goa-whereas, in point of fact, it happens neither to be a Cedar nor to come originally from Goa-so also on the same principle, or want of principle, our tree in question has been named and surnamed by such descriptions as Taxodium and Cypress.

The word "taxodium" means like a Yew, and

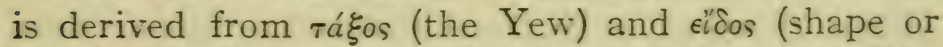
form). Against the employment of the word Distichum, although it may not be very illuminating we will not exercise our national privilege of grumbling. It is a word derived from the Greek word

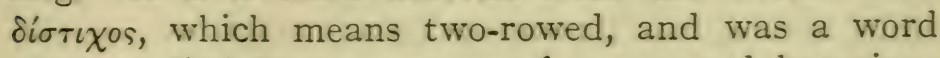
once applied to a measure of verse, and has since been appropriated by the botanical world to signify leaves arranged in two ranks. As the arrangement 
of the leaves of a Yew is two-rowed, so is the disposition of the leaves upon the Deciduous Cypress ; and, for the matter of that, upon a good many other trees besides them. There the likeness to the Yew begins, and there it ends. Other points, even of remotest resemblance, as far as impressionistic appearance is concerned, do not exist. No one within the memory of man, even with a head the most impregnable to teaching, or an eye the most unperfected for taking observation, could have ever mistaken the one for the other, or ever did. The deciduous, light, feathery leaf of the one, with its indescribable spring colouring of its own particular iridescent shade of hue, and, on the other hand, the Yew with its almost precisely different-as poles asunder-habits, and its murky, dark green, evergreen ways, both tell their stories of life with unmistakable meaning. What the omnipotent namegivers could have been thinking about when they dispensed this Latin prescription of name, unless it were for an express purpose of mystifying the mind of more uninstructed man, we cannot think. An unsophisticated Welshman might be pardonably excused if he expressed himself on the subject in customary idiom. In goodness' name, indeed, we do wonder and for what!

Since the days of Montezuma and by historians of those times it has gone by the name of Cypress (Linnæus named it Cupressus Disticha), and in spite of the fact that for some occult unorthodoxies it has been dismissed the ranks, the old description Cypress still clings, and the tree is still traded with under its name, notwithstanding the fact that, by such action, the fair name of the exclusive family circle of the Cupressineæ, from which it has been summarily ejected, may be irretrievably compromised. 
It is a tree with a past of picturesque traditions and interesting associations. Halos of historical and prehistorical romance surround it. It was the tree under which Cortes, the Spanish conqueror, sat, brooded, and sought inspiration after reverse in battle. Visions arise to our minds round the fame of it, the days when Montezuma and generations of Aztec kings before him must have summoned Witenagemots innumerable, and held Court revels without number beneath its shade.

As a curiosity in the vegetable kingdom, with its buttressed trunk, with its woody protuberances called " knees " standing out above ground or swamp, and anchoring its weight reared upon unstable foundations, with its huge, hollow, branching roots spreading out at times like the legs of an eighteenthcentury music-stand, it presents an appearance unrivalled and unequalled.

It has created conceptions as to its appearance from sightseers of a totally opposite character in the different places of its growth. In its eerie, weird, swamp homes in Florida and North Carolina, with grey masses of Spanish moss hanging loosely on its trunk and swayed to and fro by the wind, it has been regarded by some of those who have had the good luck to see it there as a sight dismal, doleful, and desolate. Travellers have written of it as Isaiah wrote of Babylon, "fallen and forsaken." In plainer English and to put it in brief, it seems to have given most of its wandering beholders a bad attack of the creeps.

For those who have not had the good fortune or opportunity of attending a more immediate at home in its company, we strongly recommend a look at the remarkable picture of a grove of it in Trees of Great Britain (L. Elwes and Henry, vol. i. plate 53). The scene as depicted there impels the idea that even 
the clammiest among the frog-born, would wince at the idea of any prolonged habitation at its base.

We can easily imagine, for our part, that such a scene would conjure up mental pictures of remote ages, of Eocene days when mighty beasts-Dinosaurs, Ichthyosauri, and their like-disported themselves therein, and, by their superior weight and hungry ferocity, drove out on to the ridges the lesserlimbed animals of the day, and among them the three-toed Hipparion, the precursor of the fleetfooted horse of to-day.

And then our thoughts will revert as to which of these in life's great conflict triumphed. Not the mighty Dinosaur and his kind would be monopolisers of a great earth's domain. They have retired into space many a long year ago, their would-be victims of spoliation have survived and developed gradually and surely, in scecula sceculorum. And is not this a lesson that can well be applied to the current events of to-day-I write in 1916-and may not good augury be deduced from it on behalf of the ultimate triumph of lesser nationalities? As it was then with the lesser and greater of beasts, so may it be with the greater and lesser countries of to-day. May it in turn and course of time be recorded of them, as it was of those old warriors of an ancient animal land, in language quaint and apt, as Francis Thompson wrote it, "And thy great eaters thou the greatest eatest."

It is of the lesser editions of these trees and as they grow in our British Isles that we must prate. We have no trees to compare in mightiness or historical association with those of which we have spoken. We have no trees here that soar to the $175 \mathrm{ft}$. heights of those mighty Mexicans, or approach their fabulous girths. We have nothing that can compare in size or age-perhaps only one or two that top a hundred 
feet-with the giants at Chapultepec and its Royal Gardens. We have no trees of this species that were alive and large in the golden age of Queen Elizabeth, when trees, which are still alive, were flourishing in Mexico in the reign of Montezuma. Our earliest trees hardly made appearance among us until nearly a century later, and the date of planting the champion trees at Syon, and Hounslow, and other places, seems to be yet another century on.

We have no great dismal swamps dedicated to its growth, to foster its semi-aquatic nature. But if the tree is neither so old, large, or weird, in England, it must not be imagined that it is a dull dot, or has been, on our landscape scenes. If I were asked, if any one were asked, as a tree lover who had a nominal acquaintance with titles of trees, and a nodding acquaintance with the effects they produced by their colour, shape, and so forth, as to what tree it might be desirable to plant for the betterment of scenic effect, or what tree more than another had been deplorably neglected by the cultivator, and what tree in answer to such an inquiry has been upon the lips that reply in more exceeding times of number than any other, nearly all I think would unhesitatingly answer, the Deciduous Cypress. And let it not be forgotten that he-

Who toils to leave as his bequest

An added beauty to the earth,

is worthy of grateful reminiscence.

How many thousands of unoccupied sites upon the banks of the ever-concomitant lake, lakelet, pool, or streamlet of our England homes, great and small, are there, I wonder, that would not be improved beyond recognition by the planting of these streamloving, peerless ornaments, with their radiant green 
spring colour and their rich russet autumnal bronze tints?

We used to learn in early days from a book of verses that

The English Oak is a sturdy fellow, He gets his green coat late.

The Deciduous Cypress gets his still later, but it lasts longer, on well towards February in the young trees planted in these hereabouts.

Another little idiosyncrasy of this peculiar tree should not be overlooked by the enterprising planter, and that is its capacity to flourish in water. How many visitors at Kew in their day must have wondered mightily at the strange sight of a well-grown tree of respectable girth and respectable height, with a goodly part of his trunk-length immersed in the midwaters of a pond, and still for all that looking as happy and contented with life as a duck in a lily pond! We have no prehistoric swamps here or pine-barren ponds available in our chain-harrowed lands to indulge experiments in, but the sight of that Kew specimen enjoying himself like a cow in summer cooling in a stream and seeking relief from summer flies, or an enthusiastic otter-hunter watching a ford, ought to incite the adventurous among planters-out to make search for wet depressions or dried-up waterholes that could be refilled, wherein trial of this effect might be made.

The Deciduous Cypress is so unlike any other tree that there is no need to say much upon clues to identification. We will submit a few points that perhaps may help a stranger to quicker identification.

(I) The leaves are arranged in two ranks, are very small, about $\frac{1}{2}$-inch long. At first they are bright green, with silvery underneath surface. They turn in autumn into 
a bronze shade of colour and often remain on the branches as late as January.

(2) The leading shoots are persistent, the nonleaders and budless shoots fall away with the leaves, and litter the ground underneath as if squirrels had been at work.

(3) It can be recognized from other trees in winter by a very marked appearance. The branchlets are studded all over with white dots caused by the leaf-scars.

(4) Another but less distinctive clue may be perhaps worth calling the attention of the stranger to, and that is its appearance at a distance in the sere and yellow of its days. The orange colour of its branches and twigs shows out clear against the sky, and light up a winter landscape in the same way that brightly stemmed willows are known to do, or that Japanese Larch are beginning to be recognized as doing, and as in a lesser degree our Poplars and Field Maples, both of which have a winter colour of their own when bared of leaves.

These are a few indications that give a clue to its identity in winter time, and they are distinguishing clues under which no other tree can masquerade.

We have read, heard and seen everywhere, and have every reason to believe that what we have read, heard, and seen is true, and all evidences announce the regrettable fact, that this tree of our subject has not been planted much of late years. Is it the fault of the nurserymen for not calling, or the fault of the landowners for not paying, attention to it?

In a circular-built temple of Vesta at Rome it is recorded that a sacred fire, which was regarded as essential to the well-being of that State, was kept perpetually burning and aflame; and, moreover, 
it was ordained that a heavy penalty - that of burying alive-should be imposed upon its custodians should there be any dereliction on their part of their sacred obligation.

We do not for one moment suggest that the infliction of any penalty, beyond the stings of conscience, should be imposed upon those who neglected the sacred duty of planting ornamental trees in meet places. The only moral that we would point and deferentially submit, is that here among us an ancient usage, the practice of planting Deciduous Cypresses in proper places, is in danger of extinction.

As it was the sacred duty of these vestal virgins to keep up the fire dedicated to Venus - the goddess of beauty-who, among other tutelary avocations, undertook the guarding of the family hearth, so do we equally think that it is a sacred duty for those who own and occupy lands to maintain to the utmost the beauty of all scenes upon earth. And, finally, that they could not better act up to this idea, and upon the moral of this story, than by redirecting their attention to the planting of this most picturesque of trees, that goes by the name of the Deciduous Cypress.

\section{Cryptomeria Japonica.-}

Some may perchance, with strange surprise; Have blundered into Paradise, In vasty dusk of life abroad.

FRANCIS THOMPSON.

The Cryptomeria claims a Greek origin for the rather mysterious sounding but euphonious name conferred upon it. The Greek word крлттós signifies hidden, and the word $\mu$ épos share, and we are told that it was so christened on account of a hidden relationship with the Cedar. 
We must, from a cursory observer's point of view, congratulate it sincerely on the success of its concealment. Anything more unlike a Cedar from an ordinary point of view we can scarcely imagine. The bark is different, the branches are different, the leaves are different, and the very colour of them is different. Everything about them looks as different as can be. What claims to any portion or heritage-for that is the sense of the meaning of the Greek word $\mu$ épos-of the Cedar's possessions or prepossessions the Cryptomerias might institute, would confound and dumfound, we cannot but think, the finding of any ordinarily intelligent body of jurymen. If the tree itself is cryptic on the subject of whose image he bears, so also are literary authorities-those at least that have come my way-upon the question of any supposed likeness that it may bear to our Cedars of Lebanon, Africa, or the Himalayas.

The Cryptomeria, it is admitted, bears some sort of resemblance to, not sufficient to present any confusion with, the Athrotaxis, but yet enough to set us wondering if they ever shared any common ancestry. As the Athrotaxis calls to mind some of the short-leaved Queensland Araucarias, so we would have thought, had we not learnt better by book, that some sort of relationship might have existed between the Cryptomeria and Araucaria.

As between the two, Athrotaxis and Cryptomeria, and the question which is which, there really should arise no confusion. The Athrotaxis is altogether a larger-fruited, bigger-leaved edition of the Cryptomeria. Their individual identities, when seen side by side, are as clear as the sun should be at noonday, and as pronounced as that between a greyhound and a bulldog. While the Common Cryptomeria has fine, unnoticeably incurved leaves, the Athrotaxis 
Selaginoides has thick-set, coarse, noticeably incurved leaves; and, again, the cones of the Athrotaxis are pretty nearly twice the size of those of the Cryptomeria.

Again, whereas the Cryptomeria can be often and easily seen by all who run or walk with open eye, the Athrotaxis must be hunted for only in Cornish Rivieras or in such rare spots of English earth that aspire to the reputation of a climate like-

The island valley of Avilion,

Where falls not hail, or rain, or any snow,

Nor ever wind blows loudly.

All the three of them-Cryptomeria, Athrotaxis, and Araucaria - have, however, one boast in common: they can trace back their lineage to a very remote geological period. It was, we presume, in consequence of these prehistoric proclivities and ancient-day renown that the Cryptomeria was singled out for the compliment paid when it was likened to a long-buried beauty called back to the summer lights of a new earth. Whether the trio were evolutions or developments of one common ancestral form, opens up a very pretty question for learned men to work upon and 'prentice hands to leave alone.

If we closed the chapter here it might be urged, and in justice too, that we had hardly given the Cryptomeria its due, a claim neither denied to the regnant power of darkness nor lowliest criminal before the Bar.

Travellers of botanical knowledge and arboricultural research have one and all proclaimed its greatness. Native Japs have echoed their voice, and told us of its many uses. As a utilitarian member of the Woodwork Arts and Crafts Association it ranks high, and is computed by them as near next in wood value to their priceless Cypress (C. Obtusa). 
Whether in its character as the dominating personality of vast woodland areas, or as the sole representative of pure forests self-sown and selfgrown, it has been literally raved about by visitors, weather-beaten old travellers, and far-famed plant collectors. In these ranks, too, there are many to whom ecstasies are alien by nature and habit; but who, nevertheless, in spite of the promptings of an inborn reserve, have been moved to declamations of enthusiasm on its behalf, as they looked out upon these huge forest areas of Japan, with Cryptomerias towering to majestic heights and attaining a still more mighty circumference, arising from beds of undergrowing Cryptogams, ferns, mosses, and lichens, with their trunks embedded in the deader company of decayed tree-stumps and their everattendant fungi, but still rising superior to all around and revelling in a conquering growth. It is then, on such occasions and beholding such scenes, that all the sight-seers, whether prosaic or poetical of temperament, have offered up spontaneous tribute, and in one clear clarion voice sung out their hymn of praise.

Intuitively, one and all, they seem to have succumbed to some spell of mysterious influence upon entering their precincts, as if it were that some inner conscience arose and said :

A sacred presence overbroods

The earth whereon we meet,

These winding forest paths are trod

By more than mortal feet.

\section{WHITIIER}

And when we read of these scenes, and of all they bring and of all they leave, how many a once youthful traveller, we picture to ourself, must repent that in those unfledged days, - which in so many cases are the only days of life that can be dedicated to distant 
travel,-he had not better equipped himself with some smattering of knowledge, at least, of tree lore and plant life. Then something more tangible might have remained for ever and ever by him, something deeper, something more lasting, than a mere recalling from those early days' wanderings of the collective features of certain sceneries and a few impressionist memories of country-sides passed through. Eheu! fugaces labuntur anni. Alas! the days that are gone, and the years that have flown by.

Cryptomeria Japonica, var. Elegans.-As the Cupressus Pisifera has its juvenile form of variety called Squarrosa, so has the Cryptomeria also its jugend form-that is to say, its primordial, or first leaves, do not change to adult form. The difference between these two is, in reality, so manifest that it would not be worth mention were it not for the fact that on some occasions I have noticed that the casual observer, who knows one by name, is rather prone to apply this to the other. The briefest comparison between the two side by side dispels any doubt on the subject for ever and aye. While the branchlets of the C. Squarrosa are composed of frondose sprays, from the little branchlets of the C. Elegans the primordial leaves spread outwards at right angles on all sides. While on the subject of leaves it may be noticed that the leaves of the C. Elegans are rather reflexed than incurved, and so of reverse shape to those of the Cryptomeria Japonica.

No one can find fault with the high-sounding name Elegans, except on those not infrequent occasions on which its various stems break away from the perpendicular, and produce a sprawling, and, at variance with its description, inelegant effect.

The tree, however, stands pruning well, and a little judicious lopping will often relieve the situation. 
Sciadopitys Verticillata (Japanese Umbrella TREE).-

To garnish the story with here a streak Of Latin, and there another of Greek.

WHITIIER.

It would be hard to describe the sensations of any one who had undergone a long practical acquaintance with the well-known trees of our homely woodlands at a first sight of this extraordinary-looking tree. After a stare of wild surprise he might begin to wonder which of the two, man or tree, had been transported to another planet.

On being told its name, and asked either to pronounce, spell, or construe it,-if his education had not run on classical lines and in Latin or Greek grooves,--I can well imagine that his eyes would open still wider. Like Tennyson's ocean-shell, he might so regard it as yet another miracle of design to which learned men had given a clumsy name. What would be more interesting to hear is the opinion he would hazard as to its affinity, and among what tribe of trees he would place it. Probably the majority of votes-I am not referring to the closer student, but to the man in a hurry, who has either boldly to jump to a conclusion, pronounce it, or remain mutewould be cast in favour of the Pine, some sort of Pine -he might have ventured opinion-with thicker and coarser leaves.

If it is looked at a little more closely there will be found a light-brown stem, growing darker as it gets older. At intervals along it, from $\mathrm{I}$ to $\mathrm{I} \frac{1}{2}$ inches, the branchlet appears to swell out into a sort of flowervase shape, and ends in a crown-like summit. From the tips of these summits grow in whorls the fraudulent make-believe leaves-for things are not always what they seem-and these growths, although they look like leaves and perform the functions of leaves, are 
not the real leaves of the plant, but are a sort of herbaceous branchlet, of a " neither fish, nor flesh, nor good red herring " nature, neither true leaf nor branchlet, but a mixture of both called Cladodes or Phylloids by botanists. The real article, the true leaves-or, may we say, the apologies for leaves?are minute-looking brown scales, growing appressed and decurrent to the stem, in the same way as they grow on the Cypress, and ending in an obtuse point. Altogether the whole story points to a great comedown in the glorious career of leaves in general. Their familiar green glories, their whole being, their very purity of descent, in the case of this tree, seem to have been merged in what appears to most as lifeless likenesses of their former selves, which botanists, as we have said, mysteriously call Cladodes, or Phylloids, and which, loosely interpreted from dead language origin, seems to imply a branchlet or leaf, with a screw loose somewhere in its composition.

In its family history this tree seems as forlorn of near relations as any waif or stray in a foundling hospital ; but, as sometimes even the most desolate of derelicts may light upon a haven, so has our friend the Sciadopitys found his city of refuge. It has formally been received into the rather menagerie, come-one-come-all household of the Taxodineæ, and been adopted by them as one of their number.

Once in the day of its early introduction to western civilization, we read that it carried on and made overtures of alliance with the members of the Yew family, but that from that prim household it was promptly ejected. Perhaps some day it may be as summarily dismissed from its present asylum, as was the Gingko from the Salisburineæ, and given a family name of its own. To the more uninitiated, it certainly seems deserving of a place in an isolation hospital.

If any plant in the world was entitled to claim 
mono-typical distinction and to enter into a kingdom of its own, we should have thought that in this most curious of trees, that answered to the most prolonged and curious of names, we should have found a winning candidate.

The meaning of its name, after usual processes of investigation and translation and various other prosodian researches, reads "Whorled Umbrella Pine."

This etymological result is arrived at and explained by the indisputable fact that in the Greek language

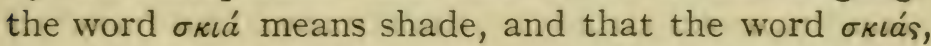
in a sort of natural sequence, implies anything that is used for the purpose of shading. The Latin word representing $\sigma \kappa i a$ is umbra, hence umbrella; which, if we are indulging in dreams of derivations, was an article of modern use evolved from this Latin word umbra. Personally, I must say that I never understood, in my educational days, that the Greeks in the days of Athenian culture or in any GræcoRoman times, used umbrellas, but in a modern-day sense the word " umbrella" can be regarded as a fair, if somewhat a loose, translation of the Greek word бкıás.

It must be further impressed that this tree was not designated as an Umbrella Pine for the same reason that the Pinus Pinea, Stone or Umbrella Pine-the tree immortalized by Turner, Claude, and other landscape painters of Italian scenery-was so called. It was not on account of the fact that at a landscape distance it assumes the sheltering shape of a modern Mother Gamp, but for the far less sublime reason that its green should-be leaves (more correctly called Phylloids or Cladodes), resemble the shape of the ribs or spikes of the modern umbrella; that part of the anatomy of the article in question which schoolboys were wont-in the memory and practical experi- 
ence of many, I feel no doubt - to put to the unholy use of what was called "spiking." That, being interpreted as a youthful practice, was the bringing down of your anti-aircraft weapon-originally designed for defence and not offence-upon that of your adversary, and the consequent impaling of the silken covering of some victimized, parent-paid, latest acquisition in the shape of schoolboy outfit.

In the natural position of their growth, it may be argued that the leaves rather resemble the state of an umbrella-covering blown inside out by wind-blast; but, if turned more or less upside down, they answer to the description given them. Again, it may be put forward by the hyper-critical that, whereas the ribresembling Cladodes on the tree number from ten to thirty, the number of spikes on the most spacious of family ginghams has never been known to exceed the number of seven or eight.

But these are but petty criticisms, unworthy of the theme, or of a name which explains itself clearly to the most unreceptive-minded of students. When we add that the second part of its lengthy first name is derived from títus (Pine), and its second name, Verticillata, means whorled, our story of the origin of the name is completed, and in its accomplishment we take the pride to ourselves of having mastered the fact that both the herbaceous foliation of this abnormal tree, and the steel ribs of the common umbrella, are produced in whorls.

In the midst of this above-described complicated arrangement of should-be leaves, reclines, or should recline, gracefully in a position fit for a princess in a fairy-tale illustration, the cone. It is a stumpylooking, and-unlike the ideal princess in the picturenearly as-broad-as-it-is-long sort of specimen, of very similar appearance to the Cembra Cone.

The tree has the character of being a slow grower 
and requiring a continuous moisture at the roots. Experience here endorses that, and a tree grown under these conditions in nine years has grown from a height of $3 \mathrm{ft}$. to a height of $12 \mathrm{ft}$., and at an altitude of $800 \mathrm{ft}$. But this, from all we can learn, is a growth of rather remarkable exception.

The Sciadopitys is one of those exceptional trees that seems to brighten up and improve all round after a sentence of transportation. Like a prophet that has no honour in his own country, it seems to be treated in its native land as a negligible quantity, while in our lands it is fêted as a distinguished stranger of uncommon habits and agreeable appearance. Wherever it arrives it is tended with care and pampered unsparingly. As in the story of the well-fed house-dog in Esop's Fables, the same animal, when let loose to fend for himself, presented a very different side of character, both in disposition and appearance. In Japan, from the evidences of those who have undertaken special expeditions to make its nearer acquaintance, it presents the appearance of an elongated maypole skimpily clad and scantily capped. Here, on the other hand-say, after at most only a sojourn of fifty years with us, where it has received the minute attentions of a lapdog solicitude,it exhibits a condition of a well-nourished, branchedfrom-top-to-toe apparition.

How much the dunce that's sent to roam Excels the dunce that stays at home,

might a native of Hondo make remark and paraphrase upon if he chanced on one of our cherished specimens in an English garden! We can only add that, if the Japs do not rate them highly, we do, and from a lawn-scape or arboretum point of view they are much appreciated by many of us. 


\section{ARAUCARIAS}

(OF THE NATURAL ORDER CONIFERÆ, OF THE FAMILY PINACE\&, OF THE TRIBE ARAUCARINEE)

The prudent will observe what passions reign In various plants.

Ovid.

In such strains as these have the poetical world written, from the days of Ovid and onward, upon the sensibilities of plant life. Had some stray versifiers turned their minstrel attention towards the subject of the sensibilities of human feelings, and how these feelings upon occasions have been displayed towards certain representatives of the tree world, what a telling text might they not have found to discourse upon from the unamiabilities of the Araucaria Imbricata, or Puzzle Monkey, and what rules for guidance might they not have laid down, not only for the prudent, but for even the thick-skinned and venturesome to observe.

Our remarks upon this particular tribe of treesas far as they more immediately concern our little sea-girt island-are practically reduced to a monologue upon that old-established and familiar friend, which men, women, and children, ofttimes from tangible testimonies derived from various methods of experiment, have acquired the habit of addressing as the Puzzle Monkey, but which, when given due titular rank, should assume and have conferred upon it the more dignified name of Araucaria Imbricata.

There are other, Australasian, Araucarias, and very striking-looking trees they are too, in their queer way, but they do not flourish under the more chilly conditions of our out-of-door situations. 
There is one called the A. Bidwellii, or in its more homely circles the Bunya Bunya, a name which we owe to the euphonious sources of an Australian aboriginal, or black fellow, lingo. It is a tree that sports enormous cones, carries lengthy leaves, and bears in some respects a resemblance to certain long-leaved Yew varieties. There is another called the A. Cunninghamii, of more particularly littoral and tropical Queensland fame, which bears leaves of Cryptomeria resemblance.

Another variety called the Norfolk Island Pine (A. Excelsa), which is fast becoming quite a common corner-window side-show in many English homes, is a plant that ever wears a wistful look, and seems to plead for indoor life in winter-time.

Then there is its variety-A. Goldieana from New Caledonia, A. Rulei, A. Cookii, A. Balansæ, all from the same equatorial and tropical quarters. The Agathis Australis, the Kauri Pine of New Zealand, and presumably the Cunninghamia from China, belong to the same group, and there is yet another Araucaria-one from South Brazil (A. Brasiliana)which about completes the list, so far, of these weird curios of tree life, spectacular demonstration of which we are denied in English outdoor gardens, and in consequence opportunity of making observation upon or exhibiting intelligent attitude towards them.

There is a humiliating chapter in the life-history of the Puzzle Monkey, but one which honesty compels us to unfold, and in it there is written, in letters clear and curt, that as a tree with us, by almost general consensus of opinion, it has signally failed to acquire merit, either in the eyes of the landscape gardening fraternity or the silvicultural enthusiast. But even if that be admitted, it cannot be denied that the tree is possessed of certain originalities of character that should render it an interesting study, even to I6 
those who cannot persuade themselves to look upon it as a "thing of beauty and a joy for ever."

We will specify a few of these little idiosyncrasies, some of which it lays claim to the sole proprietorship of :-

(I) It is, as all authorities have maintained, the only indigenous tree, south of the Equator in the New World, that has grown to timber-producing size in the stranger temperatures of more northern lands.

(2) It has not only physical features that have earned it the reputation of offering a deterrent obstacle to the climbing ambitions of the monkey tribe, but alsa presents to view a bark that Miss North described as of a " neat honey-comb-like pattern, which reminded her of a child's puzzle." A tree that can provide puzzles which alike check monkeys and baffle children must assuredly be possessed of qualities that are both subtle and original, and entitle it to consideration from us, if not esteem.

(3) It ranks with the Gingkos, Cryptomerias, and a few select others, as among the oldest of trees found in geological strata. It has been discovered in the Eocene formations of England and France, so that at one time it must have presented a more frequent and wide-spread appearance upon the face of the earth than we have found it to do in our day. It has also been found to be an habitué of realms more ancient still, and as deep down in those geological evidences of the world's history known as the Jurassic Strata of the Secondary Era, that dateless date when reptiles swarmed and swam, and reigned supreme. Can any man, beast, or 
plant, beset with determined desire to prove an ancient lineage, dare venture farther into the claims of long descent?

The tree has still further accomplishments than those we have mentioned. The plentiful white resin of its natural propensities has a healing, and the nuts of its cones an appetising effect, especially prized by the Arauco Indians of South America, from whom comes its name. As a cultured viand on the Epicurean tables of our fashionable resorts, so far as we know, it has made no habitual appearance, despite the fact, if it is so as we read of it, that the fruit of a big tree of this kind has been said to have fed ravenous families of Chilian children by the score for periods indefinite, or, we may add, for periods possibly unauthenticated.

It is a generally accepted home truth that nearly all the turpentine and resin consumed is obtained from Pines. If it were possible to enter Araucarias in such a competition, the Pines might lose their old monopoly, for the Puzzle Monkey literally reeks of them, fore and aft, and from every pore.

Those versed in saw-bench experiences have always regarded the cutting up and the quartering of it with an undisguised and holy terror, that neither time nor further acquaintance have ever diminished. It is these ever-flowing resinous properties that have so consistently defied the blades of their knives, blunted their edges, and brought it a well-earned unpopularity on such scenes of practical workmanship.

A fairly large tree $(35 \mathrm{ft}$. high and $5 \mathrm{ft}$. 6 in. in girth), cut down here, quite corroborates these traditions. For two years after its generally admitted decease it seemed obstinately bent on refusal to accept the inevitable. The log, as it lay in the lumber-yard for two years, kept on sprouting its green leaves with optimistic persistency. Even the 
very bark at the butt looked like healing over and starting afresh upon a new lease of life, and, be it truthfully admitted, to the consternation of all who had planned the downfall, and brought about its extinction from a scene that it failed, in their ideas of true beauty, to harmonize with. The complexity of emotions that surged round that poor old prostrate Chilian trunk recalls the story of the moribund patient carried into hospital. When the faculty made pronouncement of his death he began to show signs of revival, whereupon his wife peremptorily bade him lie still, since the doctors, she said, must know best what was the matter with him.

It has been my lot to see some well-sized butt-length boards, shown at Forestry Exhibitions of the Royal Agricultural and Shropshire and West Midland Shows. The consensus of opinion among the timber-dealing fraternity and the cognoscenti of wood-structure value, was decidedly in the wood's favour. It exceeded their expectations, but, as timber is not readily disposed of to timber merchants unless it be in quantities, further experience of it upon those rare occasions when it finds its way into a timber-yard, must be confined for the present to estate work by private owners.

We need not waste any words upon the subject of its identification. It was told to St. Paul, in a forcible way, that it is hard to kick against the pricks. Any experiments upon these lines would establish the fact and truth of its prickly nature, and the undesirability of attempts to entrust any parts of your person to contact or competition with its foliage. There is no use blinking the fact that our now old homespun friend, the Puzzle Monkey, is beginning to attain an unenviable fame of unpopularity with us.

We are not holding in any way a brief on its behalf, but there are one or two little scraps and tittles of evidence in the direction of extenuating circum- 
stances that in common fairness ought not to be forgotten or omitted from the indictment. First and foremost of these is, that it is generally, more often than anywhere else, to be found planted in the indecorous position of a 20-ft.-square grass plot, in front of an inartistically built suburban villa, with one prickly-clothed branch protruding into the parlour window and another into the panes of glass of what should be the best-lighted bedroom of the ill-treated dwelling-house. Under these circumstances what wonder if it, as an ornamental product of the earth, presents a sad dissembling of an appropriate appearance! Monkeys copy their masters, we have often heard tell, but the poor old Puzzle Monkeys have no other option than to follow the fashions of those who plant them, and "Fashion," as Victor Hugo once said, "has committed more crimes than revolutions." For this error of planters-an error greatly in excess of any demerit on the part of the tree in the abstract-we have no palliation to offer. Were the poor tree itself given a chance, were its supersaturated system for a short time endowed with the power of speech, might it not say, and say with some truth, "You have placed me in positions unfitted, and in whereabouts that are totally out of place with any keeping of my traditions, and then you have turned round and called me ugly! Had you instead planted me in groups in your woodlands, where my stems would have been laid bare by self-pruning processes, as was my state when first you found me in Chili, and were my topmost heights given chance to soar into the blue, far and high and against the skies of heaven, as is permitted to your native product, the Pine of Scotland, for instancethen might I, even had I not commanded your admiration, at least have escaped the wither of your contempt." 


\section{CUNNINGHAMIA SINENSIS OR LANCEOLATA}

\section{(OF THE TRIBE ARAUCARINEÆ)}

The flora of the mystic mine world Around me lifts on crystal stems The petals of its clustered gems.

WHITTIER.

The Cunninghamia by its appearance-and these appearances, upon a further investigation among the written-up pages of its past, do not belie the impression-seems to betray evidences that it has been unearthed from some "mystic mine world," and forthwith bidden again from there to take up its place again upon a more modern earth.

It is one of those trees that lends an idea that at one time it had been a tenant of prehistoric swamps, and a near neighbour of snakes, mosquitoes, and swimming fowls; or that it dated back from those qualis ab incepto times that we are told of, when all the world, physical and animal, was either young, very young, or unarrived. As it has been credibly ascertained and scientifically reported that it represents one of the oldest types of vegetation existent, all such impressions are satisfactorily endorsed, and therefore need not be apologized for.

In taking up a rightful place among the genera of a modern botanical world, it has had its vicissitudes. Those who pull the ropes make the bells ring, and those who rule in the botanical world call the tune. Finally, it may be said to have been consigned by them to the care of the Araucarineæ, but not before it had been tossed to and fro like a nobody's child, among tree tribes descript and tree tribes nondescript. We ought, in fairness to its career, whether it aggrandizes it or not in the eyes of the world, to add 
that in its day it has been regarded with suspicion as a missing link between the Puzzle Monkey and Taxodineæ families.

To those who wish to logically locate the precise niche in the temple of tree totemism that it has been called to occupy, we will add, for the purposes of illumination, that it is described in the Kew lists as of the tribe Araucarineæ, of the family Pinaceæ, and of the order of the Coniferæ.

We must add a warning note, that not only is this particular household represented by a Cunninghamia Sinensis, but within its limited portals we read of another occupant named after the Cunningham clan, with a title near enough in sound of name to create bewilderment and discourage farther quest among those outside the esoteric circle of Doctrinaire Dendrologists.

Besides the C. Sinensis of S. China, there is also in this same group an Araucaria Cunninghamii, the so-called Moreton Bay Pine from Australia, and they are two very distinct trees in spite of the family connection and similarity of name origin. The latter was named after the early Australian explorer, Allan Cunningham, while the Chinese subject of our discourse was named more especially after one James Cunningham, the discoverer of the tree ; or possibly, as Loudon says, in honour of these two illustrious surnamesakes, so happily blest with the distinguishing prenomens of Allan and James.

It was the composition of the cone, we read, that finally tipped the beam in placing the C. Sinensis among the Araucarinæ. What concerns us most here is what other trees it looks most like, and what it might be likely to be taken for. In general appearance it has little in common with our A. Imbricata. The look of the leaf is said to bear the nearest resemblance to that of the Brazilian Araucaria. But 
for those who dwell among their own people and in places remote from the temperate house at Kew, there is not much chance afforded of following up these points that they bear in common.

There are some who quite pardonably might imagine that it bore an outward and visible resemblance to certain of the Cephalotaxi family, but the more spiny, slender, grass-like leaves, with their long tapering-to-a-point appearance, of the Cunninghamia dissociate it severely from any Cephalotaxi. There are other and very marked individualities in its foliage. The green leaf of the Cunninghamia is adpressed to the stem, and on the young branchlets retains upon its decurrent length the colour of the leaf. Perhaps the most conclusive clue to its identity lies in the fact that the margins of its leaves are minutely toothed, but not so minutely that it cannot be recognised without glasses.

As a tree with us it is, on the whole, little known. It was introduced more than a century ago, but living trees are estimated not to be much more than sixty years old. It has always had a reputation for feeling too acutely the nipping air of northern latitudes, to the detriment of its health, colour, and complexion. It has always rather affected a "sighing for Dixie" appearance, and borne a character for debility. It is supposed to be rather exacting in its demands for heat and humidity, of which, we may safely say, the latter is a more accessible commodity than the former in our particular zone.

Messrs. Elwes and Henry have recounted observations of quite a fair show of respectably grown trees. One we know of, and one growing well at Coed Coch, N. Wales (the Hon. Mrs. Lawrence Broderick's), have escaped the notice of their chain-harrowing investigations.

What more concerns us at the present day is the 
fact that a great many seeds were brought back by Wilson a few years ago from Western China, and if so be it, they have been collected from hitherto unvisited areas of severer climes, and from places whereon falls a more plentiful sprinkling of snow and cold than heat or rain. We who have risen plants from these sources may perhaps be permitted to indulge in hopes that these young trees, now three or four years old, that promise so far so well, will continue to flourish until they become a green-clad blessing, rather than a brown-coloured curse-as they have often previously proved-upon our particular plot of earth, for the delectation of another generation of island dwellers.

We have brought these trees into our review more with the idea of drawing attention to this recent importation of seed, and also for calling attention to the interesting account Mr. Wilson has given of them and their wood value, from recent experiences.

Trees, no less than men, although not wittingly aspirants to fame, are equally liable to find themselves unexpectedly the recipients of peculiar honours.

The peculiar greatness that has been thrust upon this tree by its own people in its own country is that its fragrant wood has provided the costliest of coffins for mandarins, and for other of the Celestials who are either mighty, great, or wealthy in the lands of the Flowery Kingdom.

Whether measured at a maximum (as does $\mathrm{E}$. Wilson) of I,500 ounces of silver per plank, or as Elwes and Henry have estimated and reduced it, to an English standard of sixty golden sovereigns, there is no gainsaying the fact that such a price demanded for coffin boards is a staggering consideration for any economic householder, however earnestly he may be desirous of paying lavish respect to a defunct relation. 
We venture to think that it exceeds the price paid by any multi-millionaire of modern days for a similar article in Western lands. Here in Great Britain, some two pounds' (or less) worth of best British-grown, silver-grained, seasoned oak, or half that price paid for an equivalent in brown boards of impervious elm, amply, and often more than amply, satisfies the most fastidious tastes of the highest born in the land, or the ultra-extravagant desires of the superwealthy.

What sums were paid, at a long day ago, for the richly chased and stoned sarcophagus, or how they compared with the price of an artistically lacquered coffin made from a C. Lanceolata, or Sha Shu as the Chinese call it, which had perhaps lain for centuries buried below the earth, we do not know.

The custom clearly demonstrates that there are still extant nations of men and women who, like the Egyptians of old and other ancient races, are wishful to sacrifice more wealth upon their sepulchres than their living abodes; who are perfectly resigned, in their life upon earth, to put up with a hovel, if they feel assured that a palace of art will adorn their long, last resting-place.

There does not seem to be any recognized difference as between what has been called the C. Sinensis and the C. Sinensis var. Lanceolata. 


\section{VII}

\section{TAXACEF}

(OF the NATURAL ORder CONIFERE, of THE FAMILY TAXACE $E$, OF THE TRIBES (I) SALISBURINE更, AND (2) TAXINEÆ)

For never knew that swarthy grove

The verdant hue that fairies love.

SIR W. SCOTT.

To dissociate at a glance all these long-leaved sable kinsmen of our well-known Yew may, owing to the rarity of their presence and the still greater rarity of the presence of any fruit upon them, be regarded as a task of no mean difficulty, but it is a task that pales into insignificance before an attempt to master all the Taxad terms in use-Taxaceæ, Taxineæ, Taxeæ, Taxodinæ, Taxodium. When confronted with them you experience a maddening desire, once and for all, to disengage yourself from the influence of words and the bondage of botany. When all their precise applications and significances have been conquered, and committed to the tablets of an unforgetting memory, a feat more worthy of a Senior Wrangler than a tree-student rambler has been achieved.

All these unpromoted rank and file of the Yew family - to wit, the Cephalotaxi, Torreyas, Podocarps, Prumnopitys, Saxegothea-have their distinguishing leaf, as well as their still more distinguishing fruit differences. Where the difficulty comes in, 
is how, when, and where are ordinary mortals to obtain a sight of them together, and acquire experience of them from direct object-lessons.

In the disposition and measurement of their leaves, irrespective of the marked fruit distinctions, they show other differences. Some are long-, some are shortleaved. Some leaves are pectinate, others not, and they stand out from the central axis of their stems from all sorts of situations, scattered, alternate, or opposite.

We will adduce instances, and when we refer to long- or short-leaved we will take the standard as being either longer or shorter than the Common Yew, which we will approximate as, under usual conditions, at $\frac{3}{4}$ in.

(I) Those that are long-leaved and pectinately arranged on their lateral branches. The Cephalotaxi and Torreyas.

(2) Those that are long-leaved and not arranged pectinately, but standing out at different angles as above explained. Podocarpus Chilensis, P Macrophylla, and P. Nubigena.

(3) Those that are short-leaved and not pectinately, but as above explained arranged. Podocarpus Alpinus and Totara, while the Prumnopitys and Saxegothea are, in leaf disposition, spirally arranged and densely crowded.

The presence of their fruits - if we could only issue a mandamus for their appearance-would soon banish doubts and dispel difficulties. Between the rather elongated, pear-shaped fruit-or when in dried fruit condition fashioned more after the form of an almond within its pitted shell-of the Cephalotaxi, and the rounder structure of the purple plum fruit of the Prumnopitys, there is nothing in common, While the bulbous, apoplectic-looking stalk that 


\section{CEPHALOTAXUS AND PODOCARPUS}

props up the fruit of the Podocarps asserts an unmistakable independence of form and figure.

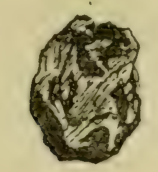

PRUMNOPITYS

ElEgaNS

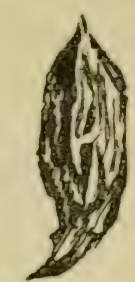

Cephalotaxus

FORTUNEI

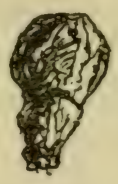

Podocarpus

Speaking of this Yew fraternity from the point of view of ornamental attraction, we might sum them up and say of them, that without magnitude to inspire us here, without flowers to render them visions of a perfected beauty, without the perfume of Araby to ingratiate them with others, they are interesting for all that, and fulfil a destiny in many a garden ground which tends towards the enrichment of its scenery.

\section{CEPHALOTAXUS}

(OF the tribe SALISBURINEÆ) AND PODOCARPUS (OF THE TRIBE PODOCARPEÆ)

But here 'twixt rock and river grew

A distant grove of sable Yew.

Sir Walter Scott.

We do not wish to convey the impression that Sir W. Scott had in mind any planning out of suitable situations for new plant-life importations when he wrote these lines. Yet there exists no earthly reason why the Cephalotaxus and Podocarpus should not occupy such Scylla and Charybdis positions as the poet suggests, and present an appearance as described in the above-quoted couplet. It reads as if it might describe a spot especially chosen or created for the 
disposition of these foreign cousins of our Yew. In all probability Sir W. Scott was sublimely unconscious of the very existence of either of them. He died in the thirties of the last century, while the Cephalotaxus and Podocarpus made their début amongst us at a later date, in the forties or fifties of the same epoch. Our British-grown Podocarps go unmentioned on the pages of Loudon, and are severely left alone in the seven volumes of the Trees of Great Britain; presumably for the all-sufficient reason that so far they have failed here to attain to the dignity, or rise to the height, of the status of recognised and fullblown treehood.

With a light-hearted disregard for botanical etiquette we have coupled together, for the purpose of a discussion upon them, those (the Cephalotaxus and Podocarpeæ) whom Kew's genealogical table has put further asunder. In that list they are enumerated as intertribally, if not directly tribally, connected.

To allocate them in stricter regard to their place in the genealogical tree and propinquity of relationship, as fellow sub-tribesmen, the Cephalotaxus should range alongside the Torreyas as fellow Salisburineans, and the Podocarps come next to the Yew as fellow Taxineans.

The long-spun-out Greek names that they bear have been ominously avoided by the majority of authors who traverse the many highways and bypaths of composition. They are words, evidently, that, qua words, neither invite writers nor entice poets. There is often a Dorian harshness about the sound of Greek nouns manufactured into English expressions of language, that flings defiance at the varied capacities and concentrated talents of all the efforts of the combined nine Muses thrown into one.

The name Cephalotaxus is derived from the Greek words $\kappa \epsilon \phi a \lambda \eta^{\prime}$ (head)-in allusion to the form of the 


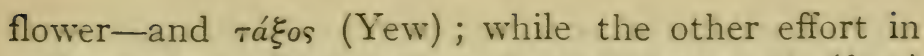
nomenclature, Podocarpus, is traced to modós (foot)

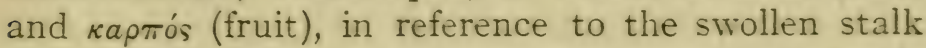
or peduncle of the fruits; an example of wordpainting that we must remark, en passant, must be to some painfully reminiscent of that human frailty we commonly call gout.

Their appearance too, comely as we think it in approved places, hardly incites pictorial notice. There is no record, poetical or even prosaic, as far as we know, of Youth sporting with Amaryllis in their subtle shade, or Dryad dancing beneath their canopy. Maori maidens may, for all we know, have played such pranks under their spacious boughs, for the Podocarpus Totara, in its native soil, is second only in repute to the giant Kauri Pine (Agathis Australis) of New Zealand fame; and the New Zealander, on a visit to the Mother Country, in spite of the rather abject appearance it presents here, if perchance a sight of it meets his eye, hails it as an old friend and pays meet adoration to it as a household god.

We will now treat of the family differences of the Cephalotaxi, inter se. The C. Drupacea is easily distinguished from the C. Pedunculata and the C. Fortunei by its shorter leaves, with their fewer stomata and other differences referred to in the table, p. 298.

When we attempt to explore the shifting grounds of the family differences of the C. Pedunculata and the C. Fortunei we near trouble. Parents, and those very intimate with them, can, it is said, often when others farther afield signally fail, recognize human twins of closest resemblance. Whether it may be accounted a confession of weakness or not, the differences between these two species of trees must have caused many novices as much bewilderment in dissociation as ever pair of heavenly twins caused any one inside a nursery, or outside a family circle. 
It is possible that constant opportunity might lessen the difficulties. They still remain to many like the twin brothers Castor and Pollox

So like they were, no mortal

Might one from other know.

Personally I have ignominiously failed to learn, or discern, a short cut to a safe landing-stage on this question. My conclusions result in the subjoined reductio ad absurdum :

C. Fortunei. Branches more slender and less divided Scaly stalks of flowers than C.

, , shorter Pedunculata.

, , Leaves with finer points

After this failure I can only, and in all ill-nature, wish, if any one is asked which is which or why is which, joy and satisfaction in answer.

As the C. Pedunculata may be a cross between the C. Fortunei and the C. Drupacea, it is perhaps no cause for wonder that likenesses ensue, but the C. Fortunei seems to have been very much the prepotent factor of the arrangement. While authorities say that the number of stomata on the lower surface range from eighteen to twenty-one, the number of lines on a leaf before me are clearly twenty-four.

We ought not to leave the subject before calling identifiers' attention to a fastigiate form of this tree, and one not at all uncommonly seen. Its leaves spread from all sides of the stem upon its vertical branches, and it has no lateral branches with leaves arrayed in pectinate form. As the Yew one day produced a sort of unexplained fastigiate freak in the so-called Irish Yew, so has its long-leaved affinity, 
the Cephalotaxus, followed example and provided a mystery birth, in the shape of a similarly constituted sport, which goes by the full name of Cephalotaxus Pedunculata var. Fastigiata.

\section{PODOCARPS}

I want to get back, I want to get back,

To the place where I was born.

\section{a Soldier's Song, Michigan.}

These homesick lines seem a refrain suited to the presence of Podocarps in England, and the distant homes they pine for are variously situate, in Australia, Asia, and S. America. Their leaves in the abstract may bear a resemblance to the Cephalotaxi, but the disposition of them does not. While those of the Cephalotaxi are pectinately arranged (except the fastigiate form) on the lateral branches, those of the Podocarpi arise at various angles from the stems and are variable in their shape and attachment. While the Cephalotaxi present to our view the neat, combed effect of a well-dressed and parted head of hair, the Podocarpi, to pursue the metaphor, might pardonably be said to follow after the fashion of that state of lock disarray, so often noticeable in the head-gear affected by professors of music and poetry.

In St. Matthew's Gospel we read the words that "a tree is known by its fruit." It is the fruit of the Podocarps, or rather the stalk of the fruit, that has distinguished them from other trees in the estimation of savants, and that is responsible for their holding an isolated position in the tribal table of the tree-world.

As has been remarked, they are not the sort of trees or bushes constantly met with, but if they were chanced on, the differences in their length of leaf is 
alone a fairly conspicuous guide to differentiation. The P. Chilina appears to be the one more habitually grown with us than the others. While the length of its leaf is 2 in. to $2 \frac{3}{4}$ in., the length of the Nubigena, which grows in a few favoured places, is only from I to 2 in. in length, and the Macrophylla with his more sickle-shaped leaves, as by his name he ought, outtops the two by an average measurement of something between 3 and 4 in.

The P. Totara and Alpinus are both comparatively short-leaved. Not only does the P. Chilina differ in length from the P. Macrophylla, but in the presence of stomata-stomata inconspicuous it may be, but stomata for all that, and of which the P. Macrophylla is destitute.

The P. Chilina (sometimes wrongly called P. Andina, an obsolete synonym for the Prumnopitys) has leaves, the under-side of which are of a yellowish colour. The stomata are hardly visible to the naked eye, but under microscopic persuasion become as clear as sun at noonday. To amateur apprehension this undersurface seems to consist of a yellowish midrib, with two rather greener marginal bands, and between them some sixteen to twenty rows of minute-looking stomatic bands set out in wide rows. A specimen before me also presents without microscopic aid one half-baked-looking attempt at a growth of its most curious-looking fruit. The impression left with me is that of a long stalk growing out from the stem and terminating in a green fruit, of a dolichocephalous (longer than broad) shape, and to complete the picture, propped up with an arrangement that suggests a high collar on an unnaturally large-sized neck. This is that swollen peduncle or stalk so much vaunted, and what botanists term the fleshy receptacle.

The P. Nubigena has a few south-westerly haunts 
where it has contrived to keep the even tenor of its way, and one such city of refuge has a specimen found at Llanarth (Mr. P. D. Williams), near the Lizard in Cornwall. The leaf is half the size of that of the P. Chilina, and shows without microscopic aid two very distinct stomatic bands between two green margins and central bands, each nearly as wide as the stomata row.

The P. Neriifolius is mentioned in our Table, a tree sometimes called P. Macrophylla var. Acutissima. It is described in Plantce Wilsoniance (Sargent) " as a handsome tree growing in the warmer part of Szechuan, and more especially on Mt. Omei." If the latter situation may read promising, the sentence preceding seems to hold out no hope for it here on earth with us.

The P. Alpinus is only a four-foot bush with us, but highly recommended as hardy in Veitch's book of Conifers. Whether it is a more mountainous relation of the $P$. Totara-it was once called the P. Totara Alpina-or not, it comes from the same quarter of the globe.

The P. Totara we have previously alluded to. As a tree it has yet its spurs to win with us.

In New Zealand it is a tree ornamented with dark-green leaves, and much in request for timber purposes. Here its leaves, so far, in early stages present a dingy yellow colour. In a four or five years' experience of it here (Stanage Park, Radnorshire), at an elevation of $750 \mathrm{ft}$. above the level of the sea, it wears the aspect of a plant, with a depressing lack of healthful joy about its appearance, engaged in an uphill struggle for existence which so far it has maintained.

We must confess from this, our own, experience of an attempt to extend to it a welcome, that it does not look so well pleased a guest in our midst as we 
could wish. Nor does it seem inclined to show that natural attachment which we should like to see a distinguished New Zealander display towards the mother country. So far as the lately arrived batch has progressed among us, we might, ill-naturedly possibly, but not without some show of reason, describe it in its present condition as without a look to bless itself with.

\section{TORREYAS}

(OF THE TRIBE SALISBURINEÆ, OF THE FAMILY TAXACE $Æ$, OF THE ORDER CONIFER $Æ$ )

All green was vanished save of Pine and Yew, That still displayed their melancholy hue.

Crabbe.

The Torreyas are another set of the long-leaved relations of the Yew. Their nearest tribal relations are the Cephalotaxi.

As the Equidæ family comprise among their ranks many members-to wit, the horse, the zebra, and the ass-combining glaring differences and certain resemblances, so there are to be found in the family circle of the Taxaceæ all sorts and conditions of singularities. As the ass, in spite of his longer ears and other discrepancies, still retains a close relationship to the horse, so do the Torreyas and Cephalotaxi, in spite of their longer leaves and other differences, still remain members of the family of Yews.

As the ass has become a term of derision among men, so have the Torreyas generally incurred uncomplimentary distinction among botanists. They have been dubbed with such actionable prefixes ąs Fetid and Stinking, both adjectives spelt in large 
capital letters, to render the title, we can only assume, more assured and enduring.

There is so little opportunity offered to most of us to form our own impartial judgment upon the prowess of our olfactory capabilities, that it would be perhaps presumptuous to ventilate, even faintly, such an unpractised opinion upon so delicate a subject. But in the case of the T. Californica, from the not very exhaustive experience of only a few tries, I should feel inclined to vote in favour of mitigating the unsavoury impeachment. The charge of malodour preferred against the $T$. Grandis, in spite of the fact that the unfragrant adjectives have been applied all round to the Torreyan tribe, has been dismissed by some authorities. The Nucifera and Taxifolia may, for all I know, fully deserve the reputation. As neither the T. Grandis nor the $T$. Taxifolia, between which some confusion seems to exist, appear to be English grown-our winters have proved too much for them-we need hardly follow the question of their exhalations to a bitter end.

As trees they are very rarely to be met with in our country, and the T. Californica is the only species of them that attains tree-form dimensions. A few only are mentioned in the Trees of Great Britain, and there is another unmentioned there that grows at Scorrier (John Williams), Cornwall, a sizable tree, and one that it is believed was brought and planted there by W. Lobb in the fifties of the last century.

On the subject of size we should add that E. Wilson, in his I9I4 expedition to Japan, came across a $T$. Nucifera at Kamo, in the Satsuma Province, $93 \mathrm{ft}$. high, I $8 \mathrm{ft}$. in girth.

On the question of identifying them, we have first to set to work on the task of discriminating between them and the Cephalotaxi. We will enumerate a few of the differences. 
(I) The Torreyas have two very distinct grooves on the under-side of the leaf. The Cephalotaxi have not.

(2) The Torreyas have two depressed narrow lines of stomata upon the lower surface of the leaves, that do not occupy much more space than the impression of a pointed pencil across a piece of paper. The Cephalotaxi have two broad lines of stomata.

(3) The bud scales of the Torreyas stick out in pairs at right angles, and bud scale marks are noticeable at the base of leaves. The buds of the Cephalotaxi are composed of overlapping scales (imbricated), and there are no bud scars visible on the branchlets.

(4) The colour of leaf of the Torreyas is a dark, lustrous, shining green, and gives the impression of having been glazed or varnished. The tip of the leaf of a Torreya is long and spiny, while the tip of the Cephalotaxus has a shorter pointed apex.

(5) Another marked difference is the way in which the long bayonet-shaped leaves of the Torreyas point forward towards the end of the branchlet.

We have, then, called in to the assistance of identification five points in particular: (I) the grooves, (2) the thin rows of stomata, (3) the buds and bud scars, (4) the glossy colour of leaves, and (5) their forward pointing direction; and to these we might have added the colour of the branchlets, which on new shoots are a bright green and on last year's shoots a rich red.

We have compared them side byside with the Cephalotaxi, but the Abies Bracteata and the Keteleerias have both been dragged into the maelstrom of similarities. 
But both of them have leaves situated on stems after the manner of the Silver Firs, and which when pulled off leave a circular disc mark, whereas the Cephalotaxi and Torreyas have leaves like the Yew; that is to say, mounted on raised continuations of leaf stalks, running lengthways alongside of the stem, as if they were part and parcel of it. On the top of this a small twisted leaf stalk or jointed base connects them with the outstanding leaf. Thus the Taxacean leaves occupy a very different position in their mode of attachment to stem from that occupied by a leaf on a Silver Fir, which we have fully descanted on in its appointed place, as also upon the impression left after pulling off the leaf. They also occupy a different position from that of a Spruce leaf, which is mounted on a hard, woody peg-like projection, as has been explained under the description of Spruces.

The scar left after pulling off a Taxacean leaf, be it Yew, Cephalotaxis or Torreya, is much more in character with, from a position and shape point of view, that of a leaf wrenched off a Douglas Fir or a jointed-at-base Juniper. If any one cared to take the trouble to pursue a little amateur botanical investigation in this direction-even if Torreyan Yews and Bracteata Silver Firs were not forthcoming to make a trial of-no difficulty could possibly be incurred in obtaining the service of a Silver Fir and Yew leaf-clad twig, wherefrom similar results and similar comparative analogies could be obtained. On them you could compare the differences of attachment of leaf to stem, and thus would be constituted one of those object-lessons from observation that are so much more illuminating to most than the reading of writings; and the Taxacean Yews and Silver Fir trees satisfactorily severed for ever and aye from any chance of confusion of connection in the investigator's mind. 


\section{THE YEW}

(OF THE NATURAL ORDER CONIFER $\Subset$, OF THE

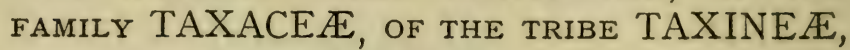
OF THE SUB-TRIBE TAXEÆ)

Like the black and melancholy Yew Tree, Dost think to root thyself in dead men's graves, And yet to prosper?

T. Webster, The White Devil, A.D. I6I2.

"The Vine loves the hills, the Yew tree the north wind and the cold " (Bacchus amat colles, Aquilonem et frigora Taxi), at least that is how Bohn's Classical Library-better known to scholars as the Virgil crib-translates it, but Æolus, of wind-bag fame, seems to have reckoned Aquilo as one of his particularly boisterous products that hailed from the west.

So wrote Virgil I,945 years ago, at a golden age when " song was great," and in the close companionship of the kindred spirits of Horace and Mæcenas. What sage advice you offered us, illustrious poet, in those schoolboy days of our instruction! Had we been taught to grasp your meanings, rather than stutteringly to attempt a construe of your verses, or write out your lines for punishment, what an agricultural instruction might we not have imbibed! You read us lectures therein on the growing of crops, the treatment of soil, the planting and grafting of trees, the breeding of animals, and last and least, the ways of bees. Had we been allowed to investigate the drifts of your reasonings from those forbidden translations, to which-in spite of your rules to the contrary, learned masters of classical lore-we always contrived access, what experiences might we not have accumulated in the culture of our lands and the feeding of our flocks and herds! 
We might have learnt too, from your opening Ecologue, that in those days non-combatant farmers ran risks of dispossession of their holdings in favour of fighting heroes, and from your tale of repatriation pointed morals at some recruiting or war agricultural meetings, on village schoolroom platform, or stony steps of market town on market days. O Education, $\mathrm{O}$ Education, what blunders have been committed in your name! and you, O learned teachers of our youth-and far from unappreciated now by us at distant date from the hours of your ministrationwho had, we well know, climbed the giddy pinnacles of Parnassus, scaled the steep gradients of Olympian heights, and fed on the literary delights of an Augustan age, how long, sometimes I wonder, would it have been before your fountains of knowledge in these particular directions, of to you a strange and bucolic life, had dried up and ceased to flow?

We cannot vie with Virgil, perhaps, in all he taught, yet we can humbly claim at least a little wakeful progress in our generation. We have learnt, and that of late years only, that with an application of nitrate of soda, followed by plentiful dressings of farmyard manure-for the Yew is a gross feeder, and an omnivorous lover of rich treatment-you may, in six or seven years, achieve a very respectable garden hedge from small plants, or if you so wish, by obtaining larger specimens-and the Yews transplant with more ease than any other tree-in a still shorter space of time you may arrange for still more bountiful results. Care should always be taken in replanting to place their roots in the same position to the points of the compass as they occupied in the nursery. Old Virgil knew all about this, and told us in so many words-of which I give the translation-that in those days the planter "even marked on the bark the quarter of the sky, that in whatsoever way each 
stood, in what part it bore the southern heat, what sides it turned to the Northern Pole, they may restore it to the same position. Of such benefit is custom to trees of tender years." For the gratification of an older school of classical scholars we will textually quote the original :

Quin etiam cœli regionem in cortice signant ;

Ut, quo quæque modo steterit, qua parte calores

Austrinos tulerit, quæ terga obverterit axi,

Restituant: adeo in teneris consuescere multum est.

The lesson to be learnt seems to be that the shortened roots become so by inclemency of aspect, that the lengthier roots on the other side of the uplifted plant have become so on account of their attitude towards a more genial aspect, and that if you reversed the positions in the process of transplanting, the shorter roots would take a weary length of misspent time in developing and throwing out their lateral roots, while the longer roots would be retarded or gradually grow less, and so Q.E.D., as Euclid says, time would be wasted and but dilatory results accomplished.

Apropos of this care observed in replanting, I should like to quote from an extract that appeared in the Journal of Forestry, vol. i. 1877-8, p. 489, on the planting of trees at Stanage Park, Radnorshire, at the end of the eighteenth and the beginning of the nineteenth century, written by the owner, my relative and predecessor, Charles Rogers.

"In planting single trees I have followed the Dutch method of giving them precisely the same situation, with regard to the points of the compass, as that in which they stood before they were moved; and I find that the roots shoot, and the trees recover themselves much sooner in this way, than when transplanted without consideration." The Dutch, 
if they claimed originality in these practices, took too much upon themselves, but have we not ever been educated up to the idea, have we not always been told-

That in matters of Commerce the fault of the Dutch Is in giving too little, and asking too much?

In this instance it looks a little as if the Dutch had appropriated an inventor's credit for methods that were recognized and noted in the Virgilian days, and labelled them as home-made or Hollands. Appearances are, at any rate, against them.

The Yew is a memento mori symbol of many a landscape distance, and the uncrowned king among trees of the village churchyards wherein "the rude forefathers of the hamlet sleep." It stands out as silent and ever-present a witness as the gravestone itself, testifying mutely to undying facts, and pointing to one great and universal epitaph for all departed humanity :

For thus our fathers testified

That he might read who ran,

The emptiness of human pride,

The nothingness of man.

By many a villager, too, it is regarded as an old friend and landmark, to be recalled when away in distant lands, and to be greeted as such on a return home. It has been associated by many a wanderer with childish scenes, and perhaps with memories sadder. It has been at times accounted murky, melancholy, and mournful ; it has been described as sable, sombre, and gloomy in many a book of prose and poetry, yet even in them it is allowed that it has contributed, by its venerable appearance and appropriate colouring, a certain undefined pleasing melancholy to scenes not easily forgotten. 
Other reasons may be accountable for its presence in churchyards. Its wood was used for quarrel and crossbow, as the weapon of defence of the day, when wars were waged with long-bows and battle-axes, and muskets and arquebuses were still unknown quantities.

The Greek word ró $\xi_{o \nu}$ (a bow) was evolved

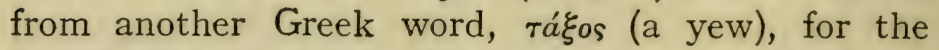
reason, we are told, "because they made bows and arrows from it" (quod ex eo sagittas et arcus faciebant).

But this does not exhaust all reasons assigned for its presence in hallowed precincts. The yew contains a poisonous alkaloid called taxine (presumably derived from the Greek word signifying Yew), which acts as a heart poison on animals of lowered vitality, or unaccustomed by the acquired habits of slow stages to its effects. These poisonous properties were probably well known to the ancients. Virgil alludes to yews as hurtful or noxious (taxos nocentes), and the well-fenced-in churchyards, in spite of the incontestable fact, so wisely propounded and so frequently quoted, that "those inside cannot get out, while those outside have no wish to get in," show pretty clearly that our forefathers of a long time back had realized these poisonous properties. They knew that the high walls or fences of such places were a safe barrier against the entry of grazing animals in the neighbourhood.

Many are the curious phrases and fables that stand to the renown of this God's acre planted tree. Their very position and presence there invites them, and their poisonous properties add cubits to their superstitious reputation. They were regarded as symbols of immortality, and emblematic of "a reflourishing state to come," as Evelyn in his Silvia quaintly puts it; as Palm Sunday decorations, as 
concomitances of death chambers and burial ceremonies.

Lay a garland on my hearse,

Of the dismal Yew,

is the refrain of Aspasia's song in The Maid's Tragedy (Beaumont and Fletcher). And if we were to touch upon a more unpleasant topic of their fame, it would be to say that the prosperity of their growth and that of the community around were considered to be vastly benefited by their presence in churchyards. It was asserted that they attracted and absorbed the deadly exhalations and gases of the graveyard, those luminous phenomena that so often terrified old women and children - and doubtless, for the matter of that, many a member of the other sex on a night return journey from the village alehouse-when they assumed the shape of Jack-o'-lantern and Will-of-the-wisp, and haunted the surroundings.

To descend to a more prosaic interpretation of their occupation of these sites. There is a story told of a gunner on board a ship, who was summoned into the presence of his superior officer to give explanation of his failure to fire a salute. His apology was to the effect that there were countless reasons, but the first was all-sufficient; he had no gunpowder. There may be countless reasons for planting Yews in churchyards, but one should suffice for most, and it is this, that a poisonous tree which is in requirement for national purposes is best planted out of reach of any opportunity to destroy animal life, which is also necessary for national purposes.

But all these conjectured problems we must here leave to the further consideration of those actuated by a desire to ransack the inner workings of the minds of planting men, who lived before the age of gunpowder and put them there. 
The Yew has been always regarded as a longerlived tree than the Oak. Its life is estimated by a well-worked-out consensus of opinion (Veitch, Book of Conifers) at I,250 years ; we may presume, however, that neither this nor Tennyson's allusion to its "I,000 years of gloom," nor even the 900 years we hear so often assigned to the Oak, need be taken to represent anything more than the average limit of life, at which the subject in question can only reasonably hope to arrive in a robust state of health. That it may linger unhewn and unmolested in a shell-like state of decay can hardly be expected to enter into these calculations. Elwes recounts that the big Yew tree at Tisbury (Wiltshire) contains within its hollow trunk a younger stem. A similar instance of this hydra-headed growth of a young tree rooted in a hollow trunk, rejoicing in all the promise of a perpetual youth, occurs at Downton Hall (Ludlow), the abode of Sir W. Rouse Boughton, and we daresay in many other elsewheres.

The bewildering question arises to our mind, should such a tree, on a matter of age, be reckoned as a new tree or as the old tree? If the latter, the plant has seemingly succeeded where the alchemist of old failed, and discovered the elixir of a perpetually prolonged life; or, again, under this condition of things, what is to become of the record in longevity of our tree life, as a little pleasant and controversial topic of conversation among us over our walnuts and wine? But revenons à nos moutons, and to return to our subject, the age of trees as propounded by authorities. Such airily imposed limitations of age, we presume, must not be taken to preclude the possibility of a longer existence, any more than the Psalmist's allotment of three-score and ten years of life conceded to human frailty must be regarded as representing actuarially any final 
and fixed views on the subject of these durations of life.

If the Oak tree, as some say, in a few specially long-lived instances saw Roman legions, what sights might not the Methuselah among Yews have feasted his eyes upon? Perhaps the forefathers of those ancient Britons, whom Julius Cæsar beheld, and described as smeared in the dye of woad, clad in the tawny shins of wild beasts, with streaming locks and flying moustachios, disconcerting by feats of horsemanship the old hands of his cohorts.

Of its wood, both old writers and modern writers have nothing but good to say. It resists decay, it was much in use for furniture, it responds to polish and to topiary work. At the present day little is heard of it commercially. Trees that only come into the markets in their twos and threes are with difficulty disposed of to the timber merchant. The trade like quick results, and ever hanker after markets that speedily respond. An old New Forest saying tells us that a post of Yew will out-last a post of iron. An old chronicler tells us that its veins exceed in beauty those of most trees, and that tables made of it are superior to mahogany. But old writers, any more than modern writers, must not be regarded as final in everything they write. Such comparisons must be taken cum grano salis; that is to say, as salt in condiment, only sparingly.

Botanically, it is with few exceptions diœcious ; it has no resin ducts; it is of great antiquity geologically, and though not dating so far back as the Araucarias, Cryptomerias, and Gingkos, for instance, to the Jurassic formations and the dates when reptiles swayed an early world, it can lay claim by long descent to a direct connection with British soil, dating from the times of the earlier appearances of mammals. 
It has flowers and fruit of shape and make so distinctive that the various species are almost regarded as monotypic. Its ovuliferous flower starts life as a cone and ends as a seed-nut in a succulent aril, open at the top, but its bright-red socalled berries are too well known to need further description.

Other countries besides England and Ireland lay claim to a proprietary interest in their own particular form of Yew. China, Japan, Canada, Mexico, Florida, and Pacific Coast regions have their own peculiar name attached to their own particular specimens. They differ, maybe, in mere matters of detail, but so slightly that they have been for the most part reckoned by the botanical world as members of one family, hailing from a different geographical habitat. If they cannot be looked upon as fraternal, in the same sense as Wordsworth's group of Borrowdale Yews, at all events they can all be rightly considered as cousins not very distantly removed.

From a scenic point of view the Yew has won its admirers and numbered up its detractors.

Though the Yew may be said to represent Erebus (darkness) rather than his more radiant offspring, Ether (light), and Hemera (day), yet scattered about as dark, motionless specks upon the grey, green, silent, and bare expanses of such places as, for instance, say the Hampshire Downs, they are the making to many of grand scenic effect. Before any one makes any final pronouncement on the subject, we think they ought to make an expedition by boat down the River Wye, from Ross to Chepstow, in early summer, when the dark-clad Yews stand out in contrast to the light green colouring of their deciduous surroundings, bursting into spring attire on the wellwooded hill-sides. We wish too-but it is too late in the day for that-that we could have asked old 
Virgil to accompany us on that rapid-flowing river in June,

When the distinguished Yew is ever seen,

Unchanged his branch, and permanent his green,

and wring from him, perchance, some mitigating expressions of his condemnations of a tree which, as a feature in our landscape, although at times maybe melancholy, is ever picturesque.

Before quitting the subject of the Yew, brief mention must be made of the so-called Irish Yew.

\section{THE IRISH YEW}

\section{T. Baccata var. Fastigiata}

O thicker, deeper, darker growing,

The solemn vista to the tomb.

WHITTIER.

It was some I 50 years ago that our venerable Yew, the glory of many a country-side, the joy of all the Toxophilites, produced a female freak above Florence Court (the Irish seat of Lord Enniskillen), in the shape of an upright, fastigiate-shaped specimen of its race, and clad in the more primitive garb of a juvenile leaf.

From her, by cuttings, since no male form of flower has appeared on her boughs, all the Irish Yews of to-day, so plentifully planted and seen everywhere, have derived origin. They have been extensively planted in churchyards, and often in avenue formation.

As to scenic merits generally, their ideal place under the sun, how and where they should be planted, these are questions for individual tastes. Without venturing any myself, there is little doubt that I8 
opinions upon the subject have been, and will be again, often and unreservedly expressed in divers directions, by many observers, on many occasions, as opportunities arise. And these seem all-sufficient reasons that we should quit the subject here.

\section{(I) PRUMNOPITYS, AND (2) SAXEGOTHEA}

\section{CONSPICUA}

(OF the NATURAL ORder CONIFER $Æ$, oF THE FAMILY TAXACEÆ, OF THE TRIBE TAXINEÆ, OF THE SUB-TRIBE PODOCARPEAE)

The first-named of these two representatives of the sub-tribe Podocarpeæ is another of the Greek built-up words that calls for effort of pronunciation in speech, and scholarship to construe. It is a wordqua word-that, if you wish to effect a clear pronunciation of, suggests the desirability of following the footsteps of the Athenian orator Demosthenes to the seashore, and there practising utterance of it, pebble in mouth, before the roar of the sea. Nothing but the direst necessity of words could have been accountable for the invention of such a name.

It is derived from the Greek words $\pi \rho \circ \hat{v} \mu \nu \circ \nu$ (wild

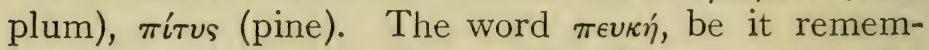
bered, applies to the Spruce Fir (Picea), not to the Pine. Its claim to individuality is that, though it is nearly allied to the Podocarpus, its peduncle (the stalk of its fruit) does not become fleshy, while its bud scales are valvate (open at the edges), and not imbricated (overlapping). Its fruit is a stone contained in a thin layer of fleshy covering (but without a fleshy peduncle) about $\frac{1}{2}$ or $\frac{3}{4}$ in. long, and a little less wide. It has the appeararice of a wild damson.

Its shorter leaves are very densely and spirally inserted, but thrown into rather an irregular-looking 
pectinate arrangement. They have short stalks and two dull glaucous strips of stomata.

It was introduced by $\mathrm{R}$. Pearce from Chili and the Andes in 1860 , and was once called P. Andina (no connection with the Podocarpus Chilina sometimes described as P. Andina). There is a beautiful tree at Eastnor Castle, Ledbury, which presents a very striking appearance. Generally, and elsewhere, it seems to assume rather the shape and dimensions of a plumose-looking bush than a tree.

The P. Spicata so far with us is only a conservatory plant.

\section{Saxegothea Conspicua}

Another of these S. American plants that hails from Chile and Patagonia, and presents with us only a rare and generally stunted appearance. It is a tree that few have the opportunity of making a personal acquaintance with or investigation of. Excellent pictures of its leaves, flowers, and terminal cones are given in Veitch's Book of Conifers and Clinton Baker's book. From its appearance there it has the look of a short-leaved Prumnopitys, but the leaves are more uniformly pointed, and show whiter and more conspicuous bands of stomata on the lower surface. They are also decurrent at the base, which is a clue to identification. Its branches droop, and while the older are of a yellow-brown colour, the younger shoots are of a dull pale-green hue.

The mythological Chimera, that fell a victim to the redoubtable rider of Pegasus, Bellerophon, was described as an animal composed of three distinct living bodies - a lion, a goat, and a dragon. The Saxegothea goes two better; it is described by Lindley as having the male flowers of a Podocarp, the female cone of a Kauri Pine, the fruit of a Juniper, the seed of a Dacrydium, and the habit of a Yew, 
and by the possession of this remarkable assortment of characteristics lays claim to a missing-link fame as between the Coniferæ and Taxaceæ, but the latter are the winners upon points.

It was introduced by W. Lobb in 1847 and named after the Consort of our great Queen Victoria, Prince Albert of Saxe-Gotha, and is often called Prince Albert's Yew. 


\section{IDENTIFYING TABLES}

\section{NATURAL ORDER OF CONIFERA}

\section{THE PINACE压 FAMILY}

TRIBE I.-CUPRESSINEAE

\begin{tabular}{c|c} 
Sub-tribe I : Junipers & Sub-tribe $2:$ Callitrinæ \\
Subdivisions & Subdivisions or Species \\
Callitris \\
(a) Sabinæ Oxycedrus \\
Widdringtonia
\end{tabular}

Sub-tribe 3 : Thuyinæ

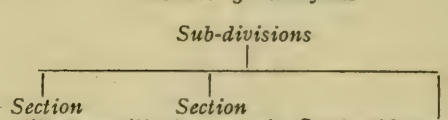

(a) Fitzroyas (b) Eucupressi Section (d) Euthuya Section (c) Chamæcyparis (Atborvitæ) Section (e) Macro-thuya Section (f) Thujopsis Section (g) Biota (including Thuya Orientalis and I,ibocedrus)

\section{TRIBE II.-TAXODINAE}

\section{Species}

\section{Athrotaxis}

Sequoia Gigantea (Wellingtonia)

Sequoia Sempervirens (Californian Red Wood)

Cryptomeria

Taxodium Distichum (Deciduous Cypress)

Sciadopitys Verticillata (Japanese Umbrella Tree)

\section{TRIBE III.-ARAUCARINE}

\section{Species}

A. Imbricata (Monkey Puzzle or Chile Pine)

A. Bidwillii (Bunya)

A. Exxcelsa (Norfolk Island Pine)

A. Cunninghamii (Moreton Bay Pine)

A. Rulei

A. Brasiliensis, etc.

Agathis Australis (New Zealand Kauri Pine) Cunninghamia Sinensis
TRIBE IV.-ABIETINE,

Sub-tribe Picea (Spruces)

Sub-divisions

(I) Tsuja (Hemlock Spruce)

(2) Eu-Piceæ Spruce Trees

(3) Omorica (Flat-leaved Spruce Trees)

Sub-tribe Laricex (Larch
and Cedars)
Sub-divisions or Sections
Larches
Cedars

Sub-tribe Sapinex (Silver Firs)

Sub-divisions Keteleerias Abies (Silver Firs) Pseudo-tsuga Douglasii (Douglas Fir)
Sub-tribe Pinex (Pines)

Sub-divisiors or Groups Strobi (White Pines)

Cembra (Stone Pine)

Gerardiana (Plane Bark Pines)

Balfourianæ (Fox-tail)

Cembroides (Nut Pines)

Pseudo-strobus (Mexican or Tropical)

Tædæ (Torch or Pitch)

Banksia (Scrub)

Pinaster (Scots Pine and theother 2 -leaved representative of the group)

\section{THE TAXACEF FAMILY}

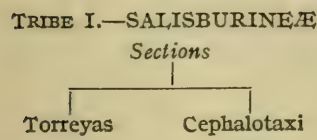

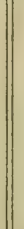

TRIBE II.-TAXINEE

\begin{tabular}{|c|c|}
\hline & \\
\hline Sub-tribe I & Sub-tribe 2 \\
\hline $\begin{array}{l}\text { Taxeæ (Yews) } \\
\text { ns: Taxads and Yews } \\
\text { Phyllocladus } \\
\text { Dacrydium }\end{array}$ & $\begin{array}{c}\text { Podocarpex } \\
\text { (Canadian Yews) } \\
\text { Sections: Podocarpi } \\
\text { Prumnopitys } \\
\text { Saxegothea } \\
\text { Microcachrys }\end{array}$ \\
\hline
\end{tabular}




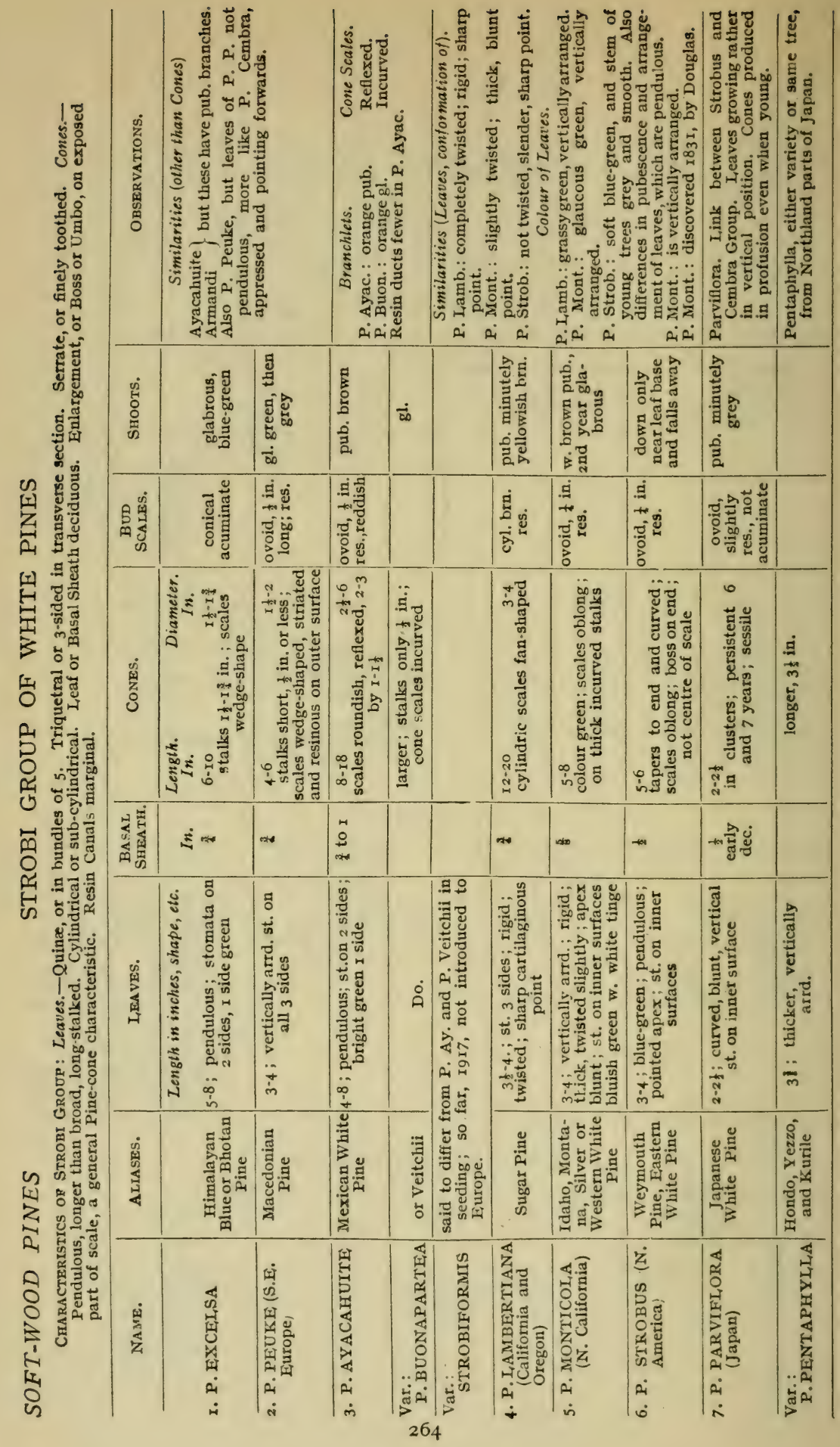




\begin{tabular}{|c|c|c|c|c|c|c|c|c|}
\hline 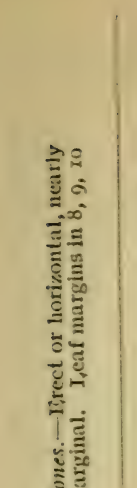 & 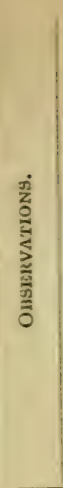 & 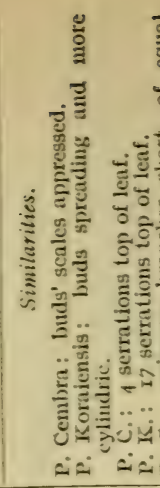 & 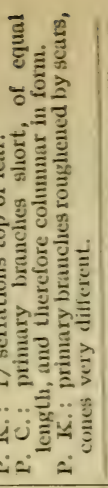 & 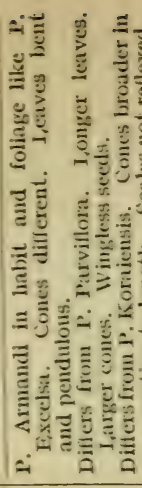 & & 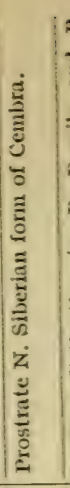 & 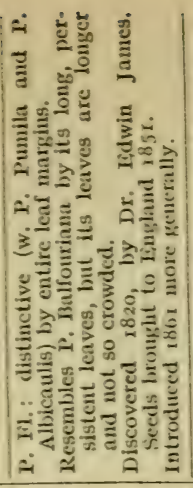 & 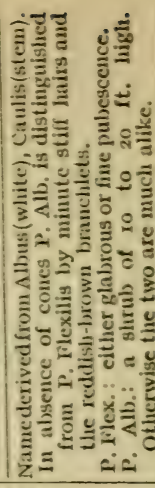 \\
\hline 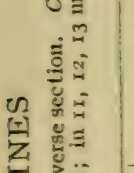 & 类 & 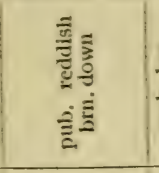 & $\begin{array}{l}\dot{\Xi} \\
\dot{\Xi} \\
\dot{\Xi}\end{array}$ & 勇 & 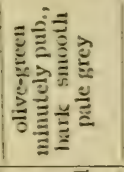 & 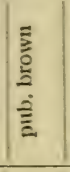 & 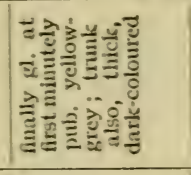 & 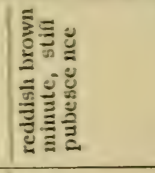 \\
\hline 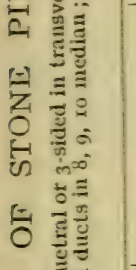 & 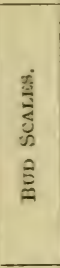 & 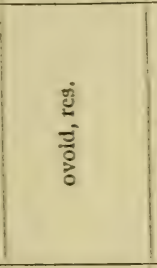 & 룰 & 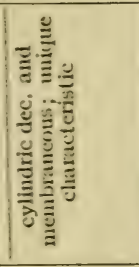 & 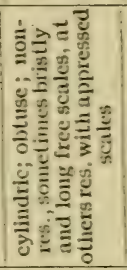 & : & 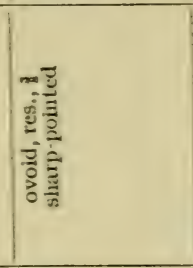 & 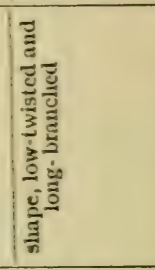 \\
\hline 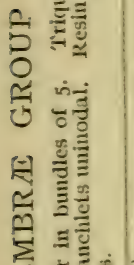 & $\frac{\dot{3}}{3}$ & 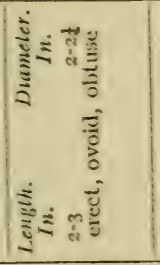 & - & 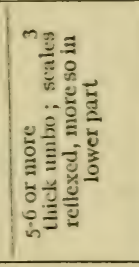 & 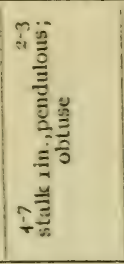 & $\frac{a}{3}$ & 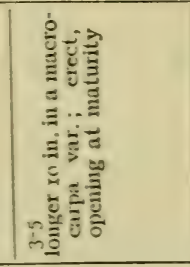 & 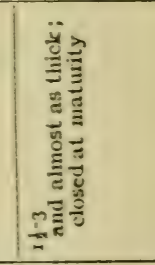 \\
\hline Uأ & 至 & $\stackrel{\infty}{\equiv} \stackrel{0}{\vdots}$ & 氖 & - & 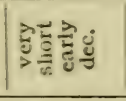 & 总. & : & - \\
\hline 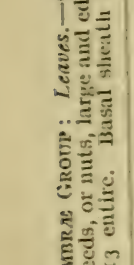 & : & 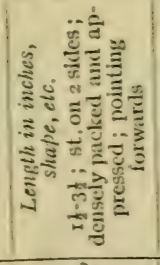 & 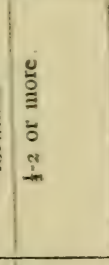 & 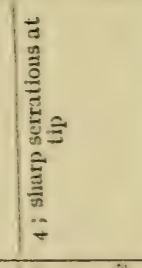 & 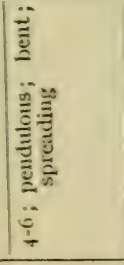 & 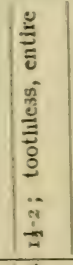 & 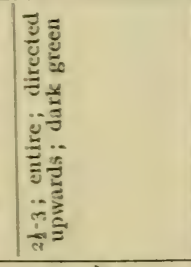 & 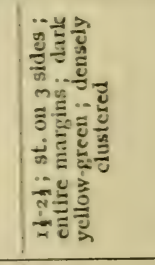 \\
\hline 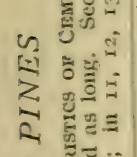 & 总 & 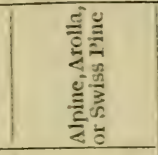 & 竎 & 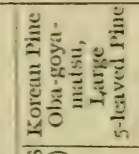 & 递 & 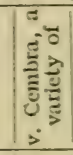 & 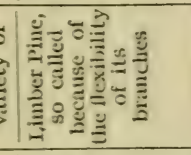 & 号号 \\
\hline 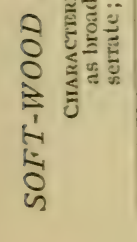 & 㟥 & 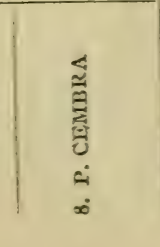 & 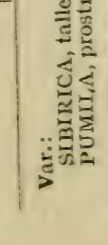 & 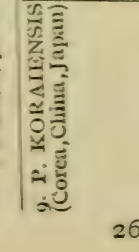 & 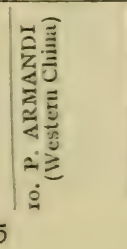 & 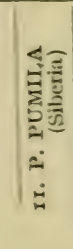 & 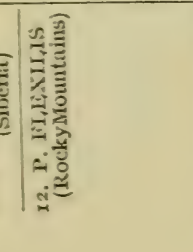 & 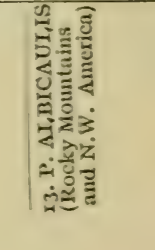 \\
\hline
\end{tabular}




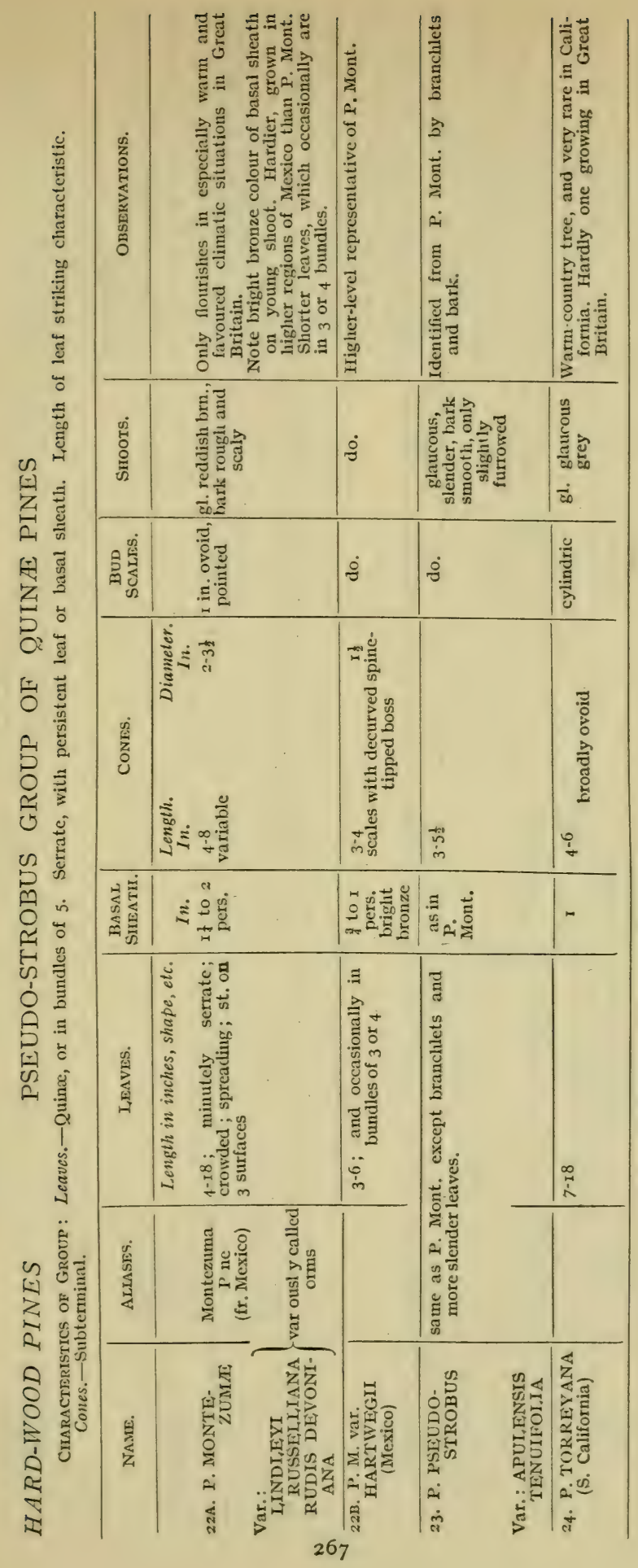




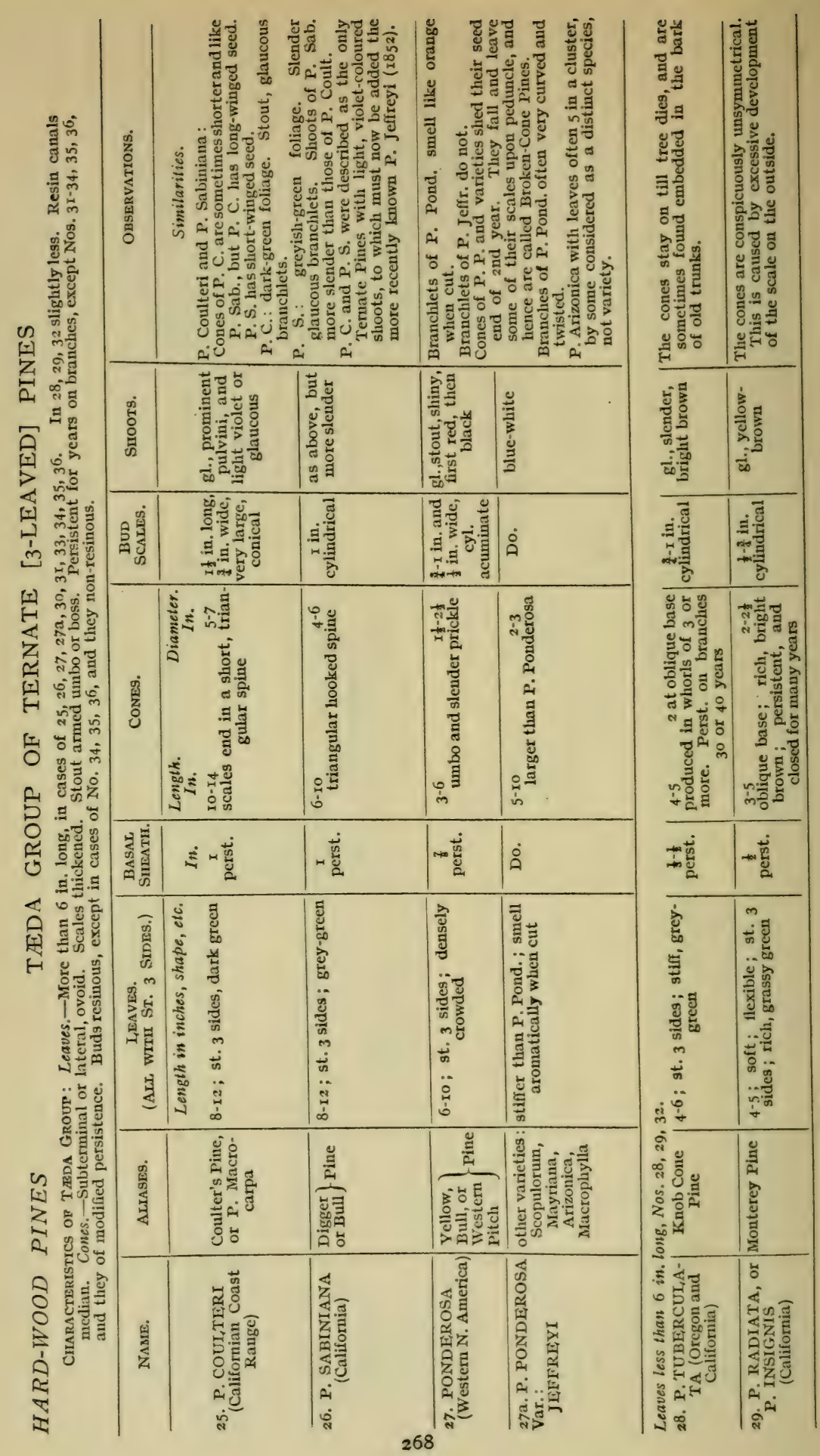




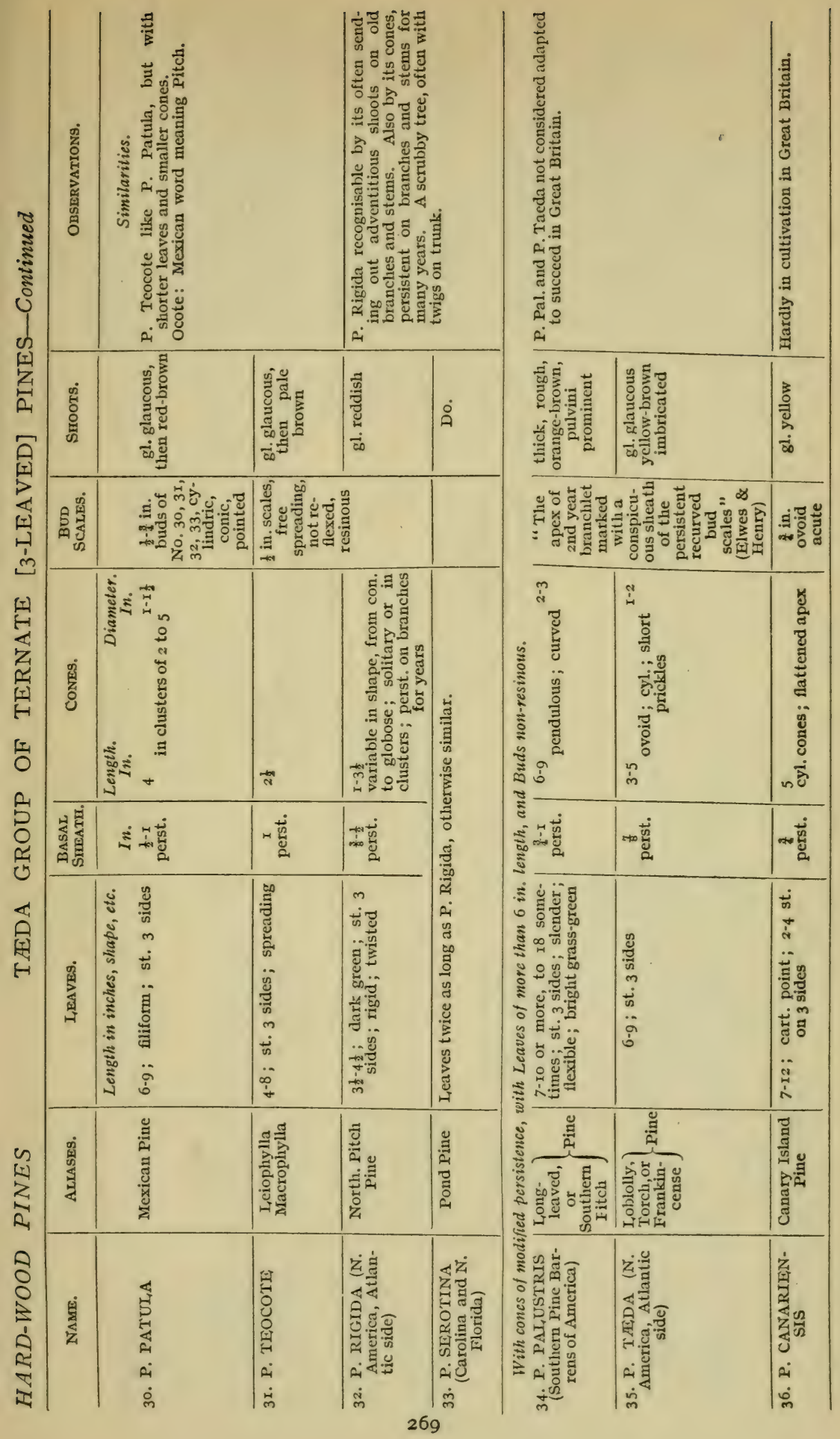




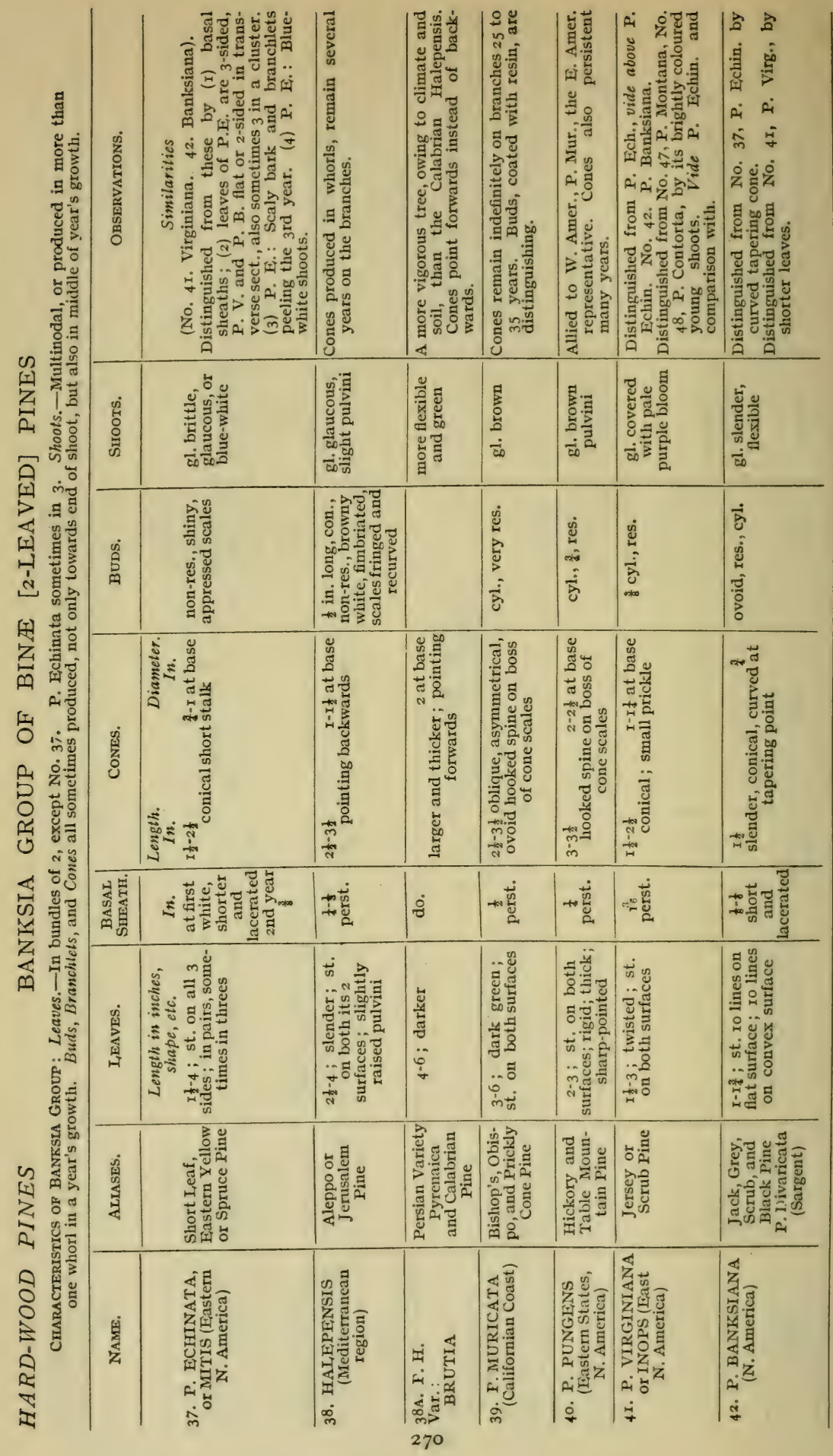




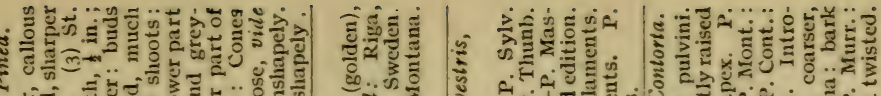
ॠ

a

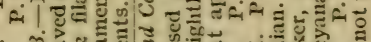

उं

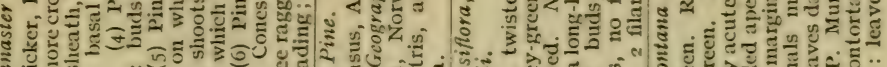
क o 产

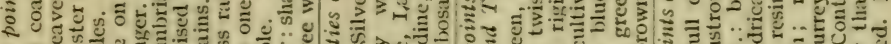

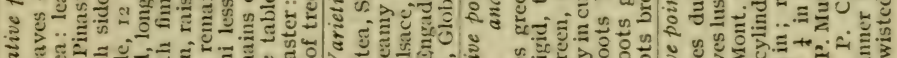

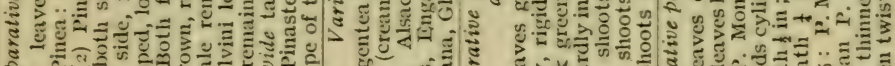

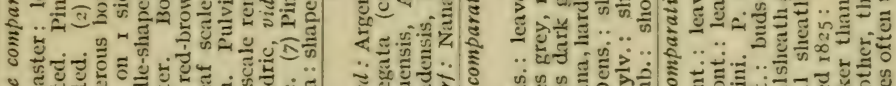

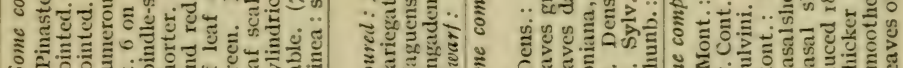

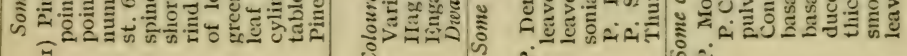

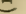

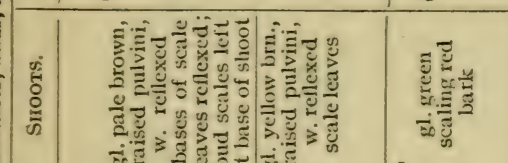
1

\begin{tabular}{|c|c|}
\hline 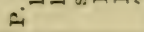 & $n=\dot{i}$ \\
\hline 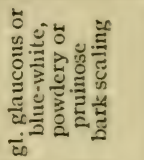 & 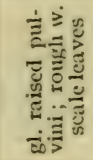 \\
\hline
\end{tabular}

幽苞

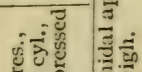

Z

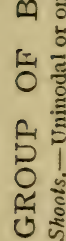

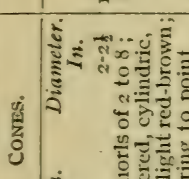

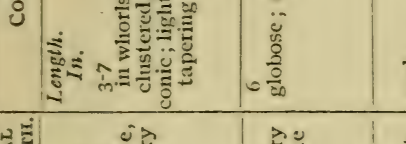

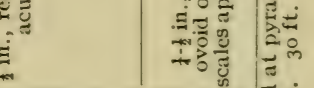

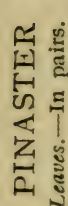

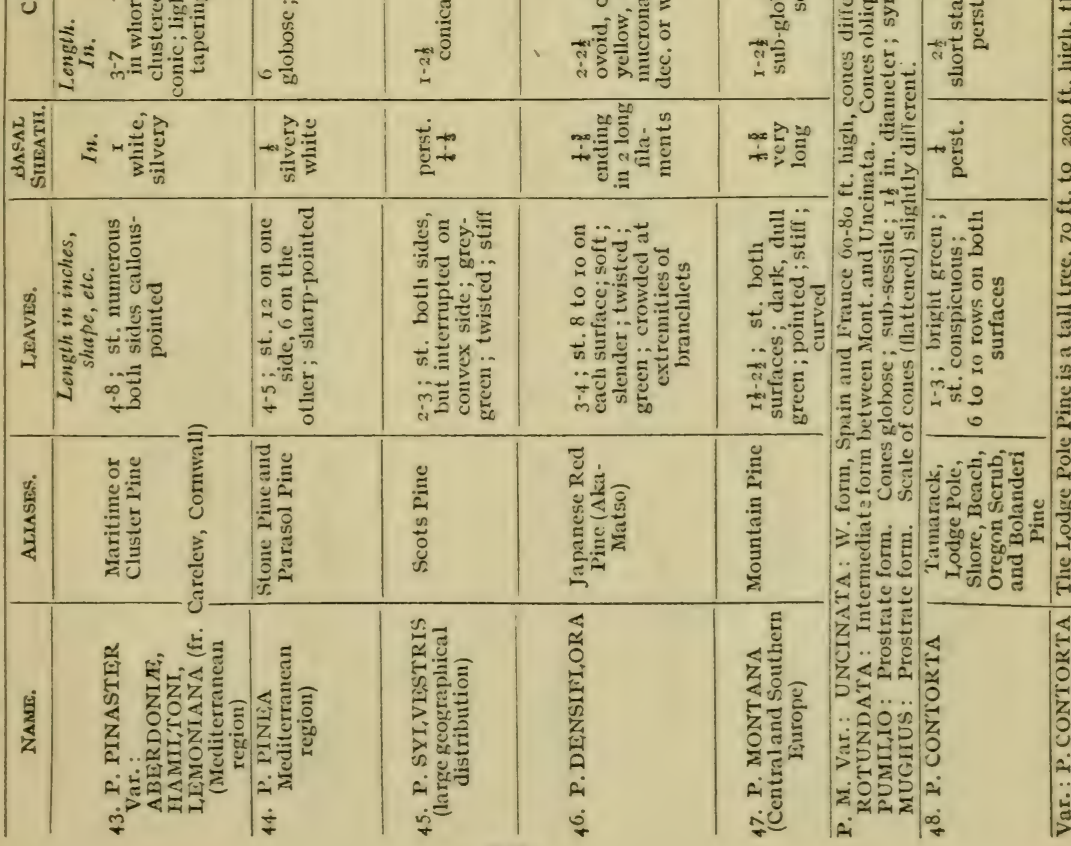

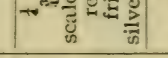

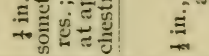

-

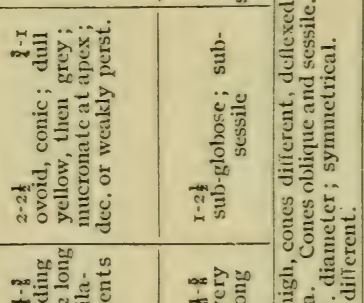

(1)

高

章

高

$\pi^{2}$

int

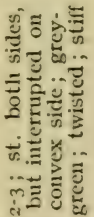

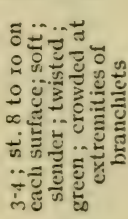

政

*त $=0$




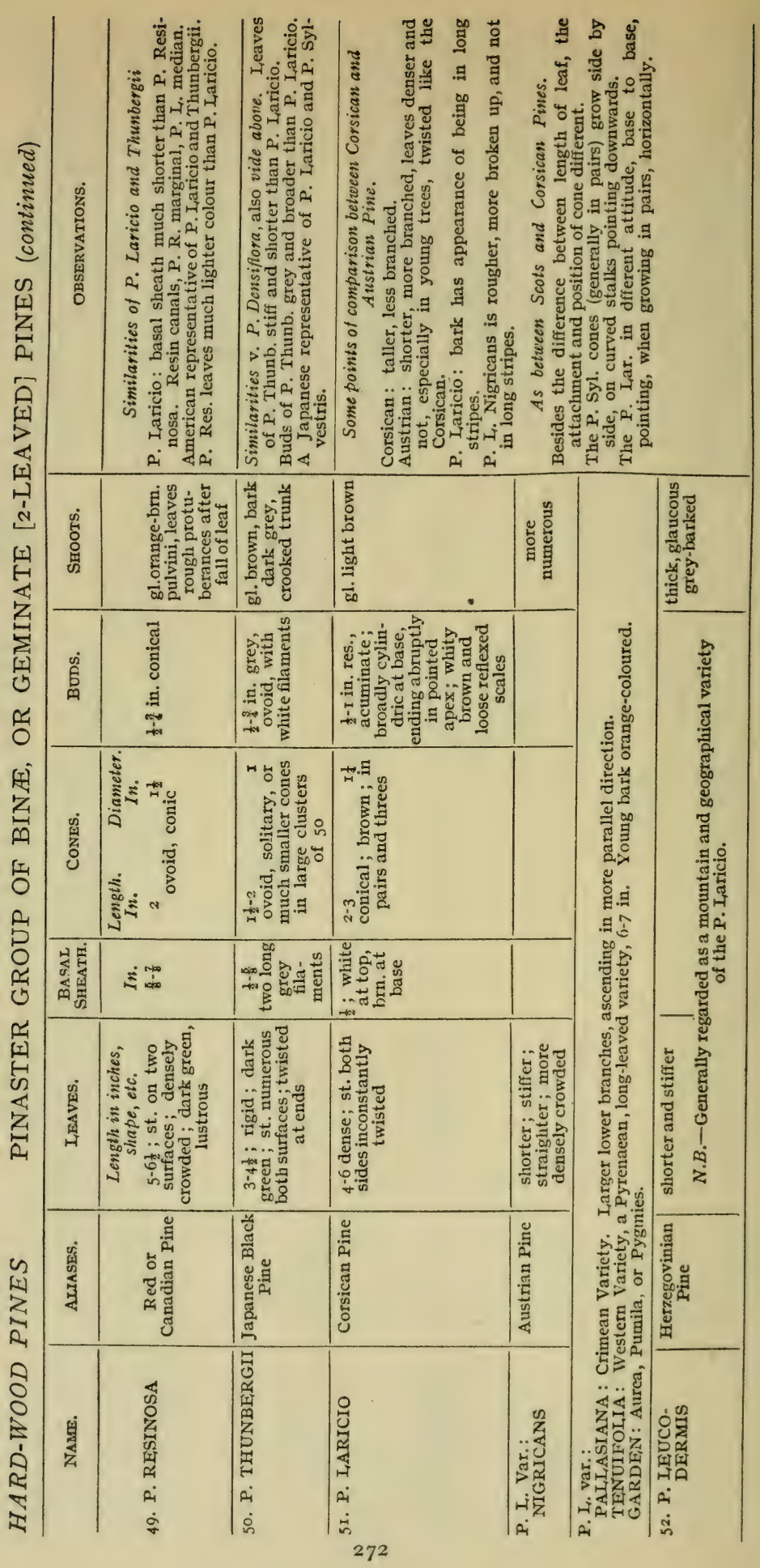




\section{ABIES (SILVER FIRS)}

I. Leaves, Arrangement of.-Although radially arranged on upright stems, on the lateral side-sfroots they are either:

(I) Truly or nearly pectinate (Latin, pecten $=a \mathrm{comb}$ ), twisted at the base and lying back and flat like a comb.

(2) Or with a V-shaped depression-that is to say, leaves pointing sufficiently upwards to leave a gap in the shape of the alphabetical letter $\mathrm{V}$.

(3) Or with median leaves-that is to say, leaves growing in the middle, on the upper side of the twig, pointing forwards, except in the case of A. Numidica, where they point backwards.

(4) Or in the two excepted cases of A. Pinsapo and Cephalonica, the leaves of which are arranged radially, like those on the Spruce, on the lateral as well as the upright stems.

2. Leaves, shape of.-Linear, flat, 2-sided in transverse section (except A. Magnifica, which is quadrangular).

3. Stomata, on one side only, except when expressly stated otherwise in table (e.g. Nos. I, 2, 5, 20, 2I, 23, 25, 26).

4. Base of leaf circular. When pulled off or fallen away, a circular scar is left.

N.B.-This differentiates Silver Fir from Spruce, where, when leaf is pulled off, it tears away the rind, and when fallen away leaves evidences of the projections.

5. Apex of leaf (vide illustration, p. 68).

\section{BRANCHLETS}

I. Cortex, or rind, is either: (a) corrugated and fissured; (b) wavy or undulating; or $(c)$ smooth.

2. Are either with or without pubescence, or with pubescence in grooves of corrugated stems.

3. Branchlets are whorled, and the sheath and bud scales make show at base of each season's shoot.

\section{Cones}

I. Shape.-Cylindrical more or less, except perhaps in case of Bracteata, Firma, Religiosa, when they are more egg-shaped. .

2. Position.-In Abies (Silver Firs) always erect. Bracts (outer scales) obvious. In Piceæe (Spruces) always pendulous. Bracts (outer scales) hidden. 


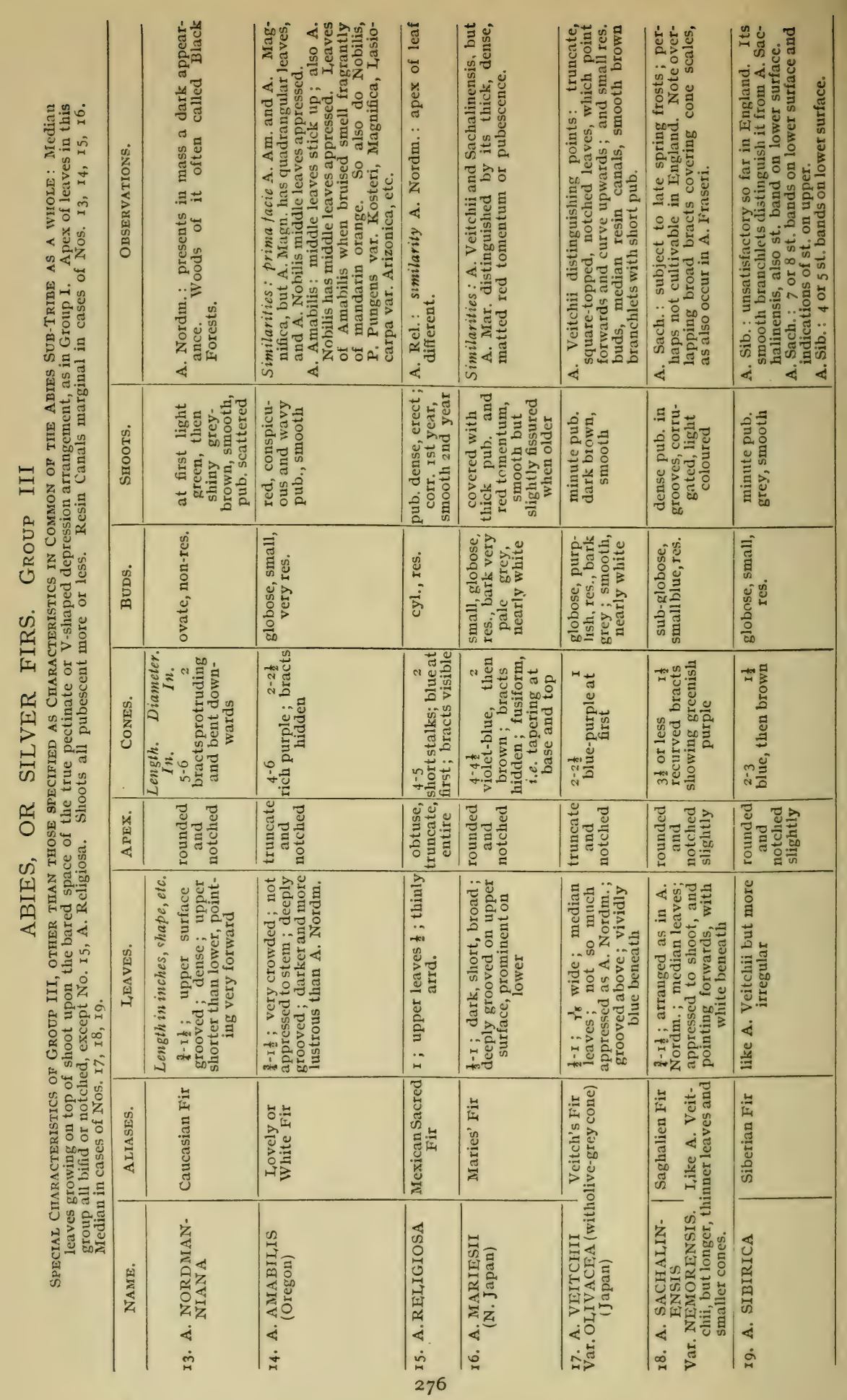




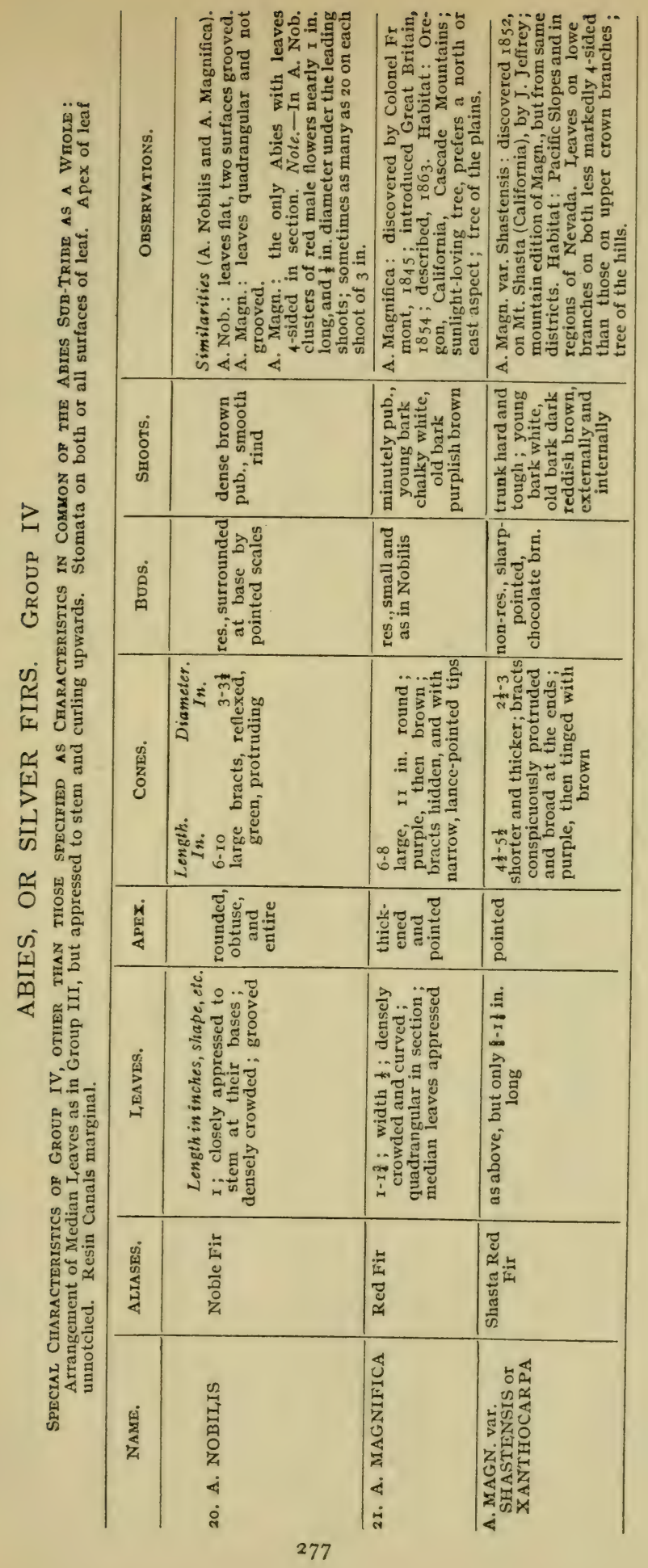




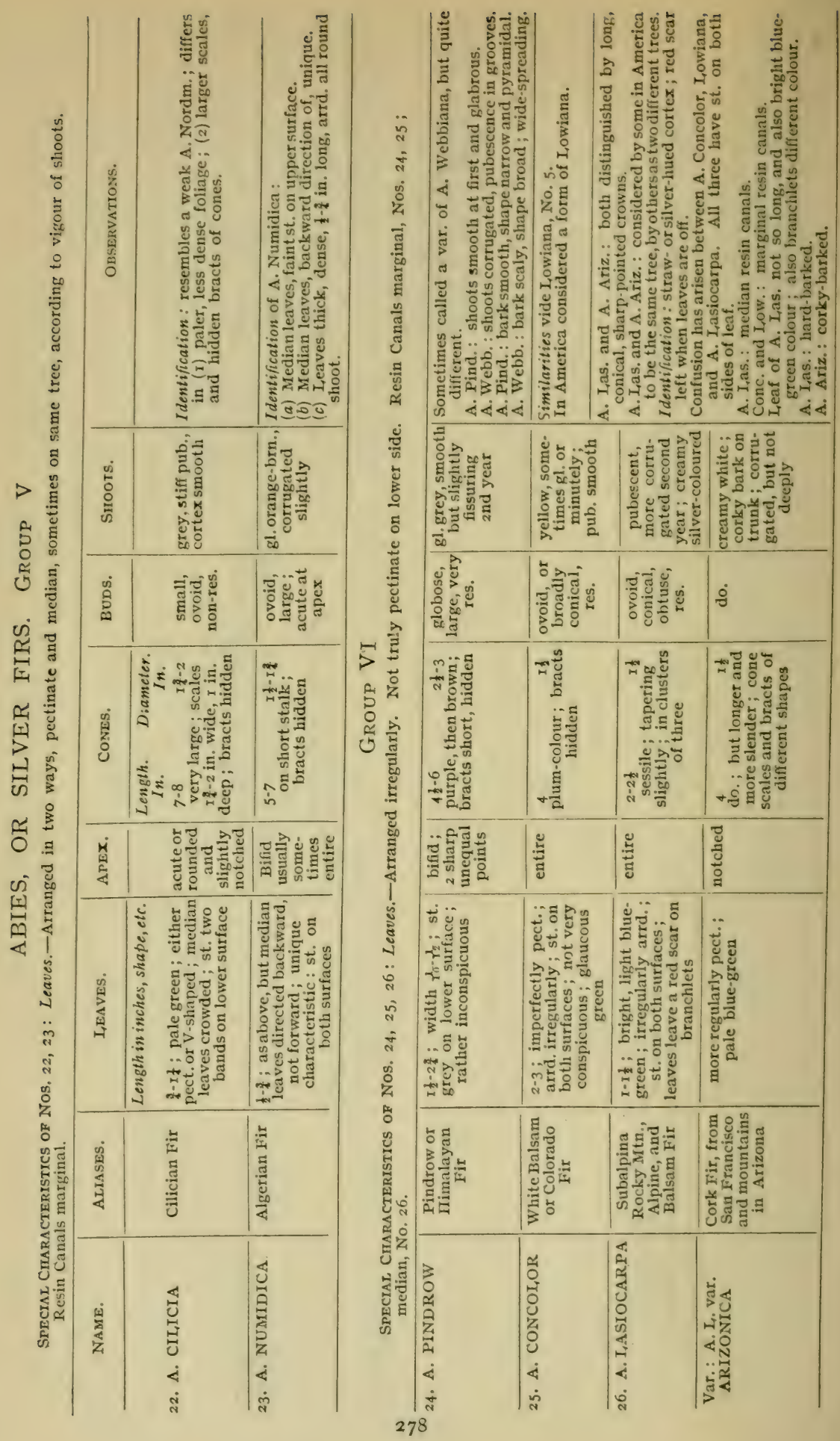




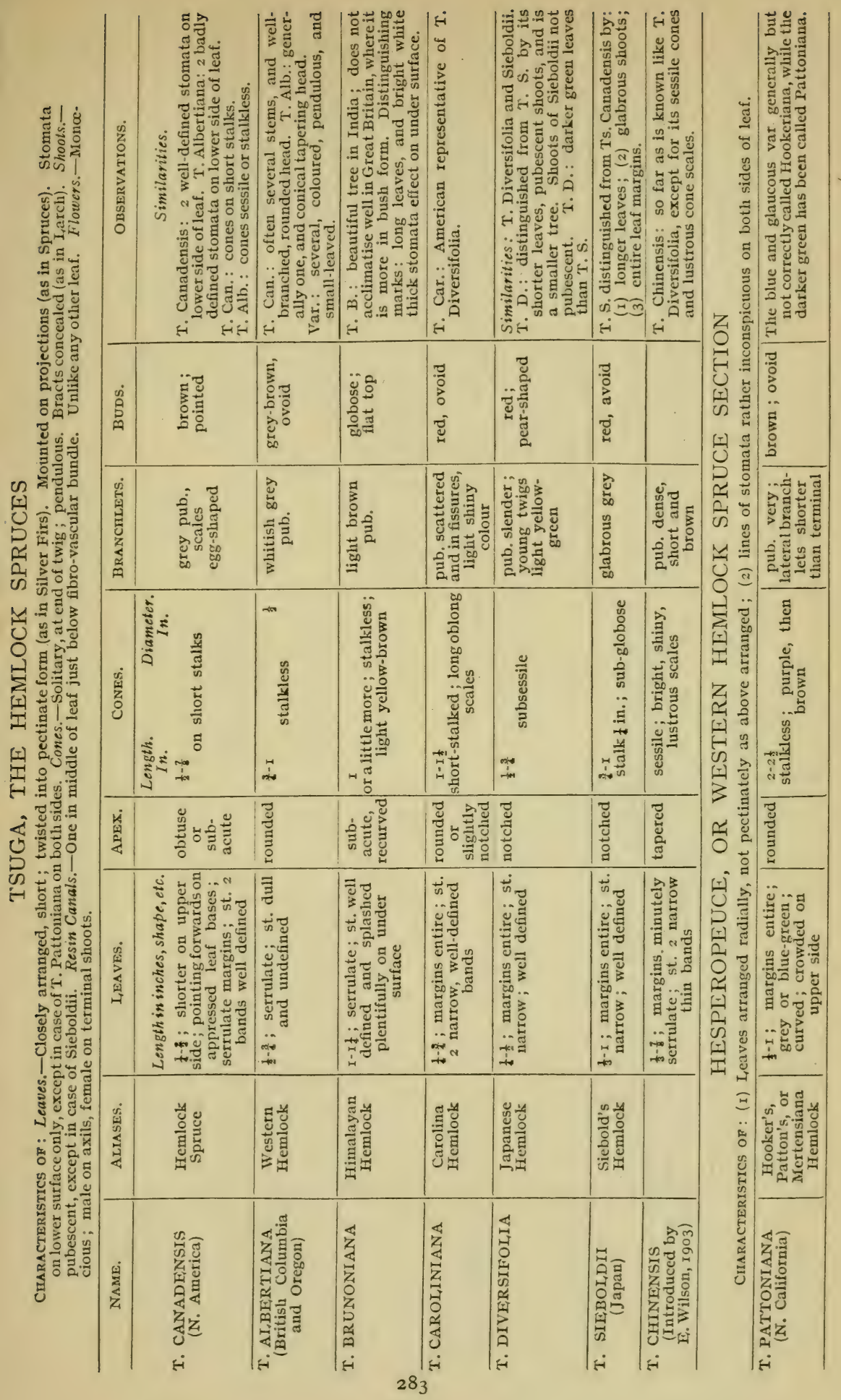




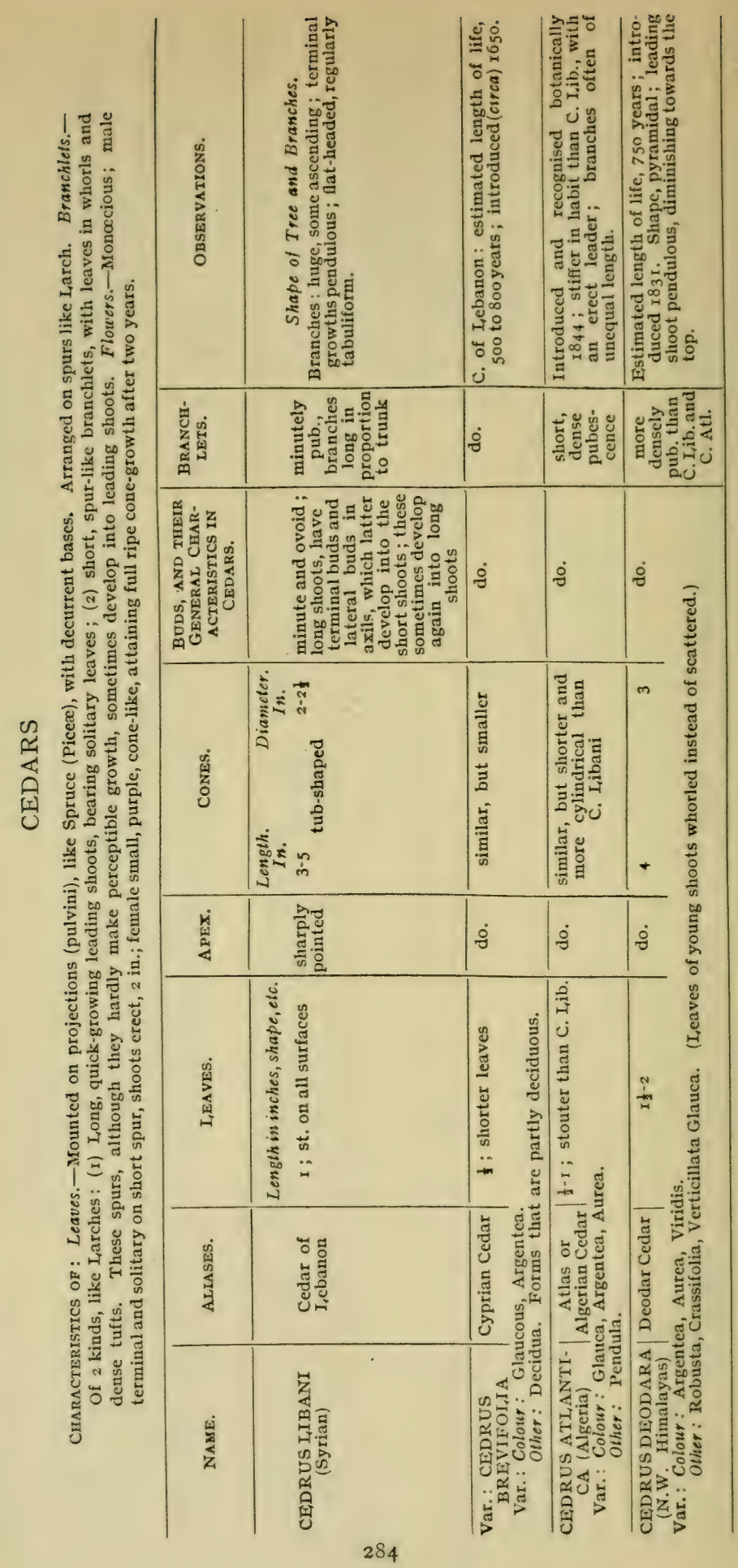




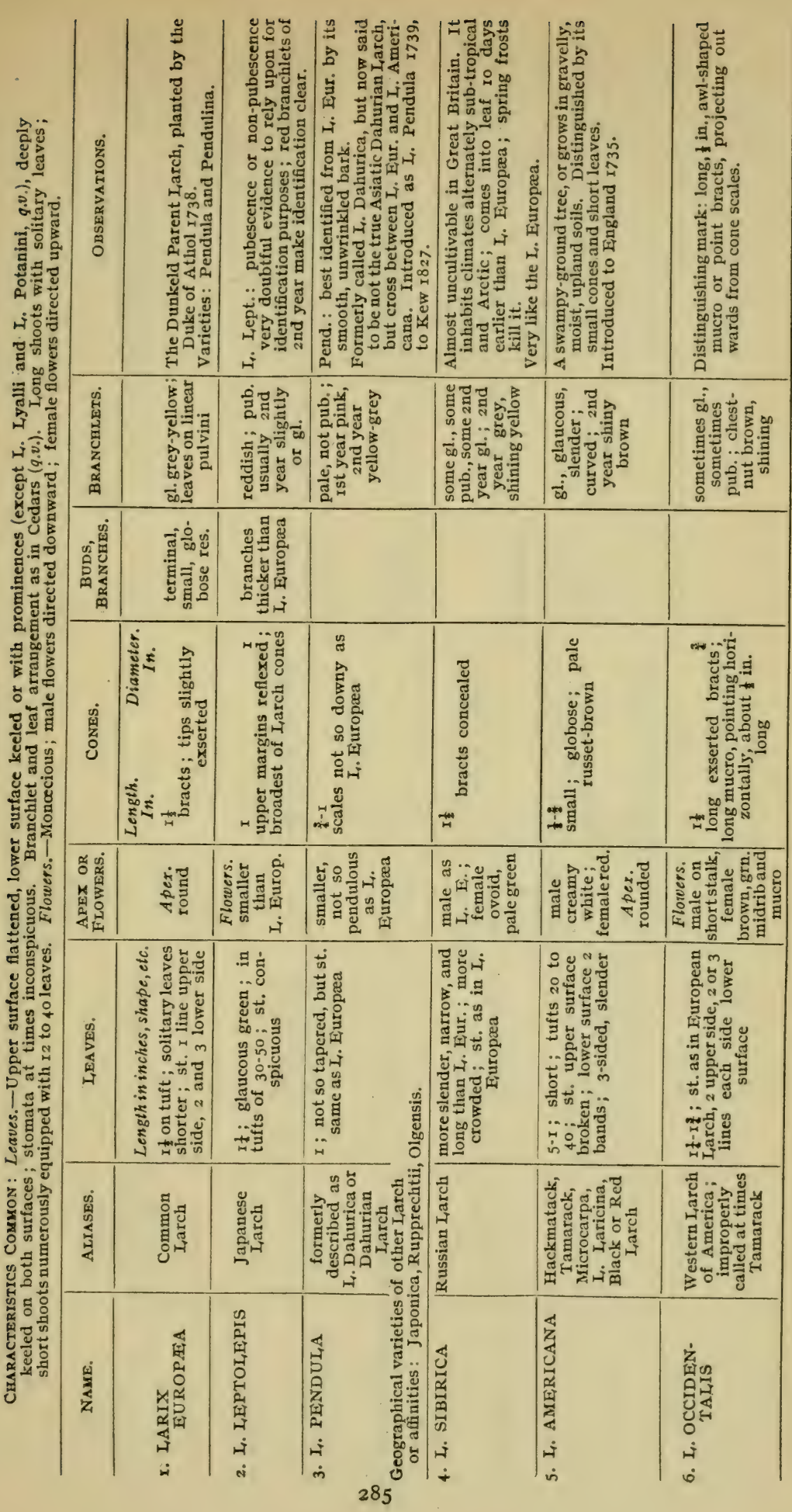




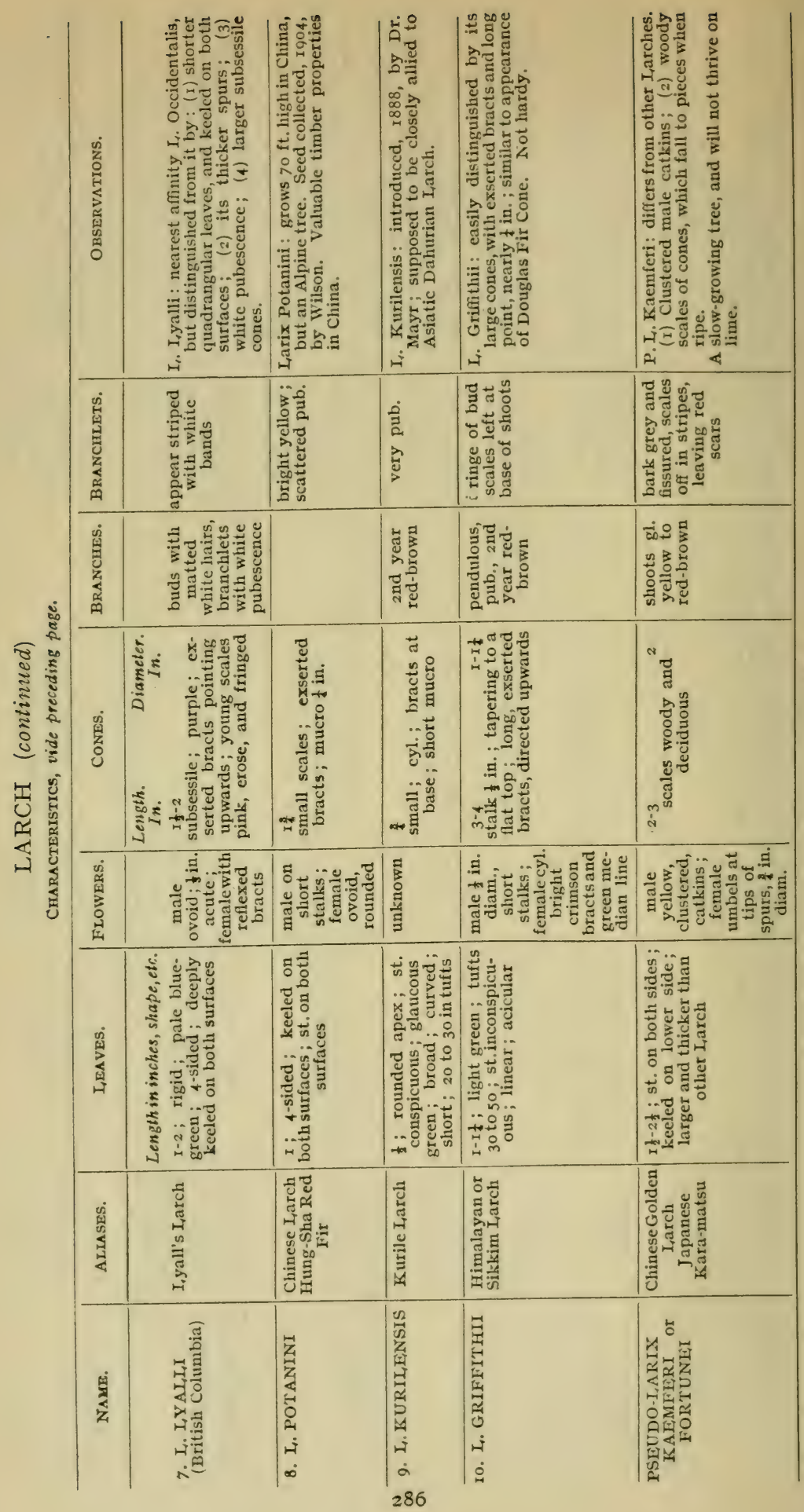




\begin{tabular}{|c|c|c|c|c|c|c|c|c|c|}
\hline 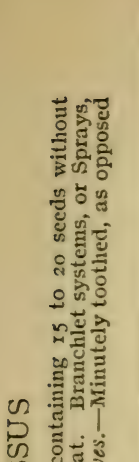 & 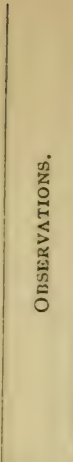 & \multicolumn{3}{|c|}{ 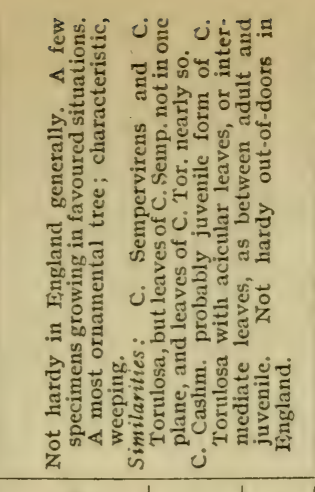 } & 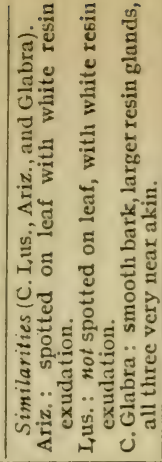 & \multicolumn{2}{|c|}{ 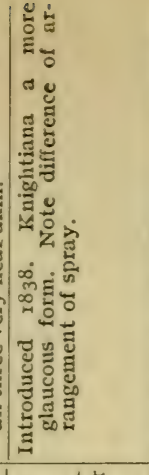 } & 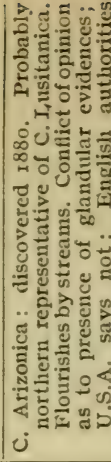 & 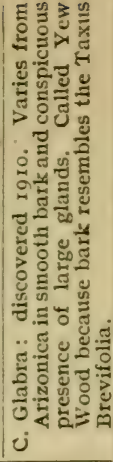 \\
\hline 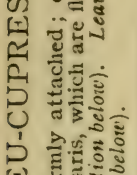 & 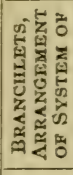 & 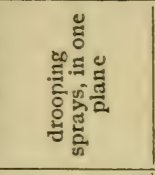 & 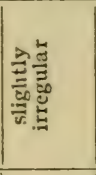 & 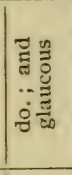 & 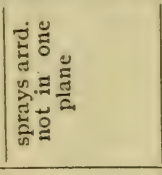 & 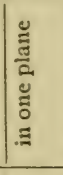 & 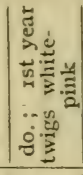 & 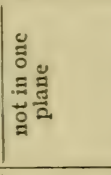 & 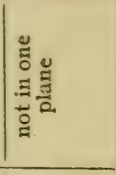 \\
\hline 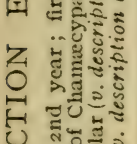 & 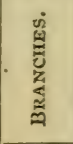 & 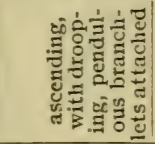 & 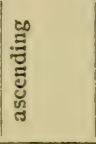 & 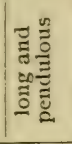 & 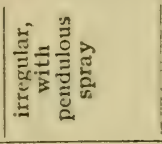 & 를 & 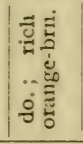 & 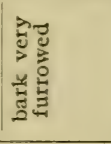 & 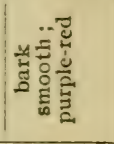 \\
\hline 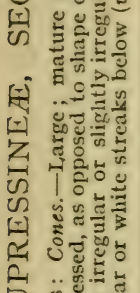 & 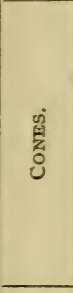 & 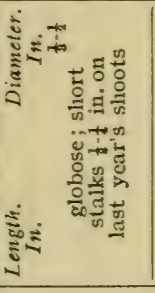 & 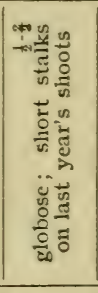 & 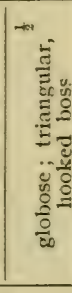 & 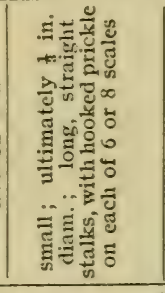 & $\dot{9}$ & 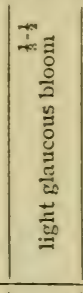 & 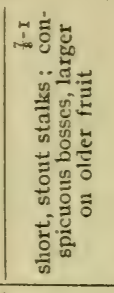 & 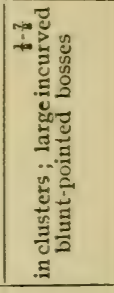 \\
\hline 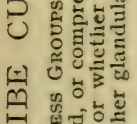 & 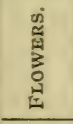 & 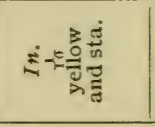 & $+\frac{3}{0}$ & & $+\frac{\partial}{0}$ & $\dot{0}$ & $\dot{g}$ & & \\
\hline 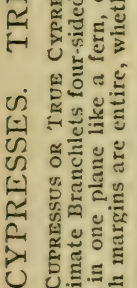 & 离 & 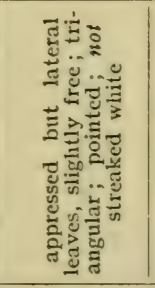 & 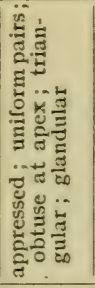 & 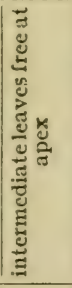 & 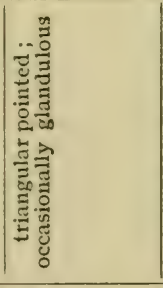 & 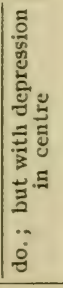 & $\stackrel{8}{\circ}$ & 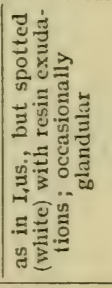 & 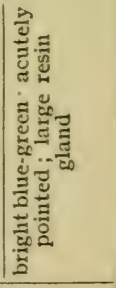 \\
\hline 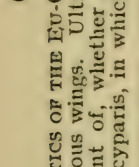 & 递 & 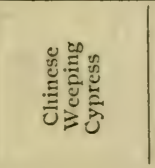 & 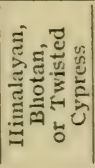 & & 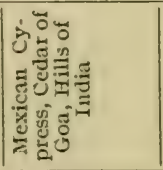 & & 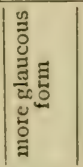 & 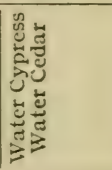 & 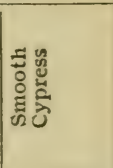 \\
\hline 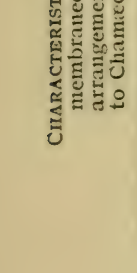 & $\frac{\sin }{2}$ & 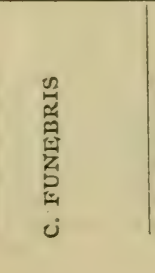 & 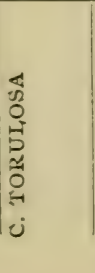 & 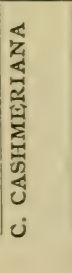 & 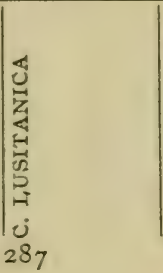 & 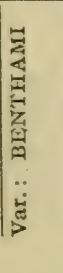 & 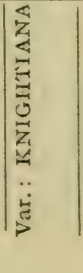 & 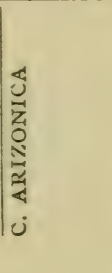 & 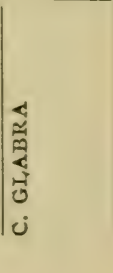 \\
\hline
\end{tabular}




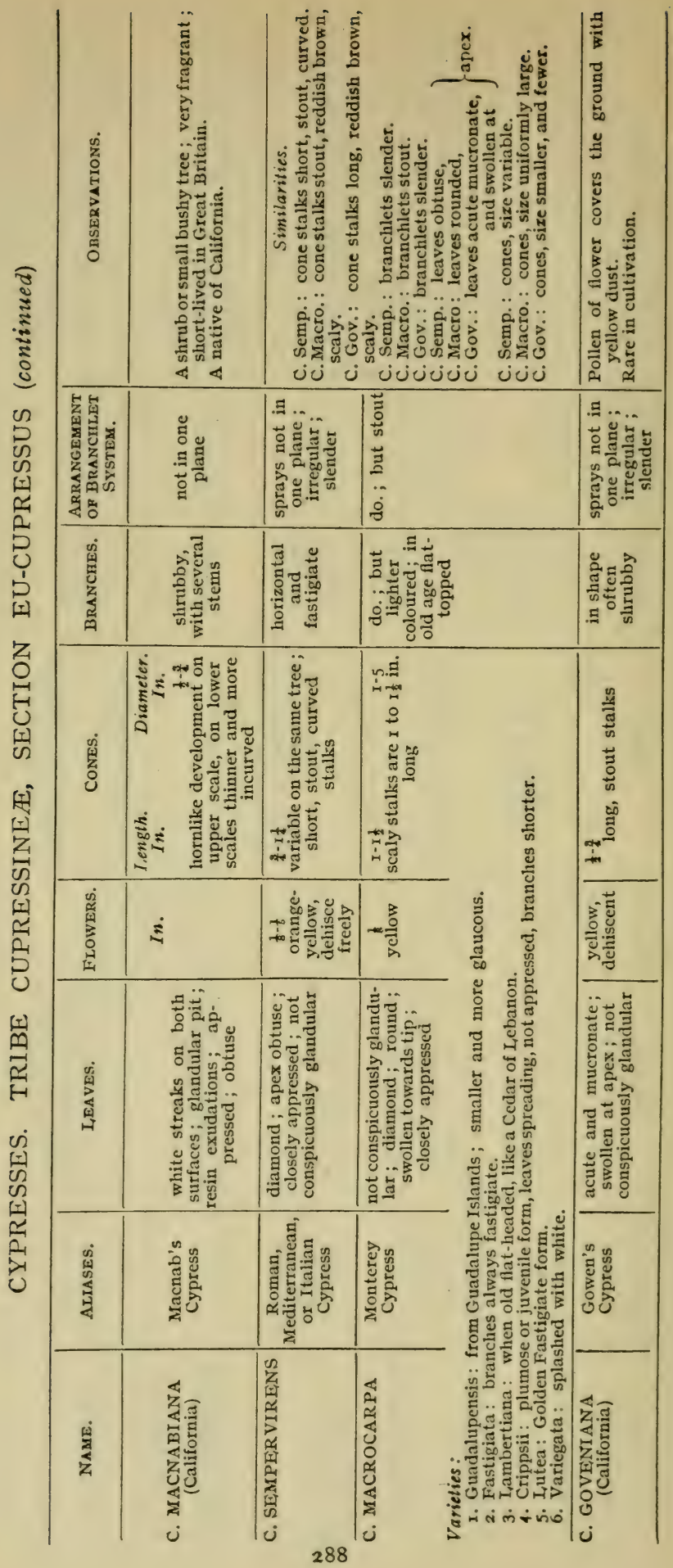




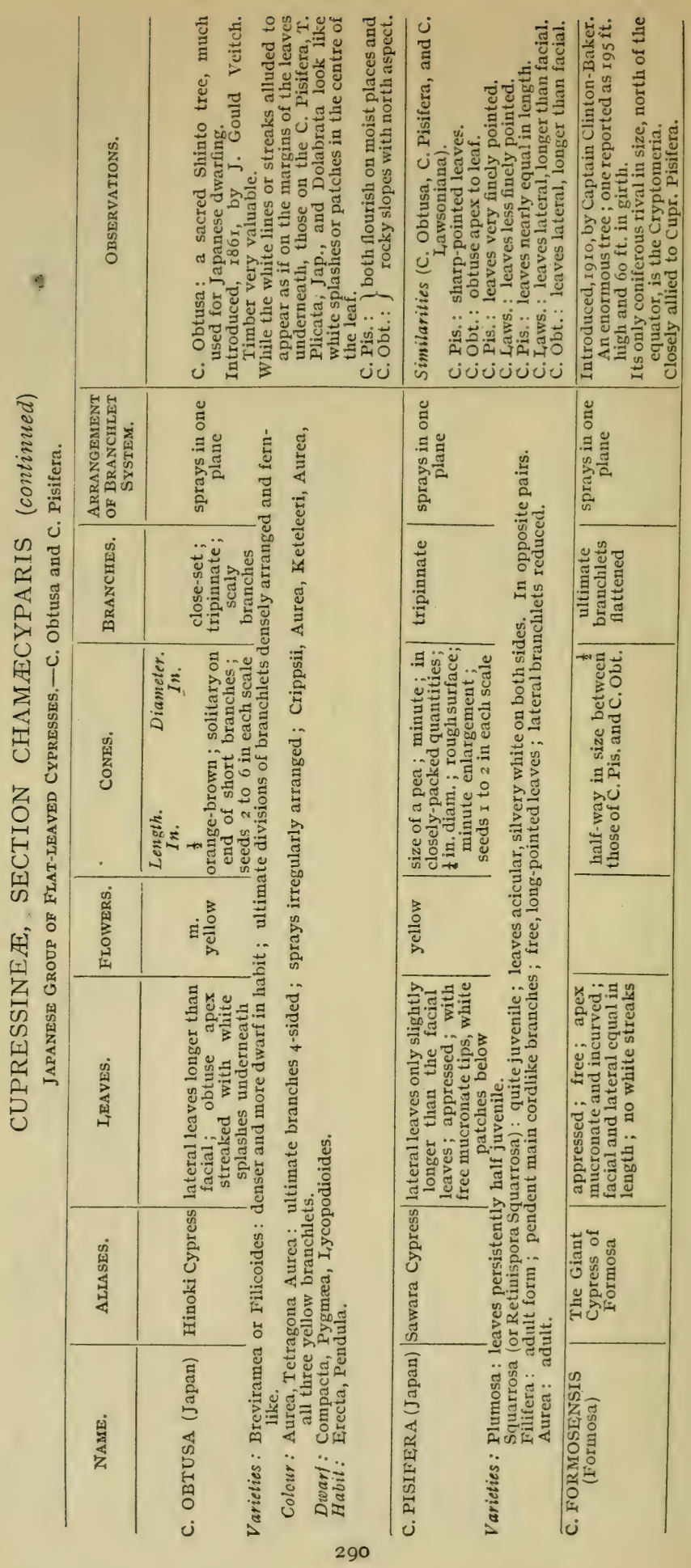




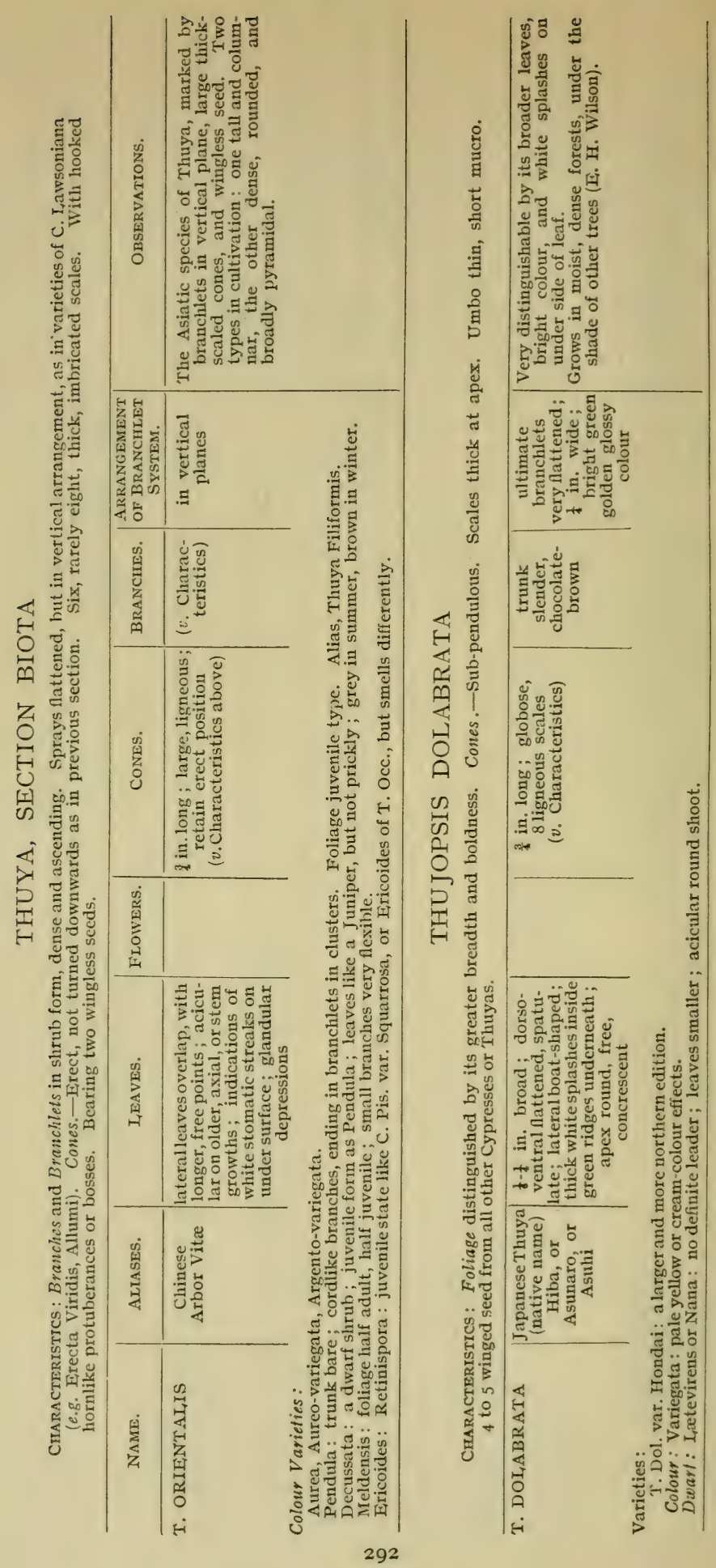





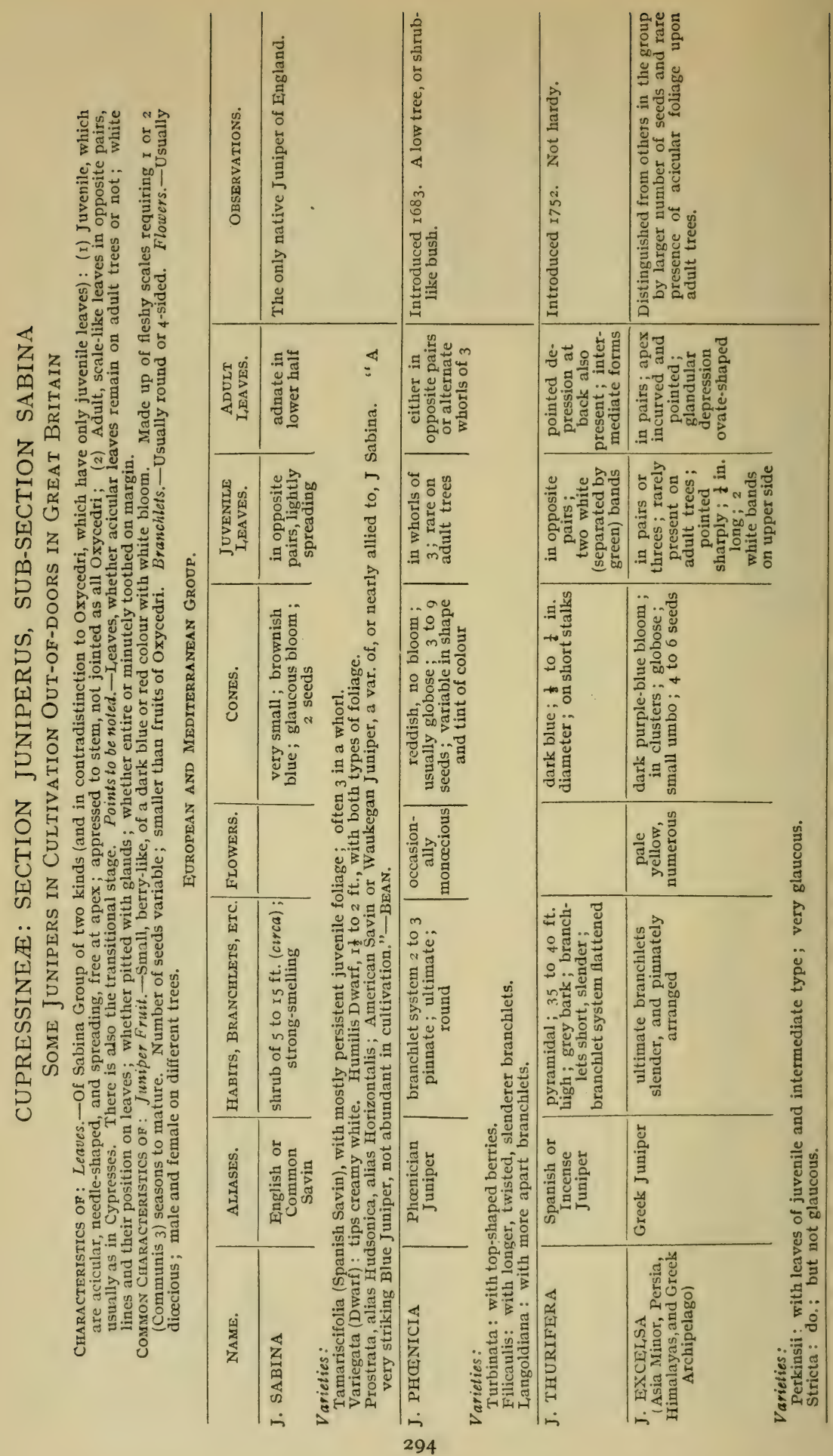




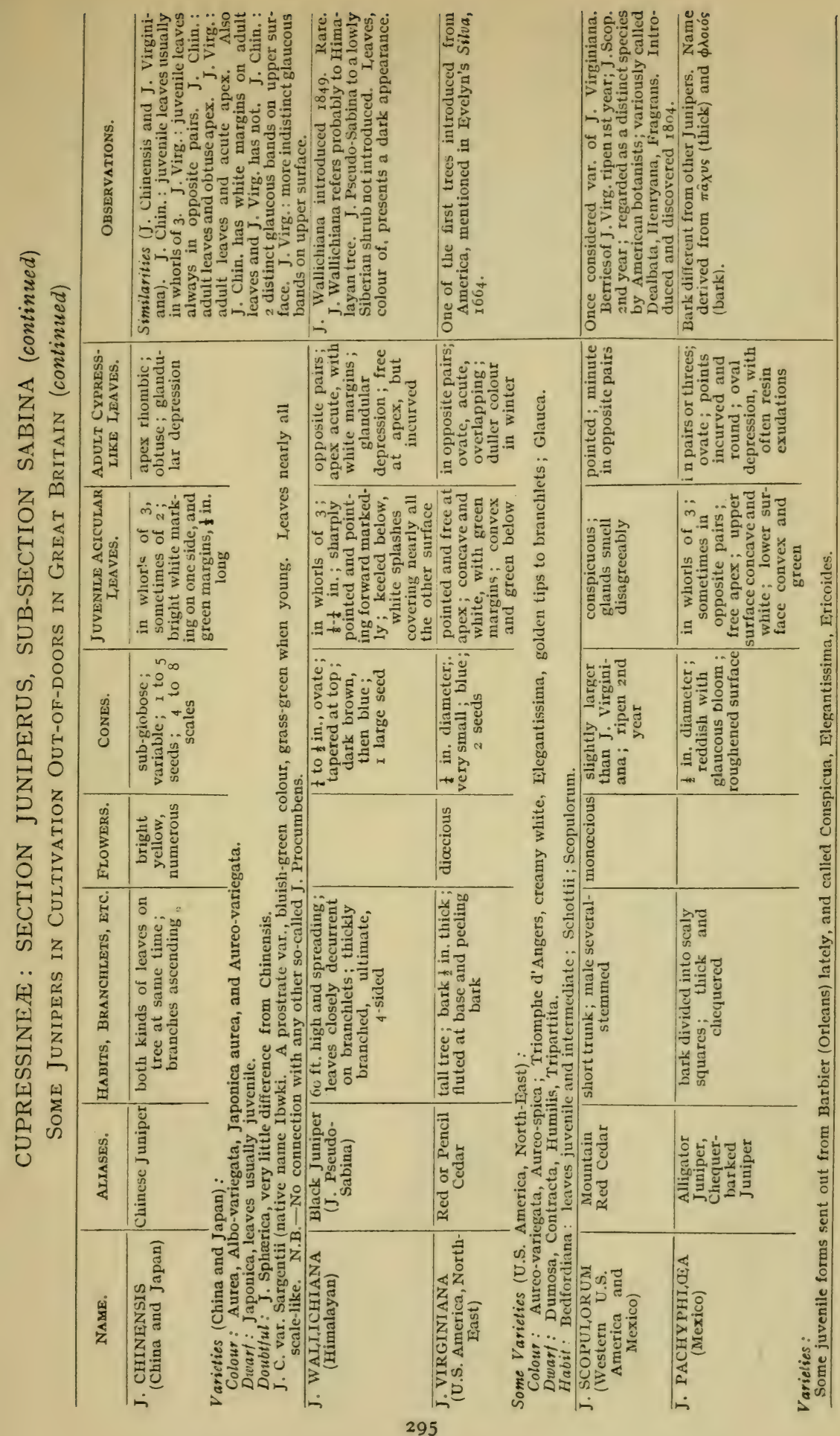




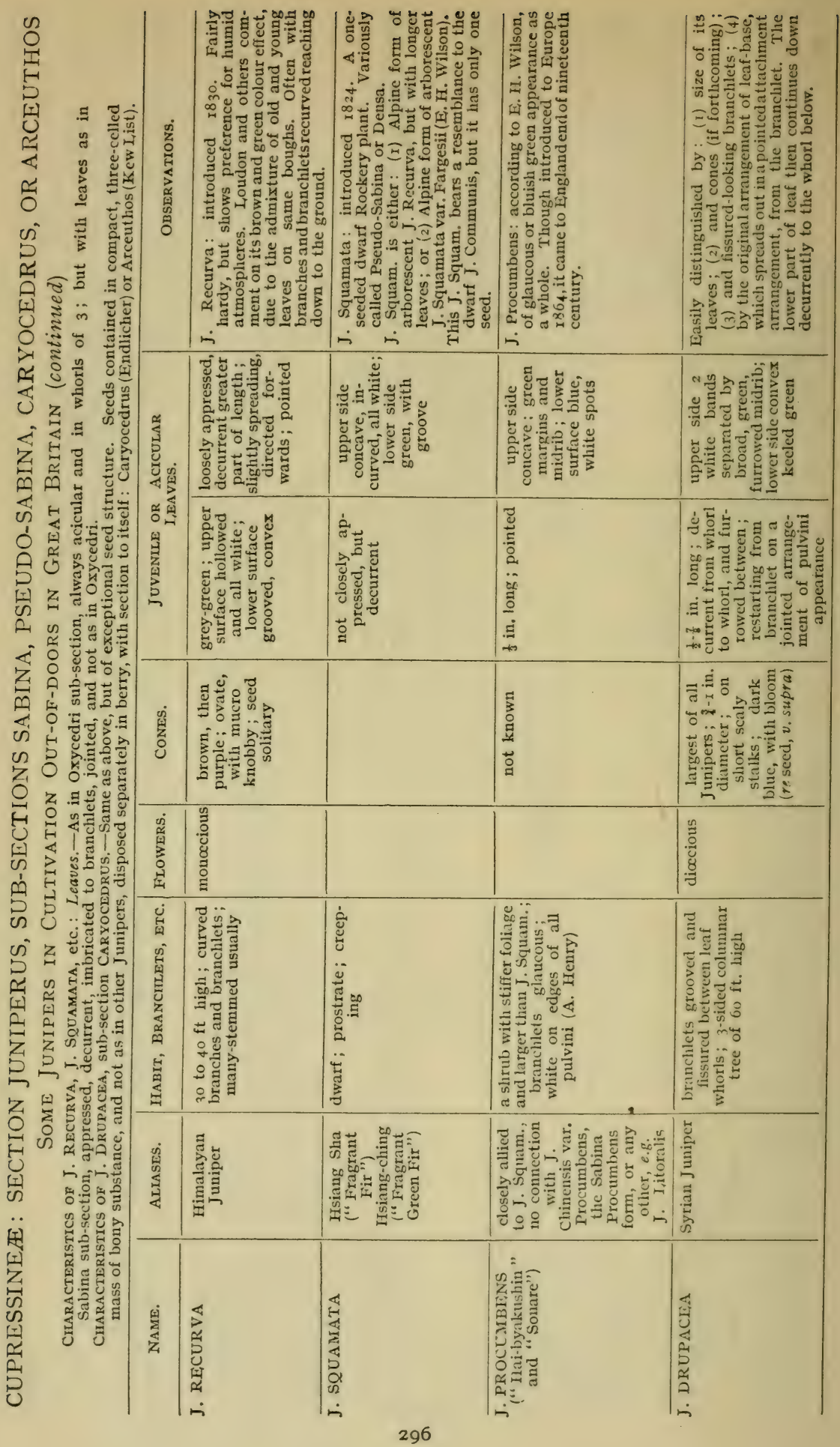




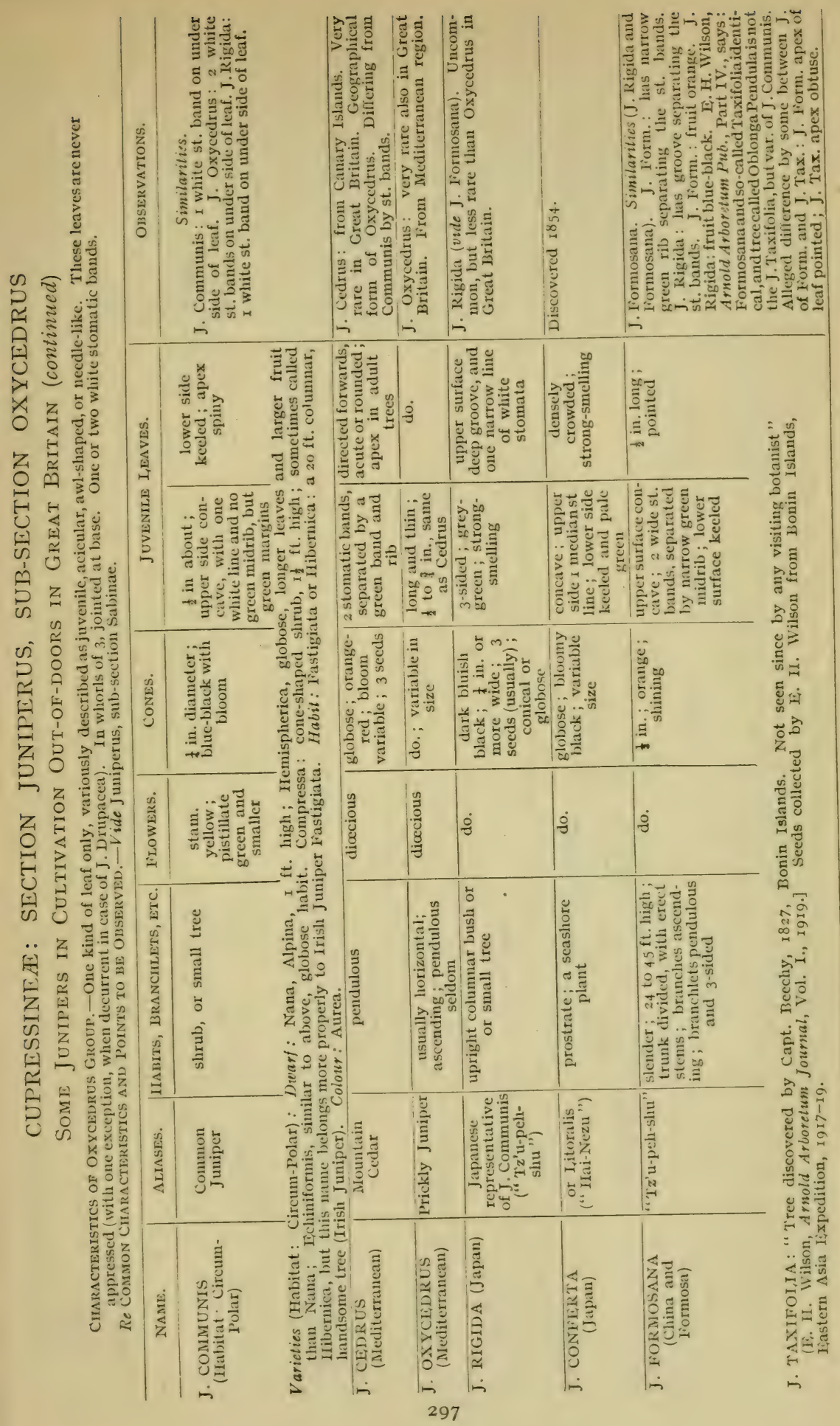




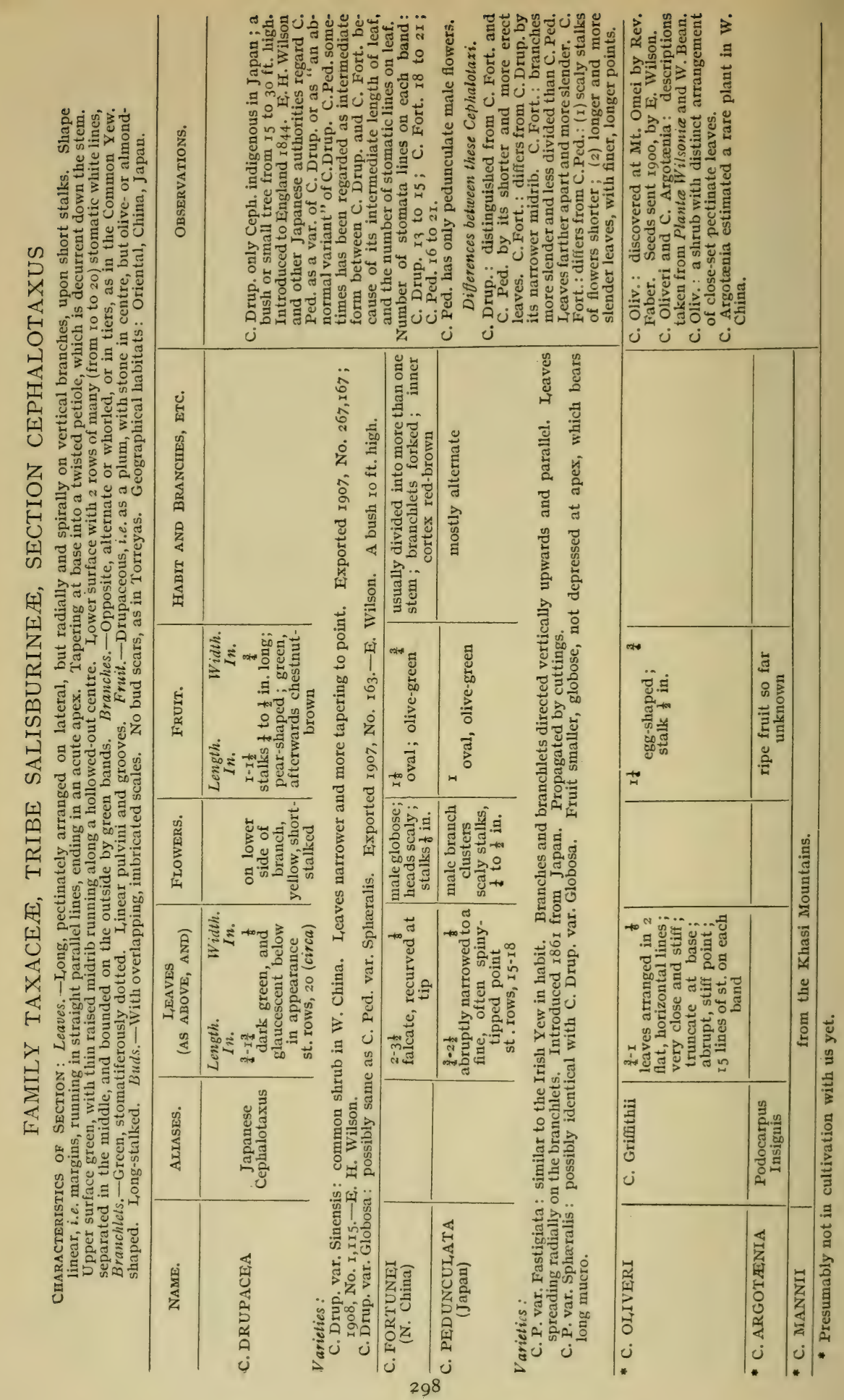




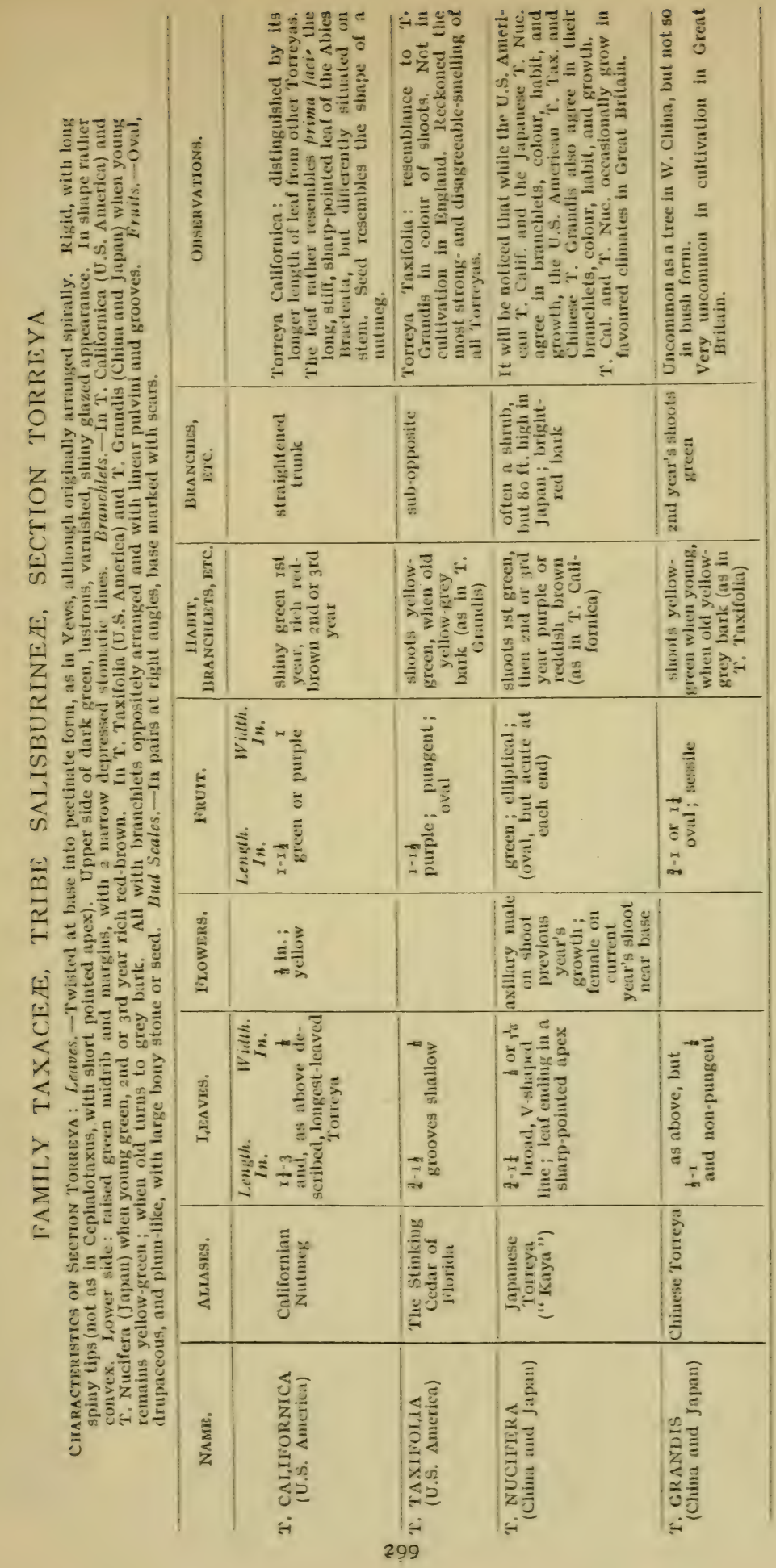




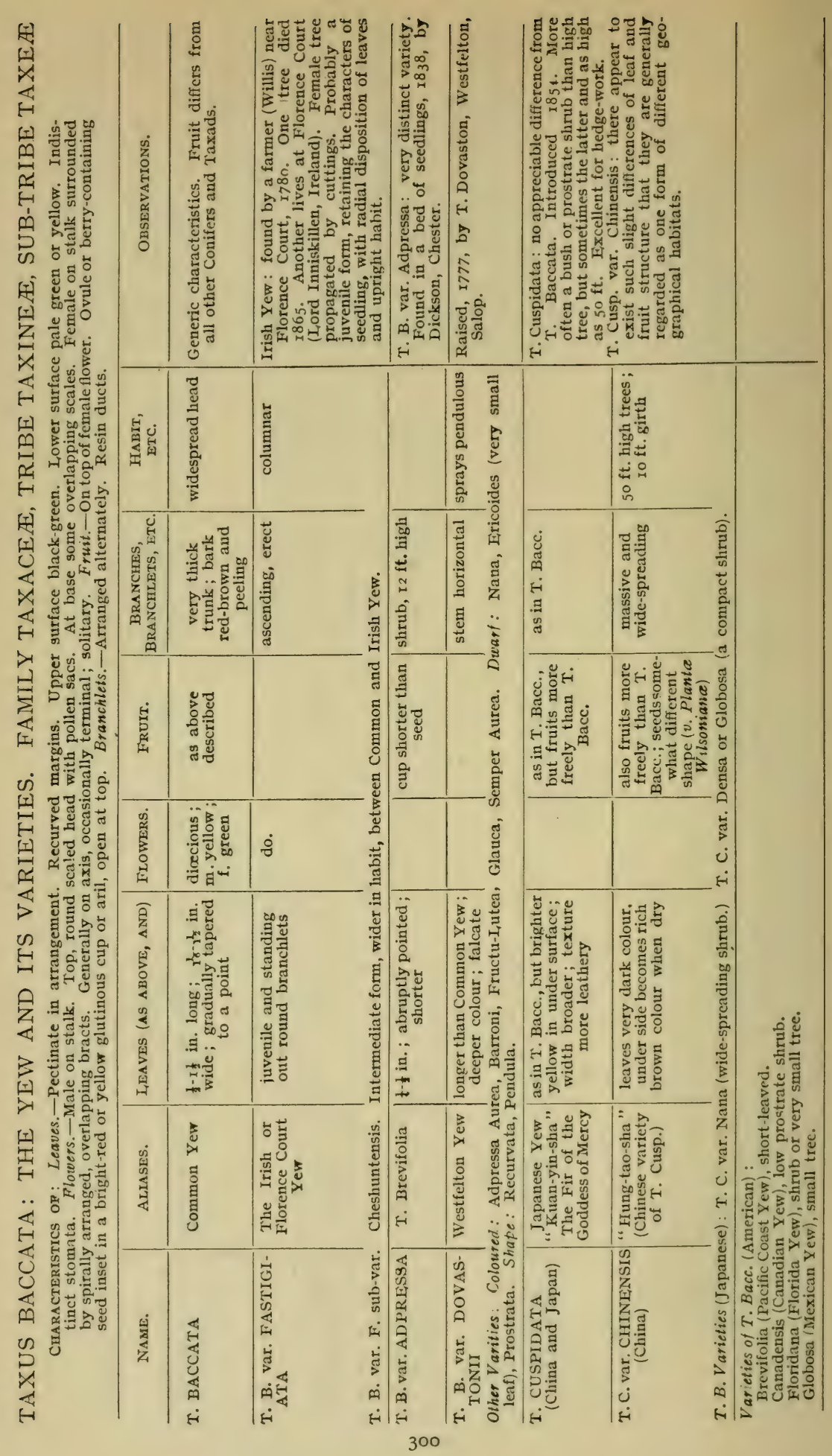




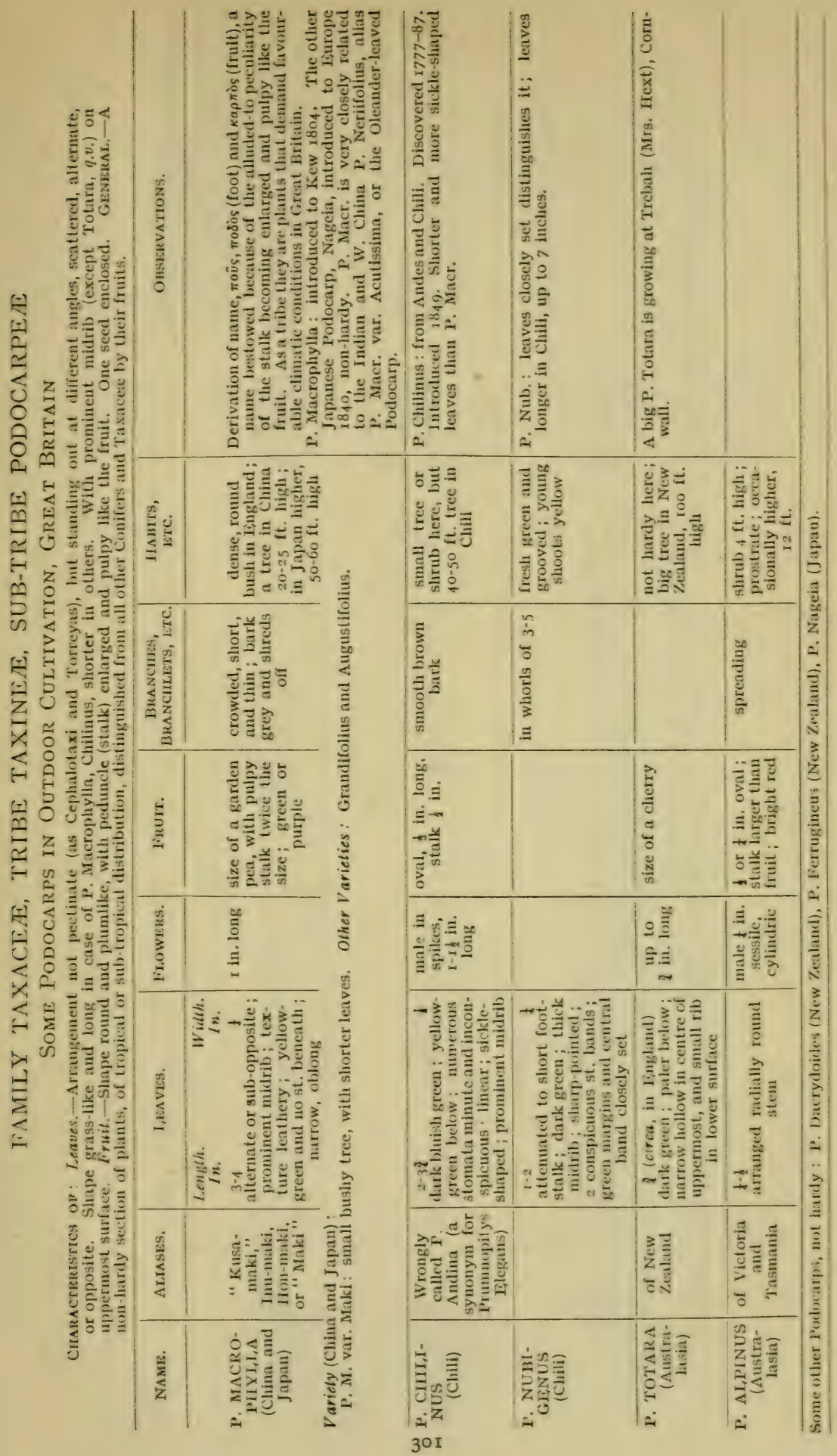




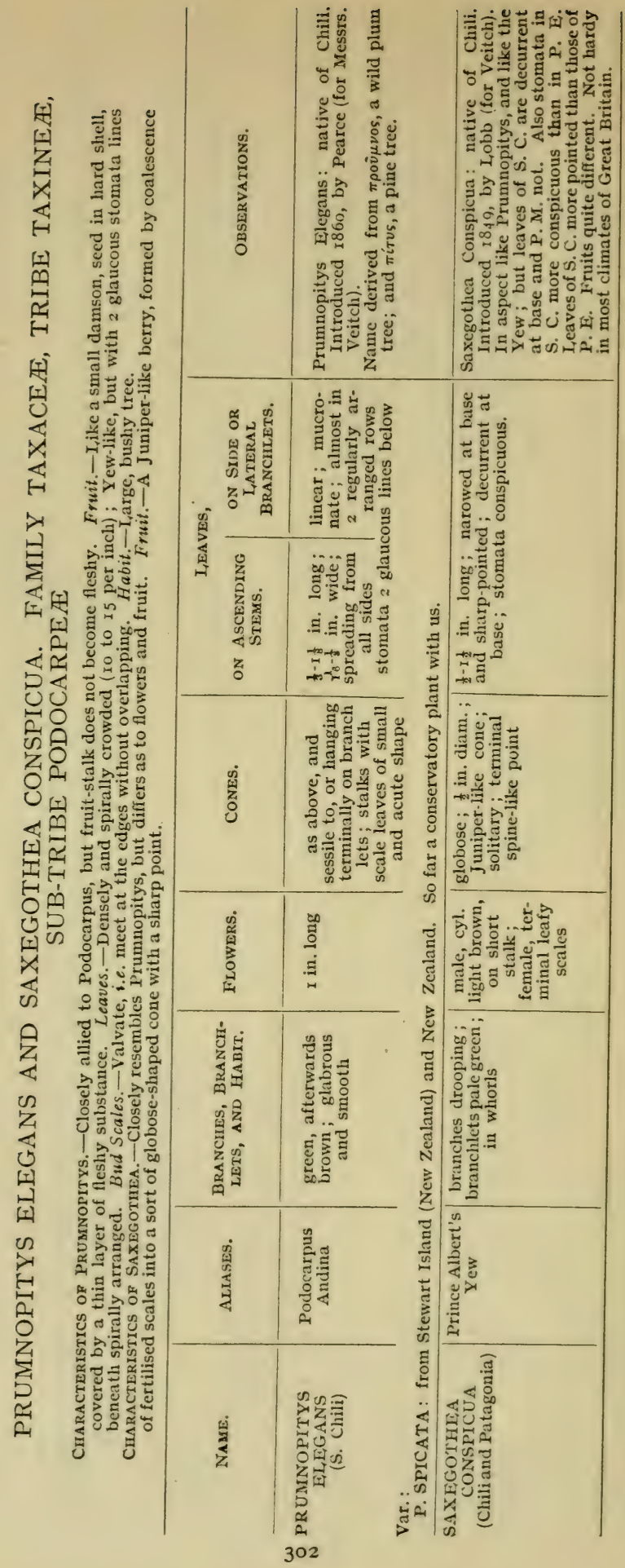




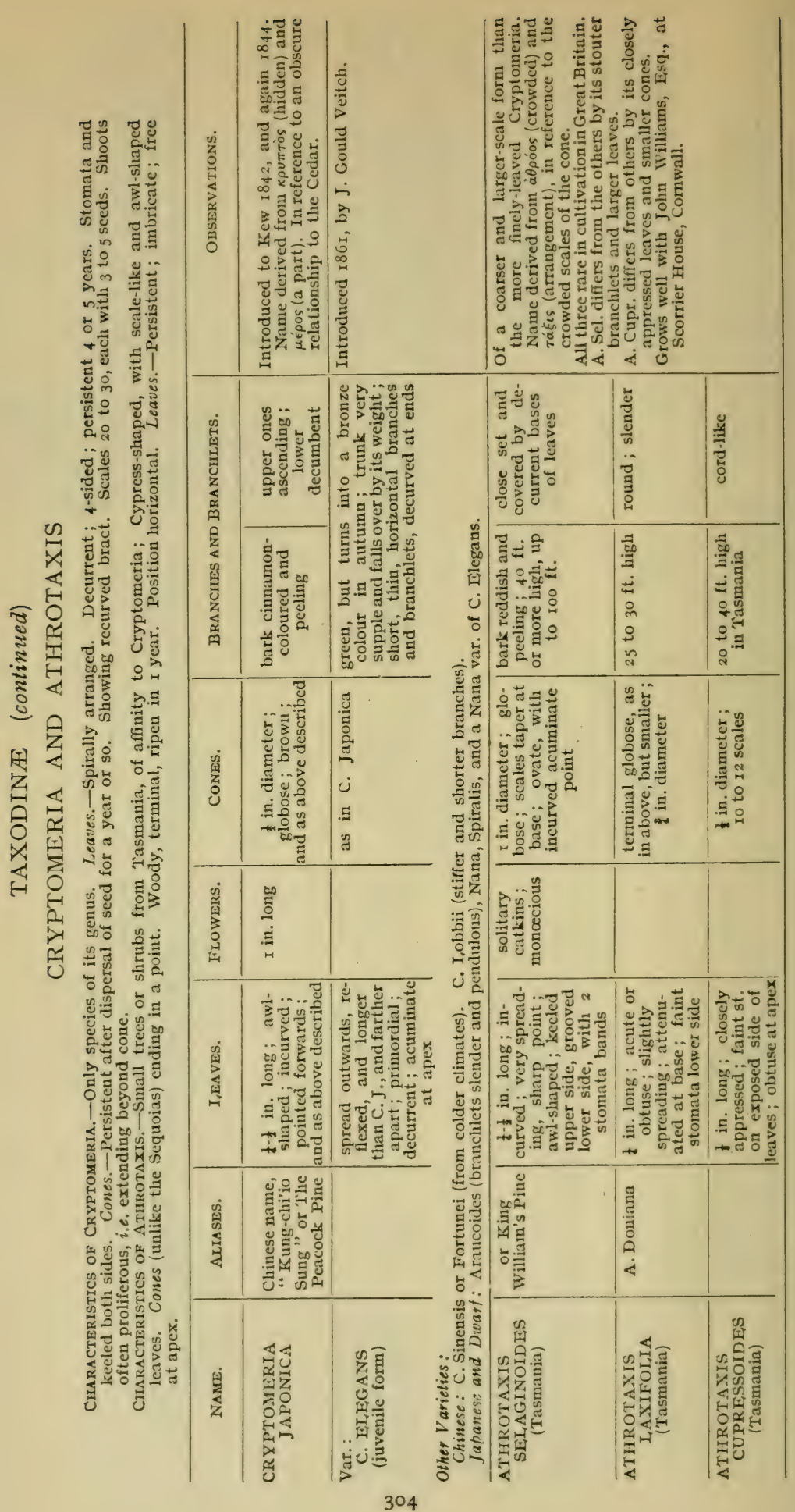



GLOSSARY OR LIST OF WORDS USED REQUIRING EXPLANATION

ABRUPt. Terminating suddenly.

Acicular (acicula $=$ a little needle). Needle-shaped, i.e. slender and sharp-pointed.

Acuminate (acumen $=\mathrm{a}$ point). Having a long, tapering point.

AcuTE. Sharp-pointed.

Adnate. Growing close to the stem.

AdPRESSED. Pressed into close contact without adhering. (Premere or pressare $=$ to press, add to.)

Adventitious (adventus $=$ a coming).. Refers to accidental or abnormal appearance. In the case of buds when they do not occur in axillary places. Used also in reference to irregular growths of shoots, e.g. in the case of witches' broom.

Alternate (alter $=$ other). A term applied to leaves or branches which do not grow out opposite to one another, but are arranged on axis or stem at different distances and on different sides.

Amorphous (Gk. a = not; morphe $=$ form). Having no definite form.

APEx (apex = peak). Top terminating point of a leaf or tree. ARIL. A glutinous covering that envelopes certain seeds, e.g. the berry fruit of the yew.

Aromatic (Gk. aroma $=$ spice). A description applicable to a sweet-smelling perfume.

ASCENDING. Directed or rising upwards.

ATROVIRIDIS (ater = black ; viridis = green). Deep, darkgreen colour.

AwL. Pointed instrument for boring holes. Applied botan. ically to leaves similarly shaped. 
Awn. Beard of corn or grass. Applied to any similarly bristly appendage.

AxIL (axilla $=$ the arm-pit). The angle between the upper side of a stem and any branch, branchlet, stalk, leaf, or any other organ that grows from it.

Axillary. Vide Axis.

AxIs (axis = axle-tree). The main stem around which, or from which, any branchlets and leaflets grow.

BACCA (noun). A berry, i.e. a succulent seed vessel, filled with pulp, in which the seed is encased.

Baccatus (adj.). Having a pulpy texture.

BARK. The rind, or covering, of the trunk and branches of an exogenous tree.

BASAL. Growing at the base of anything.

Basal Sheath. The covering that encircles the base of pine leaves. Also referred to as fascicle or bundle. Vide FASCICLE.

Bicolor (bi = twice; color = colour). Two-coloured.

BIENNIAL (bis = twice, annus = year). Lasting two years. Growing one year, flowering, fruiting, and then dying the next year.

BIFID (bis = twice; findere $=$ to split). Split sharply in two points.

BIN $Æ$ (bis = twice). Binæ used to describe pine trees whose leaves grow in twos in same basal sheath. Geminate (twin), an expression used to denote the same condition, i.e. two leaves growing in the same bundle, or basal sheath.

Bipinnate (bis = twice; pinna = feather). When both the primary and secondary divisions of a branchlet or leaflet are pinnated, i.e. grow out like a feather (pinna) along each side of this double edition of branchlets.

Blisters. Or resin pockets, formed just beneath the smooth surface of the trunk before it becomes furrowed. Often I in. or more long, and numerous. Found on Balsam Firs, on A. Grandis, also sometimes on upper stems of Douglas.

BOAT-SHAPED. In the shape of a boat with keel in miniature. Used in reference to shape of certain leaves of the Cupressineæ tribe. Vide Carinate, Keeled.

Boss (synonym Umbo [q. vide]). 
BRACTS (bractea $=a$ thin plate, or leaf, of metal). An irregularly developed leaf at base of flower or fruit stalk. Note the bracts behind cone scales, which are sometimes concealed and sometimes exserted, and of different lengths and shapes.

BREATHING-POREs. Vide STOMATA.

BuD. Young folded-up-branch or flower.

Bud Scales. The covering of winter buds.

CAllous (callosus $=$ thick-skinned). Thick-shelled.

Cambium. The sticky fluid between bark and wood of exogenous trees when new wood is forming.

CARINATE (carina = keel). Shaped like the keel of a boat. Vide Boat-Shaped, KeEled.

CARTILAGinous $\quad($ cartilago $=$ gristle). Like gristle. A description often applied to the apex of leaves of Conifers.

Ciliate (cilium = eyelash). Fringed with hairs, like the young leaf of a beech tree.

CIRCA (circa = round about). To describe " or thereabouts."

ChLOROPHYLL (chloros = pale green; phyllon = leaf). The green granular colouring matter below the surface of plants.

Clados (Gk. clados = branch). Cladodes, or Phylloid shoots. $V$ ide PHylloids, term applied to the herbaceous growths arising from the axil of the scale-like leaves of the Japanese Umbrella Tree, Sciadopitys Verticillata.

Columnar (columen $=$ an eminence; columna $=$ a pillar). Shaped like a column. Strict shape of a column vertical. Section Cuneate, horizontal circular.

Comb-shaped. Vide Pectinate.

CONE (Gk. conos = peak). The fruit of Conifers, and made up of overlapping scales. Synonym Strobile.

ConICAL. Shaped like a cone, i.e. with vertical section triangular and pointed, and horizontal section and base circular, or of a form gradually tapering down at one end.

CORIACEOUS (corium $=$ leather). Leathery.

CoRky (cortex $=$ rind or bark). Having the texture of cork. Syn. Suberose, Corky (Suber $=$ Cork Tree).

CoRRugated (ruga $=$ wrinkle). Applied to a surface falling and rising at parallel angles in wavy ridges. A term used 
to describe the surface of the twigs of some of the Abies. Synonyms : Fissured, Furrowed.

CoRTEx (cortex $=$ bark). The bark or rind of an exogenous tree.

CORYMB $($ corymbus $=$ cluster $)$. An inflorescence, or flower cluster, with lower stalks (or so-called pedicels) growing from a common central foot-stalk (or so-called rachis), lengthened so as to form a level head.

CYLINDRICAL (Gk. kylindein = to roll). A long, circular body, solid or hollow, of uniform diameter.

Deciduous $(\mathrm{de}=$ from ; cadere $=$ to fall). Applied to a tree that sheds its leaves annually.

Decumbent $($ de $=$ down; cumbere $=$ to lie). Lying down.

Decurrent $(\mathrm{de}=$ down $;$ currere $=$ to run). Applied to a leaf extended down or clinging for part of the way to the stem.

Decussate (decussare $=$ to cross and put into the form of an $\mathrm{X})$. Applied to leaves and branchlets arranged in pairs, and alternately crossing each other, or growing out at different angles from main stem or leaf stalk like the leaf, e.g. a Veronica.

Dehiscent (dehiscere $=$ to gape). Applied to a cone that opens and discharges its seed at maturity.

Dentate (dens $=$ tooth). Vide Margins.

Descending (de $=$ down, scandere $=$ to $\operatorname{climb})$. Moving or inclining downwards.

Diccious (Gk. di = twice ; oikos = house). Vide Monæcious. Plants that have the male flower on one plant and the female on another.

DISk or DISc (Gk. diskos = a round plate). Applied to the round scar left after pulling off leaves of the Abies, or Silver Firs.

Distichous (Gk. dis = twice; stichus = a line). Applied to leaves arranged oppositely and in two rows.

Divaricate $($ dis $=$ asunder ; varicare $=$ to spread $)$. Applied to branches that diverge.

DORSAL (dorsum $=$ the back).

DORSO-VENTRAL (dorsum = the back of human frame; venta $=$ abdomen or frontal part of human frame. Alluded to as Dorsal and Facial. Applied to leaves 
growing on upper and lower side of branchlet, while the leaves growing on either side are termed lateral leaves. Vide FACIAL LEAvEs.

Dowvy. Covered with soft hairs. Synonyms: Pubescent, Tomentose, Villose, Ciliate, $q$. vide.

Drupaceous (drupa $=$ an over-ripe, wrinkled olive). A fleshy and succulent fruit, containing a bony stone, e.g. the Prunus tree tribe, plum, cherry, etc.

Echinatus (echinus = hedgehog). Armed with sharp spines like hedgehog. Note Pinus Echinata.

Elliptic (Gk. elleipein $=$ to fall short). An oval, and deviation from the true form of a circle. About twice as long as broad.

EMARGINATE (emarginare $=$ to provide with a margin). Applied to leaves depressed or notched instead of pointed at summit of the leaf. Vide and compare BIFID, which suggests a more sharply defined decision.

Entire (integer $=$ whole). Vide MARgin.

EROSE (rodere $=$ to gnaw). Margins of leaf irregularly toothed. Vide MARGIN.

EXOGENOUS (Gk. exo = outside, gen. root of word signifying to grow). Applied to trees growing by successive additions to the outside. Opposed to Endogenous, which applies to a plant that grows from within, by the additions to the centre of the stem, e.g. the Palm, Grasses, etc.

EXSERTED (exserere $=$ to project). Applied to the bracts protruding over the cone scales.

Facial Leaves. Vide Dorso-ventral.

FALCATE (falx $=$ a sickle). Curved like the blade of a reaper's sickle.

Fan-shaped. Vide Plicate.

FAscicle (fascis = a bundle). Proceeding from a common point like the leaves of a larch.

FAstigiate (fastigium, the projecting point or gable end of a building). Of close, erect growth, and branches pointing upwards like the Lombardy Poplar.

Frbro-vascular (fibra $=$ thread $;$ vasculum $=$ seed vessel) . Fibro-vascular bundles are the small shaded cells seen under magnifying glasses in the middle of a transverse section of a leaf. They consist of woody tissue, spiral, and 
other vessels. In hard-wood Pines they appear divided, in soft-wood Pines as of one appearance. Vide HARD- AND SofT-wood Pines.

Filament (filum $=a$ thread). A fine, thread-like object seen on the winter buds of some conifers. Also applied to the stem-like part of a stamen. Note Piceas, Nigra, Rubra, Glehnii, Obovata, etc.

FILIFORM. Having the form of a filament.

FIMBRIATEd (fimbria $=$ a fibre, or fringe, or end of a garment). Fringed.

FREE. Applied to that part of the leaf which is detached from the stem. Note description of leaf growth "free at apex" among the Cupressineæ.

Frondose (frons= leaf). Leafy, bearing a great many leaves, but more strictly in reference to leaf-growths in which the functions of stem and leaf are combined.

FURROWED. Description of a surface channelled or fissured longitudinally. Synonym: CorRugated (q. vide).

FUSIFORM (fusus $=$ a spindle). Spindle-shaped. Enlarged in the middle of their length and tapering towards both ends like the root of a carrot.

GlabRous (glaber $=$ smooth). Without hairs. The opposite of pubescent or downy, which terms signify the presence of a minute system of hair-growths upon the shoots.

GLANDS (glans = acorn). A small excrescence on leaves or shoots, secreting the circulating juices of plant life. Among the Cupressineæ its presence or absence constitutes a helpful identifying mark.

Graucous (Gk. glaucos). An undefined colour consisting of blue-grey and green tints.

Grobose (globus $=$ an orb, sphere, or circle). Nearly circular in form.

GRANULAR (granulum $=$ a little grain of corn). In form like a grain of corn.

HABITAT (habitare $=$ to reside). The natural dwelling-place of any animal or plant.

Hard-iVood Pines. Vide Fibro-vascular. In hard-wood Pines fibro-vascular bundle divided. In soft-wood Pines not divided. Hard-wood Pines with harder and heavier wood. Early and late annual layers sharply defined. 
Soft-wood trees with light, soft wood, in which the annual rings are not well defined in early stages or late formation. Herbaceous (herba $=$ herbage). Applies to a soft annual stem that dies to the root annually, and is reproduced from a perennial root.

IMBRICATED (imbricare $=$ to cover with hollow gutter tiles, down which the rain (imber) runs). Applied to leaves overlapping like tiles on a roof. Note the scales of cones and the leaf-growth of the Araucaria Imbricata, and many others.

IXFLORESCEXCE (inflorescere $=$ to begin to blossom). Term applied to the way flowers are situated upon plants. Synonym : Flower Cluster.

INTERNODE. Vide NODE.

INvolUCRE (involvere $=$ to involve). A whorl, or ring of bracts.

KEELED. Keel-shaped, with a prominence on the back. Vide CARINATE, boat-shaped.

LACINIATE (lacinia = lappet, or small piece of a garment). Applied to leaves cut into narrow lobes and with an appearance of having been gashed with scissors.

LANCEOLATE (lancea = a lance). Having the form of a lance,

i.e. tapering at both ends. Broadest below the middle.

Oblanceolate, broadest above the middle.

LATERAL (latus = side). Applied to leaves in the Cupressineæ that grow on the side of the branchlets. Those that grow on the upper and lower side of shoot are called variously dorsal and facial, or Dorso-ventral (q. vide).

LEAF BUD. A bud producing a stem with leaves only.

LIGNEOUS (lignum $=$ wood). Wooden, or having the texture of wood.

LINEAR (linum = flax, thence a thread). Narrow, with the two sides nearly parallel, e.g. the leaf of a Yew tree.

LITORAIIs (litus $=$ the sea-shore). Growing on the sea-shore. LutEus (lutum $=\mathrm{a}$ herb used for dyeing a yellow colour) Of a deep yellow colour.

MACRo (macro $=$ long or large). Macrophylla $=$ large-leaved . MARGIN (margo = edge or border). The edge of a leaf is called its margin, e.g. entire margin is even and smooth ; serrate margin has sharp teeth like a saw pointing for- 
wards; dentate margin has sharp teeth pointing outwards; erose margin is irregularly toothed.

Median (medius = middle). Applied to the median leaves of some Silver Firs, that run along the centre of the twig on the upper side, and also to the position of the resin canals.

Medulla (medulla $=$ pith).

MEDUlLARY RAYs. The bands of cells extending across the wood from the pith to the bark, and producing the silver grain of their wood.

MEMBRANEOUs (membrana $=$ the skin or membrane that covers the separate members of the body). A substance of a fine and thin texture like the wings of a wasp.

Micro (micros $=$ small). Microphylla $=$ small-leaved.

Moncecious $($ monos $=$ single, oikos $=$ house). Having the male and female flowers on the same individual plant.

Mucronate (mucro $=$ the point of a sword [especially]). Abruptly tipped with a hard, short point.

Multinodal. Vide Node.

MuRICATE (murex $=$ a shellfish with a prickly shell). Armed with sharp points or prickles. Note Pinus Muricata.

NANA (nanus $=$ a male dwarf; nana $=a$ female dwarf). Applied to the dwarf-growing representatives of plants. Compare Prostrate, Pygmy, Repens.

NeEdle-Shaped. Synonym: Acicular. Linear, rigid, tapering to a fine point from a narrow base, as Juniper leaves.

Nigricans (niger $=$ black). Blackish. Note Pinus Nigricans or Austrian Pine.

NodE (nodus = a knot, and thence a joint, in a limb). Joint of a branch, or the point on a stem where the bud or leaf is given off.

Internode $=$ the portion of stem between two nodes.

Uninodal $=$ shoots produced in one whorl of branchlets in a year's growth.

Multinodal $=$ shoots produced in more than one whorl in a year's growth.

Notched. Vide Emarginate.

Nut. A seed enclosed within a hard shell.

Nux Baccata. A nut enclosed in a pulpy covering, as a lew berry. 
OB. A prefix signifying inversion. Note Obovate, Oblique, Oblong, Obtuse, Opposite, etc.

Obloue (obliquus $=$ slanting). Unequal-sided. Deviating irregularly from a direct line.

OBLONG (longus = long). A four-sided form longer than broad.

OBTUSE (ob = against ; tundere $=$ to beat). Blunt or rounded at the point.

Opposite $(\mathrm{ob}=$ against; positum $=$ placed $)$. Applied to leaves and branches placed in pairs on opposite side of stems, and in contradiction to the description ALTERNATE (q. vide).

Ovate (ovum = an egg). Egg-shaped, broader at base. Obovate represents shape of an egg turned upside down, and therefore broadest at the apex.

Ovord. Ditto. Egg-shaped.

Ovule. Vide Pistillate. An incipient seed.

Pectinate (pecten $=\mathrm{a}$ comb). Applied to trees-e.g. Silver Firs-whose leaves are arranged like the teeth of a comb.

Pedicel and Peduxcle (pediculus, petiolus, and pedunculus, all refer to a little foot). Terms used to describe the various kinds of foot-stalks.

PEDICEL. The stalk of a separate flower in a compound cluster.

Peduxcle. The main stalk which joins the cluster to the twig or branch, or the stalk of a solitary flower or fruit (e.g. an acorn).

Peltate (pelta $=$ shield) shield-shape. Applied to leaves, cones, etc., attached to their stalks by the centre, not the margins, e.g. a mushroom, a Chamæcyparis cone, etc.

Persistext (persistere $=$ to continue). Applied to the length of time leaves and cones of conifers remain on the tree.

Petiole. The stalk of a leaf. Vide Pedicel.

PhyLloids (Gk. phyllon = leaf). A growth half petiole, half leaf, used in connection with growths on Japanese Umbrella Tree. Synonyms: Cladodes, Herbaceous BRANCHLETS (q. vide).

Pinne (pinna $=$ feather).

Pinsate. Shaped like a feather. Applied to leaves arranged 
regularly on each side of a common stem. Vide $\mathrm{BI}$ PINNATE.

Pistillate (pistillum $=a$ pestle; pinso $=$ to pound). Central part of the flower inside the stamens and containing ovary, style and stigma, and ovules.

Pitted (puteus $=\mathrm{a}$ well). Marked with small depressions. Plicatus (plicare $=$ to fold like a fan). Plaited lengthwise like a lady's fan.

Politus (politus $=$ polished). Of shiny and polished appearance. Note Picea Polita.

PoLlEN (pollen = anything as fine as dust, hence flour, meal, etc.). The usually yellow male and fertilizing powder contained in the anthers or top of the stamens.

Pruinose (pruina $=$ hoar frost or rime). With the appearance of a plum-like indetachable bloom upon it.

PSEUdo (Gk. pseudes $=$ false). Prefix signifying false and not true to type, e.g. pseudo-Tsuja Douglasii, pseudoLarix Kœmferi, etc.

Pubescent (pubescens = beginning to grow a beard and arrive at man's estate). Hairy. Vide Downy, Tomentose.

Pulvini (pulvinus $=\mathrm{a}$ cushion). Applied to the woody enlargement at the base of some leaves, e.g. the Spruce.

Pumilus and Pumilio (= dwarf). Applied to dwarf-growing trees.

Pungens (pungere $=$ to penetrate). Implying the conveyance of a strong, disagreeable impression to the sense of smell.

Quinate ; Quin $Æ$ (quinque = five). Applied to Pines whose needle-like leaves grow in bundles of five.

RACEME (racemus = a cluster of grapes). A flower cluster or inflorescence, where flowers grow on equal-lengthed flower stalks (or so-called pedicels), and all spring from a common stalk (or so-called rachis).

RAchis (rachis = spine). The common stalk, or axis, of the cluster from which the pedicels spring. Vide PEDICEL.

RAdiatus (radius $=$ a spoke of a wheel). Spreading out from a common centre.

RECEPTACLE (recipere $=$ to receive). The swollen top of a peduncle, or stalk, from which several flowers start together. 
Recurvatus (recurvare $=$ to bend backwards). Curved back.

REFLEXED (reflectere $=$ to bend back). Bent back.

REPENS (Lat. repere $=$ to creep). Applied to creeping plants.

Resin CANALS or Resin Ducts. Intercellular spaces running parallel with the stem and through the leaf. In a transverse section of the leaf they take the form of a circular opening which is visible under a magnifying glass, or can be sometimes sufficiently made out by squeezing the leaf after it has been cut across, when the resin can be discerned exuding from the ducts. They are differently placed and vary in number in different trees. Sometimes they are situated close to the edge or the epidermis of the section of leaf, and then are described as marginal. In other trees they are placed about half-way between the centre of the leaf (where the fibro-vascular bundle is seen), and the outside edge, when they are described as median. For example, the resin canals in the Common Silver Fir are two in number and marginally placed. In the Douglas Fir the same, while the P. Laricio (Corsican and Austrian) have eight medianly placed resin ducts. The Hemlock spruces have only one placed close to, and immediately under, the fibro-vascular bundle. In the Ternate (3-in-a-bundle) Pines and the Quinæ (5-in-abundle) the resin canals are usually fewer.

These are some of the more minute characteristics of conifers that ought to be studied in the transverse section under magnifying glasses.

Reticulatus (reticulum $=$ a little net). With small intersecting lines like the meshes of a net.

REvolute (re $=$ back ; volvere $=$ to roll). Rolled back out of the ordinary direction.

RHowвоID (Gk. rhembein = to turn round and round). An imperfect oval-shaped figure and angular at the middle, and so a form more or less diamond-shaped.

SCALES. An expression connected with the word Shell, and used to denote the scales or thin layers and coverings of a fish or reptile. Applied botanically to the encrusted covering of leaf buds and cones. 
ScAR (Gk. eschara = a scar produced by burning). Applied to the mark on the stem left when a leaf has been pulled off, as in the case of the Abies or Silver Fir. Vide Disk.

Scattered. Applied in contradistinction to such terms as Whorled, Opposite $(q$. vide).

SEMr. In composition $=$ half.

SERotinus (serus = late in the day). Untimely. Applicable to anything botanically that arrives late or out of season. Note Pinus Serotina.

SERrate (serra = a saw). Vide Margin.

Sessile (sessilis $=$ low, sedere [sessum] = to sit). Growing close to, and indirectly upon, the stem without a stalk.

Sheath. Membraneous substance rolled round a stem or leaf. Vide Basal Sheath.

Smooth. Applied more generally to the surface of the twig, while Glabrous represents freedom from hair attachments. Soft-wood Pines. Vide Fibro-vascular and Hard-wood PINES.

Spathulate or Spatulate (spatula = a word used in connection with a little spade or druggist's spatule). Oblong figure, with lower end very much attenuated.

SPINDLE-SHAPED. Vide FUSIFORM.

SPUR. The woody extension from the branchlet of a cedar bough whence the leaves spring.

Souama; Souamata (squama $=$ a scale). A scaly rudimentary leaf or bract. The covering of a leaf bud. Note Juniperus Squamata.

Souamose. Covered with minute scales.

SQUARROSE; SQUARRous. Ragged, or rough, with projecting scales or deflexed leaves.

Stamen ; Staminate. One of the male organs of the flower that produces pollen, having stamens.

Stigma. Vide Pistillate.

Stomata (Gk. stoma = mouth). Lines of minute breathingpores, which give a white or pale-blue tinge to the foliage. Stone. A hard body or fruit with seed enclosed.

STRIATUS (stria $=$ a ridge between two channels). Striped or streaked.

STRICTUS (strictus $=$ contracted). Very upright or straight. Strobile. Vide Cone. 
Sub. In composition signifies somewhat or nearly.

Suber (suber = cork). Vide Corky. Note Pinus Sylvestris or Scots Pine.

Sub-sessile. Vide Sessile.

Sylvestris (silva $=$ a wood). That grows in a wood. Note Pinus Sylvestris or Scots Pine.

Syn. In composition $=$ with a growing together.

TABULIFORM (tabula $=$ a table). In the form of a table, like the boughs of a cedar tree.

TERETE (terere $=$ to rub smooth). In shape like a lead pencil. TERnATE (terni $=$ threefold). Growing in threes or whorls of three. Applied to the Pines that have 3 leaves in a bundle.

TESTA (testa $=$ the shell or covering of a testaceous animal). Hence the skin of a seed.

Tetragonal (Gk. tetra = four; gonia $=$ angle). Applied to the shape of branchlets or twigs.

TOMENTOSE (tomentum = stuffing for cushions). Vide Pubescence, Downy, but the Tomentose character is more associated with an interwoven and matted covering of hairs on the shoots.

Toothed. Synonym: Dentate. Vide Margin.

TREE. A woody perennial plant with a trunk.

$T_{R I}(t r i=3)$. In compound words three.

Tripinnate. Three times pinnate. When the leaflets of a Bipinnate leaf become themselves pinnate. Vide Pinnate, Bipinnate.

TRIQUETRAL. Three-sided or three-angled.

TRUNCATE (truncare $=$ to lop off). Cut off at the top.

TUBERCulata (tuber = a projecting substance, a protuberance or excrescence). Pinus Tuberculata so-called because of its cones growing imbedded in trunk and causing excrescences.

UMBEL (umbella = diminutive of " umbra," shade). An inflorescence which has no common footstalk (or so-called Rachis) like a Corymb, but has flower-stalks (or so-called Pedicels) of nearly equal length and radiating from one centre or stalk.

UмBо (umbo $=$ a projection or boss on a shield). The enlargement on certain cone scales. Vide Boss. 
UNDULATE (unda = a wave of the sea). Waved on the surface. UNINODAL. Vide NODE.

VALVATE (valva = the leaf of a folding door). United by the margins only. Meeting at the edges. Opening by valves like a shell.

Ventral. The facial or upper-leaf arrangement on stem, as opposed to the dorsal or lower, and also the lateral leaf arrangement. Vide Dorso-ventral.

Vertical (vertex = any point or summit). Rising in a perpendicular direction.

Verticillatus (Verticil $=$ diminutive of vortex). Arranged round in a ring or whorl. Vide WHORLS.

$\mathrm{V}$-SHAPED. Applied to arrangement of leaves in some of the Abies, which leave a gap in the centre on upper side of branchlet, leaving a space in the shape of the letter.

WHORLS (by form of whirl). Where there are more than two growths of branchlets; flowers, or leaves, borne in a circle from same nodes or joints. 


\section{N D E X}

LATIN DESIGNATION.

COLLOQUIAL NAME.

PAGES.

Abies or Silver Fir, common Abies

characteristics of .

A. Amabilis Lovely or White Fir

A. Balsamea

A. Bals. var. Hudsonia

- Balsam Fir or Balm of Gilead Fir . 275, 70, 73

A. Brachyphylla .

A. Brach. var. Umbellata .

A. Bracteata

Nikko Fir

275

(a)

Bristle Cone .

A. Cephalonica . . . Santa Lucia or Greek
A. Ceph. var. Apollinis
A. Ceph. var. Vilmorinii

A. Cilicia

A. Concolor

A. Firma

Cilician Fir : $\quad \begin{array}{ll}274 \\ \text {. }\end{array}$

White Fir, Balsam $\{278,68,70$, Fir, or Colorado Fir $\} 77,95$, I 75

A. Fraseri . . . . Fraser's Fir, Southern

A. Or She Balsam Fir 275, 70, 73

A. Homolepis • . White Fir or Giant Fir 274, 70, 75, 76

A. Lasiocarpa $77,79-82$

A. Lasiocarpa * Sub alpina, Rocky $\}_{27} 7,68,70$,
A. Las. var. Arizonica
- Cork Fir
$278,68,175$ or Mtn. Balsam Fir $\} 77,94,95$

A. Lowiana

- Californian Fir : 278, 68, 70, $76,77,95$, 274

A. Magnifica - • . Red Fir . - 277, 68, 70,

A. Magn. var. Shastensis or
A. Mariesii .
Shasta Red Fir
277
Maries' Fir .
$276,71,90$
A. Nobilis
Noble Fir
$277,68,70$,
9 I, 92, I 75
A. Nordmanniana . . Caucasian Fir.
$276,70,86$,
90, 93
A. Numidica
- Algerian Fir .
- $278,68,70$, 92,93

9I, 92 


\section{INDEX}

LATIN DESIGNATION.

COLLOQUIAL NAME.

PAGES.

\section{ABIES-continued}

A. Pectinata

- Common Silver Fir . $275,5,67,68$,

A. Pect. var. Brevifolia

A. Pect. var. Columnaris

A. Pect. var. Fastigiata

A. Pect. var. Pendula

A. Pect. var. Pyramidalis Stricta.
A. Pect. var. Tortuosa

A. Pect. var. Virgata

A. Pindrow.

A. Pinsapo .

A. Religiosa

A. Sachalinensis .

A. Sach. var. Nemorensis .

A. Sibirica .

A. Veitchii .

A. Veitch. var. Olivacea

A. Webbiana

\section{Abietia, vide Pseudo-Tsuja Douglasi}

\section{ARAUCARIAS}

A. Imbricata

var. Australian Species

var. New Zealand Species .

var. South Sea Island Species

ARBOR VITAE, vide THUYA

Arceuthos, Sub-section of Junipers

Athrotaxis .

A. Cupressoides

A. Laxifolia

A. Selaginoides

Balfouriana or Fox-Tail Group of Pines

Banksia Group of Pines .

Biota, vide Thuya Orientalis

Caryocedrus, Sub-Section of Junipers

Cedars .

C. Atlantica

C. Deodara

C. Libani

C. Lib. var. Brevifolia

Cembræ Group of Stone Pines .

Cembroides Group of Nut Pines.

Cephalotaxus

C. Argotænia
Chile Pine or Puzzle Monkey
$70,75,84^{-}$

$$
6,96
$$

275

275

275

275

- 275

. 275

- 275

Pindrow or Hima- $278,71,83$, layan Fir . . . 84,95

Spanish Fir . • 274, 69,71, 72

Mexican Sacred Fir. $\quad 276,68,71,88$

Saghalien Fir . . 276,70,88-90

* $\cdot 276$

Siberian Fir . $\quad 276,70,88,89$

Veitch's Fir . . 276,70,9I

. * 276

$275,68,70$, $82,83,84$, 95

$305,226-36$

305,4

305

305

305

296, I 88

$304,198,207$,

217

304,208

304,208

304,208

266

266,45

292

296, I93

284,148

$284, \mathrm{I} 53$

284 , I 54

$284,148-53$

284

265

$266,6,30-32$

$96,237,239$,

240,243 ,

246

298 
LATIN DESIGNATION.

Cephalotaxus-continued

C. Drupacea

C. Drup. var. Globosa

C. Drup. var. Sinensis

C. Fortunei.

C. Mannii

C. Oliveri .

C. Pedunculata

C. Ped. var. Fastigata

C. Ped. var. Sphæralis

Chamæcyparis Section

CRYPTOMERIA

C. Japonica

C. Jap. var. Elegans
C. Lobbii
C. Nana
C. Sinensis .
C. Spiralis

\section{CUNNINGHAMIA}

C. Sinensis CUPREssus

C. Sin. var. Konishii.

C. Sin. var. Lanceolata
C. Arizonica
C. Cashmeriana
C. Formosensis
C. Funebris
C. Glabra
C. Goveniana
C. Lawsoniana

COLLOQUIAL NAME.

PAGES.

\section{Japanese Cephalo-}

taxus . . $298,241,242$

. . . .298

$\begin{array}{ll} & 298 \\ \text { Chinese } & \dot{C} \text { ephalotaxus } \\ 298,239\end{array}$

S. Chinese Cephalotaxus . 298

Japanese . . 298,241, 242

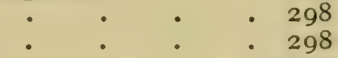

. $\quad . \quad 290,169, \mathrm{I} 74$

Kung-Chi'io-Sung or Peacock Pine . 304, 2 r 6 4, I98, 2 I620

304, I 74,220

304

. 304

304

304

$305,232-6$

305,232

305

235,236

$287,288,289$, 290, I $55^{-}$

65

Water Cypress or Cedar. . 287, I68

Hills of India: $\quad 287,169$

The Giant Cypress of Formosa . . 290

Chinese Weeping Cypress

- 287, I67

Smooth Cypress . $287, \mathrm{I} 68$

Gowen's Cypress 288, I69

- Lawson's Cypress . 289, r61, r697 I, I 75, I 79, I 80

C. Law. var. Albo-marginata 289 289

289

289

289

289

289

289

289

289

289

289

289

289

- 289 


\section{INDEX}

LATIN DESIGNATION.

COLLOQUIAL NAME.

PAGES.

Cupressus - continued

C. Law. var. Nana Alba

C. Law. var. Nana Glauca.

C. Law. var. Patula .

C. Law. var. Pendula

C. Law. var. Smithii.

C. Law. var. Wisseli .

C. Law. var. Youngi.

C. Lusitanica

C. Lus. var. Benthami

C. Lus. var. Knightiana

C. Macnabiana

C. Macrocarpa

C. Macr. var. Crippsii

C. Macr. var. Fastigiata

C. Macr. var. Guadalupensis

C. Macr. var. Lambertiana

C. Macr. var. Lutea .

C. Macr. var. Variegata

C. Nootkatensis

$$
\begin{aligned}
& \text {. . . } 289 \\
& \text {. . . } 289 \\
& \text {. . . } 289 \\
& \text {. . . } 289 \\
& \cdot . \quad \cdot 289 \\
& \text {. } . \quad . \quad 289
\end{aligned}
$$

Mexican Cypress or ${ }^{289} 287,168,209$ Cedar of Goa .f 2 Io

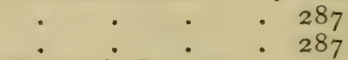

$$
\begin{aligned}
& \text { Macnab's Cypress . 288, I69 } \\
& . \quad . \quad 288, \mathrm{I} 66, \mathrm{I} 67 \\
& \text {. } . \quad 288 \\
& \cdot \quad \cdot \quad \cdot 288 \\
& \text {. } . \quad . \quad 288 \\
& \text {. . . } 288 \\
& \text {. } \quad . \quad 288 \\
& \text {. . } 288
\end{aligned}
$$

C. Noot. var. Argento-variegata . • . . 288

C. Noot. var. Compacta . . . . . 288

C. Noot. var. Glauca $\quad$. $\quad$ • . 288

C. Noot. var. Lutea . • . • • .

C. Noot. var. Pendula • . . . . 288

C. Obtusa . . . . Hinoki Cypress
C. Obt. var. Aurea
C. Obt. var. Breviramea
C. Obt. var. Compacta
C. Obt. var. Crippsii .
C. Obt. var. Erecta .
C. Obt. var. Keteleeri
C. Obt. var. Lycopodioides
C. Obt. var. Pendula
C. Obt. var. Pygmæa .
C. Obt. var. Tetragona Aurea

C. Pisifera
C. Pis. var. Aurea
C. Pis. var. Filifera .
C. Pis. var. Plumosa.

C. Pis. var. Squarrosa

C. Sempervirens .

C. Thyoides
C. Thy. var. Ericoides
C. Thy. var. Glauca .
C. Thy. var. Hovegi .
C. Thy. var. Leptoclada
C. Thy. var. Nana
C. Thy. var. Variegata

C. Torulosa .

Hinoki Cypress $\quad$. 290, I72

290

290

290

290

290

290

290

290

290

290,173

290, I 72

290

290

290

290, I72, I 76

Roman, Italian, or Mediterranean Cy-

$288,157,166$, press.

I 67

White Cedar . . 289, I73

. . 289

289

289

289,174

289

289

Himalayan, Bhotan, or Twisted Cypress $\quad 287,165-7$ 
LATIN DESIGNATION.

COLLOQUIAL NAME.

PAGES.

Deciduous Cypress, vide Taxodinæ

Eu-Cupressus Section

$287,288,165-$

Eu-Picea

Eu-Thuya Section

29I, I 74-80

Fitzroya

F. Patagonica

Fox-Tail Pines

305

$305,4, \mathrm{I} 85$

$2,29,30$

Gerardianæ Group of Plane Bark Pines

266,23

Hemlock Spruce, vide Tsuga

Hespero Peuce Section

283

Junipers, other names of .

JUNIPERS

J. Cedrus

Mountain Cedar

J. Chinensis var. Albo-variegata

Chinese Juniper

J. Chin. var. Aurea.

J. Chin. var. Japonica

J. Chin. var. Sargentii

J. Chin. var. Sphœrica

J. Communis

J. Com. var. Alpina .

J. Com, var. Aurea .

J. Com. var. Compressa

J. Com. var. Echiniformis .

J. Com. var. Fastigiata

J. Com. var. Hemispherica

J. Com. var. Nana

J. Conferta .

J. Drupacea

J. Excelsa .

J. Ex. var. Perkinsii

J. Ex. var. Stricta

J. Formosana

J. Oxycedrus

\section{J. Pachyphlœa}

J. Pach. var. Conspicua .

J. Pach. var. Elegantissima

J. Pach. var. Ericoides

J. Phœnicia

J. Ph. var. Filicaulis.

J. $\mathrm{Ph}$. var. Langoldiana

J. Ph. var. Turbinata

J. Procumbens

. $\quad 295$

. . . 295

Con

Co $\cdot 295$

I95

294-7, I 57 ,

297

I 85-95

Common Juniper

297, 192

297

297

297

297

$\begin{array}{llll}. & . & . & . \\ . & . & . & 297 \\ . & & 297\end{array}$

• . . 297

Litoralis (Hai-Nezu) 297, I94

Syrian Juniper ・ 296, I 88, I92

Greek Juniper . 294, I90, I9I,

J. Recurva • • • • Himalayan Juniper

. $\quad . \quad 294$

“官z'u-peh-shu" : 294

Prickly Juniper . 297, 189, I90,

Chequer-Barked

$$
\text { Juniper . }
$$$$
\text { I93 }
$$

$$
\text { I } 92
$$

295, I90, I92

- 295

- 295

- 295

Phønician Iuniper . 294, I90

294

- 294

- 294

296

296, I 90 


\section{INDEX}

LATIN DESIGNATION.

JUNIPERS-continued

J. Rigida

COLLOQUIAL NAME.

PAGES.

J. Sabina

J. Sab. var. Humilis

J. Sab. var. Prostrata

J. Sab. var. Tamariscifolia

J. Sab. var. Variegata

J. Scopulorum

J. Squamata

\section{J. Taxifolia}

J. Thurifera

J. Virginiana

Jap. Representative of $\mathrm{J}$. Communis,

"Tz'u-peh-shu" . 297

English or Common $294,188,189$,

Savin.

Dwarf : : 294

J. Hudsonica . . 294

• $\quad \cdot \quad \cdot 294$

Mountain Red Cedar 294

"Fragrant Fir" or "Fragrant Green Fir". • 296, 189

Spanish or incense Juniper 294, r89

Red or Pencil Cedar 295, 190, I9I,

J. Virg. var. Aureo-Spica . 192

J. Virg. var. Aureo-Variegata • • . 295

J. Virg. var. Bedfordiana . . . . . . 295

J. Virg. var. Contracta . . . . . . 295

J. Virg. var. Dumosa * . . . . . 295

J. Virg. var. Elegantissima : . . . : . 295

J. Virg. var. Glauca . • . . . . . 295

J. Virg. var. Humilis . . . . . 295

J. Virg. var. Schottii • . . . . 295

J. Virg. var. Scopulorum • • • • • 295

J. Virg. var. Triomphe d'Angers . . . 295

J. Virg. var. Tripartita • • • • • 295

J. Wallichiana * Black Juniper or J.

Pseudo-Sabina $\quad$ 295, 190

KETELEERIAS.

K. Davidiana : * Yusan (Chinese) or $\mathrm{S}$ h i m a - M o m i
(Japan) 279

K. Fortunei

Larch Cones

Larch, newly discovered .

LARCH

L. Alaskensis

L. Americana

L. Cajanderi

L. Dahurica

Geog. var. Japonica .

Geog. var. Olgensis

Geog. var. Rupprechtii

L. Europæa

$$
\begin{aligned}
& \text {. . . } 147 \\
& \text { - } 144 \\
& \text { - } 285,286,132- \\
& 7 \\
& \text { matack . } 285,140 \\
& \text {. . } \quad 145 \\
& \text { Dahurian Larch : } 285,139, \mathrm{r}_{40} \\
& \text { - } 285, \mathrm{I} 44, \mathrm{I} 45 \\
& 285,144,145 \\
& \text {. } \quad 285, \mathrm{I} 44, \mathrm{I} 45 \\
& \text { Common Larch - 285, 132-7, }
\end{aligned}
$$

L. Eur. var. Pendula.

L. Eur. var. Pendulina 
LATIN DESIGNATION.

\section{LARCH-continued}

L. Fortunei, vide L. Kaemferi

L. Griffithii .

L. Kaemferi or Fortunei

L. Kurilensis

L. Leptolepis

L. Lyalli

L. Mastersiana

L. Occidentalis

L. Pendula .

L. Potanini.

L. Sibirica .

Libocedrus Section.

LIBOCEDRI

L. Austro-Caledonica

L. Bidwilli .

L. Chilensis

L. Decurrens

L. Dec. var. Variegata .

L. Doniana

L. Macrolepis

L. Papuana

L. Tetragona

Longevity of Trees.
COLLOQUIAL NAME.

PAGES.

Himalayan or Sik- 286,14 I, I43, kim Larch . . $\mathrm{I} 44$

Chinese Golden Larch or Japanese Kara- $\} 286,143,144$

Kurile Larch . $\quad$ 286, I38, I4I

Japanese Larch . 285, 138

Lyall's Larch. 286, I38, 140, 142

- $\cdot$ I I4, I45

Western Larch of $285,138,140$ America . .f $14 \mathrm{I}$

- $\quad \cdot 285,140$

Chinese Larch 286, I44, 145

Russian Larch . 285, 138

. . . .293

$$
293,18 I-6
$$

293

293

L. Craigiana, Incense

Cedar, White Cedar of California, Bastard or Post Cedar

$293, I 8 I-4$

293

New Zealand Arbor

Vitæ (Native name

Kawaka Arbor Vitæ) 293

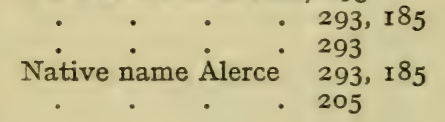

Omorica, or Flat-leaved Section of Piceæ or Spruce Trees I04, 106, I I9Oxycedrus, Sub-Section of Juniper . . . . 297

Piceæ or Spruce Trees, characteristics of . . . 28

PICE

P. Ajanensis

P. Alba

P. Alba var. Albertiana

P. Alba var. Arctica .

P. Alba var. Aurea Cœrulæa

P. Alba var. Compacta

P. Alba var. Echiniformis .

P. Albertiana

P. Alcoco

P. Bicolor, vide P. Alcockiana

P. Breweriana
23,282

I02, 280-2

Microsperma or Ajan 282 , I06, I 2 I

Spruce

122

White Spruce . . 280, 106

$. \quad . \quad 280$

. . .280

$. \quad . \quad 280$

. . . 280

Alberta $\dot{W}$ hite Spruce $28 \mathrm{r}$, 106

Alcock's Spruce (Jap.) 280, I05, I06, name Iraimoni) .f IIO-I3

Weeping American and Brewer's

Spruce $\cdot \quad 282 \quad 122$ 
LATIN DESIGNATION.

COLLOQUIAL NAME.

PAGES.

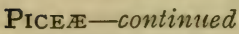

P. Engelmanni • • • Engelmann's Spruce 281, 106, r ro

P. Excelsa . . . . Common or Norway 28I, Io6, II4,

P. Ex. var. Aurea . . . . . . 28I

P. Ex. var. Clanbrassiliana . . . . . $28 \mathrm{I}$

P. Ex. var. Dicksoni. . . . . . 28I

P. Ex. var. Eremita var. Gigantea : : : $28 \mathrm{I}$

P. Ex. var. Globosa Nana. . . . . 28r

P. Ex. var. Inverta . . . . . . 28I

P. Ex. var. Pendula. . . . . . $28 \mathrm{I}$

P. Ex. var. Remontii . . . . . . 28I

P. Ex. var. Stricta . . . . . . 28I

P. Ex. var. Virgata . . . . . . 28I

P. Glehnii . . . Red Yezo Spruce : 28I, 106, II3

P. Hondoensis • . . Hondo Spruce . 282, 106, III,

I I , I2I

122

P. Maximowiczii .

P. Morinda, vide P. Smithiana

P. Morindoides or Spinulosa.

E. Himalayan or

P. Nigra - • . P. Mariana, Black,

Sikkim Spruce 282,122

Swamp, Bog, or $\}$ 281, ro6, 116, Muskeg Spruce . . II 7

P. Obovata.

Siberian Spruce . 28r, Ir3, II4

P. Omorica.

Servian Spruce

$282,120,121$

P. Orientalis $\quad \therefore \quad$ Caucasian or Oriental

Spruce . $\quad 28 \mathrm{I}, 106,1 \mathrm{I} 4$

P. Polita

- Tiger-Tail Spruce - 280, I06, I Io,

P. Pungens

- Colorado Spruce - 280, 106, rog,

P. Pung. var. Argentea . • • • . 280

P. Pung. var. Glauca - Annesleyana . . 280

P. Pung. var. Kosteriana - Glauca Pendula : 280, 109

P. Pung. var. Parryana Glauca . . . 280

P. Pung. var. Prostrata . . . . . 280

P. Pung. var. Sargentii . . . . . 280

P. Pung. var. Tabuliformis . . . . 280

P. Rubra

Red Spruce : : 28I, ro6, II3, II 6

P. Shrenkiana • • . Shrenk's Spruce - 280, 106, 108

P. Sitchensis . . Sitka, Menzies, or $282,106,120$,

P. Smithiana - . Morinda, Khutrow, $\{$ I2 I, I22

Morinda, Khutrow,
or Weeping Hima- 280, 106, 108,

P. Spinulosa, vide P. Morindoides layan Spruce 122

Pinaster Group of Pines . .

PINES

P. Albicaulis

P. Aristata.

- White Bark Pine $271,45,52$ : 53

$264-72$

- Awned Pine, Bristle Cone Pine, Hickory

$265,6,22$

$266,2,3,22$,

29, 30 
LATIN DESIGNATION.

\section{PINES-continued}

P. Armandi

P. Ayacahuite
COLLOQUIAL NAME.

PAGES.

Mexican White Pine

P. Ay. var. Buonapartea or Veitchii

P. Ay. var. Strobiformis

P. Balfouriana

P. Banksiana

P. Bungeana

P. Canariensis

P. Cembra .

P. Cembra var. Pumila

P. Cembra var. Sibirica

P. Cembroides

P. Contorta

P. Cont. var. Murreyana

P. Coulteri

P. Densiflora

P. Divaricata, vide P. Banksiana

$\cdot \quad \cdot 264,14$

P. Divaricata, Jack, Grey, Scrub, and Black Pine .

Lace Bark Pine

Canary Island Pine.

Alpine, Arolla, or Swiss Pine .

. $\quad \therefore \quad \therefore \quad$.

Three-Leaf Nut Pine

- Lodge-Pole, Beach, Scrub, Oregon, or

Bolanderi Pine . 271, 63, 65 , $0,45,51,65$ $266,23,24-7$ 269,44

$265,19,20$ $265,3,20,64$ 265

$266,2,3,31$

$$
\cdot \quad \cdot 271,63
$$

Coulter's Pine or $268,6,13,37$, P. Macrocarpa . 38,51 Japanese Red Pine ("Aka-matso") 271, 58,59

P. Echinata (or Mitis) .

\begin{tabular}{|c|c|}
\hline $\begin{array}{l}\text { P. Edulis } \\
\text { P. Excelsa . }\end{array}$ & \\
\hline $\begin{array}{l}\text { P. Flexilis . } \\
\text { P. Gerardiana }\end{array}$ & . \\
\hline P. Halepensis & \\
\hline
\end{tabular}

- Short-Leaf, Eastern Yellow, or Spruce
Pine Two-Leaf Nut Pine 266, 30, 31 Himalayan, Blue or $264,4,9$, Io, Bhotan Pine .f 12,13,20 Limber Pine . . 265, 3, 2I, 23 Gerard's Pine. . 266, 23, 24,

P. Hal. var. Brutia . - Pyrenaica and CalaP. Inops (or Virginiana) • Jersey or Scrub Pine P. Insignis or Radiata . . Monterey Pine - 268, 35, 40, P. Koraiensis 4I, 49

\section{(Oba-goya-matsu)}

P. Lambertiana . . . Sugar Pine .

P. Laricio - • .
P. Lar. var. Aurea
P. Lar. var. Nigricans
P. Lar. var. Pallasiana
P. Lar. var. Pumila.
P. Lar. Pygmy varieties
P. Lar. var. Tenuifolia Aleppo or Jerusalem

27,28

$$
270,47,48
$$

270,48 $270,45,50$,
65
$268,35,40$,
41,49
$265,18,19,20$ $264,6,12,13$, 14

- Corsican Pine. $\quad 272,59,60,6$ I - $\cdot 272$ Austrian Pine $\quad 272,62$

272

272

272

- 272 
LATIN DESIGNATION.

Pines-continued

P. Leucodermis

P. Mitis, vide P. Echinata

P. Monophylla

P. Montana

P. Mont. var. Mughus

P. Mont. var. Pumilio

P. Mont. var. Rotundata

P. Mont. var. Uncinata

P. Montezumæ

P. Mont. var. Hartwegii

P. Mont. var. Lindleyi

P. Mont. var. Rudis Devoniana.

P. Mont. var. Russelliana.

P. Monticola

P. Muricata

P. Palustris

P. Patula

P. Parryana

P. Parviflora

P. Parv. var. Pentaphylla .

P. Peuke

P. Pinaster

P. Pin. var. Aberdoniæ

P. Pin. var. Hamiltoni

P. Pin. var. Lemoniana

P. Pinea

\section{P. Ponderosa}

P. Pon, var. Arizonica

P. Pon. var. Jeffreyi

P. Pon. var. Macrophylla

P. Pon. var. Mayriana

P. Pon. var. Scopulorum

P. Pseudo-Strobus

P. Pungens

P. Quadrifolia, vide P. Parryana

P. Radiata, vide P. Insignis

P. Resinosa

P. Rigida

P. Sabiniana

P. Serotina .

P. Strobus .

P. Sylvestris

P. Tæda
COLLOQUIAL NAME.

PAGES.

$$
\begin{aligned}
& \text { Herzogovinian Pine } 272,59,62 \\
& \text { One-Leaf Nut Pine . 266, } 3 \text { I } \\
& \text { Mountain Pine } 271,63,64,65 \\
& 271 \\
& 27 I, 2 I, 64 \\
& 271 \\
& 271
\end{aligned}
$$

Idaho, Montana,

Western White Pine $264,9,10,12$

Bishop's, Obisco, $\backslash 270,39,40-5$. Prickly Cone Pine $\} \quad 48,49,50$

Long-leaved or

SouthernPitchPine $269,43,44$

Mexican Pine. $\quad$ 269, 34, 41,

Four-leaf Nut Pine

(P. Quadrifolia) . 266, 31

Iapanese White Pine 264

Hondo, Yezzo, Kurile 264

Macedonian Pine . 264, 9, I0, I2.

Maritime or Cluster

Pine . . $271,47,54,55$

. . . $27 \mathrm{I}$

..$\quad .271$

Stone or Pin de Para- 27

sol Pine. . . 54,55

Yellow, Buff, or Wes-

tern Pitch Pine

$$
\begin{aligned}
& 268,38,43 \\
& 268 \\
& 268,38 \\
& 268 \\
& 268 \\
& 268 \\
& 267,33
\end{aligned}
$$

Hickory and Table

Mountain Pine . $270,46,49,50$

Red or Canadian Pine $272,53,59$

North Pitch Pine . 269, 40,42, 43

Digger or Bull Pine. 268, 637, 38,

51
Pond Pine $\quad$. 269,44

- Weymouth Pine or $264,4,8,9$ Eastern White Pine $f$ ro, 12

Scots Pine . 271, 55-7,59

Loblolly, Torch, or Frankincense Pine 269, 44 
LATIN DESIGNATION.

\section{Pines-continued}

P. Teocote .

P. Thunbergii

P. Tuberculata

P. Torreyana

$\mathrm{P}$. Virginiana, vide $\mathrm{P}$. Inops

Podocarpæ, Sub-Tribe

PODOCARPS
P. Alpinus .
P. Chilinus
P. Dacrydoides
P. Ferrugineus
P. Macrophylla

P. Mac. var. Augustifolius. P. Mac. var. Grandifolius . P. Mac. var. Maki

P. Nageia .

P. Neriifolius

P. Nubigenus

P. Totara

PRUMNOPITYS

P. Elegans .

P. Elegans var. Spicata Pseudo Strobus Group of Pines Pseudo-Tsuja DouglasiI

Ps. Ts. Douglasii

Ps. Ts. Doug. var. Colorado Ps. Ts. Doug. var. Fretsu . Ps. Ts. Doug. var. Pendula Ps. Ts. Doug. var. Stairii . Ps. Ts. Doug. var. Taxifolia Ps. Ts. Japonica .

Ps. Ts. Macrocarpa

Sabina Sub-Section

Salisburineæ Tribe .

SAXEgothea Conspicua.

S. Conspicua

Sciadopitys Verticillata

S. Verticillata

Sequoia, vide Taxodineæ

Strobi Group of White Pines
COLLOQUIAL NAME. PAGES.

Leiophylla, Macrophylla, or Twisted Leaf Pine . . 269, 34, 42

Japanese Black Pine $272,47,58,59$

Knob Cone Pine 268, 39, 40, 49

$267,32,35$

301

$301,237,238$,

239, 240,

243-9

Victoria and Tasmania 301

Chili . . . 30r, 244

. . $.30 \mathrm{I}$

" Kusi-maki," "Inumaki," "Hon-Maki," "Maki" . 30r, 244

. . 30I

301

301

P. Macrophylla var. 301

Acutissima, or

Oleander Podocarp 301, 245

301,244

301, 244,245

$302,237,238$,

$239,244,260$

Podocarpus Andina 302

302,161

267,32

Ps. Ts. Taxifolia (Amer.), Douglas Fir, Oregon or Yellow Fir, Puget Sound Pine

$279,75,97-$ IOI, I 43

Red Fir .

279, 97-101

279

279

279

279

279

279

\section{4-6}

298, 299

Prince Albert's Yew $\begin{aligned} & 302,237,238 \\ & 302,161,262\end{aligned}$

- 303, I98

Japanese Umbrella) 303, I44, 22 IPine "Koza-maki" 5

$264,8,15$ 
LATIN DESIGNATION. COLLOQUIAL NAME. PAGES.
Tædæ Group of Pines

TAXACE $E$

Taxus Baccata

T. Bacc. var. Adpress

T. Bacc var. Adpressa

T. Bacc. var. Barroni

T. Bacc. var. Brevifolia

T. Bacc. var. Canadensis

T. Bacc. var. Dovastonii

T. Bacc. var. Ericoides

T. Bacc. var. Fastigiata

T. Bacc. var. Fast. sub-var. Chesthuntensis

T. Bacc. var. Floridana :

T. Bacc. var. Fructu-Lutea

T. Bacc. var. Glauca

T. Bacc. var. Globosa

T. Bacc. var. Nana .

T. Bacc. var. Pendula

T. Bacc. var. Prostrata

T. Bacc. var. Recurvata

T. Bacc. var. Semper Aurea

Taxus Cuspidata $268,269,35$

Com $\quad$ - 300, 237-59

. . .300

. $\quad .300$

. $\cdot 300$

Pacific Coast Yew . 300

Canadian Yew . 300

Westfelton Yew 300

• $\quad 300$

Court Yew . 300,259

Fl. $\quad \cdot 300$

300

300

300

300

300

300

300

300

300

Japanese Yew, "Kuan-yin-sha," The Fir of the Goddess of Mercy 300

T. Cusp. var. Chinensis "Huang-tao-sha"

T. Cusp. var. Densa or Globosa

T. Cusp. var. Nana

TAXODINEA

Sequoia Gigantea : Wellingtonia

Sequoia Sempervirens . . Red Woor

Seq. Semp. var. Adpressa .

Seq. Semp. var. Albo-spica

Seq. Semp. var. Glauca

Seq. Semp. var. Pendula

Seq. Semp. var. Taxifolia

Taxodium Distichum .

Thujopsis Borealis . . Yellow, Sitka, or Noot-

T. Bor. var. Argento-variegata . . . . 289

T. Bor. var. Compacta . . . . . . 289

T. Bor. var. Glauca . . . . . . . 289

T. Bor. var. Lutea * . . . . . 289

T. Bor. var. Pendula . . . . 289

Thujopsis Dolobrata . . . . . 292

T. Dolobrata . . Japanese Thuya, Hiba, 292, I64, I77,

T. Dol. var. Hondai . • • • . 292

T. Dol. var. Lætevirens or Nana: : : : 292

T. Dol. var. Variegata . . . . . 292 
LATIN DESIGNATION.

COLLOQUIAL NAME.

PAGES.

THUYAS.

T. Gigantea, vide $\dot{\mathrm{T}}$. Plicata

T. Japonica

T. Occidentalis

T. Occ. var. Aurea

T. Occ. var. Buchanini

T. Occ. var. Ellwangeriana

T. Occ. var. Erecta .

T. Occ. var. Ericoides

T. Occ. var. Lutea

T. Occ. var. Pendula

T. Occ. var. Plicata .

T. Occ. var. Plumosa

T. Occ. var. Spæthii .

T. Occ. var. Verveana

T. Occ. var. Warreana

T. Orientalis

T. Or. var. Argento-variegata

Japanese Arborvitæ 291, 177, I78, or T. Standishii . 179

- Western Arborvitæ 291, 165, I76,

• .292

T. Or. var. Aurea . • . . . . . 292

T. Or. var. Aureo-variegata . . . . 292

T. Or. var. Decussata . . . . . . 292

T. Or. var. Ericoides Retinispora * . . 292

T. Or. var. Meldensis . . . . . 292

T. Or. var. Pendula . . Thuya Filiformis : 292

T. Plicata or Gigantea . GiantThuya,Western Red Cedar, Canoe Cedar of Oregon, Lobb's Arbor Vitæ 291, 165, I78

T. Sutchuensis

TORREYAS
T. Californica
T. Grandis .
T. Nucifera.
T. Taxifolia

Tsuga or Hemlock Spruces
T. Albertiana
T. Brunoniana
T. Canadensis
T. Caroliniana
T. Chinensis
T. Diversifolia
T. Pattoniana

T. Sieboldii.

Californian Nutmeg

Chinese Torreya

Japanese Torreya or "Kaya"

I $78,179,180$

$29 I$

291

$29 I$

291

291

291

291

291

291

$292,176,177$. I 79

The Stinking Cedar of Florida . . 299

..$~ I 24$

Western Hemlock : 283, 130

Himalayan Hemlock 283, I30, I3I

Hemlock Spruce . 283, I27, I30

Carolina Hemlock . 283, r 30, I3 I

. .283

Japanese Hemlock . 283, I30, I3I

Hooker's, Patton's, or Mertensiana Hemlock - 283, 129

Siebold's Hemlock . 283, 130, I31

Wellingtonia, vide Taxodinæ

Yew, vıde Taxaceæ 
PRIITED BY

RAZELL, WATSON AND VINEY, LD., LONDON AND AYLESBURY,

ENGLAND. 


\section{TREES AND SHRUBS \\ HARDY IN THE BRITISH ISLES}

\section{BY W. J. BEAN}

Assistant Curator, Royal Botanic Gardens, Kew

With over 250 Line Drawings and 64 Half-tone Illustrations. Second Edition. 2 Vols. 48s. net.

"Here is a book which stands out by itself as the work of a master of the subject. No one who cares for trees and shrubs can possibly do without it; for not only does it describe concisely and accurately from personal knowledge all the trees and shrubs which we know, but also a great number of recent introductions, about which we know little or nothing.

"Mr. Bean, who for many years has been in charge of the most complete and correctly named arboretum in Europe, has managed to get into the space of two octavo volumes a mass of knowledge and experience which is unrivalled, and though one does not look for literary polish in a work of reference like this, his writing is fluent, precise, and free from the vague statements that in so many horticultural works leave one in doubt as to what the author means, or whether he really knows what he is writing about. ...

"In the short space at my command it is impossible to do justice to this book, which must remain for many years to come by far the best of its scope and price on a subject which will always be dear to every lover of Nature and gardens."-Mr. H. J. Elwes, in Country Life.

JOHN MURRAY, ALBEMARLE STREET, LONDON, W.1 


\section{BY E. P. STEBBING}

Head of the Forestry Department, University of Edinburgh

\section{BRITISH FORESTRY}

ITS PRESENT POSITION AND OUTLOOK AFTER THE WAR

Second Impression. 6s. net

The Field:- "Mr. Stebbing writes with authority. He has had experience in other countries, and he is now Master of Forestry in Edinburgh University. He knows what is wrong, as many others know, and his book is written in the hope that it will add strength to the effort now being made to restore to these islands the industry of timber growing. .... He puts the case extremely well, and he puts it with moderation."

\section{COMMERCIAL \\ FORESTR Y $_{\text {IN }}$ BRITAIN} ITS DECLINE AND REVIVAL

6s. net

The need for a national scheme of afforestation; what it will do for the country; the necessity for the use of public funds, and the methods by which the State can obtain the best return for its outlay, are discussed in this book by one who is an acknowledged authority on the subject.

Part I contains a brief History of British Forestry; Part II describes Forestry during the War Period; and Part III deals with The Future under the following headings: What Forestry will do for the People-What Forestry will do for the Nation-Forestry and Agriculture-The Protection of Forests-Forest Education-State Forests versus Privately Owned Forests-The Afforestation Scheme-Conclusions.

JOHN MURRAY, ALBEMARLE STREET, LONDON, W.1 
By Sir A. D. HALL, K.C.B., F.R.S., Formerly Director of the Rothamsted Experimental Station.

\section{THE SOIL.}

An Introduction to the Scientific Study of the Growth of Crops. A new edition of this standard work, thoroughly revised throughout, and re-set. " A remarkably well-arranged, well-written volume. In its way it is a masterpiece." The Times. Third Edition. Illustrated. 7s. 6d. net.

\section{FERTILISERS AND MANURES.}

" $\mathrm{He}$ is able to give innumerable practical notes on the results of experiments in manuring, and it is these which we think will form the chief attraction to the cultivator, as the results of actual work on the land do not always coincide with theories based on laboratory work alone; a great work for Agriculture, and for Horticulture also." Horticultural Advertiser. Eighth Impression. Illustrated. 7s. 6d. net.

\section{THE FEEDING OF CROPS AND STOGK.}

An Introduction to the Science of the Nutrition of Plants and Animals. "The products of Sir Daniel Hall's knowledge and experience are always welcome in the manuals which come from his facile pen, but that now under notice is expecially so, as it is complementary to his works on Soils and Manures." Agricultural Economist. 4th Impression. Illustrated. 6s. net.

\section{AGRIGULTURE AFTER THE WAR.}

"Small in size, but great in value, the work deserves wide circulation and careful consideration." The Times. Third Impression.

5s. net.

\section{A PILGRIMAGE OF BRITISH FARMING.}

"A marvellously accurate and illuminating account of agriculture. It must be for some time one of the most valuable books in the library of English agricultural literature."Hcme Counties, in the Daily Chronicle. Second Impression.

\section{THE BOOK OF THE ROTHAMSTED}

7 s. 6 d. net.

EXPERIMENTS. Second Edition Revised by E. J. RUSSELL, D.Sc.. F.R.S. Director of the Rothamsted Experimental Station. Issued with the Authority of the Lawes Agricultural Trust Committee. This new edition has been brought up to date, and new chapters are added, discussing work carried out during the past ten years.

I2s. net. 


\section{THE CULTURE OF FRUIT TREES IN POTS.}

By J TSH BRACE. The result of very many years' practical experiance of this popular form of cultivation. "A valuable contribution to a very interesting phase of fruit-culture." The Field. With Illustrations. Second Impression. 6s. net.

FRENCH MARKET GARDENING : With Practical Details of Intensive Cultivation for English Growers. By JOHN WEATHERS. With an Introduction by WILLIAM ROBINSON. "This useful and interesting work deals with every phrase of that form of intensive culture known as French Gardening. It is well written and is easily understood. Fruit, Flower and Vegetable Trades' Journal. Illustrated. 4s. 6d. net.

\section{THE KITCHEN GARDEN AND THE COOK.} An Alphabetical Guide to the Cultivation of Vegetables, with Recipes for Cooking them. By CECILIA MARIA PEARSE "The most extensive ever published in regard to the cooking of vegetables." A berdeen Daily Journal. 4s. 6d. net.

\section{TOWN GARDENING.}

A Hand-book of Trees, Shrubs, and Plants, suitable for Town Culture in the Outdoor Garden, Window Garden, and Greenhouse. By B. C. RAVENSCROFT. This work, the result of the author's experience as a practical gardener in London and suburbs, may be fully relied upon. Second Edition. Revised and Enlarged.

4s. 6d. net.

\section{A HISTORY OF GARDENING IN ENGLAND.} By The Hon. Mrs. EVELYN CECIL (ALICIA AMHERST). "It is so well-written that reading it is a pleasure. No one can read it intelligently and fail to obtain a good idea of what gardening in this country has been and is."-The Field. Third and Enlarged Edition. Illustrated. I5s. net.

\section{THE BOOK OF FLOWERS.}

By KATHARINE TYNAN and FRANCIS MAITLAND. This book makes no pretence at all to completeness or scientific knowledge. It is as though one walked in a garden or the fields and picked at random a flower here and a flower there, tying them loosely into a bunch.

$6 s$. net. 


QL 20.A1u 16 -Rogers, Cha/Conifers and their c

(-1)

35185000576437 
